IZABELA BATISTA HENRIQUES

Impacto de patologias no desempenho termodinâmico do corpo humano 
IZABELA BATISTA HENRIQUES

Impacto de patologias no desempenho termodinâmico do corpo humano

Tese apresentada à Escola Politécnica da Universidade de São Paulo para obtenção do título de Doutora em Ciências.

São Paulo 
IZABELA BATISTA HENRIQUES

\section{Impacto de patologias no desempenho termodinâmico do corpo humano}

Tese apresentada à Escola Politécnica da Universidade de São Paulo para obtenção do título de Doutora em Ciências.

Área de Concentração: Engenharia Mecânica de Energia e Fluidos

Orientador: Prof. Dr. Silvio de Oliveira Junior 
Autorizo a reprodução e divulgação total ou parcial deste trabalho, por qualquer meio convencional ou eletrônico, para fins de estudo e pesquisa, desde que citada a fonte.

Este exemplar foi revisado e alterado em relação à versão original, sob responsabilidade única do autor e com a anuência de seu orientador.

São Paulo, de janeiro de 2018.

Assinatura do autor

Assinatura do orientador

Henriques, Izabela Batista

Impacto de patologias no desempenho termodinâmico do corpo humano / I. B. Henriques - versão corr. -- São Paulo, 2018.

$138 \mathrm{p}$.

Tese (Doutorado) - Escola Politécnica da Universidade de São Paulo. Departamento de Engenharia Mecânica.

1. Exergia (análise) 2. Bioengenharia 3. Corpo humano (modelagem matemática) I. Universidade de São Paulo. Escola Politécnica. Departamento de Engenharia Mecânica Il.t. 


\section{AGRADECIMENTOS}

Ao Prof. Dr. Silvio de Oliveira Junior, pela confiança em mim depositada desde o primeiro momento. Sua orientação foi essencial, não apenas para o desenvolvimento deste trabalho, mas também para minha formação acadêmica e pessoal. Seus ensinamentos, conselhos e, principalmente, seu exemplo de conduta são a base do caminho que agora começo a trilhar.

Aos meus pais, pelo apoio e compreensão.

Ao André, por ser meu companheiro nesta trajetória. Seu carinho e sua serenidade são fundamentais para me manter na rota e seu amor e apoio incondicionais me ajudam a superar os eventuais percalços pelo caminho.

Ao Prof. Dr. Carlos Eduardo Mady, pelas contribuições na linha de pesquisa e pelas conversas sobre a vida.

Ao Prof. Dr. Cyro Albuquerque Neto, pela disponibilidade em ajudar nas mais diversas ocasiões, desde o início do Mestrado, como principal referência bibliográfica, até hoje, como colega de trabalho.

Aos colegas que passaram pelo LETE ao longo dos últimos anos.

Aos professores do PME, em especial aos professores do LETE.

A los amigos de Zaragoza, por haberme hecho sentir como en casa. Agradezco de manera especial al Profesor Luis Serra por haber aceptado recibirme en el grupo de investigación y haberme facilitado los medios para llevar a cabo mi estancia en la Universidad de Zaragoza. Debo agradecer también al Profesor José María Marín por su participación activa y total disponibilidad para ayudarme en el desarrollo de este trabajo, sin dejar de mencionar, por supuesto, su estupendo papel de entrenador por las cuestas de Juslibol. A las amigas Ana, Conchita y Mónica por haberme dejado hacer parte de sus vidas desde el primer día y haberme enseñado tan bien el estilo de vida maño.

À CAPES pelo apoio financeiro. 
"Nada na vida deve ser temido, somente compreendido. Agora é hora de compreender mais para temer menos."

(Marie Curie) 


\section{RESUMO}

HENRIQUES, Izabela Batista. Impacto de patologias no desempenho termodinâmico do corpo humano. 2018. 138 f. Tese (Doutorado em Engenharia Mecânica) - Escola Politécnica, Universidade de São Paulo, São Paulo, 2018.

Neste trabalho, o conceito de exergia é utilizado na proposição de um indicador de idade exergética que permita observar alterações da expectativa de vida de um indivíduo a partir da exergia destruída durante seu ciclo de vida. Para tal, a análise exergética é aplicada ao corpo humano e a volumes de controle menores dentro do corpo para diferentes cenários nos quais ocorram alterações nas reações metabólicas, a fim de determinar a taxa de exergia destruída em função da idade cronológica. Com essa informação, é calculado o indicador de idade exergética, podendo comparar a taxa de progressão da vida do indivíduo nas diferentes condições avaliadas com base na ideia de que há um valor máximo de exergia destruída acumulada durante a vida. Os efeitos do tabagismo e da obesidade são avaliados, e observa-se uma redução de aproximadamente 15 anos na expectativa de vida de fumantes, enquanto, para os obesos, o indicador mostra um aumento. Portanto, a identificação da obesidade como um fator de risco se deve ao desenvolvimento de patologias associadas à obesidade, e não ao aumento do metabolismo e à presença de gordura corporal subcutânea. Uma vez que maior parte das patologias relacionadas à obesidade está associada ao sistema cardiovascular, é proposto um modelo exergético do coração. Observa-se um aumento da taxa de exergia destruída na presença de hipertensão, que leva a uma redução de cerca de quatro anos na expectativa de vida. Por fim, é proposto um modelo do metabolismo de uma célula de câncer que leva em conta as alterações das rotas metabólicas, a partir do qual é possível observar um aumento de quase três vezes no metabolismo exergético de uma célula de câncer em comparação com uma célula saudável. A análise da progressão de um tumor indica que, na ausência de tratamento, a redução da expectativa de vida é de 27 anos. Além disso, no caso de tratamento, cada seis meses na presença da doença reduz a expectativa de vida em cerca de quatro anos.

Palavras-chave: análise exergética, corpo humano, metabolismo, coração, câncer. 


\begin{abstract}
HENRIQUES, Izabela Batista. Impact of pathologies on thermodynamic performance of the human body. 2018. $138 \mathrm{f}$. Tese (Doutorado em Engenharia Mecânica) - Escola Politécnica, Universidade de São Paulo, São Paulo, 2018.

In the present work, the concept of exergy is applied in order to propose an index of exergetic age that allows observing changes in life expectancy of a subject based on the exergy destruction throughout the life cycle. To do so, exergy analysis is applied to the human body and smaller internal control volumes for different scenarios where changes in metabolic reactions take place, aiming at determining the destroyed exergy rate as a function of chronological age. From this data, exergetic age index is calculated, enabling to compare the rate of life progression of the subject under different circumstances, based on the idea that there is a maximum value of cumulative destroyed exergy throughout life. The effects of smoking and obesity are evaluated and a reduction of approximately 15 years is observed for smokers, while, for obese people, the index shows an increase. Thus, the identification of obesity as a risk factor is more associated to the development of obesity-related diseases than to the metabolic rate increase and the presence of a thicker layer of subcutaneous fat. Since most of the obesity-related diseases are associated to the cardiovascular system, an exergy model of the human heart is proposed. The model reports an increase of the exergy destruction in case of hypertension that causes a reduction of about four years in life expectancy. Finally, a model of the metabolism of a cancer cell is proposed taking into account the changes in the metabolic paths, from which it is possible to observe a threefold increase of the exergy metabolism of a cancer cell, in comparison to a healthy one. The analysis of tumor progression indicates that, in the absence of treatment, the reduction of life expectancy is about 27 years. Furthermore, in case of treatment, each six months living with the disease causes a reduction of almost four years in life expectancy.
\end{abstract}

Keywords: exergy analysis, human body, metabolism, heart, cancer. 


\section{LISTA DE SÍMBOLOS}
A área [m²]
b exergia específica $[\mathrm{J} / \mathrm{kg}]$
B exergia $[\mathrm{J}]$
B taxa de exergia [W]
C constante sistema de controle
c calor específico [J/(kg.K)]
$c_{p} \quad$ calor específico a pressão constante $[\mathrm{J} /(\mathrm{kg} . \mathrm{K})]$
$c\left(t^{\prime}\right) \quad$ concentração do medicamento no instante $\mathrm{t}^{\prime}$ [mg/(kg.dia)]
d fator de inibição à vascularização [dia ${ }^{-1}$ ]
DC débito cardíaco $\left[\mathrm{m}^{3} / \mathrm{s}\right]$
e
dosagem do medicamento $[\mathrm{kg} /(\mathrm{mg} . \mathrm{dia})]$
$\mathrm{E}$
energia $[\mathrm{J}]$
fator de estímulo à vascularização [dia ${ }^{-1}$ ]
$f_{\mathrm{rp}}$
razão entre a área externa do corpo vestido e nu
9
aceleração da gravidade $\left[\mathrm{m} / \mathrm{s}^{2}\right]$
$\mathrm{g}(\mathrm{t}) \quad$ concentração do medicamento em função do tempo [mg/(kg.dia)]
G energia livre de Gibbs [J/k] ou [J/mol]
h entalpia específica $[\mathrm{J} / \mathrm{kg}]$; coeficiente de transferência de calor $\left[\mathrm{W} /\left(\mathrm{m}^{2} . \mathrm{K}\right)\right]$
H entalpia [J]; coeficiente de transferência de calor [W/K];perda de carga [m]
$\mathrm{H}_{\mathrm{p}} \quad$ taxa de transferência de entalpia [W]
$\mathrm{k} \quad$ condutividade térmica $[\mathrm{W} /(\mathrm{m} . \mathrm{K})]$
K coeficiente de perda de carga
L altura [m]
m massa $[\mathrm{kg}]$
m vazão mássica $[\mathrm{kg} / \mathrm{s}]$
M metabolismo [W] 


\begin{tabular}{|c|c|}
\hline $\mathrm{N}$ & número de células \\
\hline $\mathrm{n}$ & número de mols \\
\hline$P$ & pressão $[\mathrm{Pa}]$ \\
\hline$P G$ & percentual de gordura [\%] \\
\hline Q & calor $[\mathrm{J}]$ \\
\hline$\dot{Q}$ & taxa de transferência de calor [W] \\
\hline $\mathrm{R}$ & constante universal dos gases $[\mathrm{J} /(\mathrm{mol} . \mathrm{K})]$ \\
\hline r & taxa de divisão celular [dia $\left.{ }^{-1}\right]$ \\
\hline s & entropia específica [J/(kg.K)] \\
\hline S & entropia $[\mathrm{J} / \mathrm{K}]$ \\
\hline$\dot{S}$ & taxa de entropia $[\mathrm{W} / \mathrm{K}]$ \\
\hline Sev & severidade da estenose \\
\hline $\mathrm{t}$ & tempo $[\mathrm{s}]$ \\
\hline $\mathrm{T}$ & temperatura $\left[{ }^{\circ} \mathrm{C}\right]$ ou $[\mathrm{K}]$ \\
\hline$\overline{\mathrm{T}}$ & temperatura média $\left[{ }^{\circ} \mathrm{C}\right]$ ou $[\mathrm{K}]$ \\
\hline$U$ & energia interna [J] \\
\hline$v$ & velocidade $[\mathrm{m} / \mathrm{s}]$ \\
\hline$\dot{v}$ & vazão volumétrica $\left[\mathrm{m}^{3} / \mathrm{s}\right]$ ou $\left[\mathrm{m}^{3} /\left(\mathrm{m}^{3} . \mathrm{s}\right)\right]$ \\
\hline $\mathrm{w}_{\mathrm{st}}$ & coeficiente de saturação da pele \\
\hline w & trabalho específico $[\mathrm{J} / \mathrm{kg}]$ \\
\hline w & trabalho $[\mathrm{J}]$ \\
\hline$\dot{w}$ & potência [W] \\
\hline$x$ & fração molar \\
\hline y & fração mássica \\
\hline Z & altura $[\mathrm{m}]$ \\
\hline
\end{tabular}

\section{Letras gregas}

$\Phi$

umidade relativa [\%] 

$\eta \quad$ eficiência exergética
$\rho \quad$ massa específica $\left[\mathrm{kg} / \mathrm{m}^{3}\right]$
$\tau \quad$ constante de tempo [dia]
$v \quad$ volume específico $\left[\mathrm{m}^{3} / \mathrm{kg}\right]$
$\omega \quad$ umidade absoluta [kg de vapor/kg de ar seco]

\section{Subscritos}

$\begin{array}{ll}0 & \text { ambiente } \\ 00 & \text { pressão parcial no ambiente } \\ 1 & \text { estado inicial } \\ 2 & \text { estado final } \\ \text { a } & \text { ar } \\ \text { ac } & \text { acumulado } \\ \text { ala } & \text { alanina } \\ \text { ar } & \text { arterial } \\ \text { ATP } & \text { ATP } \\ \text { c } & \text { convecção } \\ \text { cancer } & \text { câncer } \\ \text { corpo } & \text { corpo } \\ \text { CO } 2 & \text { dióxido de carbono } \\ \text { crç } & \text { coração } \\ \text { d } & \text { destruída } \\ \text { dir } & \text { direito } \\ \text { dist } & \text { distribuída } \\ \text { dv } & \text { diastólica final ventricular } \\ \text { e } & \text { entrada } \\ \text { eng } & \text { de engenharia } \\ \text { esquerdo }\end{array}$




\begin{tabular}{|c|c|}
\hline est & estenose \\
\hline ev & evaporação \\
\hline ex & expirado \\
\hline ext & externo \\
\hline$f$ & física \\
\hline$g$ & gás \\
\hline ger & gerado \\
\hline gli & glicose \\
\hline gtm & glutamina \\
\hline $\mathrm{H}_{2} \mathrm{O}$ & água \\
\hline hi & hipotálamo \\
\hline hid & hidrólise \\
\hline $\mathrm{i}$ & i-ésimo componente \\
\hline in & inspirado \\
\hline int & interno \\
\hline j & j-ésimo componente \\
\hline lct & lactato \\
\hline liq & líquido \\
\hline local & localizada \\
\hline IV & líquido-vapor \\
\hline M & metabolismo \\
\hline MAX & máximo \\
\hline mist & mistura \\
\hline $\mathrm{N}$ & nitrogênio \\
\hline $\mathrm{NH}_{3}$ & amônia \\
\hline $\mathrm{O}_{2}$ & oxigênio \\
\hline op & oclusão da artéria pulmonar \\
\hline pele & pele \\
\hline prod & produtos \\
\hline
\end{tabular}




$\begin{array}{ll}\text { pul } & \text { pulmão } \\ \text { Q } & \text { calor } \\ \text { qu } & \text { química } \\ \text { r } & \text { radiação } \\ \text { reag } & \text { reagentes } \\ \text { ref } & \text { referência para sistema de controle } \\ \text { res } & \text { respiração } \\ \text { rev } & \text { reversível } \\ \text { rp } & \text { roupa } \\ \mathrm{s} & \text { saída } \\ \text { sb } & \text { sistólica da artéria braquial } \\ \text { sdv } & \text { saudável } \\ \text { sg } & \text { sangue } \\ \text { sist } & \text { sistólica } \\ \text { sp } & \text { sistólica média da artéria pulmonar } \\ \text { sub } & \text { substrato } \\ \mathrm{t} & \text { tecido } \\ \text { tr } & \text { calafrios ou tremores } \\ \text { VC } & \text { volume de controle } \\ \text { v } & \text { vapor } \\ \text { ve } & \text { venoso } \\ & \end{array}$




\section{LISTA DE FIGURAS}

Figura 1: Volume de controle com entrada e saída únicas.

Figura 2: Variação da temperatura corporal em função da temperatura do ar ambiente. 10

Figura 3: Representação elíptica do tronco no modelo de Ferreira (2001). 12

Figura 4: Representação do sistema termorregulador do corpo humano. 15

Figura 5: Modelo simplificado do sistema térmico. 17

Figura 6: Comparativo entre os perfis de temperatura obtidos nos modelos completo (a) e simplificado (b). 19

Figura 7: Taxa de geração de entropia em função da idade para peixes. 21

Figura 8: Taxa de geração de entropia em função do nível de exercício. 21

Figura 9: Representação dos fluxos entre corpo e ambiente proposta por Rahman (2007). .22

Figura 10: Relação entre taxa de geração de entropia e idade para diferentes níveis de atividade física. .23

Figura 11: Relação entre taxa de exergia destruída e sensação subjetiva de conforto térmico.

Figura 12: Comprimento do telômero em função do número de divisões celulares para células tronco e germinativas e células somáticas .27

Figura 13: Representação do corpo humano por meio de volumes de controle. 31

Figura 14: Estratificação do metabolismo celular no segundo volume de controle. ..36 Figura 15: Exergia destruída (a) e eficiência exergética (b) para diferentes umidades relativas e temperaturas.

Figura 16: Exergia destruída por unidade de massa em função da velocidade para cada corredor avaliado no experimento . .38

Figura 17: Exergia destruída (a) e eficiência exergética (b) em função do tempo para diferentes técnicas de indução de hipotermia. 39

Figura 18: Volume de controle adotado.

Figura 19: Comparativo das eficiências exergéticas do corpo $\left(\eta_{\text {corpo }}\right)$ do pulmão $\left(\eta_{\text {pul }}\right)$ antes e após período de aclimatação de 90 dias a $4500 \mathrm{~m}$ de altitude para corrida. 41 Figura 20: Relação entre temperatura e umidade relativa na condição de conforto térmico para diferentes níveis de atividade física. 
Figura 21: Eficiência exergética do corpo ( $\left.\eta_{\text {corpo }}\right)$ (a) e do pulmão ( $\left.\eta_{\text {pul }}\right)$ (b) em função da temperatura, umidade relativa e atividade física. .......................................43

Figura 22: Distribuição do volume de sangue no sistema circulatório.....................44

Figura 23: Partes do coração humano. .......................................................44

Figura 24: Componentes do sistema excitatório e condutor especializado do

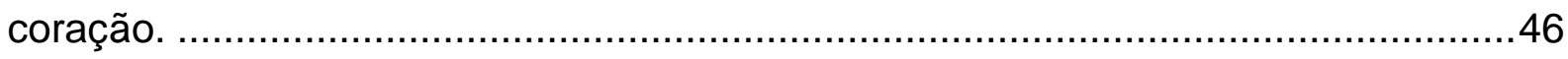

Figura 25: Sequência de eventos do ciclo cardíaco......................................48

Figura 26: Diagrama $\mathrm{p}-\mathrm{V}$ do ventrículo esquerdo, onde a área destacada em amarelo representa 0 trabalho realizado............................................................... 49

Figura 27: Variação anual da porcentagem de mortes atribuída a cada doença. .....50

Figura 28: Representação de uma estenose...............................................51

Figura 29: Representação do experimento de Oshinski et al. (1996)......................52

Figura 30: Mapa indicativo da presença de investimentos públicos em tratamentos

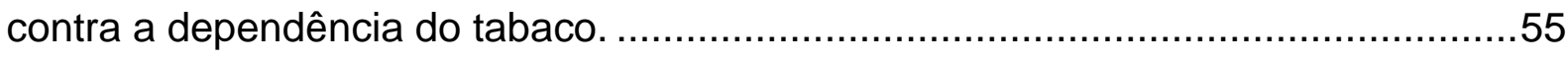

Figura 31: Variação anual da incidência de sobrepeso na população brasileira.......58

Figura 32: Variação anual da incidência de obesidade na população brasileira. ......58

Figura 33: Possibilidades de degradação do piruvato na glicólise. .........................61

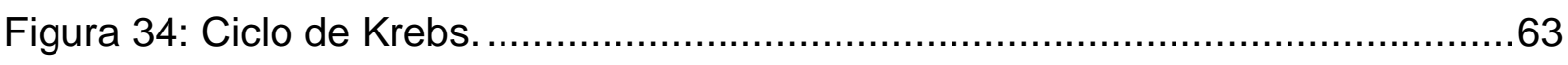

Figura 35: Curva do tamanho do tumor em função do tempo de acordo com diferentes funções de crescimento.

Figura 36: Valores de referência para exergia destruída acumulada por unidade de massa..

Figura 37: Temperatura de neutralidade de fumante e não fumante em função da idade. 68

Figura 38: Esquema do modelo exergético do coração. ....................................72

Figura 39: Formato genérico de uma conexão do tipo convergente-divergente.........81

Figura 40: Representação dos caminhos metabólicos em uma célula cancerígena. 83 Figura 41: Representação das diferenças metabólicas entre uma célula saudável e uma com câncer. .85

Figura 42: Metabolismo exergético em função da idade para fumantes e não fumantes para temperaturas de $30,4^{\circ} \mathrm{C}$ (a) e neutralidade térmica (b). 89 Figura 43: Taxa de exergia destruída em função da idade para fumantes e não fumantes para temperaturas de $30,4^{\circ} \mathrm{C}$ (a) e neutralidade térmica (b). .90 
Figura 44: Exergia destruída acumulada por unidade de massa em função da idade para fumantes e não fumantes para temperaturas de $30,4^{\circ} \mathrm{C}$ (a) e neutralidade térmica (b).

Figura 45: Eficiência exergética em função da idade para fumantes e não fumantes para temperaturas de $30,4^{\circ} \mathrm{C}$ (a) e neutralidade térmica (b). .92

Figura 46: Soma das parcelas de fluxo e transferência de exergia para o ambiente em função da idade para fumantes e não fumantes para temperaturas de $30,4^{\circ} \mathrm{C}$ (a) e neutralidade térmica (b) .92

Figura 47: Taxa de exergia destruída (a) e taxa de exergia destruída por unidade de massa (b) em função da idade para o grupo de controle, moderadamente obesos e obesos.

Figura 48: Exergia destruída acumulada (a) e exergia destruída acumulada por unidade de massa (b) em função da idade para o grupo de controle, moderadamente obesos e obesos. 95

Figura 49: Eficiência exergética para o grupo de controle, moderadamente obesos e obesos.

Figura 50: Comparativo da taxa de exergia destruída em função da potência realizada pelo corpo para normotensos (a) e hipertensos (b). 96 Figura 51: Potência aplicada no coração $\left(W_{\text {crç }}\right)$ em função da potência realizada pelo corpo para as partes esquerda e direita do coração para e normotensos e hipertensos. 98

Figura 52: Contribuição da parte esquerda para a exergia destruída total no coração em função da intensidade do exercício para normotensos e hipertensos.

Figura 53: Variação do fluxo de exergia do sangue com a intensidade do exercício para os lados direito e esquerdo do coração em normotensos e hipertensos. 99 Figura 54: Exergia destruída acumulada por unidade de massa em função da idade para normotensos e hipertensos. 100

Figura 55: Contribuição da exergia destruída no coração para a exergia destruída no corpo em função da intensidade do exercício.

Figura 56: Comparativo entre as eficiências exergéticas do corpo, dos pulmões e do coração de normotensos e hipertensos em função da potência realizada pelo corpo. 
Figura 57: Taxa total de exergia destruída em uma artéria estenótica $\left(B_{d, \text { total }}\right)$ de diferentes segmentos do corpo em função da severidade em escala linear (a) e logarítmica (b).

Figura 58: Taxa de exergia destruída devido à estenose em função da severidade em escala logarítmica. 105

Figura 59: Exergia destruída específica devido à estenose em função da severidade em escala logarítmica. 106

Figura 60: Taxa de destruição de exergia devido à estenose em função do aumento da vazão mássica de sangue para severidades de 40 (a), 60 (b) e 80\% (c). 106 Figura 61: Contribuição da estenose para a taxa total de exergia destruída em função da severidade. 107

Figura 62: Diferença de pressão em artérias estenótica em função da severidade em escala linear (a) e logarítmica (b) 108

Figura 63: Diferença de pressão em função da vazão de sangue para diferentes segmentos para severidade de 40 (a), 60 (b) e $80 \%$ (c). 109

Figura 64: Comparação entre os resultados experimentais da literatura utilizados neste trabalho e os valores teóricos do coeficiente $K_{\text {eng }}$ 110 Figura 65: Exergia destruída acumulada ao longo do ciclo de vida para taxas de divisão celular de 0,04 a 1,4

Figura 66: Imagens ampliadas da relação entre a exergia destruída acumulada em caso de câncer para diferentes taxas de replicação. 113 Figura 67: Exergia destruída acumulada por unidade de massa para eliminação do tumor em 6 meses para diferentes taxas de proliferação (a). Gráfico ampliado para valores próximos a $3600 \mathrm{MJ} / \mathrm{kg}$ (b).

Figura 68: Exergia destruída acumulada por unidade de massa para eliminação do tumor em um ano para diferentes taxas de proliferação (a). Gráfico ampliado para valores próximos a $3600 \mathrm{MJ} / \mathrm{kg}$ (b).

Figura 69: Exergia destruída acumulada por unidade de massa para eliminação do tumor em um ano e meio para diferentes taxas de proliferação (a). Gráfico ampliado para valores próximos a $3600 \mathrm{MJ} / \mathrm{kg}(\mathrm{b})$. 116

Figura 70: Comparativo entre idades cronológica e exergética para fumantes e não fumantes.

Figura 71: Comparativo entre idades cronológica e exergética para os grupos de controle moderadamente obesos e obesos do estudo de Ravusin (1982). 
Figura 72: Comparativo entre idades cronológica e exergética para hipertensos e normotensos. 119 Figura 73: Comparativo entre idades cronológica e exergética para indivíduos com e sem câncer. 120 Figura 74: Efeito do tempo para eliminação do câncer na relação entre idades cronológica e exergética. 121 


\section{LISTA DE TABELAS}

Tabela 1: Propriedades termofísicas das camadas do modelo de Mady (2013).......18

Tabela 2: Resumo das principais teorias do envelhecimento. ................................26

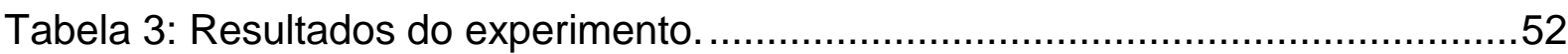

Tabela 4: Classificação do estado nutricional de acordo com o IMC. ……................56

Tabela 5: Valores de metabolismo utilizados para cada idade. ...............................69

Tabela 6: Dados de referência para cada grupo em função da idade.......................71

Tabela 7: Principais reações presentes no metabolismo da glicose e da glutamina em um tumor.

Tabela 8: Valores das variáveis envolvidas nos cálculos estequiométricos e suas respectivas fontes. .86

Tabela 9: Exergias químicas. .87

Tabela 10: Taxa de crescimento para diferentes tipos de câncer. .88

Tabela 11: Perda de carga distribuída $\left(H_{\text {dist }}\right)$, vazão mássica de sangue $(\dot{m})$ e taxa de exergia destruída em uma artéria saudável $\left(B_{d, s d v}\right)$ para cada segmento analisado. 


\section{SUMÁRIO}

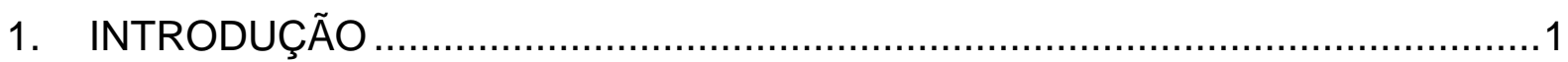

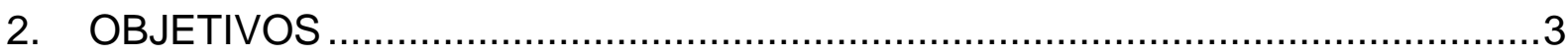

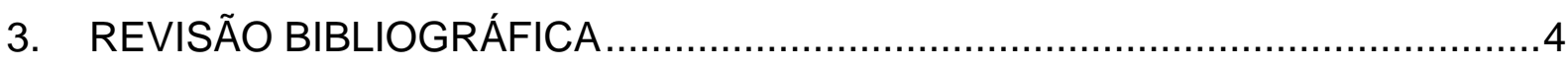

3.1 PRINCÍPIOS DE TERMODINÂMICA ……….........................................

3.2 TERMODINÂMICA E CORPO HUMANO ................................................

3.2.1 Modelo do sistema térmico ..............................................................

3.2.1.1 Transferência de calor e massa entre corpo e ambiente ................12

3.2.1.2 Transferência de calor interna ao corpo.........................................14

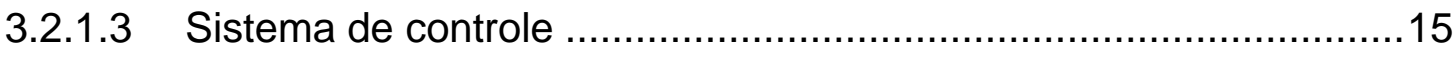

3.2.2 Modelo simplificado do sistema térmico ………...............................17

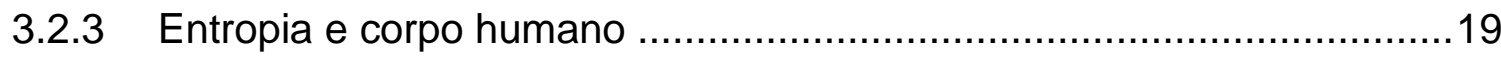

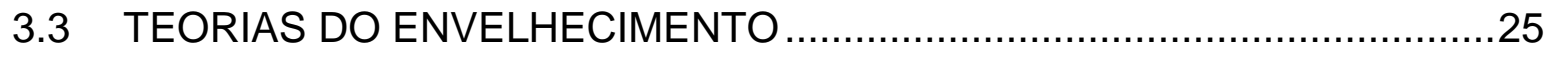

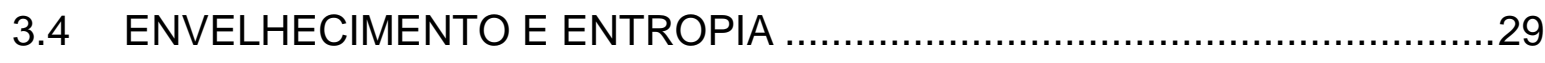

3.5 MODELO EXERGÉTICO DO CORPO HUMANO ….....................................30

3.5.1 Modelo exergético do sistema respiratório ...........................................39

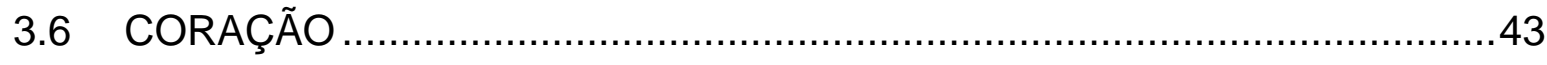

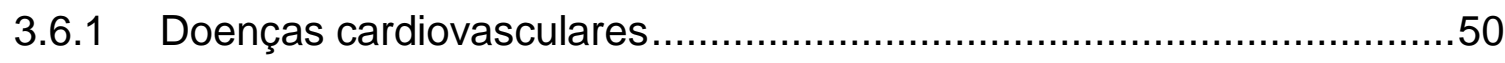

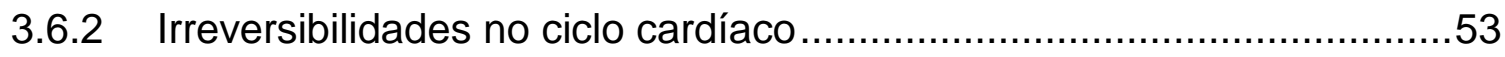

3.7 ALTERAÇÕES NA TAXA METABÓLICA ..................................................54

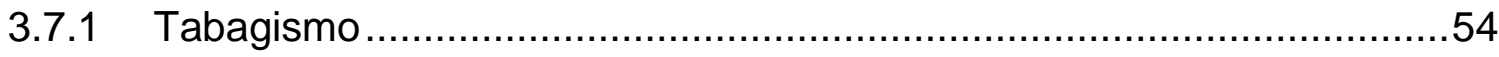

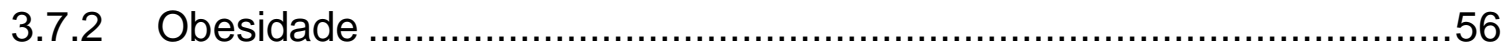

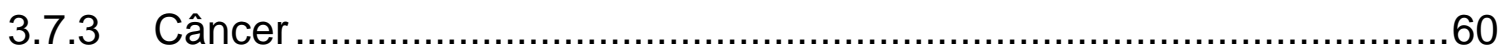

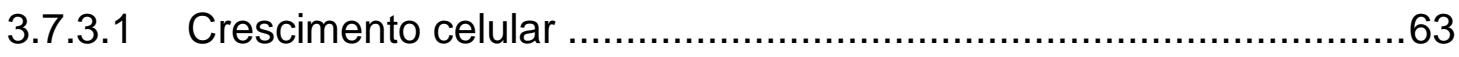

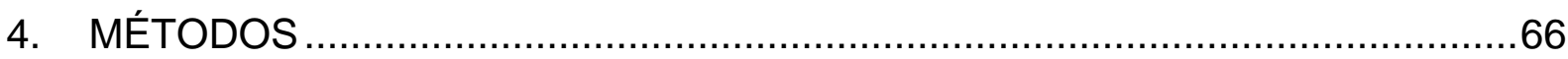

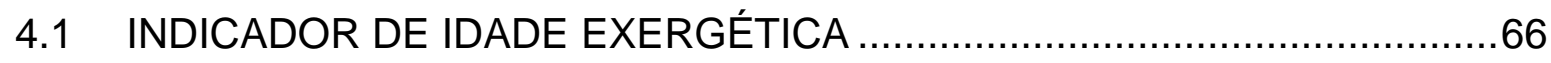


4.2 TABAGISMO

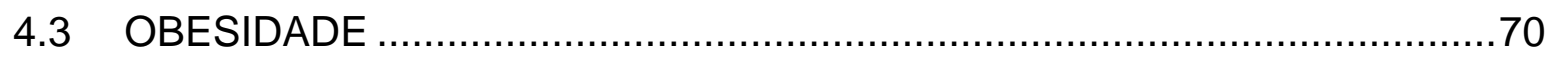

4.4 MODELO EXERGÉTICO DO CORAÇÃO ....................................................

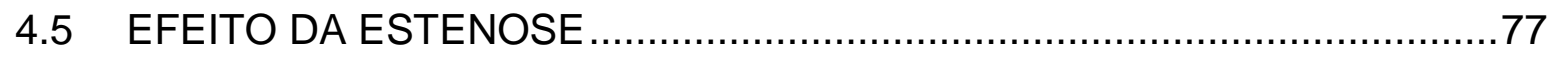

4.6 METABOLISMO EXERGÉTICO DE CÉLULAS CANCERÍGENAS ..............82

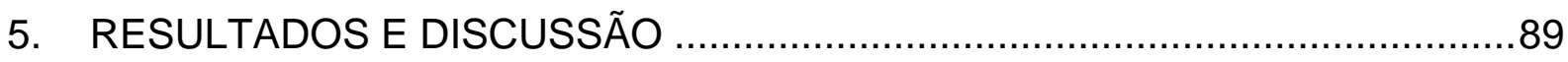

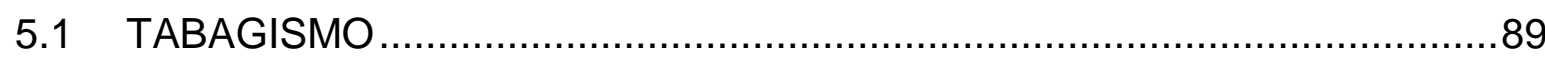

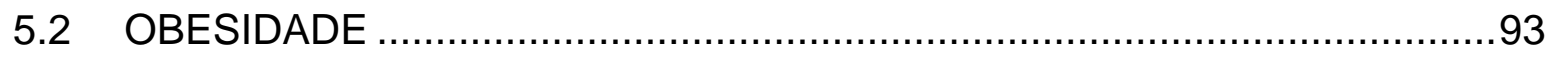

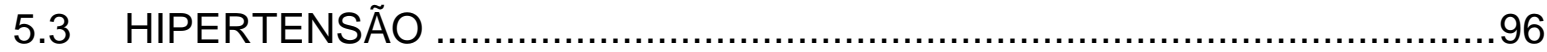

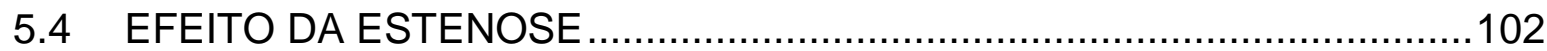

5.5 METABOLISMO EXERGÉTICO DE CÉLULAS CANCERÍGENAS .............111

5.6 INDICADOR DE IDADE EXERGÉTICA ................................................117

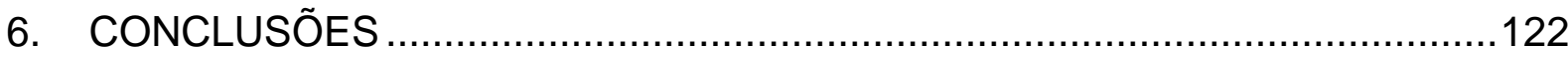

6.1 SUGESTÃO PARA TRABALHOS FUTUROS....................................125

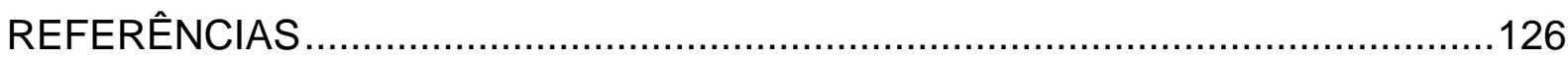




\section{INTRODUÇÃO}

O conceito de exergia surgiu da combinação dos balanços de energia da Primeira Lei da Termodinâmica e de entropia da Segunda Lei a fim de avaliar a qualidade de diferentes processos de conversão de energia. Conforme relatado por Szargut (2005), uma área potencial para a aplicação da análise exergética é o estudo de organismos vivos para estimar a eficiência dos processos de conversão de energia que acontecem em seus sistemas, órgãos e células.

Os primeiros passos para a utilização da análise exergética em organismos vivos foram dados pela aplicação da ideia de geração de entropia. Prigogine e Wiame (1946) estabeleceram o princípio da mínima geração de entropia, que define que os organismos tendem, ao longo da vida, a um estado de mínima geração de entropia. A combinação desse princípio com a ideia desenvolvida por Rubner (1908, apud SPEAKMAN, 2005) de que a quantidade de energia total gasta durante a vida de mamíferos por unidade de massa era constante, levou à investigação da geração de entropia ao longo do ciclo de vida. Silva e Annamalai $(2008,2009)$ e Hershey (2010) obtiveram valores de entropia total gerada para homens de, respectivamente, 11404 kJ/(kg.K) e 10025 kJ/(kg.K). Outros estudos indicam também que em processos de regeneração tecidual e na presença de células cancerígenas ocorre um aumento da entropia gerada no corpo (ZOTIN; ZOTINA, 1967; LUO, 2009). Adicionalmente, Annamalai e Silva (2012) determinaram a entropia gerada pelo corpo como a soma da geração de entropia dos órgãos vitais, propondo que a entropia total gerada pelo órgão no ciclo de vida é um indicador de sua degradação. Portanto, condições anormais, como patologias, levariam ao aumento da taxa de geração de entropia. Analogamente, Mady (2013) analisou, para um cidadão médio brasileiro, qual seria a variação da taxa de destruição de exergia ao longo da vida. A integração desta função do nascimento até a idade indicada como expectativa de vida média do brasileiro resultou no valor máximo de exergia destruída ao longo da vida.

Neste contexto, o presente trabalho objetiva avaliar como diferentes condições fisiológicas afetam a taxa de destruição de exergia no corpo e, consequentemente, a exergia destruída acumulada ao longo da vida. Este valor será confrontado com o valor de referência obtido por Mady (2013) para um indivíduo saudável. Desta 
maneira será possível avaliar como alterações fisiológicas impactam da destruição de exergia do corpo e principalmente na taxa na qual o indivíduo caminha em direção ao valor limite de exergia destruída acumulada. Esta avaliação será realizada por meio do indicador de idade exergética e em diferentes níveis. Primeiramente, para o corpo como um todo, serão analisados os efeitos do tabagismo e da obesidade na destruição de exergia. Na sequência, o coração será estudado tanto para indivíduos normotensos quanto para hipertensos, complementarmente à análise exergética de artérias com obstruções. Posteriormente, o metabolismo exergético de uma célula cancerígena será modelado. Por fim, os valores dos indicadores de idade exergética em cada situação avaliada serão comparados a fim de observar qual cenário apresenta o maior impacto na exergia destruída acumulada pelo corpo e, consequentemente, na expectativa de vida do indivíduo. 


\section{OBJETIVOS}

Este trabalho tem como objetivo geral propor o indicador de idade exergética e desenvolver a metodologia para sua aplicação na avaliação da expectativa de vida de indivíduos para diferentes condições nas quais ocorram alterações fisiológicas ou nas reações metabólicas.

Para tal, será determinada, para cada um dos cenários fisiológicos definidos, a exergia destruída ao longo do ciclo de vida do indivíduo por meio dos modelos exergéticos da literatura devidamente adaptados para cada cenário avaliado. A avaliação dos efeitos do tabagismo leva em conta a variação do metabolismo de um fumante, enquanto o estudo da obesidade leva em conta, além das alterações nas reações metabólicas, a variação da composição corporal. No caso do coração, será proposto um modelo exergético específico para a análise deste órgão capaz de determinar a taxa de destruição de exergia em caso de hipertensão. Finalmente, para a análise exergética da célula cancerígena será elaborado um modelo que leva em conta as alterações nas vias metabólicas de um tumor. 


\section{REVISÃO BIBLIOGRÁFICA}

\subsection{PRINCÍPIOS DE TERMODINÂMICA}

A Primeira Lei da Termodinâmica, também conhecida como lei da conservação da energia, estabelece que energia pode ser transformada, mas não pode ser criada nem destruída. A Primeira Lei para um volume de controle é expressa pela seguinte equação:

$$
\frac{d E}{d t}=\sum_{j} \dot{Q}_{j}-\dot{W}+\sum_{e} \dot{m}_{e} h_{e}-\sum_{s} \dot{m}_{s} h_{s}
$$

$\mathrm{Na}$ Equação 1, a variação temporal da energia total do volume de controle $(E)$ ocorre por meio da transferência de energia em forma de calor $(Q)$ e trabalho $(W)$ e pelo fluxo de energia através da entrada e e da saída $s$ do volume de controle. Este fluxo é caracterizado pela vazão mássica $(\dot{m})$ e pela entalpia específica $(h)$, assumindo as variações das energias cinética e potencial gravitacional desprezíveis.

A Primeira Lei estabelece que, independente dos processos que ocorram entre os estados final e inicial, a energia pode se transformar de uma forma em outra, mas sempre se conserva. Entretanto, ela não fornece nenhum indício sobre quais as transformações de energia podem e tem maior probabilidade de ocorrer e qual a quantidade máxima de trabalho útil pode ser obtida a partir de um dado sistema ou volume de controle.

A Segunda Lei da Termodinâmica, expressa pelos enunciados de Kelvin-Planck e Clausius, indica que em um ciclo termodinâmico, não é possível a conversão total de calor de uma fonte quente em trabalho, tampouco a transferência de calor espontânea de uma fonte fria para uma fonte quente. Ou seja, a Segunda Lei da Termodinâmica impõe restrições relativas à eficiência e ao sentido dos processos de conversão de energia.

As limitações impostas pela Segunda Lei estão associadas às irreverssibilidades dos processos, que fazem com que o sistema e sua vizinhança não consigam retornar 
ao estado inicial sem provocar nenhum efeito adicional no meio. A desigualdade de Clausius é a representação matemática da Segunda Lei da Termodinâmica e permite compreender quantitativamente o conceito de entropia para um ciclo termodinâmico. Na Equação 2, $\delta Q$ representa a transferência de calor na fronteira do sistema numa etapa do ciclo e $T$ é a temperatura absoluta na fronteira.

$$
\oint \frac{\delta Q}{T} \leq 0
$$

$\mathrm{Na}$ equação anterior, a igualdade prevalece para processos reversíveis e a desigualdade para processos irreversíveis. Em um processo internamente reversível, a integral cíclica anterior depende apenas dos estados inicial e final, portanto representa a variação de alguma propriedade do sistema. A essa propriedade dá-se o nome de entropia (S). Assim:

$$
d S=\left(\frac{\delta Q}{T}\right)_{r e v}
$$

O balanço de entropia de um sistema fechado é mostrado na Equação 4, na qual à esquerda da igualdade tem-se a variação da entropia, e à direita o primeiro termo representa a transferência de entropia pela fronteira do sistema e o segundo termo é a entropia gerada pelas irreversibilidades do processo.

$$
S_{2}-S_{1}=\int_{1}^{2}\left(\frac{\delta Q}{T}\right)+S_{g e r}
$$

Para um volume de controle, a variação temporal da entropia é dada por:

$$
\frac{d S}{d t}=\sum_{e} \dot{m}_{e} S_{e}-\sum_{s} \dot{m}_{s} s_{s}+\sum_{j} \frac{\dot{Q}_{j}}{T}+\dot{S}_{g e r}
$$

Onde $s$ representa a entropia específica, $Q$ a taxa de transferência de calor através da fronteira e $\dot{S}_{g e r}$ é a taxa de entropia gerada, que é nula para processos reversíveis e maior que zero para processos irreversíveis. Por isso diz-se que a entropia gerada é a medida da irreversibilidade de um processo.

Conforme pode ser observado, ao contrário da Primeira Lei da Termodinâmica, a Segunda Lei não tem caráter conservativo e sim restritivo. Com o advento das 
discussões acerca de sustentabilidade e escassez de recursos energéticos, tornouse imperativo o uso dos conceitos da Segunda Lei para melhor avaliar a qualidade das fontes e dos processos de conversão de energia. O conceito de exergia surgiu para suprir essa demanda a partir da combinação da Primeira e da Segunda Leis da Termodinâmica.

Segundo Szargut et al. (1988), exergia é a quantidade máxima de trabalho obtida quando um sistema é trazido a um estado termodinâmico de equilíbrio com os componentes do ambiente por meio de processos reversíveis e interagindo somente com esses componentes. A exergia depende, portanto, do estado em que o sistema se encontra e do estado no qual ele estará em equilíbrio com o meio.

Figura 1: Volume de controle com entrada e saída únicas.

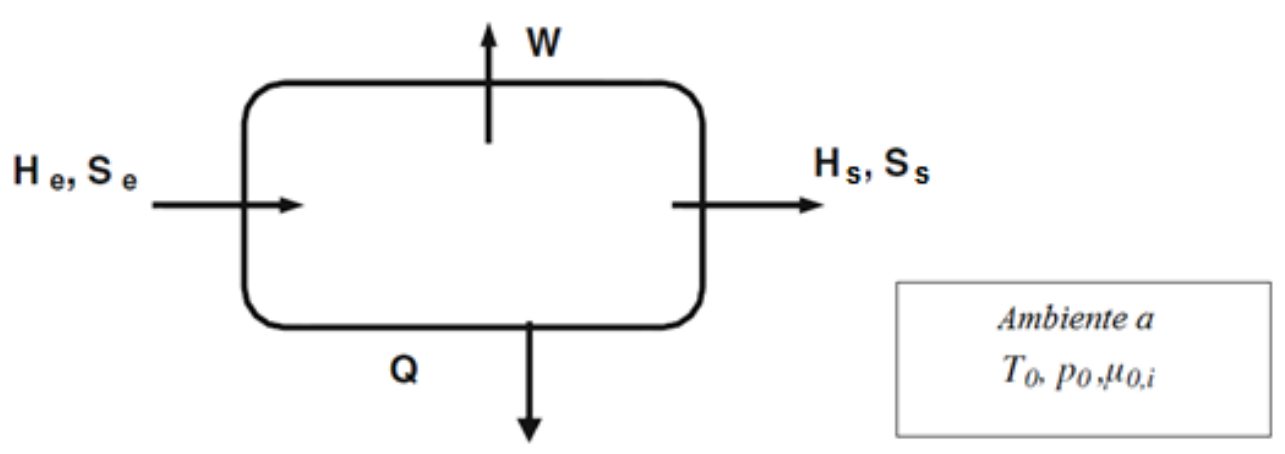

Fonte: Adaptado de Oliveira Jr. (2013).

Como mencionado anteriormente, o conceito de exergia é obtido a partir da combinação da Primeira e da Segunda Leis da Termodinâmica. Conforme demonstrado por Oliveira Jr. (2013), para condições de regime permanente e quando há apenas uma entrada e uma saída de massa do volume de controle, assim como mostrado na Figura 1, a soma do balanço de energia com a multiplicação do balanço de entropia por $-T_{0}$ fornece:

$$
\left[h_{e}-h_{s}-T_{0}\left(s_{e}-s_{s}\right)\right]=w-q\left[1-\frac{T_{0}}{q} \int_{T_{e}}^{T_{s}}\left(\frac{\delta q}{T}\right)\right]+T_{0} s_{g e r}
$$


O trabalho máximo é obtido no processo reversível, ou seja, quando a entropia gerada é nula. Assim:

$$
w_{\text {MAX }}=\left[h_{e}-h_{s}-T_{0}\left(s_{e}-s_{s}\right)\right]=w-q\left[1-\frac{T_{0}}{q} \int_{T_{e}}^{T_{s}}\left(\frac{\delta Q}{T}\right)\right]
$$

Este é o trabalho máximo que pode ser obtido entre os estados e e s. Como o conceito de exergia é relativo ao estado inicial e o ambiente, tem-se:

$$
b=h_{e}-h_{0}-T_{0}\left(s_{e}-s_{0}\right)
$$

Em que $b$ é a exergia específica do fluxo. O balanço geral de exergia para um volume de controle é definido pela Equação 9 . O termo à esquerda da igualdade é a taxa de variação da exergia do volume de controle. Os quatro termos à direita da igualdade equivalem, nessa ordem, a: soma das $j$ taxas de transferência de exergia associadas ao calor; potência efetiva realizada pelo volume de controle; taxa de variação do fluxo de exergia entre a entrada e a saída do volume de controle e a taxa de exergia destruída, que pode ser representada alternativamente por $B_{d}$.

$$
\frac{d B}{d t}=\sum_{j}\left(1-\frac{T_{0}}{T_{j}}\right) \dot{Q}_{j}-\dot{W}+\left[\sum_{e} \dot{m}_{e}\left(h_{e}-T_{0} s_{e}\right)-\sum_{s} \dot{m}_{s}\left(h_{s}-T_{0} s_{s}\right)\right]-T_{0} \dot{S}_{g e r}
$$

A exergia específica possui quatro componentes principais: cinética, potencial, física e química. As duas primeiras estão relacionadas, respectivamente, à velocidade e à ação do campo gravitacional. A exergia física está associada ao estado termodinâmico, e representa a quantidade máxima de trabalho que pode ser realizado quando o sistema ou fluxo passa para um estado termodinâmico de equilíbrio térmico e mecânico com o ambiente de referência. A exergia física específica $b_{f}$ de um sistema é calculada conforme indicado na Equação $10 \mathrm{em}$ função da energia interna, volume e entropia específicos no estado atual e no estado do ambiente de referência, além da pressão e da temperatura de referência. A expressão para um fluxo é mostrada na Equação 11 utilizando entalpias e entropia específicas, $h$ e $s$, respectivamente.

$$
b_{f}=u-u_{0}+P_{0}\left(v-v_{0}\right)-T_{0}\left(s-s_{0}\right)
$$




$$
b_{f}=h-h_{0}-T_{0}\left(s-s_{0}\right)
$$

Para gases ideais e líquidos incompressíveis as expressões das exergias físicas específicas são, respectivamente:

$$
\begin{gathered}
b_{g}=C_{\rho}\left[T-T_{0}-T_{0} \ln \left(\frac{T}{T_{0}}\right)\right]+R T_{0} \ln \left(\frac{P}{P_{00}}\right) \\
b_{\text {liq }}=c\left[T-T_{0}-T_{0} \ln \left(\frac{T}{T_{0}}\right)\right]
\end{gathered}
$$

Onde $c_{p}$ é o calor específico a pressão constante e $c$ é o calor específico. $P_{00}$ corresponde à pressão parcial do gás no ambiente.

Quando reações químicas acontecem no sistema ou no volume de controle, deve ser levada em conta também a exergia química, que indica o máximo trabalho que pode ser obtido ao levar os componentes do sistema ou fluxo a um estado de equilíbrio químico com o meio. Para o cálculo da exergia química, a pressão e temperatura do sistema ou fluxo são admitidas como iguais às do estado de referência. Portanto, esta parcela contabiliza apenas o trabalho obtido ao levar os componentes do sistema para as formas químicas elementares nas quais se encontram no ambiente de referência. As substâncias presentes neste último são definidas por Szargut et al. (1988) e apresentam exergia química nula. Os valores das exergias químicas de substâncias de uso mais comum são tabelados (SZARGUT ET AL., 1988; KOTAS, 1995). Para as demais substâncias, o cálculo da exergia química pode ser efetuado por meio de uma reação de referência que envolva a substância em questão e outras presentes no ambiente de referência. $A$ partir dos coeficientes estequiométricos $x$ dos $i$ reagentes e $j$ produtos da reação, além da energia livre de Gibbs de reação $\Delta G_{0}$, a exergia química $b_{q u}$ pode ser calculada em base molar por meio da Equação 14.

$$
\bar{b}_{q u}=-\Delta G_{0}-\left[\sum_{i} x_{i} \bar{b}_{q u, i}\right]_{\text {reagentes }}+\left[\sum_{j} x_{j} \bar{b}_{q u, j}\right]_{\text {produtos }}
$$

Para o caso de misturas, há uma parcela adicional de trabalho envolvida na separação dos componentes. A Equação 15 indica o cálculo da exergia química de uma mistura ideal de $i$ componentes. 


$$
\bar{b}_{q u, m i s t}=\sum_{i} x_{i} \bar{b}_{q u, i}+\bar{R} T_{0} \sum_{i} x_{i} \ln x_{i}
$$

Existe um método alternativo para o cálculo da exergia química de uma substância a partir da análise dos grupos químicos que a compõem, denominado de método da contribuição. Por este método, uma substância tem sua estrutura química dividida em grupos menores e sua exergia química é a soma das exergias químicas de cada grupo que a compõe. Szargut et al. (1988) apresenta as exergias químicas de grupos como $\mathrm{OH}, \mathrm{CH}_{3}$ e nitrogênio ligado a um anel aromático, por exemplo.

\subsection{TERMODINÂMICA E CORPO HUMANO}

Sob o ponto de vista termodinâmico, pode-se observar uma série de processos de conversão de energia no corpo, destacando-se a conversão da energia química de um combustível em outras formas de energia. O combustível do corpo são os alimentos ingeridos, que são metabolizados pelo organismo e fornecem energia para a manutenção das funções vitais do mesmo, execução de movimentos e manutenção da temperatura corporal (PREK; BUTALA, 2010).

O entendimento dos princípios físicos de funcionamento do corpo como um todo pode ser feito a partir da compreensão dos processos realizados separadamente pelos órgãos vitais. O coração, por exemplo, pode ser analisado como uma bomba, assim como o sistema respiratório pode ser modelado como um trocador de massa e um conjunto cilindro-pistão, onde o pulmão é o cilindro e os músculos respiratórios são o pistão, exercendo uma força para variação do volume do cilindro.

Partindo desse princípio, assim como ocorre com os equipamentos e processos mecânicos, o rendimento do corpo humano e de seus sistemas também pode ser avaliado a partir das leis e conceitos da termodinâmica. 


\subsubsection{Modelo do sistema térmico}

Os seres humanos, como animais homeotérmicos e endotérmicos, têm a capacidade de manter a sua temperatura corporal interna dentro de uma faixa estreita de temperatura, em torno dos $37^{\circ} \mathrm{C}$, para uma faixa abrangente de temperaturas do ar externo, conforme mostrado na Figura 2.

Figura 2: Variação da temperatura corporal em função da temperatura do ar ambiente.

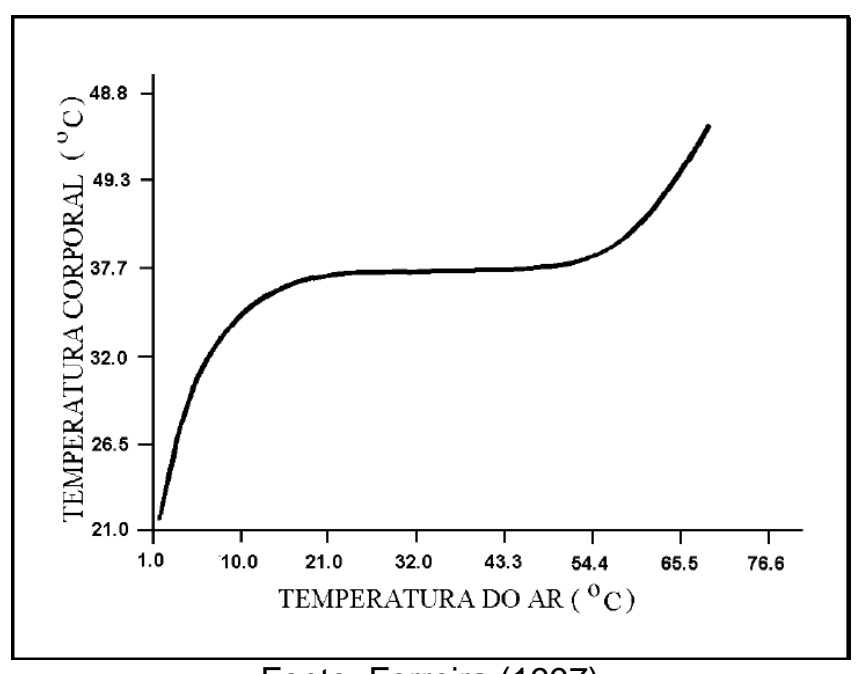

Fonte: Ferreira (1997).

A manutenção dessa temperatura é atribuição do sistema térmico do corpo, composto por outros dois sistemas: passivo e termorregulador. O primeiro está relacionado com as trocas de calor e os fluxos de entalpia entre o corpo e o ambiente, ao passo que o segundo é o sistema de controle que coordena a atuação dos mecanismos responsáveis pela manutenção da temperatura interna.

O sistema térmico do corpo humano é bastante complexo e seu funcionamento ainda não foi totalmente esclarecido. Diversos modelos foram desenvolvidos, com diferentes graus de complexidade, a fim de melhor compreender a operação desse sistema. Wissler (1961) foi o pioneiro nessa área, criando um modelo dividido em seis cilindros homogêneos onde o sangue e a variação da energia interna devido ao metabolismo são uniformemente distribuídos. Objetivando aplicações na área de Conforto Térmico, Fanger (1967) desenvolveu um modelo que representa o corpo 
como um cilindro uniforme, admitindo regime permanente, fluxo de calor uniforme, sem variação da energia interna e neutralidade térmica. Posteriormente, surgiu o modelo de Gagge (1972), também constituído por um cilindro, porém apresentando algumas evoluções com relação ao modelo de Fanger (1967). Gagge (1972) dividiu o cilindro em duas camadas, núcleo e pele, acrescentando ao balanço de energia do corpo parcelas referentes à convecção sanguínea e a condução entre as camadas. Além disso, seu modelo permite a análise do sistema térmico em regime transiente. Posteriormente, Wissler (1985) aprimorou seu modelo anterior, dividindo o corpo em dezesseis cilindros que, por sua vez, foram divididos em quatro camadas (núcleo, músculo, gordura e pele) com propriedades térmicas variáveis. Cada segmento possui seu próprio reservatório sanguíneo e a transferência de calor entre veias e artérias adjacentes também foi considerada.

Evoluindo na questão da divisão em camadas, Fiala (1999) apresentou um modelo dividido em sete camadas: cérebro, pulmão, osso, músculo, víscera, gordura e pele. Cada um dos quinze segmentos era dividido em três setores anulares cuja combinação das camadas era variável. Ferreira (2001) apresentou um modelo composto também por quinze segmentos, porém de seções transversais elípticas, para melhor adequação à geometria real de cada segmento. Às sete camadas apresentadas por Fiala (1999), somou-se o coração. Além disso, a composição de cada segmento também é variável. Pela sua complexidade e abrangência, o modelo de Ferreira (2001) será mais bem detalhado a seguir.

O modelo foi elaborado considerando um indivíduo padrão de $67 \mathrm{~kg}, 14 \%$ de gordura, 1,76 m de altura, 1,8 $\mathrm{m}^{2}$ de área superficial e $47 \mathrm{~W} / \mathrm{m}^{2}$ de metabolismo basal. A partir de imagens reais dos segmentos do corpo e utilizando um editor de imagens, foi determinada a excentricidade da elipse representativa de cada segmento, sendo alguns segmentos divididos em mais de uma seção para representar a variação da composição das camadas, conforme mostrado na Figura 3 para o caso do tronco. Cada uma das oito camadas é caracterizada de acordo com seu volume, condutividade térmica, calor específico, vazão de sangue, massa especifica e metabolismo basal. 
Figura 3: Representação elíptica do tronco no modelo de Ferreira (2001).
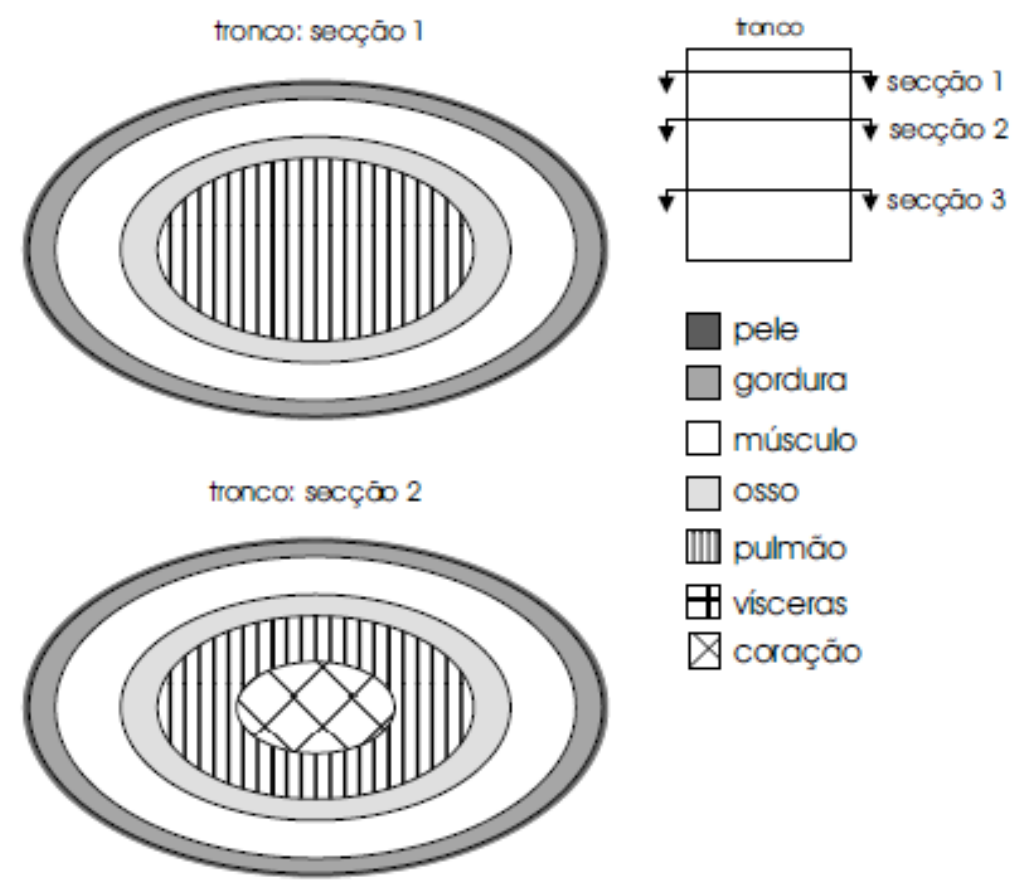

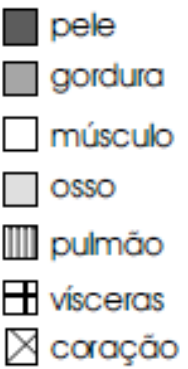

tronco: secçōo 3

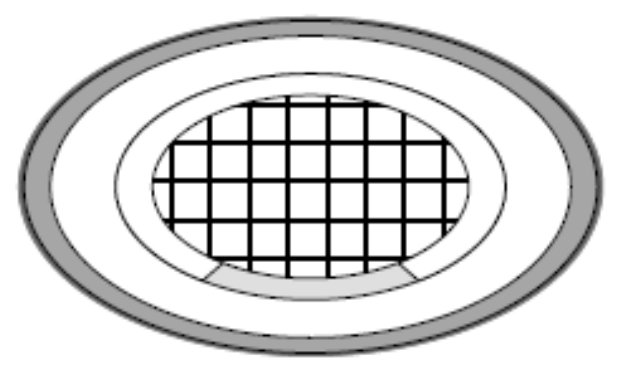

Fonte: Ferreira (2001).

Alguns aspectos do modelo, bem como os princípios do seu sistema de controle, serão detalhados nas próximas seções.

3.2.1.1 Transferência de calor e massa entre corpo e ambiente

As interações entre o corpo e o ambiente se dão pela transferência de calor por convecção e radiação e pelos fluxos de entalpia da evaporação e respiração. O valor da parcela relativa à convecção é obtido por: 


$$
\dot{Q}_{c}=f_{r p} h_{c}\left(T_{r p}-T_{a}\right)
$$

sendo: $\dot{Q}_{c}=$ taxa de calor transferido por convecção $\left[\mathrm{W} / \mathrm{m}^{2}\right]$;

$f_{r p}=$ razão entre a área externa do corpo vestido e nu;

$h_{c}=$ coeficiente de transferência de calor por convecção $\left[\mathrm{W} /\left(\mathrm{m}^{2} . \mathrm{K}\right)\right]$;

$T_{r p}=$ temperatura da superfície externa da roupa $\left[{ }^{\circ} \mathrm{C}\right]$ ou $[\mathrm{K}]$;

$T_{a}=$ temperatura do ar ambiente $\left[{ }^{\circ} \mathrm{C}\right]$ ou $[\mathrm{K}]$.

O calor transferido por radiação é:

$$
\dot{Q}_{r}=f_{r p} h_{r}\left(T_{r p}-\bar{T}_{r}\right)
$$

sendo: $\dot{Q}_{r}=$ taxa de calor transferido por radiação $\left[\mathrm{W} / \mathrm{m}^{2}\right]$;

$h_{r}=$ coeficiente linearizado de transferência de calor por radiação $\left[\mathrm{W} /\left(\mathrm{m}^{2} . \mathrm{K}\right)\right]$;

$\bar{T}_{r}=$ temperatura radiante média $\left[{ }^{\circ} \mathrm{C}\right]$ ou $[\mathrm{K}]$.

O cálculo da entalpia transferida do corpo para o ambiente por evaporação é constituída de uma parcela referente à difusão de água para a pele e de outra referente à evaporação do suor, conforme a Equação 18. O coeficiente $w$ indica a saturação da pele, variando de 0,06 , quando só há difusão, a 1, quando a pele está coberta de suor.

$$
H_{e v}=w_{s t} \frac{P_{v, p e l e}-\phi_{a} P_{v, 0}}{R_{e v, r p}+\frac{1}{f_{r p} h_{e v}}}
$$

sendo: $H_{e v}=$ fluxo de entalpia associado à evaporação $\left[\mathrm{W} / \mathrm{m}^{2}\right]$

$w_{s t}=$ coeficiente de saturação da pele;

$P_{v, p e l e}$ - pressão de saturação do vapor na superfície da pele [Pa];

$\Phi_{a}=$ umidade relativa do ar;

$P_{v, 0}=$ pressão parcial do vapor no $\operatorname{ar}[\mathrm{Pa}]$;

$R_{e v, r p}=$ resistência à evaporação imposta pela roupa $\left[\left(\mathrm{Pa} \cdot \mathrm{m}^{2}\right) / \mathrm{W}\right]$;

$h_{e v}=$ coeficiente evaporativo [W/(Pa.m²)] Equação 19 


$$
h_{e v}=1,74 \times 10^{-2} h_{c}
$$

O fluxo de entalpia através da respiração ocorre pela variação da umidade e da temperatura do ar inspirado e expirado e é dado por:

$$
H_{r e s}=\dot{m}_{a} h_{l v}\left(\omega_{e x}-\omega_{i n}\right)+\dot{m}_{a} c_{p, a}\left(T_{e x}-T_{i n}\right)
$$

sendo: $H_{\text {res }}=$ fluxo de entalpia associado à respiração [W];

$\dot{m}_{a}=$ ventilação pulmonar [kg de ar seco/s];

$h_{l v}=$ entalpia de vaporização da água $[\mathrm{J} / \mathrm{kg}]$;

$\omega_{e x}=$ umidade absoluta do ar expirado [kg de vapor/kg de ar seco];

$\omega_{\text {in }}=$ umidade absoluta do ar inspirado [kg de vapor/kg de ar seco];

$c_{p, a}=$ calor específico do ar seco $[\mathrm{J} /(\mathrm{kg} . \mathrm{K})]$;

$T_{e x}=$ temperatura do ar expirado $\left[{ }^{\circ} \mathrm{C}\right]$ ou $[\mathrm{K}]$;

$T_{\text {in }}=$ temperatura do ar inspirado $\left[{ }^{\circ} \mathrm{C}\right]$ ou $[\mathrm{K}]$.

3.2.1.2 Transferência de calor interna ao corpo

O modelo é dividido em segmentos e compartimentos que podem apresentar temperaturas diferentes. Portanto, dentro do corpo também existe transferência de calor. Internamente ao corpo ocorre transferência de calor por condução tridimensional nas camadas, além da convecção entre sangue e tecido. A variação da temperatura do tecido é dada aplicando-se o balanço de energia, conforme indicado na Equação 21. Os termos à direita da igualdade representam, respectivamente, a condução de calor no tecido, a troca de calor por convecção entre sangue e tecido e o metabolismo.

$$
\rho_{t} c_{t} \frac{d T_{t}}{d t}=k_{t} \nabla^{2} T_{t}+\dot{V}_{s g} \rho_{s g} c_{s g}\left(T_{a r, i}-T_{t}\right)+\dot{M}
$$

sendo: $\rho_{t}=$ massa específica do tecido $\left[\mathrm{kg} / \mathrm{m}^{3}\right]$;

$c_{t}=$ calor específico do tecido $[\mathrm{J} /(\mathrm{kg} . \mathrm{K})]$; 
$T_{t}=$ temperatura do tecido $[\mathrm{K}]$;

$t=$ tempo $[\mathrm{s}]$

$k_{t}=$ condutividade térmica do tecido $[\mathrm{W} /(\mathrm{m} . \mathrm{K})]$;

$V_{s g}=$ vazão de sangue no tecido $\left[\mathrm{m}^{3} /\left(\mathrm{m}^{3} . \mathrm{s}\right)\right] ;$

$\rho_{s g}=$ massa específica do sangue $\left[\mathrm{kg} / \mathrm{m}^{3}\right]$;

$c_{s g}=$ calor específico do sangue $[\mathrm{J} /(\mathrm{kg} \cdot \mathrm{K})]$;

$T_{a r, i}=$ temperatura do sangue arterial dos pequenos vasos do elemento $i[\mathrm{~K}]$;

$\hat{M}=$ metabolismo por unidade de volume $\left[\mathrm{W} / \mathrm{m}^{3}\right]$.

\subsubsection{Sistema de controle}

O sistema de controle da temperatura corporal do modelo é acionado a partir dos valores de temperatura medidos pelos sensores térmicos localizados na pele e no hipotálamo. Os atuadores na regulação da temperatura são a vazão de sangue na pele, a sudorese e os calafrios. A Figura 4 mostra o diagrama de blocos do sistema de controle.

Figura 4: Representação do sistema termorregulador do corpo humano.

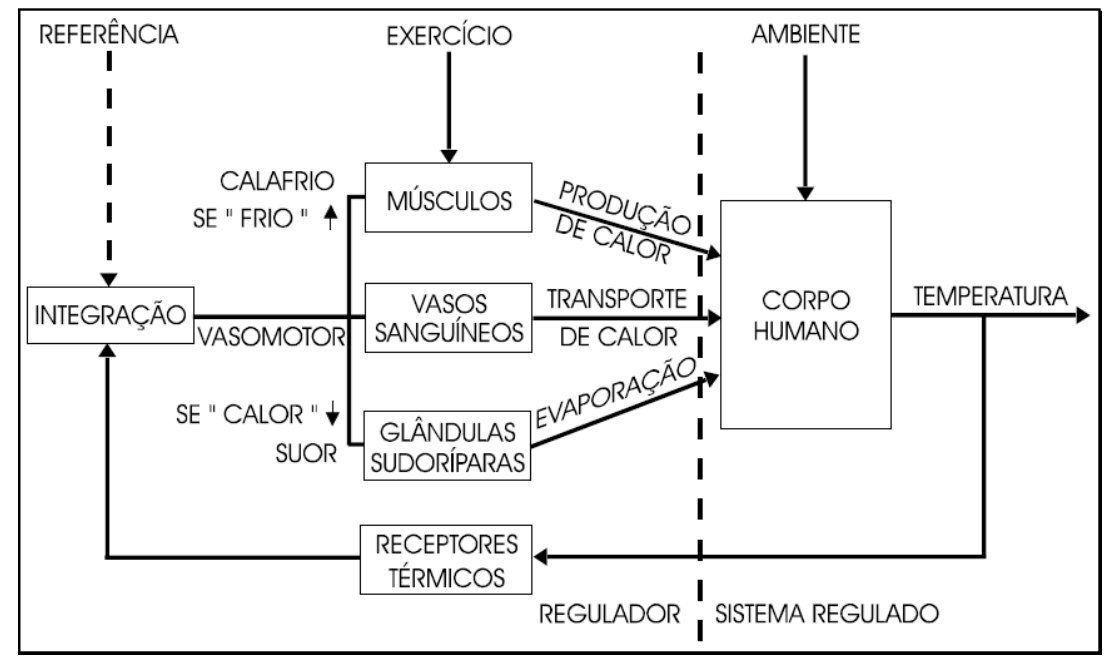

Fonte: Ferreira e Yanagihara (1997).

A variação da vazão de sangue na pele é fornecida pela Equação 22 e seus valores mínimo e máximo são, respectivamente, $0,5 \mathrm{ml} /(100 \mathrm{~g} \cdot \mathrm{min})$ e $20 \mathrm{ml} /(100 \mathrm{~g} \cdot \mathrm{min})$. 


$$
\Delta \dot{V}_{s g, j}=K_{1}\left(T_{h i}-T_{h i, \text { ref }}\right)+K_{2}\left(\bar{T}_{\text {pele }}-\bar{T}_{\text {pele }, \text { ref }}\right)
$$

sendo: $\Delta \dot{V}_{s g, j}=$ variação da vazão de sangue na pele do elemento $j[\mathrm{ml} /(100 \mathrm{~g} . \mathrm{min})]$;

$K_{1}=$ constante $[10 \mathrm{ml} /(100 \mathrm{~g} \cdot \mathrm{min})]$;

$T_{h i}=$ temperatura do hipotálamo $\left[{ }^{\circ} \mathrm{C}\right]$;

$T_{h i, r e f}=$ temperatura de referência do hipotálamo $\left[{ }^{\circ} \mathrm{C}\right]$;

$K_{2}=$ constante $[1 \mathrm{ml} /(100 \mathrm{~g} \cdot \mathrm{min})]$

$\bar{T}_{\text {pele }}=$ temperatura média da superfície da pele $\left[{ }^{\circ} \mathrm{C}\right] ;$

$\bar{T}_{\text {pele,ref }}=$ temperatura média de referência da pele $\left[{ }^{\circ} \mathrm{C}\right]$.

O controle da sudorese inclui o efeito da temperatura local da pele e é expresso pela Equação 23.

$$
H_{e v, j}=\left[K_{3}\left(T_{h i}-T_{h i, r e f}\right)+K_{4}\left(\bar{T}_{\text {pele }}-\bar{T}_{\text {pele, ref }}\right)\right] \exp \left[\frac{\left(\bar{T}_{\text {pele }, j}-\bar{T}_{\text {pele, ref }}\right)}{10}\right]
$$

sendo: $H_{e v, j}=$ fluxo de entalpia associado ao suor no elemento $j\left[\mathrm{~W} / \mathrm{m}^{2}\right]$;

$\bar{T}_{p e l e, j}=$ temperatura média da superfície da pele no elemento $j\left[{ }^{\circ} \mathrm{C}\right]$;

$K_{3}=$ constante $\left[197 \mathrm{~W} /\left(\mathrm{m}^{2} .{ }^{\circ} \mathrm{C}\right)\right]$;

$K_{4}=$ constante $\left[23 \mathrm{~W} /\left(\mathrm{m}^{2} . \stackrel{\circ}{ } \mathrm{C}\right)\right]$.

A variação do metabolismo devido à geração de calafrios, ou tremores, é dada por:

$$
\begin{gathered}
\Delta M_{t r} A_{D}=K_{5}\left(T_{\text {hi,ref }}-T_{h i}\right)\left(\bar{T}_{\text {pele, ref }}-\bar{T}_{\text {pele }}\right)+K_{6}\left(\bar{T}_{\text {pele,ref }}-\bar{T}_{\text {pele }}\right) \\
A_{D}=0,007184 m_{\text {corpo }}^{0,425} L_{\text {corpo }}^{0,725}
\end{gathered}
$$

sendo: $\Delta M_{t r}=$ variação do metabolismo devido aos calafrios $\left[\mathrm{W} / \mathrm{m}^{2}\right]$;

$K_{5}=$ constante $\left[41,9 \mathrm{~W} /{ }^{\circ} \mathrm{C}^{2}\right]$

$K_{6}=$ constante $[8,1 \mathrm{~W} / \stackrel{\circ}{ } \mathrm{C}]$;

$A_{D}=$ área superficial da pele ou área de Du Bois $\left[\mathrm{m}^{2}\right]$; 


$$
\begin{aligned}
& m_{\text {corpo }}=\text { massa corporal }[\mathrm{kg}] \\
& L_{\text {corpo }}=\text { altura corporal }[\mathrm{cm}] .
\end{aligned}
$$

\subsubsection{Modelo simplificado do sistema térmico}

Devido à sua complexidade geométrica, a utilização do modelo descrito anteriormente não é adequada para casos onde os dados antropométricos são consideravelmente distintos dos apresentados pelo indivíduo padrão, como no caso de crianças e obesos. Tendo em mente a aplicação da análise termodinâmica do corpo desde o nascimento até a velhice, Mady (2013) propõe um modelo simplificado que permite alterações antropométricas com maior facilidade. Conforme indicado na Figura 5, o modelo consiste em um cilindro com quatro camadas concêntricas representando pele, gordura, músculo e núcleo.

Figura 5: Modelo simplificado do sistema térmico.

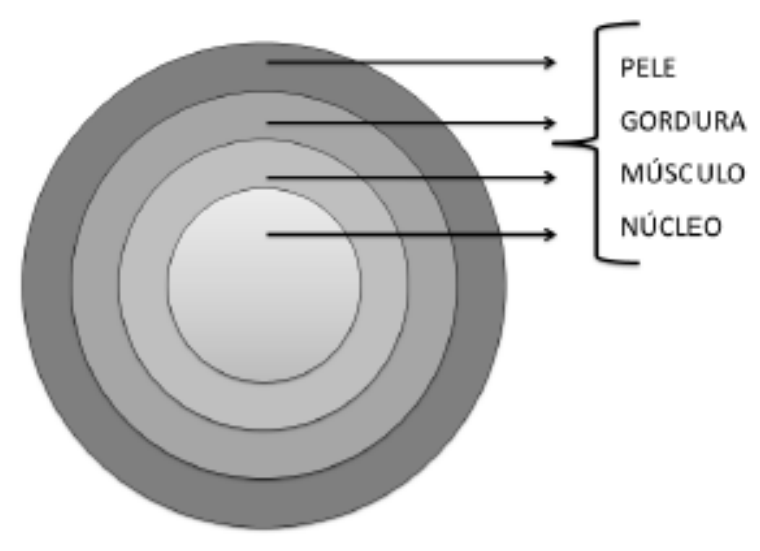

Fonte: Mady (2013).

As propriedades de cada camada foram determinadas por meio de média ponderada das propriedades termofísicas dos órgãos e tecidos apresentadas por Ferreira (1997). Desta maneira, chegou-se aos dados apresentados na Tabela 1, em que $\rho$, $k, c, M^{\prime \prime \prime}$ e $w b_{t}$ representam, respectivamente, massa específica, condutividade térmica, calor específico, metabolismo por unidade de volume e perfusão sanguínea. Pela configuração do modelo, é possível variar a altura do cilindro e a espessura de 
cada uma das camadas de modo a se obter um modelo com características antropométricas e composição corporal próximas às do indivíduo objeto de estudo. Dada sua simplicidade, o processo de ajuste dos parâmetros do modelo dificilmente obtém todas as características iguais às do indivíduo. Nesse caso, por serem dados mais relevantes nos cálculos térmicos, deve-se determinar a altura e as espessuras da camada priorizando a convergência dos valores de metabolismo e área superficial.

Tabela 1: Propriedades termofísicas das camadas do modelo de Mady (2013).

\begin{tabular}{lccccc}
\hline Camada & $\boldsymbol{\rho ( \mathbf { k g } / \mathbf { m } ^ { \mathbf { 3 } } )}$ & $\boldsymbol{k}(\mathbf{W} /(\mathbf{m} . \mathbf{K}))$ & $\boldsymbol{c}(\mathbf{J} /(\mathbf{k g} \cdot \mathbf{K}))$ & $\boldsymbol{M}^{\prime \prime \prime}\left(\mathbf{W} / \mathbf{m}^{\mathbf{3}}\right)$ & $\left.\mathbf{w b}_{\boldsymbol{t}}\left(\mathbf{m}_{\mathbf{s g}} \mathbf{3}^{\mathbf{3}} / \mathbf{m}_{\mathbf{t}}{ }^{\mathbf{3}} \cdot \mathbf{s}\right)\right)$ \\
\hline Pele & 1085 & 0,43 & 3680 & 368,1 & 361,7 \\
\hline Gordura & 920 & 0,21 & 2300 & 368,4 & 76,7 \\
\hline Músculo & 1085 & 0,51 & 3800 & 684,2 & 542,0 \\
\hline Núcleo & 1119 & 0,50 & 2679 & 2653,0 & 4155,0 \\
\hline
\end{tabular}

Fonte: Mady (2013).

O modelo se baseia no método da capacitância concentrada e nas hipóteses simplificadoras de que as propriedades são uniformemente distribuídas pelo volume; a condução de calor é unidimensional na direção radial; a temperatura é constante em cada camada; o sangue possui temperatura uniforme e dependente do tempo e deixa o tecido em equilíbrio térmico com o mesmo; não é considerada a resistência da roupa e o modelo encontra-se em posição ereta. A distribuição de temperatura no modelo é dada pela Equação 26, de forma análoga à Equação 21, onde a variação da energia interna é resultado da transferência de calor por condução nas camadas, convecção entre sangue e tecido e conversão de energia associada ao metabolismo. A Figura 6 confronta os resultados obtidos pelo modelo completo de Ferreira (2001) com os obtidos pelo modelo simplificado de Mady (2013).

$$
\rho_{t} c_{t} V_{t} \frac{\partial T_{t}}{\partial t}=\frac{\partial}{\partial r}\left(k_{t} A_{t} \frac{\partial T_{t}}{\partial r}\right)+\left(\rho_{t} V_{t}\right)\left(\rho_{s} c_{s}\right) w b_{t}\left(T_{s}-T_{i}\right)+M^{\prime \prime \prime} V_{t}
$$


Figura 6: Comparativo entre os perfis de temperatura obtidos nos modelos completo (a) e simplificado (b).

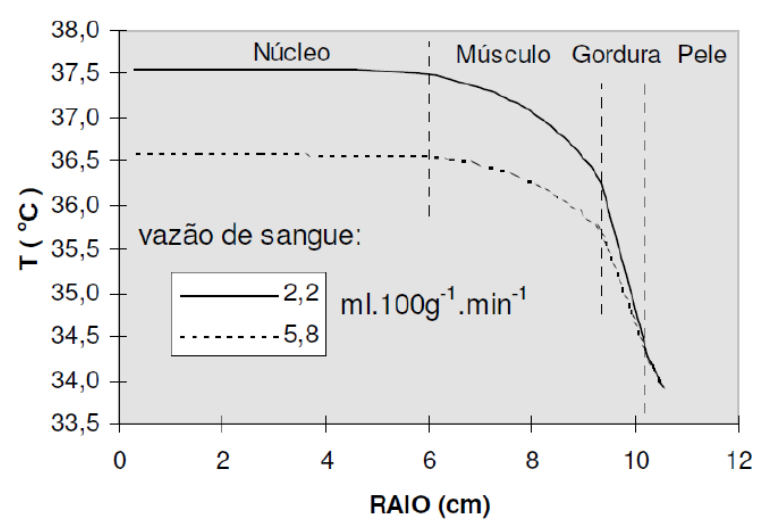

a

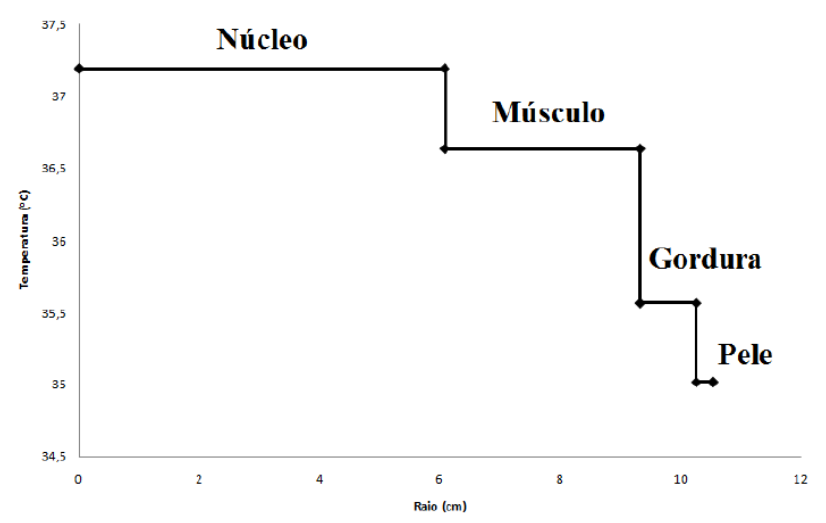

b

Fonte: Mady (2013).

\subsubsection{Entropia e corpo humano}

Uma das primeiras tentativas de relacionar o funcionamento do corpo à sua variação de entropia foi apresentada por Schrödinger (1944) no livro What's life. Segundo ele, o corpo, assim como todos os outros sistemas biológicos, tende a um estado de equilíbrio com o ambiente onde sua entropia seria máxima. A fim de evitar este estado, que equivale à morte, o corpo alimenta-se de entropia negativa do ambiente. Esse fluxo de entropia negativa, denominada por Schrödinger de negentropy, não contraria a Segunda Lei da Termodinâmica, uma vez que o corpo não é um sistema fechado.

llya Prigogine, autor do princípio de mínima geração de entropia para sistemas estacionários de não-equilíbrio, aplicou inicialmente seus conceitos a sistemas biológicos durante o desenvolvimento de sua teoria que the rendeu em 1977 o Prêmio Nobel de Química. Relacionando a maior parte da entropia gerada ao metabolismo, ele concluiu que os organismos vivos tendem a um estado de geração mínima de entropia (PRIGOGINE; WIAME, 1946).

Zotin e Zotina (1967) testaram a validade do princípio de mínima geração de entropia a partir de dados experimentais relativos à taxa metabólica de diferentes espécies animais desde o desenvolvimento embrionário até a fase adulta. Segundo 
os autores, na fase de desenvolvimento embrionário, na qual o embrião é considerado um sistema fechado, e na presença de células cancerígenas e regeneração tecidual, há um aumento da taxa de geração de entropia. Entretanto, durante o desenvolvimento e envelhecimento, essa taxa é progressivamente reduzida, comprovando o princípio de Prigogine.

Outro autor que também trabalhou no sentido de comprovar esse princípio foi Balmer (1982). A fim de estudar experimentalmente o ciclo de vida completo de um animal, ele escolheu como objeto de estudo um peixe cujo ciclo de vida dura cerca de doze meses. Seus resultados, mostrados na Figura 7, além de comprovar o princípio de Prigogine para o desenvolvimento e envelhecimento, também estão de acordo com Zotin e Zotina (1967) com relação ao desenvolvimento embrionário. Outra conclusão relevante é que, para animais cuja temperatura corporal varia com a temperatura ambiente, denominados pecilotérmicos, o metabolismo depende da temperatura.

Aoki (1987, 1989, 1990, 1991) desenvolveu uma série de estudos relacionados à geração de entropia em seres vivos. Além de comprovar o princípio da mínima geração de entropia para humanos, Aoki (1990) estudou os efeitos da atividade física na geração de entropia do corpo a partir de dados experimentais de Hardy e Du Bois (1938), concluindo que, com relação à entropia gerada em condição basal, há um aumento de 1,5 a 2,4 vezes para exercício leve e de 6 a 8 vezes para exercício pesado. Dados referentes à entropia gerada em condição basal, exercício pesado e repouso pós-atividade são descritos na Figura 8. Outra informação relevante obtida por Aoki (1991) indica que, para seres humanos, não há influência significativa da temperatura ambiente na geração de entropia. Juntamente com o estudo de Balmer (1982), pode-se concluir que a geração de entropia em animais homeotérmicos não é significativamente influenciada pela temperatura externa. 
Figura 7: Taxa de geração de entropia em função da idade para peixes.

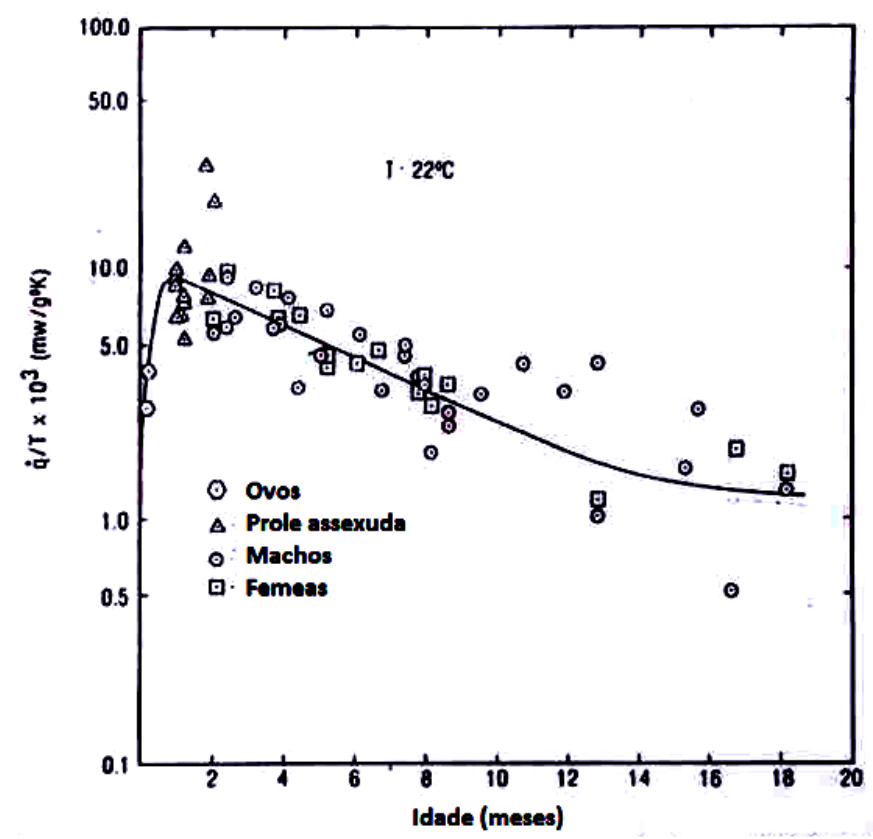

Fonte: Adaptado de Balmer (1982).

Figura 8: Taxa de geração de entropia em função do nível de exercício.

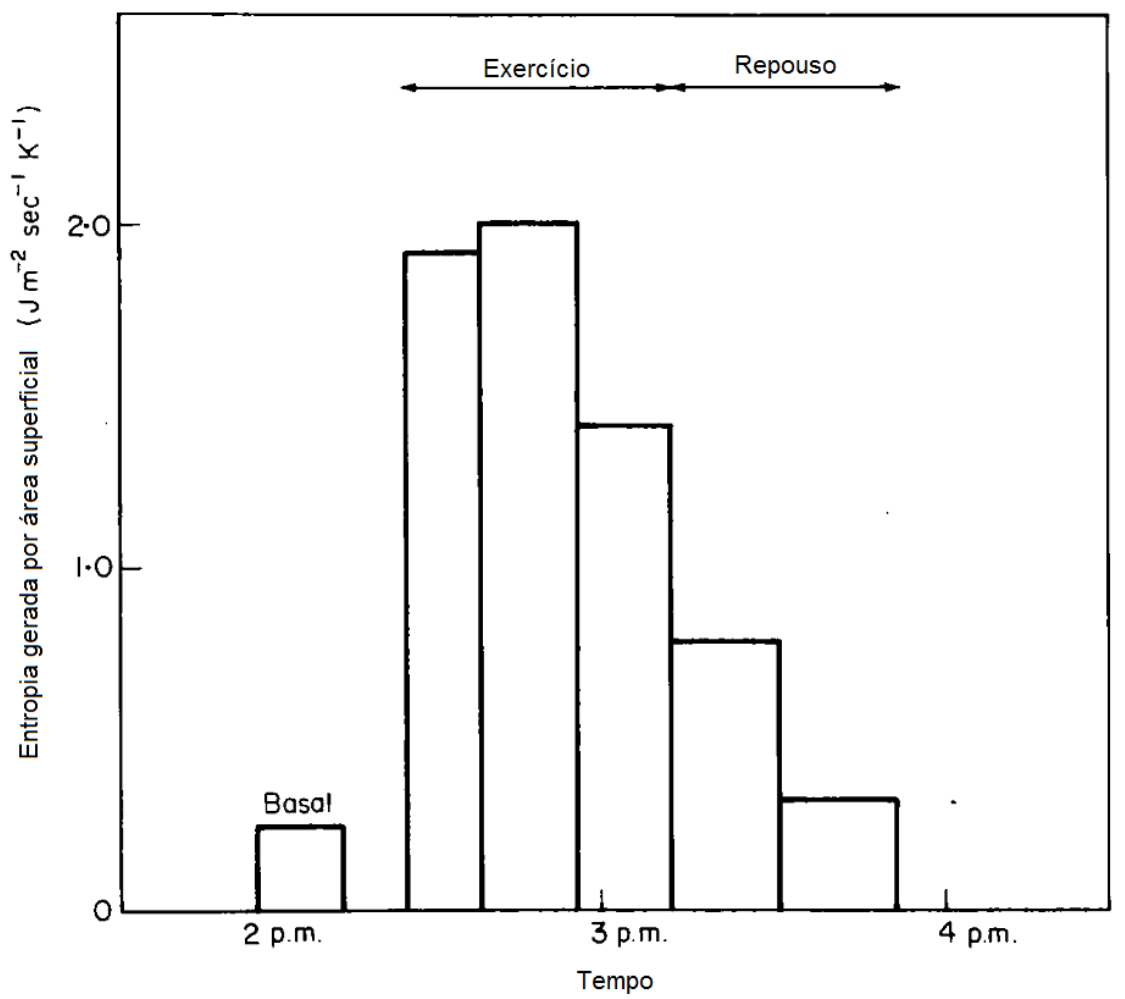

Fonte: Adaptado de Aoki (1990).

A primeira aplicação de análise exergética ao corpo foi feita por Batato et al. (1990). Seu principal resultado indica que o metabolismo exergético é muito próximo do 
energético e que a eficiência exergética do corpo, para condições basais, é próxima de zero. Um modelo completo do corpo baseado na Segunda Lei da Termodinâmica foi proposto por Rahman (2007). Os fluxos de entropia são mostrados na Figura 9. A partir de seu modelo, o autor calculou os valores de entropia gerada para diferentes níveis de atividade física. Assim como em Aoki (1990), os dados obtidos por Rahman (2007) indicam uma relação direta entre atividade física e geração de entropia, conforme mostrado na Figura 10. Porém, o aumento da entropia gerada devido à atividade obtido pelo último não foi tão significativo quanto o primeiro.

Figura 9: Representação dos fluxos entre corpo e ambiente proposta por Rahman (2007).

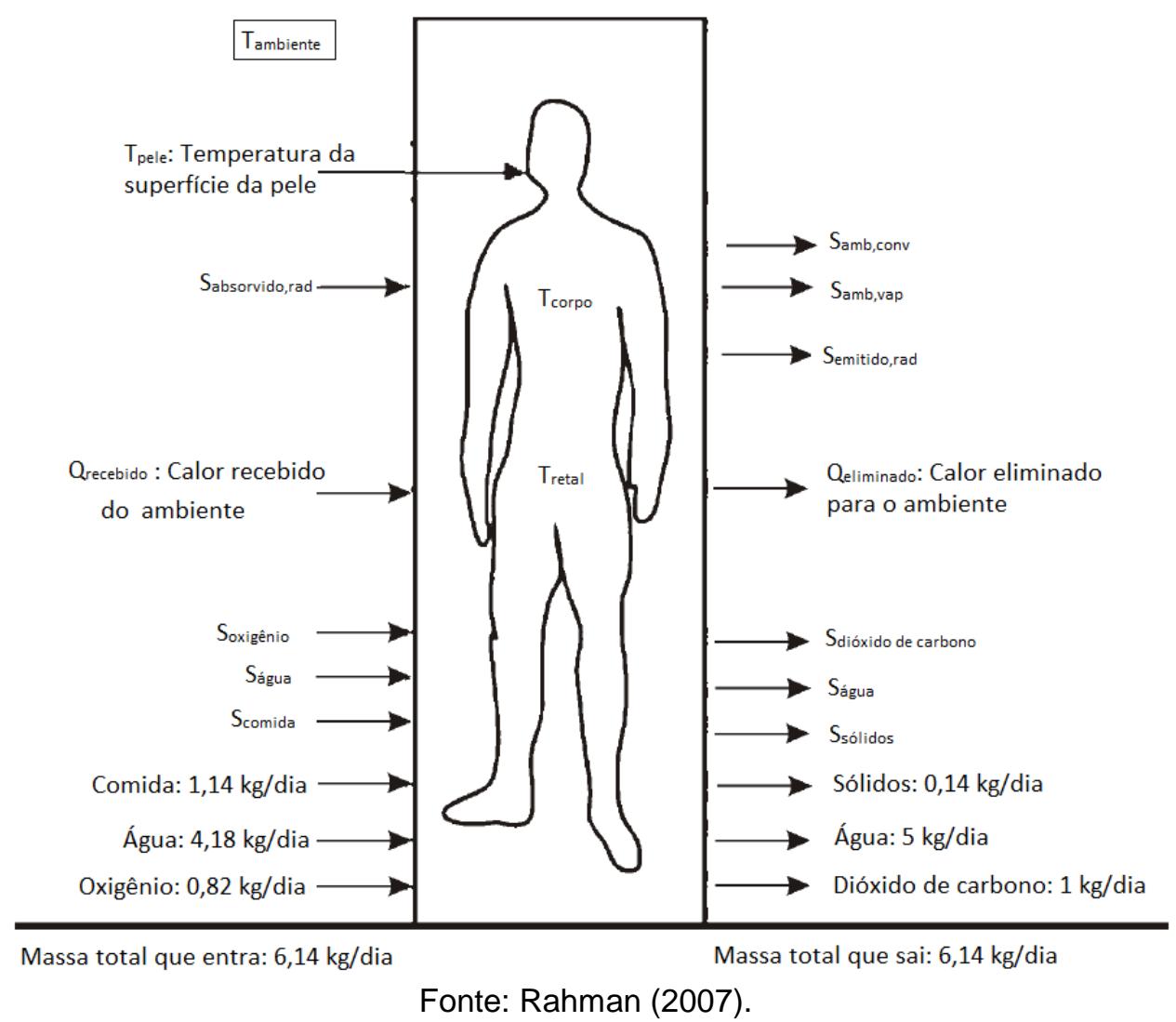


Figura 10: Relação entre taxa de geração de entropia e idade para diferentes níveis de atividade física.

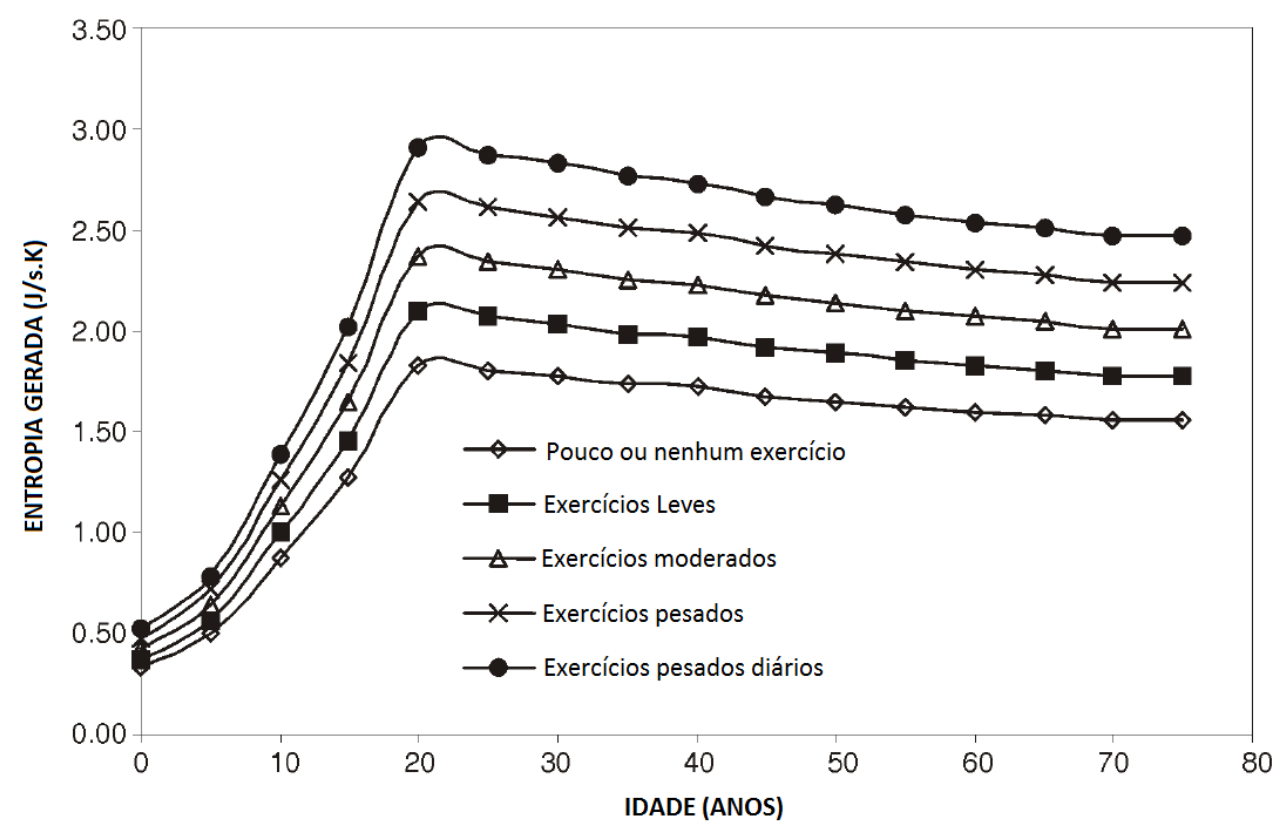

Fonte: Adaptado de Rahman (2007).

O aumento da entropia gerada devido ao exercício físico também foi comprovado por Silva e Annamalai (2008). Adicionalmente, esses autores estudaram o efeito da composição da dieta na expectativa de vida a partir dos dados de entropia gerada e concluíram que apenas a ingestão de proteínas tem efeito direto na expectativa de vida (SILVA; ANNAMALAI, 2009). Em uma dieta onde a ingestão de proteína segue o mínimo recomendado por nutricionistas, a expectativa de vida aumenta em pouco mais de três anos. Além disso, eles calcularam a expectativa de vida para a sociedade americana e obtiveram valores próximos aos estatísticos.

Ainda com relação à influência da atividade física, Albuquerque Neto et al. (2010) aplicaram a análise exergética ao corpo humano, separando-o em sistema respiratório e tecidos. Os autores concluíram que durante a realização de atividades físicas, a maior parte da exergia destruída no corpo ocorre nos pulmões.

Mady (2013) desenvolveu um modelo completo para análise exergética do corpo, que foi aplicado posteriormente à condição de atividade física, concluindo que a eficiência exergética do corpo aumenta de acordo com o nível de atividade física. Neste mesmo trabalho, a análise exergética também foi aplicada ao corpo a fim de melhor compreender o comportamento do sistema termorregulador adotado no 
modelo de Ferreira (2001). A exergia destruída e a eficiência exergética do corpo foram calculadas em função das constantes do sistema de controle, cujos valores validados para o modelo a partir de dados experimentais corresponderam aos pontos de mínima exergia destruída e máxima eficiência exergética. Este modelo será apresentado com mais detalhes na seção 3.5.

Outras aplicações dos conceitos de exergia destruída foram realizadas na área de conforto térmico. Baseado no modelo térmico de Gagge (1972), Prek (2006) aplicou a análise exergética ao modelo para diferentes temperaturas do ar e radiante média. Ele observou que, para uma dada condição fisiológica, há apenas uma combinação de variáveis que resulta uma destruição mínima de exergia e que há uma relação entre esse valor e o nível de conforto térmico do indivíduo com relação ao ambiente.

Figura 11: Relação entre taxa de exergia destruída e sensação subjetiva de conforto térmico.

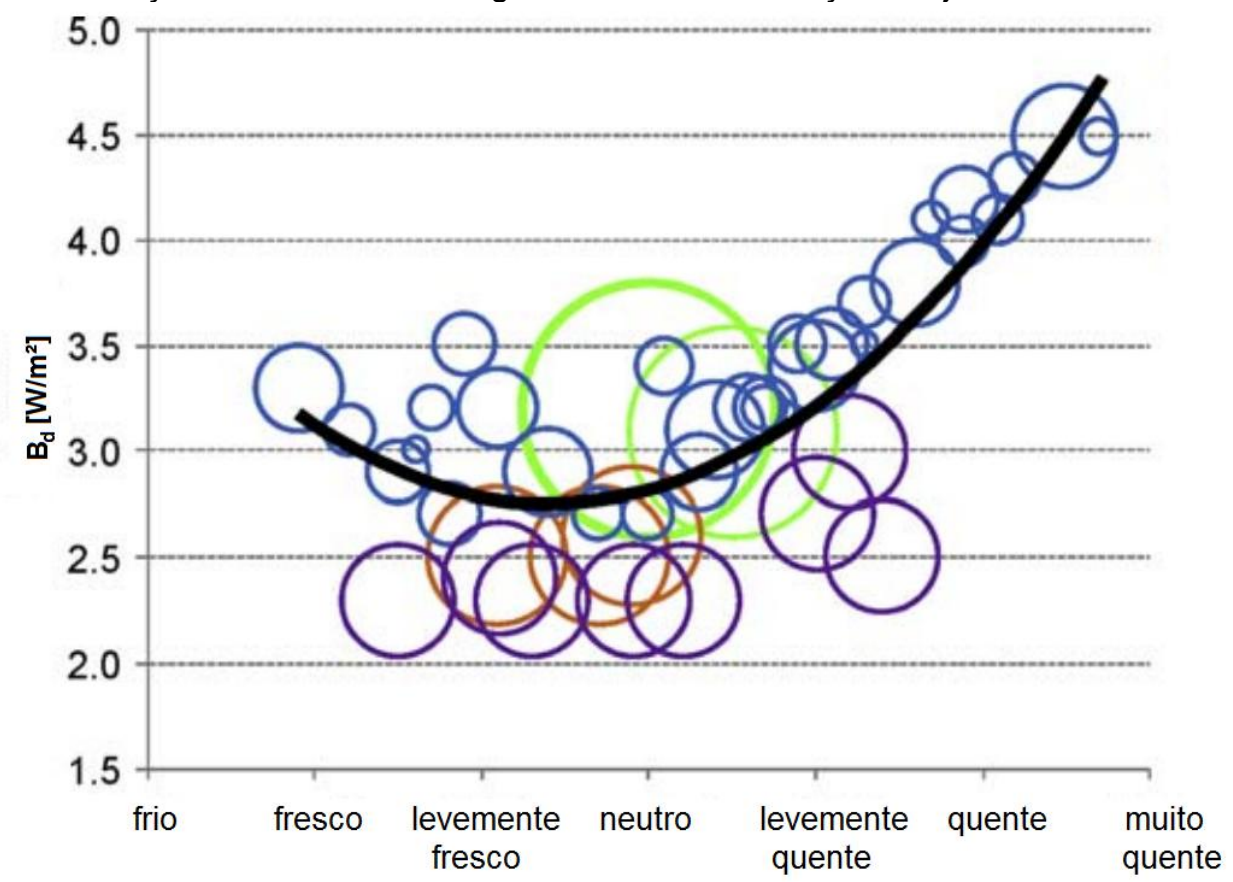

Fonte: Adaptado de Simone et al. (2011).

Simone et al. (2011) relacionaram a exergia destruída com a sensação subjetiva de conforto térmico a partir de dados de estudos anteriores para diferentes temperaturas do ar e radiante média. Confrontando os cálculos de exergia destruída pelo corpo dos indivíduos com seus votos relativos à sensação térmica, conforme exposto na Figura 11, indicou-se que o ponto de mínima exergia destruída corresponderia às condições ambientais que proporcionam sensação próxima do 
conforto térmico, ou seja, o nível mínimo de exergia destruída indicaria a condição na qual a satisfação do indivíduo com relação ao ambiente ocupado é máxima.

Reduzindo o volume de controle de análise, Genc et al. (2013) calcularam a exergia destruída de um neurônio para diferentes concentrações de glicose e concluíram que em condições extremas de privação de nutrientes, estas células destroem menos exergia. Outro trabalho associado ao metabolismo de nutrientes foi desenvolvido por Rodrigez-Illera et al. (2017). A análise exergética foi aplicada para a avaliação de diferentes tipos de carboidratos semi-industrializados, levando em conta não apenas os aspectos químicos associados às reações de oxidação, mas também a destruição de exergia nas cadeias produtivas.

\subsection{TEORIAS DO ENVELHECIMENTO}

O envelhecimento é caracterizado por um conjunto de mudanças morfofuncionais que ocorrem ao longo da vida a partir da maturação sexual e é característica de organismos multicelulares (REGOLIN; KARNIKOWSKI, 2009). Mesmo com os recentes avanços nas áreas de biologia molecular e genética, os mecanismos envolvidos no envelhecimento humano ainda não estão totalmente elucidados, havendo diferentes teorias, nenhuma completamente satisfatória, para explicá-los (JIN, 2010). A Tabela 2 lista algumas das principais teorias acerca do envelhecimento humano. Em seguida três das teorias mais discutidas são mais bem detalhadas: telomérica, taxa de vida e radicais livres.

A teoria telomérica, também denominada de senescência programada, é uma extensão do limite de Hayflick, que sugere que as células possuem um limite máximo de divisões, cerca de 50, a partir do qual começam a apresentar sinais de envelhecimento. O limite de Hayflick surgiu em 1965 por meio de observações experimentais de Leonard Hayflick e foi posteriormente explicado e detalhado por Alexey Olovnikov em 1971, originando a teoria telomérica. 
Tabela 2: Resumo das principais teorias do envelhecimento.

\section{Categoria/Teoria Descrição}

\section{Evolutiva}

\begin{tabular}{ll}
\hline Acúmulo de mutação & $\begin{array}{l}\text { Mutações que afetam a saúde e só se manifestam na velhice são } \\
\text { negligenciadas na seleção natural. }\end{array}$ \\
\hline Soma descartável & $\begin{array}{l}\text { Células somáticas só são mantidas para assegurar a continuidade } \\
\text { reprodutiva. Após a reprodução, se tornam descartáveis. }\end{array}$ \\
\hline Molecular & \\
\hline Regulação gênica & $\begin{array}{l}\text { Envelhecimento é causado por mudanças nas expressões dos genes, } \\
\text { regulando tanto o desenvolvimento quanto o envelhecimento. }\end{array}$ \\
\hline Erro catastrófico & $\begin{array}{l}\text { Queda na fidelidade da expressão gênica com a idade prejudica a } \\
\text { síntese proteica e resulta no aumento da fração de proteínas anormais }\end{array}$ \\
\hline Mutação somática & Acúmulo de dano molecular, primeiramente no DNA. \\
\hline Desdiferenciação & $\begin{array}{l}\text { Acúmulo gradual de dano molecular aleatório compromete a expressão } \\
\text { gênica. }\end{array}$ \\
\hline
\end{tabular}

\section{Celular}

\begin{tabular}{ll}
\hline Telomérica & $\begin{array}{l}\text { Fenótipos de envelhecimento são causados por um aumento na } \\
\text { frequência de células senescentes como resultado do encurtamento dos } \\
\text { telômeros. }\end{array}$ \\
\hline Radicais livres & $\begin{array}{l}\text { Metabolismo oxidativo produz radicais livres altamente reativos que } \\
\text { causam danos a proteínas, gorduras e DNA. }\end{array}$ \\
\hline Uso e desgaste & Acúmulo de danos normais. \\
\hline Apoptose ou morte & $\begin{array}{l}\text { Morte programada de células por eventos genéticos ou crise no } \\
\text { celular }\end{array}$ \\
genoma.
\end{tabular}

\section{Sistema}

\begin{tabular}{ll}
\hline Neuroendócrina & $\begin{array}{l}\text { Alteração do controle neuroendócrino da homeostase resulta em } \\
\text { alterações fisiológicas relacionadas à idade. }\end{array}$ \\
\hline Imunológica & $\begin{array}{l}\text { Declínio da função imunológica resulta no aumento de doenças } \\
\text { infecciosas e autoimunes. }\end{array}$ \\
\hline Taxa de vida & Assume uma quantidade fixa de potencial metabólico para cada \\
& organismo.
\end{tabular}
Fonte: Adaptado de Weinert \& Timiras (2003).

De acordo com Olovnikov (1996), apenas na década de 90 sua ideia acerca do envelhecimento celular veio à tona devido à publicação de resultados experimentais que a suportavam (HARLEY, 1991). A teoria da senescência programada propõe que a explicação para o limite de Hayflick está nos telômeros, que são sequências especializadas de DNA localizadas no fim da cadeia cromossômica e que se encurtam a cada divisão celular. No processo de replicação do DNA, o fim da cadeia 
não é copiado exatamente, havendo perda de informação na divisão celular. Por esse motivo existiria um número máximo de divisões antes da manifestação dos sinais de envelhecimento celular. A Figura 12 indica a diferença do processo de encurtamento do telômero em células tronco e gaméticas e demais células, denominadas de somáticas.

Um ponto interessante desta teoria está relacionado às células cancerígenas e a uma enzima denominada telomerase. Esta última é responsável por preencher o fim da cadeia de DNA perdido na divisão celular. Porém sua ação é predominante em células reprodutivas e também em células cancerígenas, o que permite a sua permanente multiplicação no corpo (HARLEY, 1991) Portanto, elevada concentração de telomerase é um indicativo da presença de tumores.

Figura 12: Comprimento do telômero em função do número de divisões celulares para células tronco e germinativas e células somáticas.

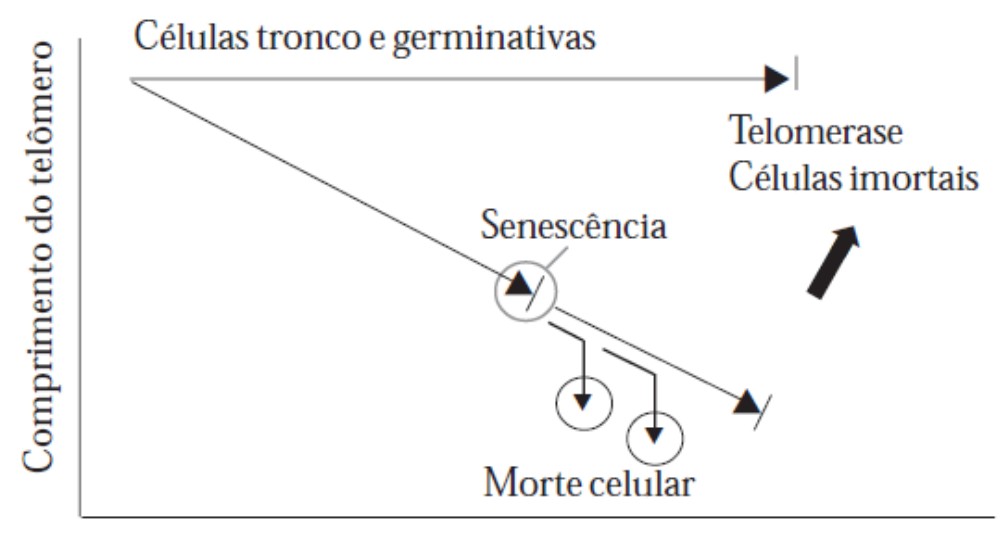

Divisões celulares

Fonte: Teixeira e Guariento (2010).

A teoria da taxa, ou velocidade, de vida, foi proposta por Pearl em 1928 baseandose na ideia defendida por Rubner (1908, apud SPEAKMAN, 2005) de que a taxa metabólica por unidade de massa diminuía conforme o tamanho característico da espécie aumentava, bem como a duração do seu ciclo de vida. De acordo com Pearl (1928), o produto entre metabolismo por unidade de massa e a duração do ciclo de vida seria constante para uma dada espécie. Portanto, a longevidade seria inversamente proporcional à taxa metabólica do indivíduo por massa e existiria um limite determinado geneticamente para a obtenção de energia via metabolismo 
(MOTA ET AL., 2004). Esta teoria está associada à ideia de que animais maiores vivem mais.

Posteriormente, Speakman (2005) identificou, a partir de comparações entre diferentes espécies da classe dos mamíferos, que o gasto metabólico possui relação inversa com o tamanho do corpo e a longevidade. Desta maneira, para cada espécie, haveria um valor máximo de gasto energético que, quando atingido, indicaria o fim da vida. Assim como há vários estudos comprovando experimentalmente esta teoria, também há outros que não mostram qualquer relação entre as variáveis citadas, especialmente para casos com variação de temperatura e atividade física, indicando que a teoria da taxa de vida pode estar no caminho certo para explicar a máxima duração da vida, mas ainda não oferece o esclarecimento completo (VAANHOLT, 2007; JIN, 2010).

A fim de melhor explicar a influência do metabolismo na expectativa de vida, Denham Harman propôs em 1955 a teoria dos radicais livres, que são substâncias químicas altamente reativas produzidas durante a oxidação dos nutrientes. Os radicais livres possuem elétrons desemparelhados que os tornam quimicamente instáveis, aumentando a taxa de reação com substâncias essenciais ao bom funcionamento celular, tais como lipídios das membranas celulares, proteínas e cadeias de DNA mitocondrial e celular, também provocando um desequilíbrio entre substâncias oxidantes e antioxidantes, levando ao chamado estresse oxidativo. 0 acúmulo, tanto dos danos causados por essas reações quanto do estresse oxidativo, leva ao envelhecimento celular, devido, principalmente, ao declínio da função mitocondrial provocado por alterações no DNA mitocondrial (HARMAN, 1955; MOTA ET AL., 2004). Resultados experimentais de Ku et al. (1993) mostraram que as taxas de produção de ânion superóxido e peróxido de hidrogênio nas mitocôndrias são inversamente proporcionais à expectativa de vida em sete espécies de mamíferos, entre roedores e ruminantes.

Essa pequena revisão sobre teorias do envelhecimento permite visualizar a complexidade desse processo e compreender a dificuldade em se chegar a uma explicação única e definitiva, uma vez que cada teoria apresenta argumentos plausíveis, ainda que nem todos tenham sido comprovados experimentalmente em humanos. Entretanto, apesar de suas diferentes abordagens, as três teorias 
descritas anteriormente apresentam uma interseção ao ligar o envelhecimento aos processos irreversíveis que ocorrem no corpo. Por esta razão, alguns autores se dedicaram a estudar a relação entre o envelhecimento e a entropia gerada no corpo humano.

\subsection{ENVELHECIMENTO E ENTROPIA}

Conforme enunciado pela Segunda Lei da Termodinâmica, a entropia de um sistema fechado e sede de processos irreversíveis, assim como o tempo, caminha apenas na direção do seu aumento. Devido a essa relação direcional entre as duas grandezas, a entropia é denominada por alguns autores, especialmente aqueles envolvidos em mecânica quântica, de flecha do tempo, do inglês arrow of time, e é constantemente utilizada em estudos relacionados à idade e surgimento do universo (LAYZER, 1975; HAWKING, 1985; VENEZIANO, 1999).

Segundo Hershey (2010), ao longo da vida, o corpo vai de um estado de elevada ordem a outro de desordem máxima, que corresponderia à morte. Por esta razão, o autor propõe a utilização da entropia como uma escala mais adequada para avaliação da progressão da vida em vez do tempo. Além disso, haveria uma quantidade máxima de energia liberada pelo corpo por meio do metabolismo que corresponderia ao nível máximo de entropia gerada a partir do qual não seria mais possível a manutenção da vida do indivíduo. Por essa razão, o aumento do metabolismo, decorrente, em alguns casos, de patologias, estaria associado a uma redução do tempo de vida. Esta ideia está em consonância com a teoria da taxa de vida e também foi explorada por outros autores. Silva e Annamalai (2008, 2009), assumindo que toda a entropia gerada pelo corpo se deve ao metabolismo e partindo dos dados estatísticos de expectativa de vida da sociedade americana, chegaram a um valor máximo de entropia gerada durante a vida de 11404 kJ/(kg.K). Análise semelhante referente à entropia total gerada ao longo da vida foi feita também pelo próprio Hershey (2010). Ele propõe o indicador de idade entrópica para avaliar a progressão da vida por meio do valor da entropia acumulada, cujos valores máximos no ciclo de vida humano por ele calculados equivalem a 10025 kJ/(kg.K) 
para homens e 10678 kJ/(kg.K) para mulheres, o que resultaria numa vida máxima de 103 e 110 anos, respectivamente.

A fim de extrapolar o conceito de idade entrópica proposto por Hershey e Silva e Annamalai, Mady (2013) aplicou a análise exergética, que será mais bem detalhada na próxima seção, ao modelo simplificado descrito no item 3.2.2 para obter a exergia destruída acumulada por unidade de massa do nascimento até a velhice para a população brasileira. Para a adaptação do modelo foram utilizados dados de altura e peso da população brasileira disponibilizados pelo IBGE (Instituto Brasileiro de Geografia e Estatística) para idades de 0 a 80 anos. Com essas informações, determinou-se a área superficial e os metabolismos basal e sedentário, que foram posteriormente utilizados para definir a altura e as espessuras das camadas constituintes do modelo simplificado para cada idade.

Os valores de exergia destruída pelo corpo em cada idade por unidade de massa foram integrados ao longo do ciclo de vida de 0 a 80 anos e chegou-se ao valor de $3091 \mathrm{MJ} / \mathrm{kg}$ de exergia destruída acumulada para condição basal e $3599 \mathrm{MJ} / \mathrm{kg}$ para atividade sedentária. O rendimento exergético foi de $3,5 \%$ e $4,3 \%$ para, respectivamente, basal e sedentário.

\subsection{MODELO EXERGÉTICO DO CORPO HUMANO}

O modelo exergético do corpo humano desenvolvido por Mady (2013) será apresentado com mais detalhes por ser o mais completo com relação aos fluxos de calor, entalpia e massa entre corpo e ambiente e a interação com o metabolismo celular. Esses fluxos são mostrados na Figura 13. O corpo foi dividido em dois volumes de controle, a saber: sistema térmico, circulatório e respiratório, denominado VC1, e metabolismo celular, chamado de VC2. No primeiro volume de controle são considerados a transferência de calor por radiação $\left(Q_{r}\right)$, convecção $\left(Q_{c}\right)$ e calor metabólico $\left(Q_{M, c o r p o}\right)$, os fluxos de entalpia da evaporação $\left(H_{e v}\right)$, do ar inspirado $\left(H_{i n}\right)$ e do expirado $\left(H_{e x}\right)$ e a parcela de trabalho realizado pelo corpo $(W)$. Já no segundo volume de controle, onde ocorrem as reações metabólicas, há a entrada de oxigênio e nutrientes e saída de dióxido de carbono e do calor liberado 
pelas reações metabólicas $\left(Q_{M, c o r p o}\right)$ para $\mathrm{VC} 1$. Para intervalos de tempo iguais ou superiores a um dia, a variação da massa do corpo devido ao fluxo e acúmulo de substâncias é negligenciado.

Figura 13: Representação do corpo humano por meio de volumes de controle.

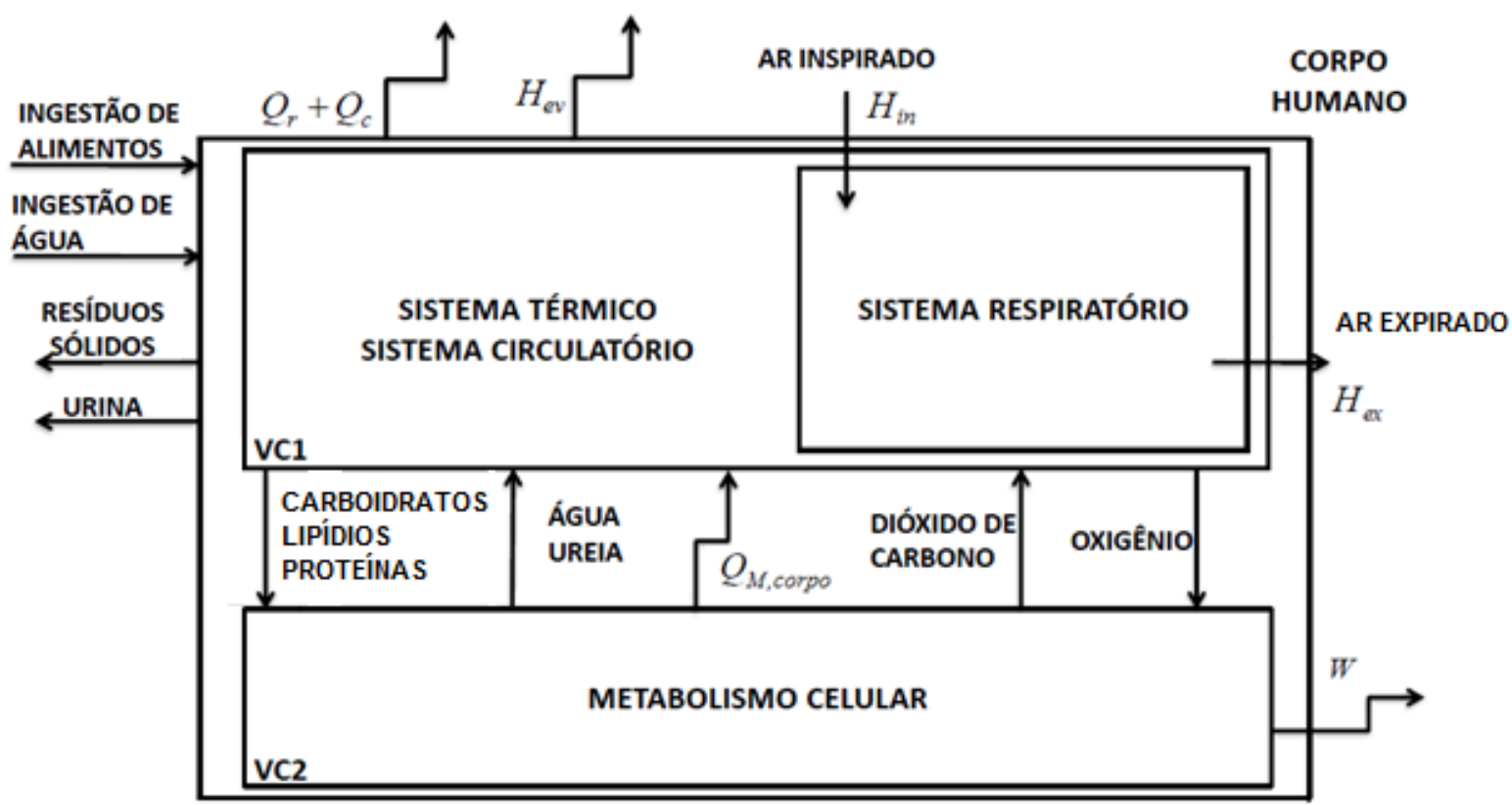

Fonte: Adaptado de Mady (2013).

A soma da taxa de variação da energia interna metabólica $\left(M_{\text {corpo }}\right)$ e da taxa de variação da energia interna do corpo devido a variações da temperatura ambiente $\left(\left.\frac{d U_{\text {corpo }}}{d t}\right|_{\Delta T}\right)$ corresponde à variação total da energia interna do corpo, conforme explicitado na Equação 27.

$$
\frac{d U_{\text {corpo }}}{d t}=-M_{\text {corpo }}+\left.\frac{d U_{\text {corpo }}}{d t}\right|_{\Delta T}
$$

Analogamente para a variação de exergia do corpo, desconsiderando variações de volume:

$$
\frac{d B_{\text {corpo }}}{d t}=-\dot{B}_{M, \text { corpo }}+\left.\frac{d B_{\text {corpo }}}{d t}\right|_{\Delta T}=-\dot{B}_{M, \text { corpo }}+\left(\left.\frac{d U_{\text {corpo }}}{d t}\right|_{\Delta T}-\left.T_{0} \frac{d S_{\text {corpo }}}{d t}\right|_{\Delta T}\right)
$$

sendo: $B_{\text {corpo }}=$ exergia do corpo $[\mathrm{J}]$;

$\dot{B}_{M, \text { corpo }}=$ taxa metabólica em base exergética [W]; 


$$
S_{\text {corpo }}=\text { entropia do corpo }[\mathrm{J} / \mathrm{K}] \text {. }
$$

Aplicando-se o balanço de energia ao VC1 e assumindo que a variação da energia interna do corpo devido a variações de temperatura ocorre totalmente em VC1, temse:

$$
\left.\frac{d U_{V C 1}}{d t}\right|_{\Delta T}=\left.\frac{d U_{\text {corpo }}}{d t}\right|_{\Delta T}=\dot{Q}_{M, \text { corpo }}-\left(\dot{Q}_{c}+\dot{Q}_{r}+\dot{H}_{e v}+\dot{H}_{e x}-\dot{H}_{i n}\right)
$$

No segundo volume de controle ocorrem as reações metabólicas celulares, que consistem em reações de oxidação onde os reagentes, cuja entalpia é representada

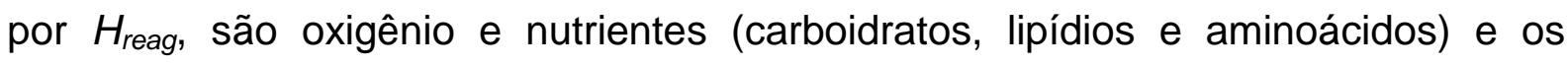
produtos $\left(H_{\text {prod }}\right)$ são dióxido de carbono, água e ureia. Como parte da energia proveniente das reações metabólicas é convertida em ATP (adenosina trifosfato) e posteriormente em trabalho, o balanço de energia de VC2 corresponde a:

$$
\left.\frac{d U_{V C 2}}{d t}\right|_{\Delta T}=\dot{H}_{\text {reag }}-\dot{H}_{\text {prod }}-\dot{Q}_{M, \text { corpo }}-\dot{W}
$$

Como, por hipótese, os efeitos da variação da temperatura ambiente na energia interna do corpo acontecem apenas em VC1:

$$
\begin{gathered}
\dot{H}_{\text {reag }}-\dot{H}_{\text {prod }}-\dot{Q}_{M, \text { corpo }}-\dot{W}=0 \\
\dot{Q}_{M, \text { corpo }}=\dot{H}_{\text {reag }}-\dot{H}_{\text {prod }}-\dot{W}
\end{gathered}
$$

Uma vez que o metabolismo ( $\left.M_{\text {corpo }}\right)$ é definido como a diferença entre as entalpias dos reagentes e dos produtos, conclui-se que, em condições basais, $M_{\text {corpo é igual a }}$ $Q_{M, c o r p o}$ Seu cálculo é realizado a partir da Equação 33 em função das vazões de oxigênio consumido, dióxido de carbono produzido e nitrogênio excretado por meio da urina (MADY, 2013).

$$
M_{\text {corpo }}=\dot{Q}_{M, \text { corpo }}=1179 \dot{m}_{\mathrm{O}_{2}, \text { corpo }}+2502 \dot{m}_{\mathrm{CO}_{2}, \text { corpo }}-129 \dot{m}_{\mathrm{N}, \text { corpo }}
$$

Portanto:

$$
\left.\frac{d U_{\text {corpo }}}{d t}\right|_{\Delta T}=M_{\text {corpo }}-\left(\dot{Q}_{c}+\dot{Q}_{r}+\dot{H}_{e v}+\dot{H}_{e x}-\dot{H}_{\text {in }}\right)-\dot{W}
$$


Aplicando a análise exergética ao primeiro volume de controle, tem-se

$$
\left.\frac{d B_{V C 1}}{d t}\right|_{\Delta T}=\left.\frac{d B_{\text {corpo }}}{d t}\right|_{\Delta T}=\dot{B}_{Q_{M, \text { corpo }}}-\left(\dot{B}_{c}+\dot{B}_{r}+\dot{B}_{e v}+\dot{B}_{e x}-\dot{B}_{\text {in }}\right)-\dot{B}_{d, V C 1}
$$

sendo: $B_{V C 1}=$ exergia do volume de controle $1[\mathrm{~J}]$;

$\dot{B}_{Q M, c o r p o}=$ taxa de exergia liberada para VC1 devido às reações metabólicas de VC2 [W];

$\dot{B}_{c}=$ taxa de exergia transferida por condução [W];

$\dot{B}_{r}=$ taxa de exergia transferida por radiação [W];

$\dot{B}_{e x}=$ fluxo de exergia pelo ar expirado [W];

$\dot{B}_{e v}=$ fluxo de exergia pela evaporação [W];

$\dot{B}_{\text {in }}=$ fluxo de exergia pelo ar inspirado [W];

$\dot{B}_{d, V c 1}=$ taxa de exergia destruída no volume de controle 1 [W].

As parcelas relativas às exergias transferidas por convecção e radiação são

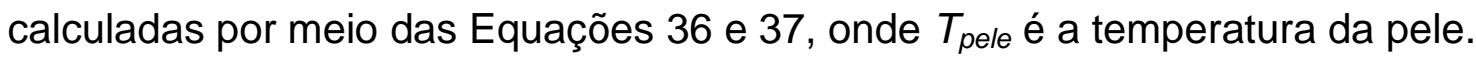

$$
\begin{aligned}
& \dot{B}_{c}=\left(1-\frac{T_{0}}{T_{\text {pele }}}\right) \dot{Q}_{c} \\
& \dot{B}_{r}=\left(1-\frac{T_{0}}{T_{\text {pele }}}\right) \dot{Q}_{r}
\end{aligned}
$$

O fluxo de exergia pela evaporação é dado por:

$$
\dot{B}_{e v}=\dot{m}_{e v}\left[h_{l v}-T_{0} s_{l v}+R_{v} T_{0} \ln \frac{P_{v, s}}{P_{v, 0}}\right]
$$

onde $\dot{m}_{e v}$ é a vazão mássica de suor, $h_{l v}$ a entalpia de vaporização da água e $R_{w}$ a constante dos gases para o vapor.

Os fluxos de exergia do ar inspirado e expirado, representados, respectivamente, pelos índices in e ex, são calculados por meio das seguintes equações:

$$
\dot{B}_{\text {in }}=\sum_{g} \dot{m}_{g, i n}\left[y_{g, i n} c_{p, g}\left(T_{i n}-T_{0}-T_{0} \ln \frac{T_{i n}}{T_{0}}\right)+y_{g, i n} T_{0} R_{g} \ln \frac{P_{g, i n}}{P_{g, 0}}\right]
$$




$$
\dot{B}_{e x}=\sum_{g} \dot{m}_{g, e x}\left[y_{g, e x} c_{p, g}\left(T_{e x}-T_{0}-T_{0} \ln \frac{T_{e x}}{T_{0}}\right)+y_{g, e x} T_{0} R_{g} \ln \frac{P_{g, e x}}{P_{g, 0}}\right]
$$

sendo: $m_{g}=$ vazão mássica do gás $g[\mathrm{~kg} / \mathrm{s}]$;

$y_{g}=$ fração mássica do gás $g$;

$c_{p, g}=$ calor específico do gás $g[\mathrm{~J} /(\mathrm{kg} . \mathrm{K})]$;

$R_{g}=$ constante do gás $\mathrm{g}[\mathrm{J} /(\mathrm{kg} . \mathrm{K})]$;

$P_{g, 0}=$ pressão parcial do gás g no ambiente [Pa].

A análise exergética do segundo volume de controle fornece:

$$
\left.\frac{d B_{V C 2}}{d t}\right|_{\Delta T}=\dot{B}_{\text {reag }}-\dot{B}_{\text {prod }}-\dot{B}_{Q_{M, \text { corpo }}}-\dot{W}-\dot{B}_{d, V C 2}
$$

Assim como para a energia interna, a variação da exergia de VC2 devido a variações de temperatura também é nula. Portanto:

$$
\dot{B}_{d, V C 2}=\dot{B}_{\text {reag }}-\dot{B}_{\text {prod }}-\dot{B}_{Q_{M, \text { corpo }}}-\dot{W}
$$

O metabolismo exergético ( $\left.B_{M, c o r p o}\right)$ é definido como a diferença entre as exergias químicas dos reagentes e dos produtos ao passo que $B_{Q M, c o r p o}$ é calculado a partir das temperaturas de referência ( $\left.T_{0}\right)$ e do corpo ( $T_{\text {corpo }}$ ), conforme Equações 43 e 44 . Isto posto, conclui-se que, em base exergética, a igualdade entre o metabolismo e o calor gerado pelo mesmo não é válida.

$$
\begin{gathered}
\dot{B}_{M, \text { corpo }}=\dot{B}_{\text {reag }}-\dot{B}_{\text {prod }} \\
\dot{B}_{Q_{M . \text { corpo }}}=\dot{Q}_{M, \text { corpo }}\left(1-\frac{T_{0}}{T_{\text {corpo }}}\right)
\end{gathered}
$$

Substituindo a Equação 43 em 42:

$$
\dot{B}_{d, V C 2}=\dot{B}_{M, \text { corpo }}-\dot{B}_{Q_{M, \text { corpo }}}-\dot{W}
$$

A fim de definir uma expressão para o cálculo do metabolismo exergético, o autor assumiu que os nutrientes utilizados pelo corpo são glucose, ácido palmítico e um 
aminoácido médio, representando, respectivamente, os carboidratos, lipídeos e proteínas. A partir dos valores de exergia química desses componentes e dos coeficientes estequiométricos das reações de oxidação, foi definida uma expressão para o metabolismo exergético em função do oxigênio consumido, do dióxido de carbono produzido e do nitrogênio excretado.

$$
\dot{B}_{M, \text { corpo }}=9558 \dot{m}_{\mathrm{O}_{2}, \text { corpo }}+3928 \dot{m}_{\mathrm{CO}_{2}, \text { corpo }}+456 \dot{m}_{N, \text { corpo }}
$$

A exergia destruída pelo corpo é a soma das exergias destruídas em cada volume de controle. Assim:

$$
B_{d, \text { corpo }}=B_{M, \text { corpo }}-\left.\frac{d B_{\text {corpo }}}{d t}\right|_{\Delta T}-\left(\dot{B}_{c}+\dot{B}_{r}+\dot{B}_{\text {ev }}+\dot{B}_{\text {ex }}-\dot{B}_{\text {in }}\right)-\dot{W}
$$

A eficiência exergética do corpo é definida como:

$$
\eta_{\text {corpo }}=\frac{\dot{B}_{M, \text { corpo }}-\left.\frac{d B_{\text {corpo }}}{d t}\right|_{\Delta T}-\dot{B}_{d, \text { corpo }}}{\dot{B}_{M, \text { corpo }}-\left.\frac{d B_{\text {corpo }}}{d t}\right|_{\Delta T}}=1-\frac{\dot{B}_{d, \text { corpo }}}{\dot{B}_{M, \text { corpo }}-\left.\frac{d B_{\text {corpo }}}{d t}\right|_{\Delta T}}
$$

O metabolismo celular, representado no segundo volume de controle, pode ser dividido em duas partes para melhor entendimento dos seus processos internos. A primeira etapa compreende a oxidação completa dos nutrientes, representada pelo metabolismo exergético ( $B_{M, \text { corpo }}$ ), e a formação das moléculas de ATP, que são responsáveis pela liberação de energia para o corpo a fim de realizar trabalho. $A$ partir da energia química armazenada nas moléculas de ATP, uma quantidade máxima de trabalho $W_{M A X}$ pode ser realizada. Este processo rejeita calor $\left(Q_{M, A T P}\right)$ e destrói uma certa quantidade $B_{d, A T P}$ de exergia, expressa por:

$$
\dot{B}_{d, A T P}=\dot{B}_{M, \text { corpo }}-\dot{B}_{Q_{M}, A T P}-\dot{W}_{M A X}
$$

O ATP produzido na primeira etapa do metabolismo celular é hidrolisado na segunda, liberando energia e permitindo que o corpo realize trabalho. A conversão da energia armazenada nas moléculas de ATP em trabalho gera irreversibilidades e também rejeita calor $\left(Q_{M, h i d}\right)$. A exergia destruída nesta parte do metabolismo celular é 


$$
\dot{B}_{d, h i d}=\dot{W}_{M A X}-\dot{W}-\dot{B}_{Q_{M}, h i d}
$$

A exergia destruída no metabolismo celular é a soma da exergia destruída em cada etapa. Portanto,

$$
\dot{B}_{d, V C 2}=\dot{B}_{M}-\dot{B}_{Q_{M}, A T P}-\dot{B}_{Q_{M}, h i d}-\dot{W}=\dot{B}_{M}-\dot{B}_{Q_{M, \text { corpo }}}-\dot{W}
$$

Tendo em mente que o calor rejeitado pelo metabolismo é a diferença entre o metabolismo e o trabalho realizado, vale destacar que quanto menor o trabalho realizado a partir da máxima quantidade disponível, maior o calor rejeitado $Q_{M, c o r p o}$. Entretanto, no cálculo da exergia destruída da Equação 51, considera-se a parcela $B_{Q M, c o r p o}$, que é o produto do calor rejeitado pelo fator de Carnot, o que resulta em um aumento inferior ao incremento de $Q_{M, c o r p o}$ e, consequentemente, à redução de $W$. Deste modo, ocorre um aumento da exergia destruída. As etapas do metabolismo celular e suas parcelas exergéticas estão esquematizadas na Figura 14.

Figura 14: Estratificação do metabolismo celular no segundo volume de controle.

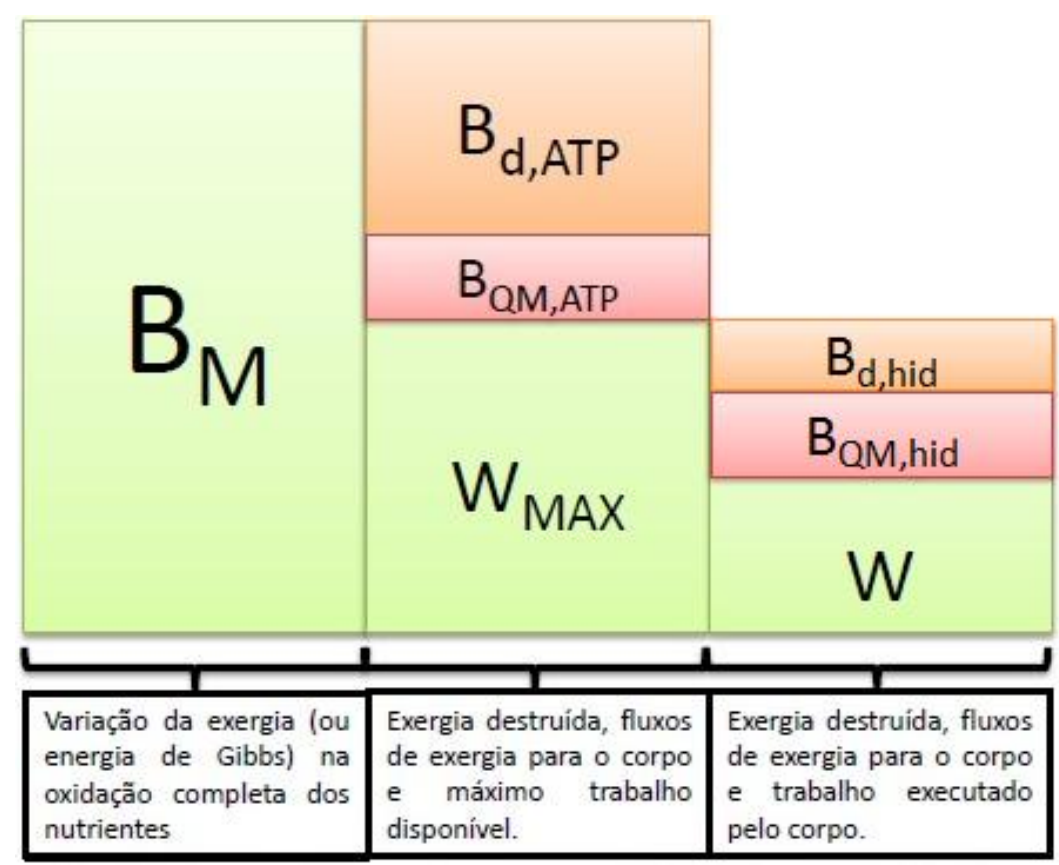

Fonte: Adaptado de Mady (2013).

O modelo foi utilizado para uma série de aplicações. Na área de conforto térmico, a variação da temperatura de neutralidade ao longo do ciclo de vida foi analisada, concluindo-se que seu menor valor ocorre para a idade de 18 anos, onde o 
metabolismo é máximo. Observou-se também que tanto a exergia destruída quanto a eficiência exergética tendem a diminuir com a idade. Variando as condições de temperatura e umidade relativa para um adulto de idade média contatou-se que o corpo torna-se mais eficiente em altas temperaturas e baixas umidades. Por fim, a partir da Figura 15 e de dados da ASHRAE (American Society of Heating, Refrigerating and Air Conditioning Engineers), conclui-se que para umidades relativas entre 40 e $60 \%$, a temperatura ambiente na qual a exergia destruída é mínima corresponde àquela de neutralidade térmica.

A análise da atividade física foi realizada por meio de dados experimentais de respirometria e temperatura de onze corredores com diferentes níveis de treinamento durante a realização de teste cardiopulmonar. Com relação às interações entre corpo e ambiente, concluiu-se que, durante a corrida, a transferência de exergia associada à radiação e à convecção passa a ser menor que os fluxos devido a vaporização e respiração em decorrência do aumento da sudorese e da ventilação. Por esta razão, a exergia destruída, indicada na Figura 16, aumenta enquanto a eficiência exergética diminui com o aumento da velocidade do corredor. Entretanto, comparando-se a faixa de valores da eficiência exergética em repouso e em atividade, observa-se que durante a corrida o corpo é mais eficiente do que em repouso. Outra conclusão do trabalho indica que para um mesmo valor de exergia dissipada pelo metabolismo ( $\left.B_{Q M, \text { corpo }}\right)$, os corredores mais bem treinados possuem maior capacidade de realização de trabalho. 
Figura 15: Exergia destruída (a) e eficiência exergética (b) para diferentes umidades relativas e temperaturas.
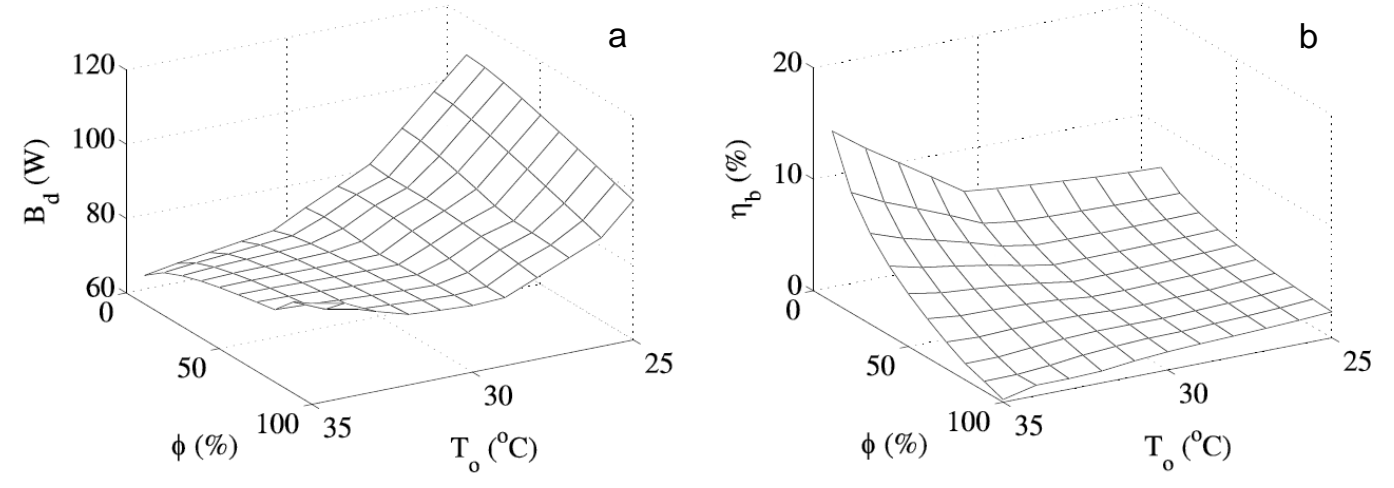

Fonte: Mady (2013).

Figura 16: Exergia destruída por unidade de massa em função da velocidade para cada corredor avaliado no experimento .

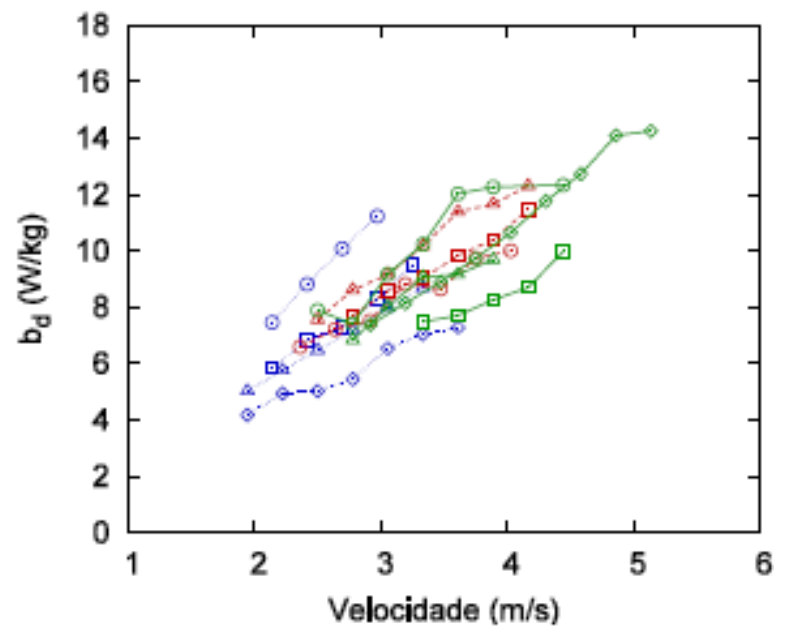

Fonte: Mady (2013).

No contexto médico, três diferentes técnicas de indução de hipotermia foram comparadas por meio da exergia destruída e da eficiência exergética durante os procedimentos de resfriamento e aquecimento. As vias de indução de hipotermia simuladas por meio do modelo de Ferreira (2001) foram: dispositivo extracorpóreo, cateter intravenoso e resfriamento da superfície da pele. De acordo com estes parâmetros, o resfriamento extracorpóreo mostrou-se mais adequado. Entretanto, a análise do índice exergético, ou razão dos fluxos de exergia, proposto pelo autor aponta para o uso de cateter intravenoso, pois este apresenta resfriamento e aquecimento mais gradual, levando a uma maior variação de exergia do corpo para 
uma quantidade fixa de exergia retirada. A exergia destruída e o rendimento exergético são mostrados na Figura 17.

Figura 17: Exergia destruída (a) e eficiência exergética (b) em função do tempo para diferentes técnicas de indução de hipotermia.
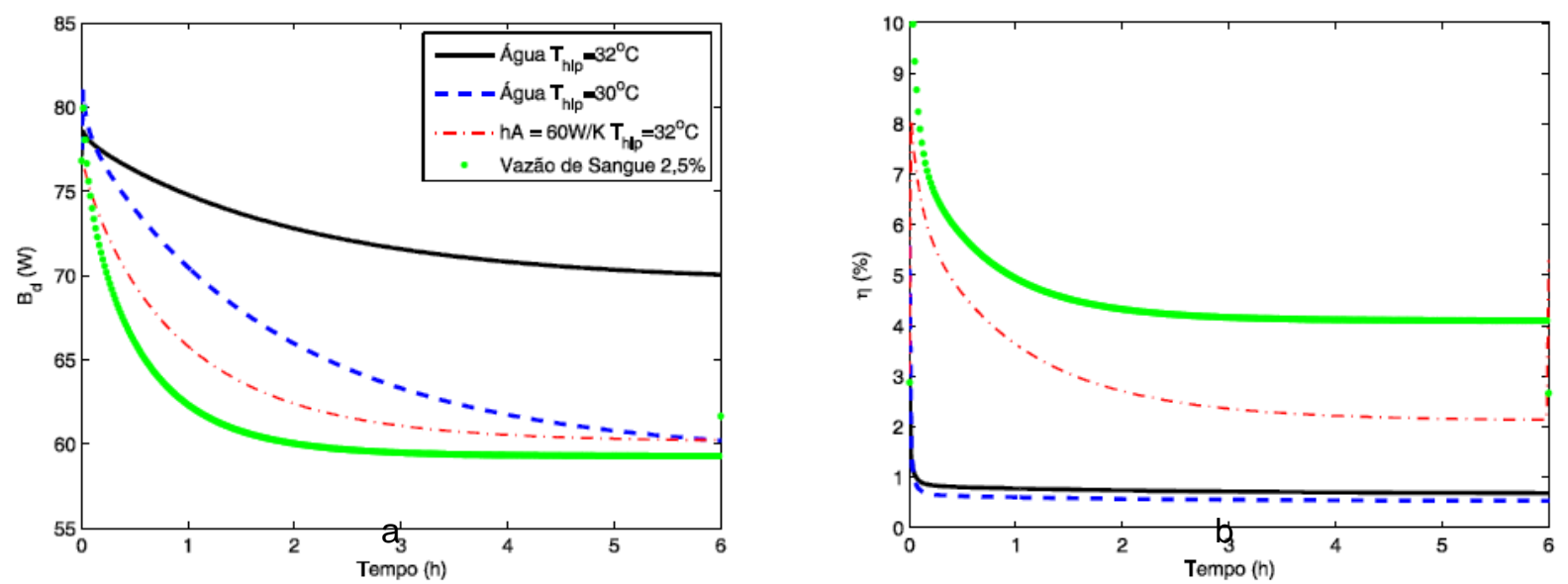

Fonte: Mady (2013).

\subsubsection{Modelo exergético do sistema respiratório}

Henriques (2013) desenvolveu um modelo exergético do sistema respiratório e, aplicando-o em conjunto com os modelos exergético do corpo (MADY, 2013) e térmicos do corpo e do sistema respiratório (ALBUQUERQUE NETO, 2010), obteve o comportamento exergético padrão de um indivíduo saudável para diferentes condições ambientais e níveis de atividade física. O volume de controle for definido em torno dos pulmões e vias aéreas, conforme indicado na Figura 18. 
Figura 18: Volume de controle adotado.

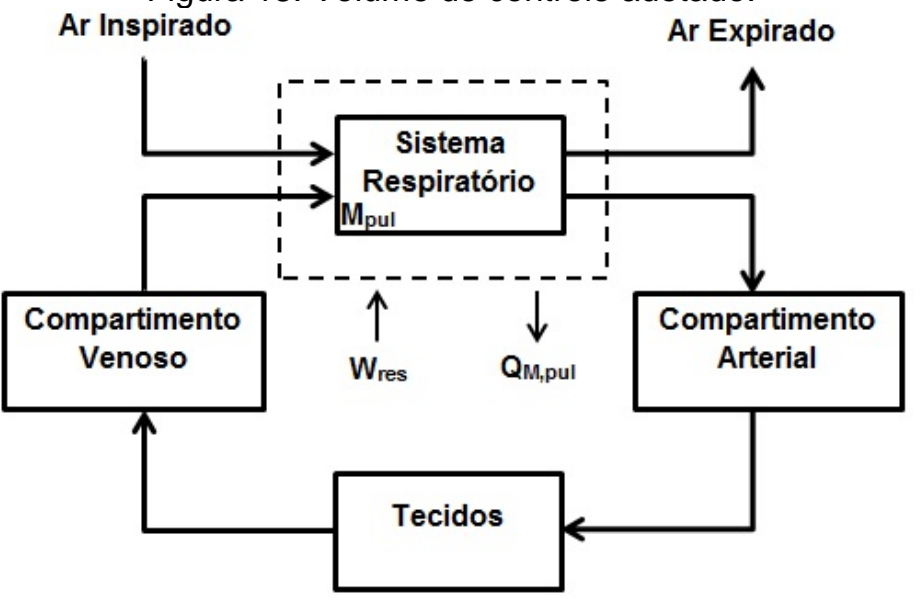

Fonte: Henriques (2013).

Em base exergética, as componentes do balanço correspondem aos fluxos de exergia associados ao sangue venoso e ao ar inspirado na entrada, ao sangue arterial e ar expirado na saída, à taxa de variação da exergia do sistema devido ao metabolismo exergético do pulmão, a uma taxa de transferência de exergia devido ao metabolismo energético e à potência de respiração, que é aplicada ao sistema pela vizinhança. Portanto:

$$
\dot{B}_{d, p u l}=\dot{B}_{M, p u l}+\dot{B}_{s g, v e}+\dot{B}_{a, i n}+\dot{W}_{\text {res }}-\dot{B}_{s g, a r}-\dot{B}_{a, e x}-\dot{Q}_{M, p u l}\left(1-\frac{T_{0}}{T_{c o r p o}}\right)-\left.\frac{d B_{p u l}}{d t}\right|_{\Delta T}
$$

Assim como Mady (2013) fez para o corpo, a eficiência exergética do sistema respiratório é calculada como a razão entre a exergia útil e a exergia fornecida. $\mathrm{O}$ principal processo da respiração é a difusão gasosa que ocorre devido à diferença de concentração dos gases da respiração no sangue e no ar. Em termos exergéticos, a difusão gasosa é induzida pelas exergias do sangue venoso e do ar inspirado. Adicionalmente, o trabalho de respiração, o metabolismo exergético do pulmão e a variação da exergia do pulmão devido a variações da temperatura ambiente também alimentam o sistema. Portanto,

$$
\eta_{p u l}=1-\frac{\dot{B}_{d, p u l}}{\dot{B}_{M, p u l}-d B_{p u l} /\left.d t\right|_{\Delta T}+\dot{W}_{\text {res }}+\dot{B}_{s g, v e}+\dot{B}_{a, i n}}
$$

Em casos onde a temperatura é constante e substituindo $B_{d, p u l}$ pela Equação 53: 


$$
\eta_{p u l}=\frac{\dot{B}_{s g, a r}+\dot{B}_{a, e x}+\dot{B}_{Q_{M}, p u l}}{\dot{B}_{M, p u l}+\dot{W}_{\text {res }}+\dot{B}_{s g, v e}+\dot{B}_{a, i n}}
$$

A aplicação dos modelos exergéticos do corpo e do sistema respiratório a diferentes níveis de atividade física, altitudes e períodos de aclimatação (HENRIQUES, 2013) permitiu observar que, conforme a altitude é aumentada, a eficiência exergética do corpo ( $\left.\eta_{\text {corpo }}\right)$ aumenta, enquanto a eficiência exergética do pulmão $\left(\eta_{\text {pul }}\right)$ diminui. Notou-se também que, devido ao aumento substancial do metabolismo exergético do corpo com a atividade física, $\eta_{\text {corpo }}$ segue o aumento da intensidade do exercício, apesar do aumento de $B_{d, \text { corpo }}$. Contudo, $\eta_{p u l}$ é afetada negativamente pelo aumento da intensidade da atividade física, em conformidade com o aumento da sua exergia destruída. Por fim, os autores indicam que o desconforto durante a prática de atividades físicas a altas altitudes pode estar associado ao sistema respiratório, uma vez que a eficiência exergética do corpo aumenta tanto com a altitude como com a intensidade do exercício, enquanto o contrário acontece com o pulmão, indicando que o desempenho exergético de outros órgãos e sistemas melhora sob essas mesmas condições. Os resultados relativos às eficiências exergéticas durante a corrida para indivíduo aclimatado e não aclimatado são exibidos na Figura 19.

Figura 19: Comparativo das eficiências exergéticas do corpo $\left(\eta_{\text {corpo }}\right)$ do pulmão $\left(\eta_{\text {pul }}\right)$ antes e após período de aclimatação de 90 dias a $4500 \mathrm{~m}$ de altitude para corrida.

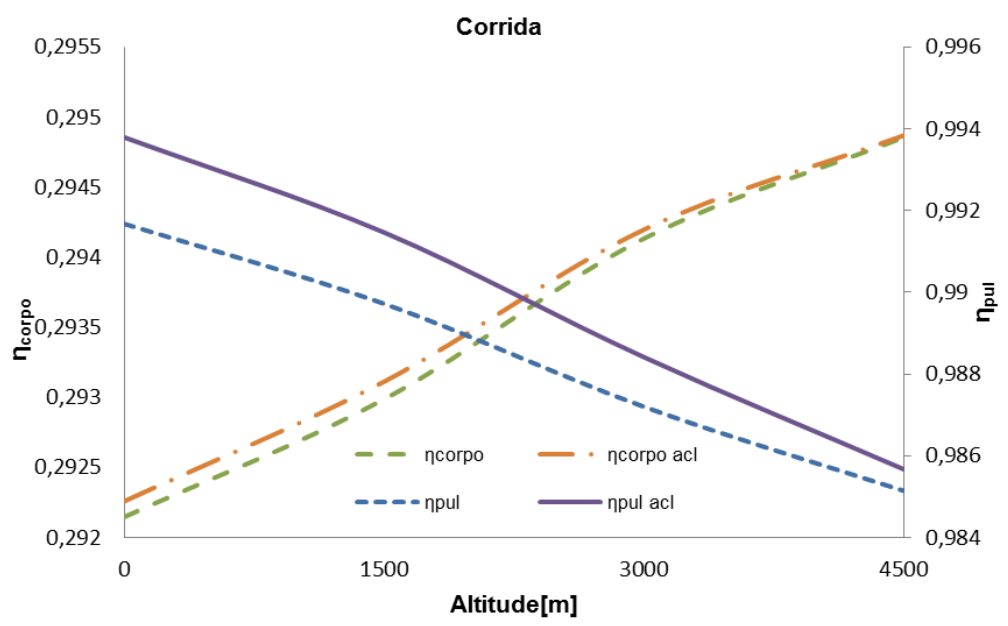

Fonte: Henriques (2013). 
A análise exergética também foi aplicada ao corpo e ao sistema respiratório para diferentes temperaturas, umidades relativas e também intensidades de atividade física (HENRIQUES, 2013). A partir dos dados relativos à mínima exergia destruída no corpo para as diferentes condições simuladas, pode-se obter os pontos de conforto térmico para cada nível de atividade física, conforme mostrado na Figura 20. Nota-se que com o aumento da atividade, ocorre uma redução da temperatura de conforto. Observa-se também que o efeito da umidade na temperatura de conforto é mais evidente em repouso que em atividade, o que se deve à dominância dos mecanismos de transferência de calor por convecção e radiação em repouso conforme a umidade aumenta, ao passo que em atividade física a contribuição da respiração é mais expressiva.

Figura 20: Relação entre temperatura e umidade relativa na condição de conforto térmico para diferentes níveis de atividade física.

$\mathrm{T} \times \boldsymbol{\phi}$ a $\mathrm{B}_{\mathrm{d}, \text { corpo }}$ mínimo

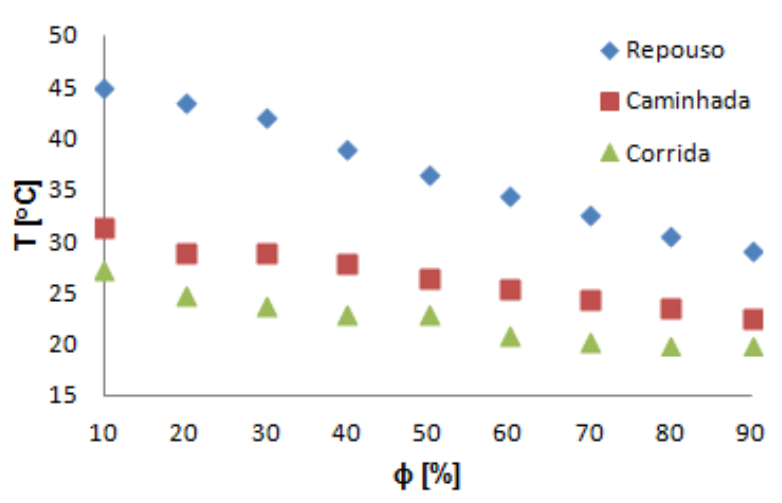

Fonte: Henriques (2013).

Os resultados obtidos para as eficiências exergéticas no corpo e no pulmão em função da temperatura e da umidade relativa estão indicados na Figura 21. Nota-se que as eficiências exergéticas do pulmão e do corpo têm comportamentos notoriamente diferenciados. Pode-se observar que a eficiência exergética do corpo é mais afetada pela intensidade do exercício, ao passo que a eficiência exergética do pulmão é mais influenciada por condições ambientais, o que pode indicar que o desempenho geral do corpo durante atividade física é mais influenciado por outros sistemas do que pelo respiratório. 
Figura 21: Eficiência exergética do corpo $\left(\eta_{\text {corpo }}\right)$ (a) e do pulmão $\left(\eta_{\text {pul }}\right)$ (b) em função da temperatura, umidade relativa e atividade física.
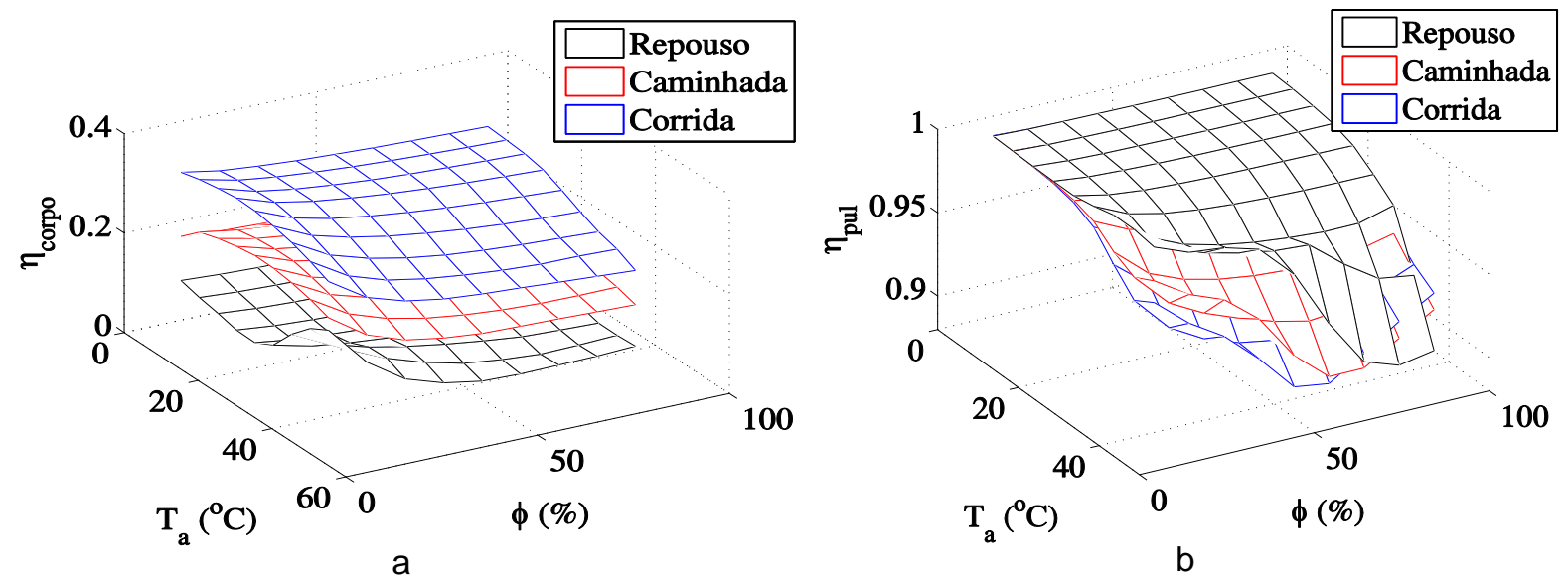

Fonte: Henriques (2013).

\subsection{CORAÇÃO}

Nesta seção serão tratados aspectos fisiológicos e anatômicos do coração. As referências utilizadas foram Guyton e Hall (2006) e Feher (2012).

O sistema circulatório tem como função primordial o transporte de nutrientes, gases, hormônios, resíduos e energia na forma de calor por convecção no corpo humano, o qual ocorre por meio do sangue, tornando o processo mais efetivo do que se fosse realizado por meio de difusão. Portanto, a circulação sanguínea é essencialmente um sistema de transporte de fluido, onde os vasos sanguíneos funcionam como tubulações, tendo o coração como bomba e o sangue como fluido de trabalho, conforme esquematizado na Figura 22.

O coração, responsável por conferir a potência propulsora necessária para conduzir o sangue para os órgãos, tecidos e células do corpo, é um órgão muscular localizado na cavidade torácica sob o osso esterno e à frente da coluna vertebral e do esôfago. Sua porção superior é ligeiramente deslocada à esquerda do plano mediano. O coração pode ser dividido em partes direita e esquerda, comumente referidas como coração direito e coração esquerdo. Cada parte, por sua vez, é dividida em duas cavidades, denominadas de átrio e ventrículo, que são separadas pela válvula tricúspide na porção direita e pela válvula mitral na porção esquerda. A 
Figura 23 apresenta as partes do coração, bem como as veias e artérias que o conecta ao restante do sistema cardiovascular.

Figura 22: Distribuição do volume de sangue no sistema circulatório.

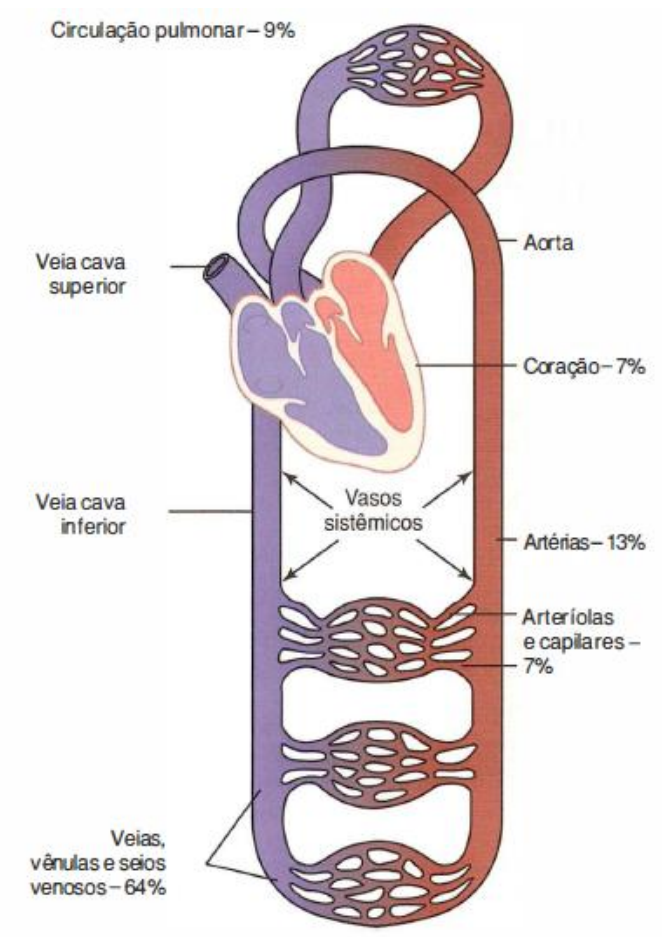

Fonte: Guyton e Hall (2006).

Figura 23: Partes do coração humano.

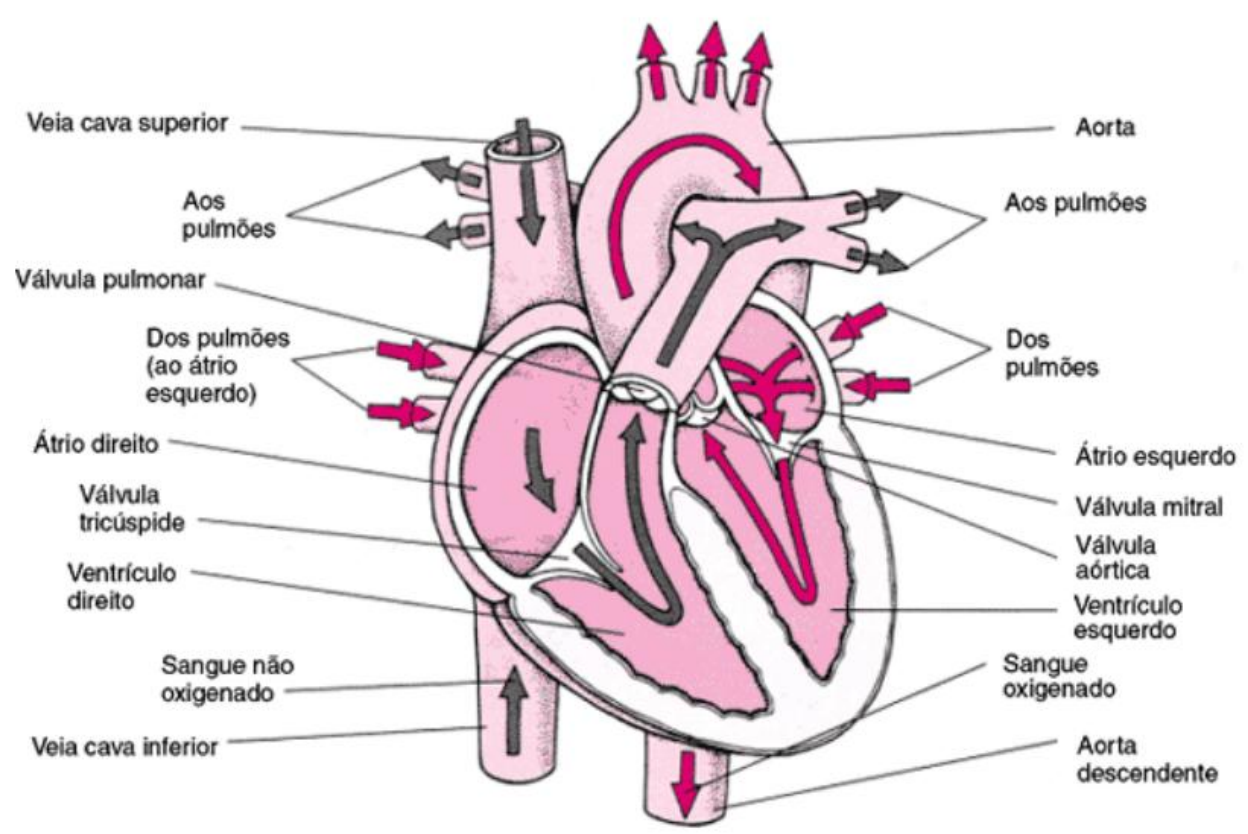

Fonte: Costa (2008). 
O sangue venoso que deixa os órgãos é coletado por veias maiores até chegar às veias cava que o conduzem até o coração direito, onde o sangue é bombeado e direcionado para os pulmões através das artérias pulmonares. Após a troca gasosa nos pulmões, o sangue arterial rico em oxigênio flui para o coração esquerdo através das veias pulmonares e é bombeado para o restante do corpo pela artéria aorta. A capacidade de bombeamento do coração se deve ao fato deste órgão ser um músculo com cavidades internas cuja contração produz aumento da tensão nas paredes e da pressão nas câmaras. A estrutura muscular cardíaca pode ser dividida em músculo atrial, músculo ventricular e ainda em um tecido muscular especializado que coordena sinais elétricos através do coração. Os dois primeiros operam como a maioria dos outros músculos do corpo, exceto pela duração da contração, que é mais longa. Já o último não tem capacidade de contração, mas é responsável por conduzir e coordenar os sinais elétricos dos átrios e ventrículos.

O denominado ciclo cardíaco compreende os eventos entre o início de um batimento e o início do próximo. O gatilho para o início do ciclo é dado pelo nodo sinusal, ou sinoatrial, a partir da geração espontânea de potencial de ação, ou estímulo elétrico. Este componente é formado pelo tecido muscular especializado mencionado anteriormente e se localiza na junção entre átrio direito e veia cava superior. 0 estímulo elétrico inicial se propaga pela rede internodal até o nodo atrioventricular, onde o impulso sofre um atraso antes de ir para o ventrículo, garantindo seu completo enchimento antes da contração. O impulso é levado para os ventrículos por meio do feixe atrioventricular e posteriormente conduzido a todas as partes do ventrículo pelo feixe de fibras de Pukinje. Esses nodos e fibras auto-excitáveis, mostrados na Figura 24 compõem o chamado sistema excitatório e condutor especializado do coração, responsável pelo sincronismo e controle das contrações durante o ciclo cardíaco. 
Figura 24: Componentes do sistema excitatório e condutor especializado do coração.

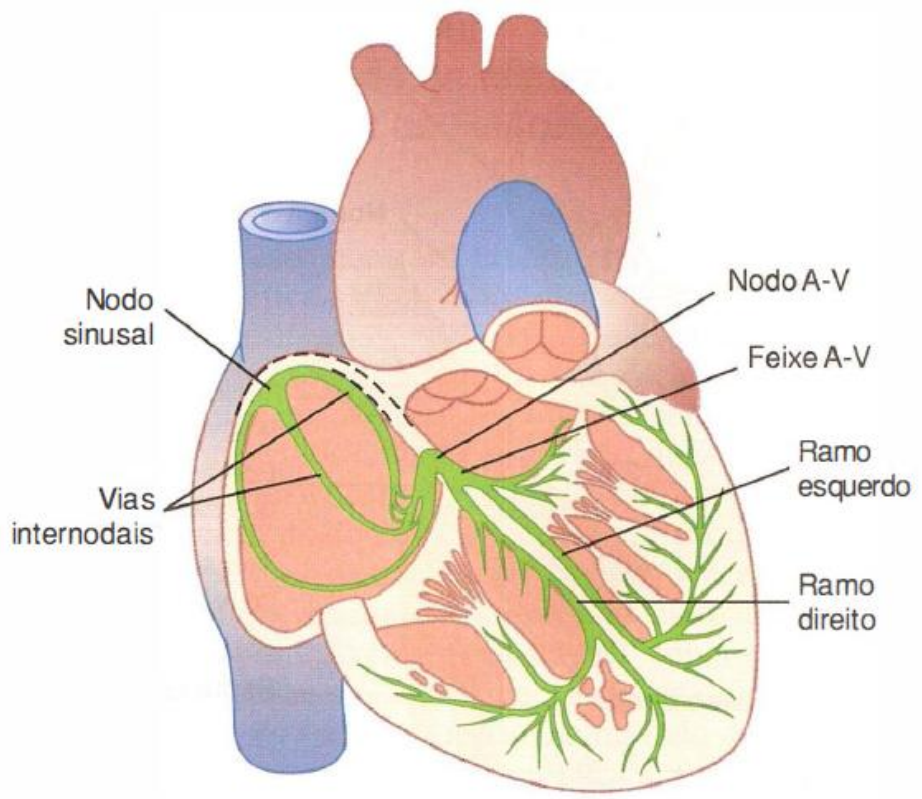

Fonte: Guyton e Hall (2006).

Os processos de relaxamento e contração do coração são denominados de diástole e sístole, respectivamente. A Figura 25 mostra a sequência dos eventos cardíacos a partir da variação da pressão e do volume do ventrículo esquerdo em função do tempo, bem como a emissão de sons cardíacos, para um ciclo enquanto o diagrama pressão-volume do ventrículo esquerdo é apresentado na Figura 26. Conforme mostrado em ambas as figuras, o ciclo cardíaco no ventrículo pode ser dividido em quatro fases distintas: enchimento, contração isovolumétrica, ejeção e relaxamento isovolumétrico.

A entrada de sangue no coração ocorre devido ao relaxamento e consequente redução da sua pressão interna. Após ser preenchido pelo sangue, o átrio se contrai e, a partir do ponto onde sua pressão é maior que a do ventrículo, a válvula mitral, no caso do coração esquerdo, se abre permitindo a passagem do sangue e promovendo o enchimento do ventrículo. É importante salientar que, em qualquer estágio do ciclo cardíaco, sempre há um volume de sangue no ventrículo. 0 estímulo de contração chega até o ventrículo e neste momento a válvula se fecha para evitar o retorno de sangue para o átrio. A contração acontece, mas não ocorre esvaziamento, portanto não há variação do volume ventricular. Esta etapa acontece 
até o momento em que a pressão intraventricular supera a pressão na artéria, promovendo a abertura da válvula arterial e a ejeção de sangue para a artéria. No início do processo de ejeção ainda ocorre um leve aumento da pressão até que a artéria se distenda. A pressão começa a cair conforme o sangue flui pela artéria. $O$ fechamento da válvula arterial ocorre quando a pressão ventricular é inferior à arterial, mas ainda há um volume residual de sangue no coração. A partir deste ponto a pressão no ventrículo cai abruptamente no processo de relaxamento isovolumétrico. O ciclo é reiniciado a partir da reabertura da válvula mitral. A partir da Figura 25 é possível notar que tanto a contração isovolumétrica quanto o relaxamento isovolumétrico ocorrem num curto intervalo de tempo e o fechamento das válvulas produz os sons audíveis durante o ciclo cardíaco. O processo na porção direita ocorre de maneira análoga com a atuação da válvula tricúspide.

Vale destacar que o ventrículo esquerdo é maior que o direito, pois o primeiro deve bombear sangue para todos os órgãos periféricos do corpo enquanto o primeiro recebe o sangue dos órgãos e aumenta sua pressão de modo a garantir sua condução até os pulmões num percurso onde há menor perda de carga.

Na Figura 26 as curvas de pressão sistólica e diastólica correspondem à variação da pressão arterial durante o ciclo cardíaco. Entende-se que as artérias que receberão o sangue bombeado pelo coração impõem uma pressão resistiva ao sistema. As setas vermelhas indicam a relação entre pressão e volume no ventrículo esquerdo. Portanto, a área delimitada em amarelo representa o trabalho realizado durante um ciclo cardíaco. Pode-se observar no gráfico que o período de enchimento, onde o volume aumenta, ocorre a baixa pressão e a fase de ejeção, na qual ocorre redução do volume, acontece a alta pressão. Desta maneira, a determinação do trabalho líquido durante o ciclo cardíaco indica que trabalho é realizado sobre o sistema. 
Figura 25: Sequência de eventos do ciclo cardíaco.

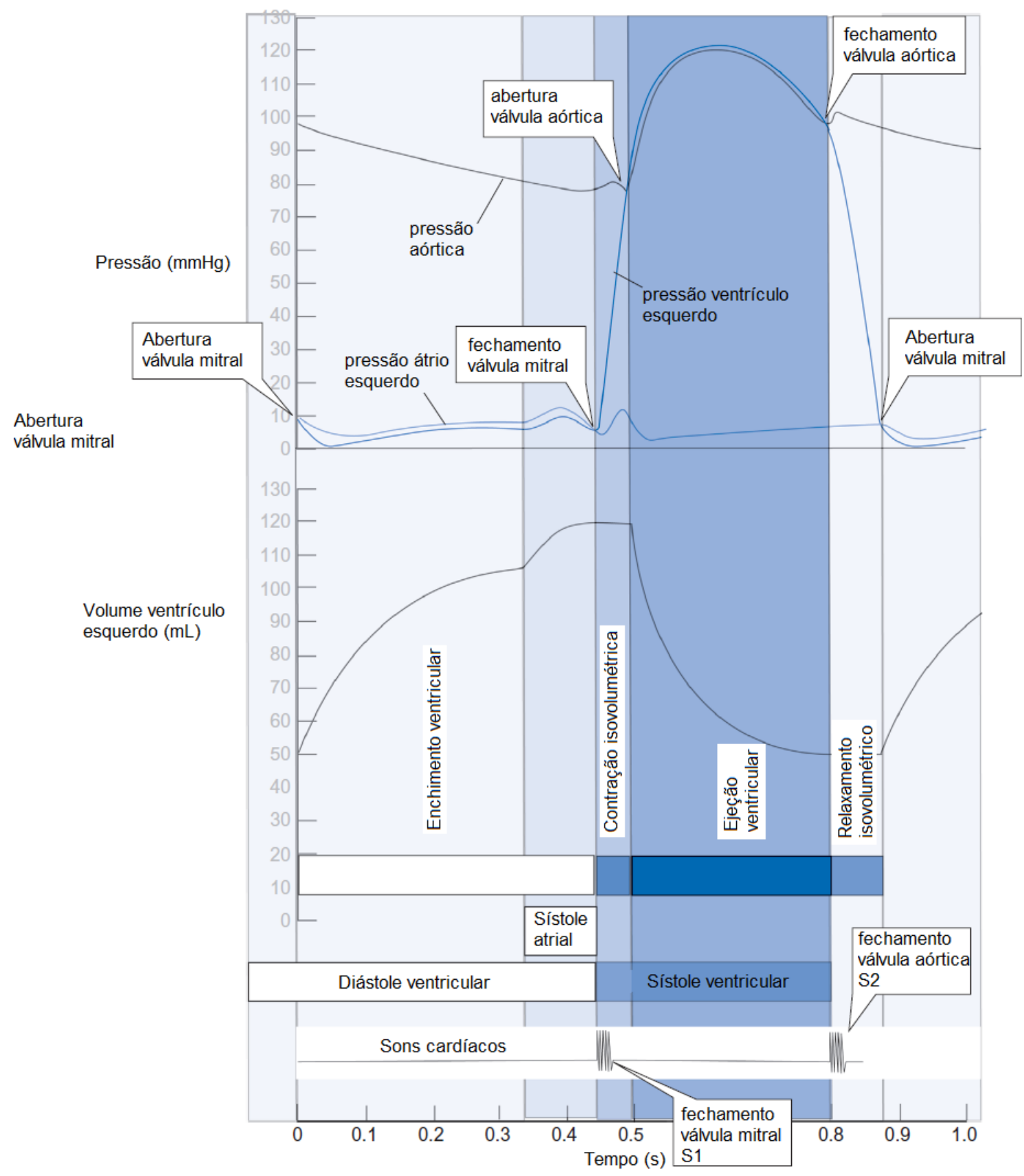

Fonte: Adaptado de Feher (2012). 
Figura 26: Diagrama $p-V$ do ventrículo esquerdo, onde a área destacada em amarelo representa o trabalho realizado.

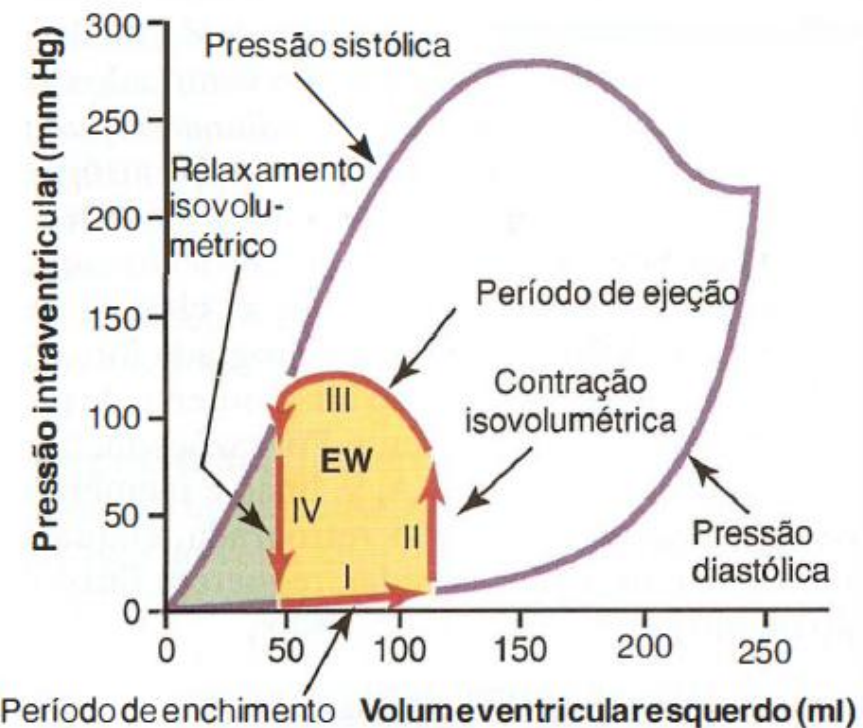

Fonte: Guyton e Hall (2006).

O diagrama $\mathrm{p}-\mathrm{V}$ do coração pode ser aproximado por duas isovolumétricas entre duas isobáricas. Alexander (1964) propôs a utilização das pressões médias sistólica da artéria braquial $\left(P_{s b}\right)$ e de oclusão da artéria pulmonar $\left(P_{o p}\right)$ como pressões de, respectivamente, ejeção e enchimento do coração esquerdo. Para o lado direito, são utilizadas analogamente as pressões sistólica média da artéria pulmonar $\left(P_{s p}\right)$ e diastólica final ventricular $\left(P_{d v}\right)$. Para a determinação da potência líquida durante 0 ciclo cardíaco, o valor do débito cardíaco $(D C)$, que representa a vazão volumétrica de sangue, é usado, conforme mostrado nas Equações 55 e 56 . Devido às diferenças de pressão, o trabalho no ventrículo direito é cerca de um sexto do valor determinado para o esquerdo (GUYTON; HALL, 2006).

$$
\begin{aligned}
& W_{e s q}=D C\left(P_{s b}-P_{o p}\right) \\
& W_{d i r}=D C\left(P_{s p}-P_{d v}\right)
\end{aligned}
$$




\subsubsection{Doenças cardiovasculares}

Doenças cardiovasculares são aquelas que atingem o coração e os vasos sanguíneos. De acordo com a Organização Mundial da Saúde (OMS, ou WHO, em inglês), as doenças cardiovasculares são a maior causa de mortes em todo o mundo, representando, no ano de 2012, 37\% das mortes por doenças crônicas em pessoas com menos de 70 anos. A Figura 27 mostra as doenças cardiovasculares como maior causa de mortes, bem como sua tendência de crescimento até o ano de 2030. Neste grupo de doenças destacam-se a aterosclerose, cardiopatia reumática, doenças congênitas, trombose e embolia pulmonar.

Figura 27: Variação anual da porcentagem de mortes atribuída a cada doença.

$\begin{array}{lll}\text { 田 Doenças cardiovasculares } & * \text { Condições perinatais } & \star \text { Tuberculose } \\ \text { \& Câncer } & * \text { Condições maternas } & \otimes \text { Malária } \\ \text { ○ Diabetes } & \text { Doenças respiratórias crônicas }\end{array}$

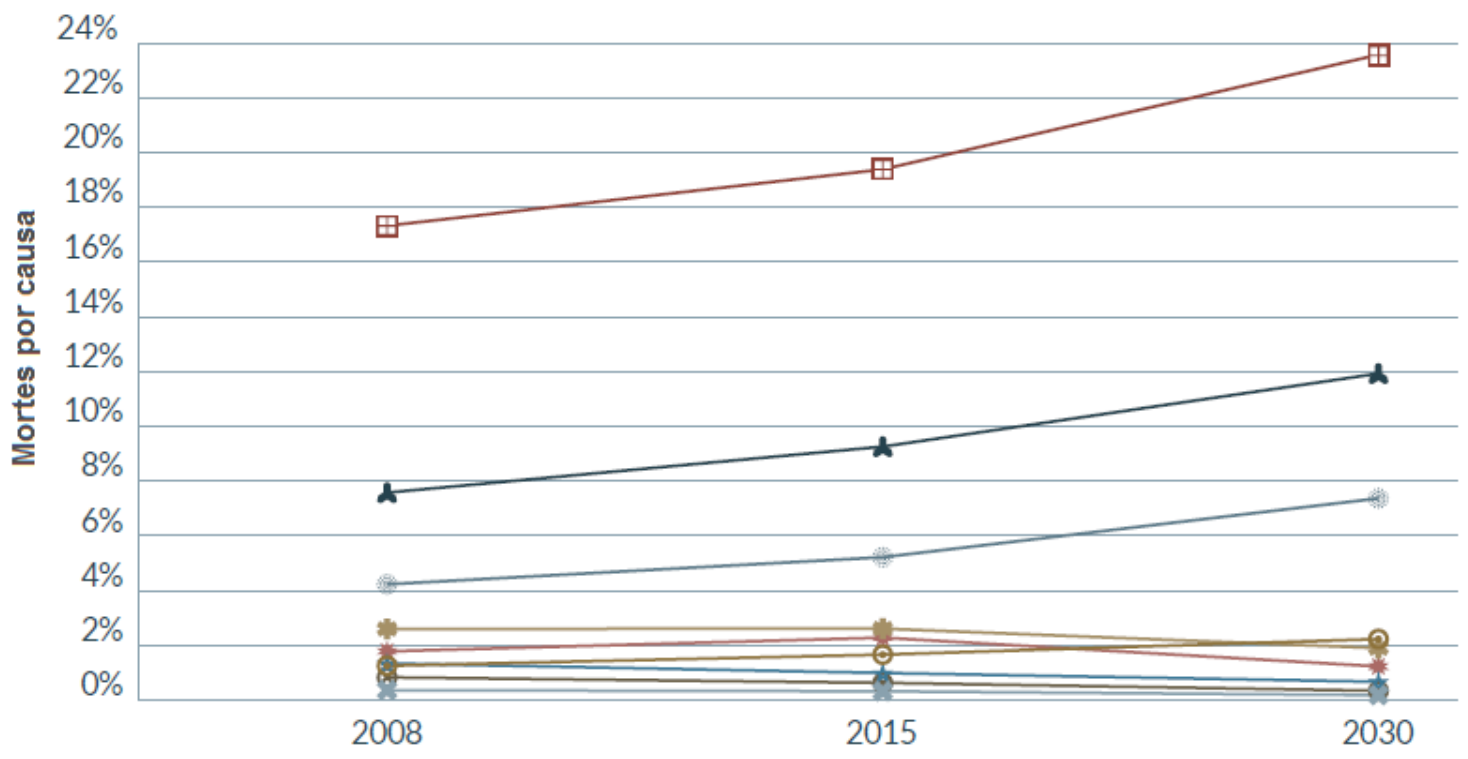

Fonte: Adaptado de WHO (2015b).

No contexto geral do sistema circulatório, a aterosclerose merece destaque. Este quadro clínico representa um conjunto de doenças nas quais ocorre acúmulo de gordura, especialmente colesterol, na parede dos vasos sanguíneos, levando ao espessamento e perda de elasticidade destes, além da redução da área da seção 
transversal interna do vaso. Dependendo do local do corpo onde ocorre, a aterosclerose recebe diferentes denominações como, por exemplo, doença coronariana, no caso de ocorrer nas artérias coronárias que circundam o coração e são responsáveis pelo suprimento de oxigênio e demais nutrientes ao músculo cardíaco.

A cada ponto de estreitamento dá-se o nome de estenose, que é quantificada pela razão entre a área reduzida e a área original. A presença de estenoses ao longo da circulação sanguínea aumenta a resistência à passagem do fluxo de sangue e a perda de carga, como mostrado na Figura 28. Em casos extremos, a presença de estenoses pode levar à ocorrência de acidente vascular cerebral e infarto, onde ocorre bloqueio do fluxo sanguíneo impedindo sua chegada ao cérebro ou ao coração, respectivamente.

Figura 28: Representação de uma estenose.

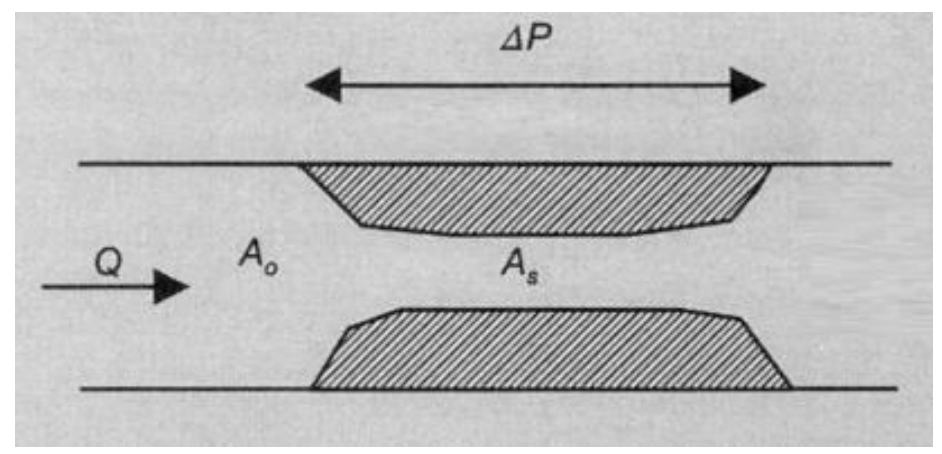

Fonte: Westerhof et al. (2005).

Oshinski et al. (1996) realizaram uma série de experimentos envolvendo tanto pacientes quanto modelos materiais capazes de reproduzir o fluxo sanguíneo em artérias com estenoses. Modelos de seções de artérias feitos em vidro com diferentes níveis de estreitamento foram construídos e as pressões foram medidas a distâncias correspondentes a dois diâmetros do tubo a montante, e dez diâmetros a jusante, a fim de considerar os efeitos de turbulência e recuperação de pressão após a estenose. Conforme mostrado na Figura 29, a dilatação observada após a estenose, conforme relatado por Wilton e Jahangiri (2006), foi levada em conta. Reduções de diâmetro de 50, 55, 60, 70, 80 e 90\% foram testadas. A partir da combinação dos resultados obtidos com pacientes e os experimentos com os 
modelos físicos, os autores determinaram os coeficientes associados à queda de pressão devido à estenose em função de sua severidade, medida pela redução percentual do diâmetro. Os resultados são mostrados na Tabela 3.

Figura 29: Representação do experimento de Oshinski et al. (1996).

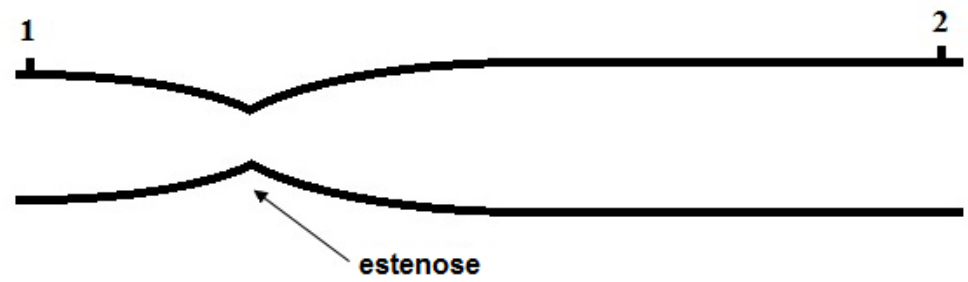

Fonte: Oshinski et al. (1996).

Tabela 3: Resultados do experimento.

\begin{tabular}{cc}
\hline $\begin{array}{c}\text { Severidade da } \\
\text { estenose [\%] }\end{array}$ & $\begin{array}{c}\text { Coeficiente de queda de } \\
\left.\text { pressão [mmHg.s } \mathbf{~} / \mathbf{m}^{2}\right]\end{array}$ \\
\hline 50 & 2,3 \\
\hline 55 & 2,8 \\
\hline 60 & 2,9 \\
\hline 70 & 4,2 \\
\hline 80 & 4,3 \\
\hline 90 & 4,9
\end{tabular}

Fonte: Oshinski et al. (1996).

Um quadro clínico recorrente associado ao sistema cardiovascular é a hipertensão. De acordo com a OMS, a hipertensão é identificada por pressão sistólica superior a $140 \mathrm{mmHg}$ e pressão diastólica superior a $90 \mathrm{mmHg}$. Esta patologia é classificada na área médica como idiopática, ou seja, sua origem é desconhecida ou espontânea. Entretanto, sabe-se que seu desenvolvimento está associado à ingestão excessiva de sal, estresse, alterações nas reações metabólicas e reações autoimunes em gestantes. Além do coração, os rins também são afetados pela hipertensão, pois sua capacidade de filtrar o sangue é comprometida pela alta pressão do sangue. Frohlich et al. (1983) realizaram um experimento no qual parâmetros cardiovasculares, incluindo pressões sistólicas e diastólicas, foram medidos para normotensos e hipertensos. De acordo com este estudo, a pressão sistólica é 34,9\% superior em hipertensos, enquanto a pressão é diastólica é $29,3 \%$ superior. Devido ao aumento da pressão e, consequentemente, do trabalho do 
coração, o metabolismo deste órgão também aumenta na ocorrência de hipertensão. De acordo com Strauer (1979), este aumento é cerca de 35\%.

A hipertensão é considerada uma doença silenciosa que não apresenta sintomas que indiquem o seu desenvolvimento e possam levar ao diagnóstico precoce e à prevenção do seu avanço. Após um estudo conduzido por cerca de sete anos, Miyagi et al. (2002) identificaram que o aumento excessivo nos valores de pressão arterial durante a prática de exercício físico pode ser um indicativo de tendência a futuro desenvolvimento de hipertensão. Durante este estudo, 726 indivíduos não hipertensos tiveram suas pressões sistólica e diastólica medidas em repouso e durante atividade em bicicleta ergométrica com taxas de trabalho variando de $25 \mathrm{~W}$ a $125 \mathrm{~W}$ e foram submetidos a acompanhamento clínico nos anos seguintes. Os dados médios para o grupo de 20 a 29 anos indica que um aumento normal na pressão sistólica entre repouso e pedalada a $125 \mathrm{~W}$ está em torno de $43 \%$. Nos anos seguintes, 15,7\% dos participantes desenvolveram hipertensão e o risco dentre aqueles que obtiveram aumentos de pressão anormais durante o teste na bicicleta mostrou-se de três a quatro vezes maior.

De maneira geral, os principais fatores de risco para o desenvolvimento das doenças cardiovasculares são de ordem comportamental, podendo, portanto, ser evitados a fim de prevenir a ocorrência dessas doenças. Dietas não saudáveis, sedentarismo, tabagismo e abuso de álcool figuram entre os principais fatores de risco que levam a efeitos intermediários como hipertensão, aumento da glicose e do colesterol no sangue, além de sobrepeso e obesidade.

\subsubsection{Irreversibilidades no ciclo cardíaco}

A discussão acerca do caráter irreversível do ciclo cardíaco ainda é incipiente. Muñoz-Diosdado et al. (2010) considera cada ciclo cardíaco como quasi-reversível, mas o conjunto de ciclos após um intervalo de tempo como irreversível. Os autores sugerem ainda uma redução das irreversibilidades com o aumento da idade, o que está em consonância com outros estudos (AOKI, 1991; RAHMAN, 2007; MADY, 2013). Porém, afirmam que a presença de doenças tende a reduzir as 
irreversibilidades, contrariando Luo (2009), que obteve indícios de que a entropia gerada em células cancerígenas é maior que em células saudáveis.

Dini et al. (2012) mencionam a importância da avaliação do ciclo cardíaco sob a perspectiva da Segunda Lei da Termodinâmica, enfatizando que o coração é um órgão gerador de entropia que ajuda a manter o corpo em um estado de nãoequilíbrio com o meio, equilíbrio esse que seria característico do momento da morte.

\subsection{ALTERAÇÕES NA TAXA METABÓLICA}

\subsubsection{Tabagismo}

Estima-se que haja mais de um bilhão de fumantes no mundo e esse número global é crescente, apesar de estar diminuindo em países de alta renda (WHO, 2014a). O tabagismo causa uma a cada dez mortes no mundo e é considerado a mais importante causa de morte evitável no mundo desenvolvido, além de ter impacto nas mortes prematuras globais (FAGERSTRÖM, 2002). O consumo de tabaco pode provocar diferentes tipos de câncer, enfisema pulmonar, doença coronariana e derrame. O ponto positivo é que alguns efeitos do tabagismo podem ser revertidos quando o consumo de tabaco é interrompido ainda em fase jovem. A Figura 30 indica dados da OMS sobre os investimentos públicos em tratamentos contra a dependência do tabaco, onde os tons mais fortes indicam maior financiamento governamental. Como pode ser observado, o Brasil possui destaque neste tipo de iniciativa, bem como em divulgação de campanhas a respeito dos malefícios do cigarro e aprovação de leis antifumo. 
Figura 30: Mapa indicativo da presença de investimentos públicos em tratamentos contra a dependência do tabaco.

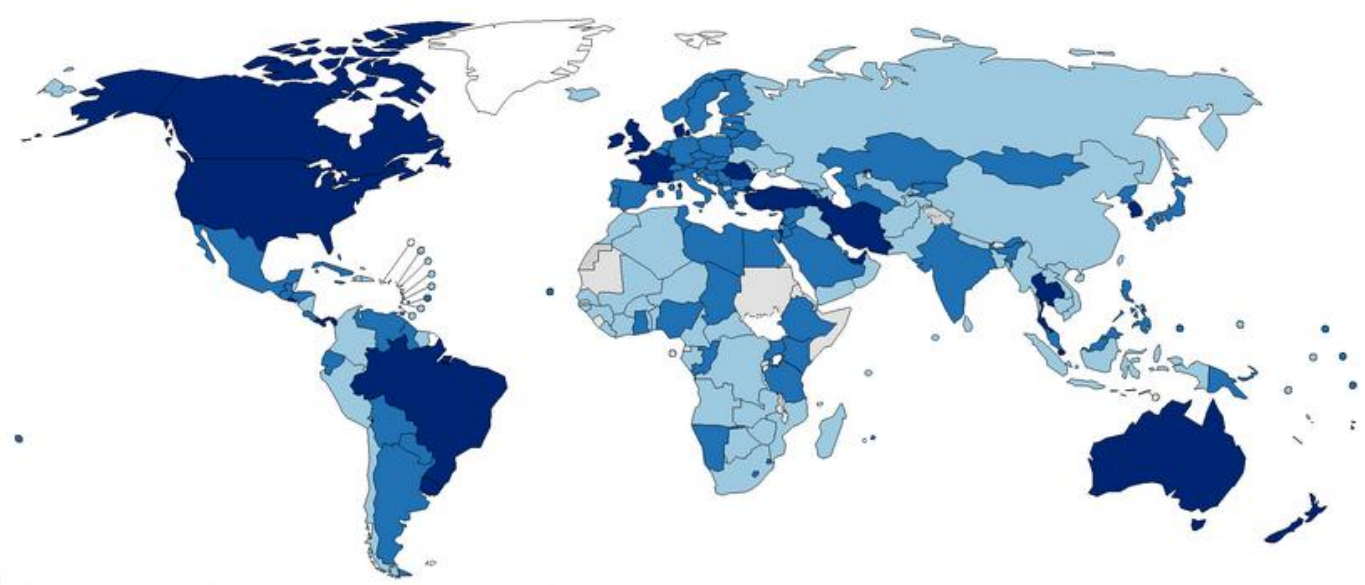

Fonte: WHO (2014b).

O abandono do tabagismo encontra como principal dificuldade a dependência química provocada pela nicotina. Entretanto, um fator comportamental impede diversas pessoas de tentarem abandonar este vício: o receio do ganho de peso. Burse et al. (1982) mostraram que o ganho de peso realmente ocorre em períodos de abstinência de nicotina devido a alterações endócrinas ligadas aos hormônios reguladores do apetite. Variações da taxa metabólica de fumantes saudáveis, não fumantes e ex-fumantes foi investigada por Moffat e Owens (1991). O grupo de fumantes foi classificado como fumantes compulsivos por fumaram mais de dez cigarros por dia e não apresentavam nenhuma doença característica do consumo de tabaco. Eles concluíram que, desconsiderando o efeito termogênico que segue ao consumo de cigarro, o metabolismo em repouso por área superficial dos fumantes é $20 \%$ maior que o de não fumantes e ex-fumantes. O efeito termogênico citado anteriormente foi avaliado por Kromhout (1988) e estimado em um aumento do consumo energético diário de 262 quilocalorias, equivalente a uma taxa de 12,7 W. 


\subsubsection{Obesidade}

Obesidade e sobrepeso são definidos, de acordo com a Organização Mundial de Saúde, como o acúmulo anormal ou excessivo de gordura que apresenta risco à saúde. Quantitativamente, o grau de obesidade é avaliado por meio do Índice de Massa Corporal (IMC) apresentado na Equação 57, onde a massa $m_{\text {corpo é avaliada }}$ em quilogramas e a altura $L_{\text {corpo }}$ é medida em metros.

$$
I M C=\frac{m_{\text {corpo }}}{L_{\text {corpo }}^{2}}
$$

A Tabela 4 indica a classificação do estado nutricional de um indivíduo de acordo com seu IMC a partir de padrões estabelecidos pela Organização Mundial da Saúde. Como pode ser observado, assume-se que um indivíduo é obeso quando seu IMC é igual ou superior a 30. Esses valores são referência para indivíduos adultos que já tenham completado a fase de crescimento corporal.

Tabela 4: Classificação do estado nutricional de acordo com o
\begin{tabular}{lc}
\multicolumn{1}{c}{ IMC $\left[\mathbf{k g} / \mathbf{m}^{2}\right]$} & Classificação \\
\hline$<18.5$ & Baixo peso \\
\hline $18,5-24,9$ & Adequado \\
\hline $25,0-29,9$ & Sobrepeso \\
\hline $30,0-34,9$ & Obesidade grau I \\
\hline $35,0-39,9$ & Obesidade grau II \\
\hline 40,0 & Obesidade grau III \\
\hline
\end{tabular}

Fonte: WHO (2015b).

A utilização do IMC para classificação de obesidade é amplamente criticada na comunidade científica por não levar em conta a composição corporal do indivíduo. Romero-Corral et al. (2008) mostraram por meio de um estudo experimental com 13601 indivíduos que o IMC apresenta baixa correlação com o percentual de gordura medido por bioimpedância para indivíduos em faixas intermediárias de IMC, principalmente homens e idosos. Os autores indicaram ainda que a utilização do valor de $30 \mathrm{~kg} / \mathrm{m}^{2}$ como faixa de obesidade deixou de considerar como obesos mais da metade dos indivíduos com excesso de gordura corporal. Além disso, este índice 
não diferencia o tipo de gordura que está em excesso. Segundo Huffman e Barzilai (2010), enquanto a gordura visceral causa distúrbios na atuação da insulina, a gordura subcutânea pode ser benéfica contra distúrbios metabólicos. Entretanto, o IMC ainda é o índice mais utilizado para identificação de obesidade devido à facilidade de obtenção dos valores de massa e altura e a possibilidade de determinação de seu valor para um grupo grande de indivíduos (CERVI ET AL., 2005).

De acordo com a OMS (WHO, 2015b), o número global de obesos mais que dobrou desde 1980. Em 2014, 39\% dos adultos acima de 18 anos apresentavam sobrepeso e $13 \%$ eram obesos. Além disso, maior parte da população mundial vive em países onde sobrepeso e obesidade matam mais que a desnutrição, sendo que a obesidade era antes considerada um problema de países com rendas mais elevadas, por ser consequência do consumo excessivo de alimentos ricos em gordura e também do sedentarismo. A combinação dos dois últimos leva a um balanço calórico positivo, com isso a energia excedente é estocada no corpo na forma de gordura.

O Ministério da Saúde divulga anualmente dados relativos à presença de sobrepeso e obesidade na população brasileira. Os resultados do Vigitel 2014 (MINISTÉRIO DA SAÚDE, 2014) indicam uma tendência de aumento da frequência de sobrepeso e obesidade desde 2006, quando o estudo começou a ser realizado, conforme indicado nas Figura 31 e Figura 32. 
Figura 31: Variação anual da incidência de sobrepeso na população brasileira.

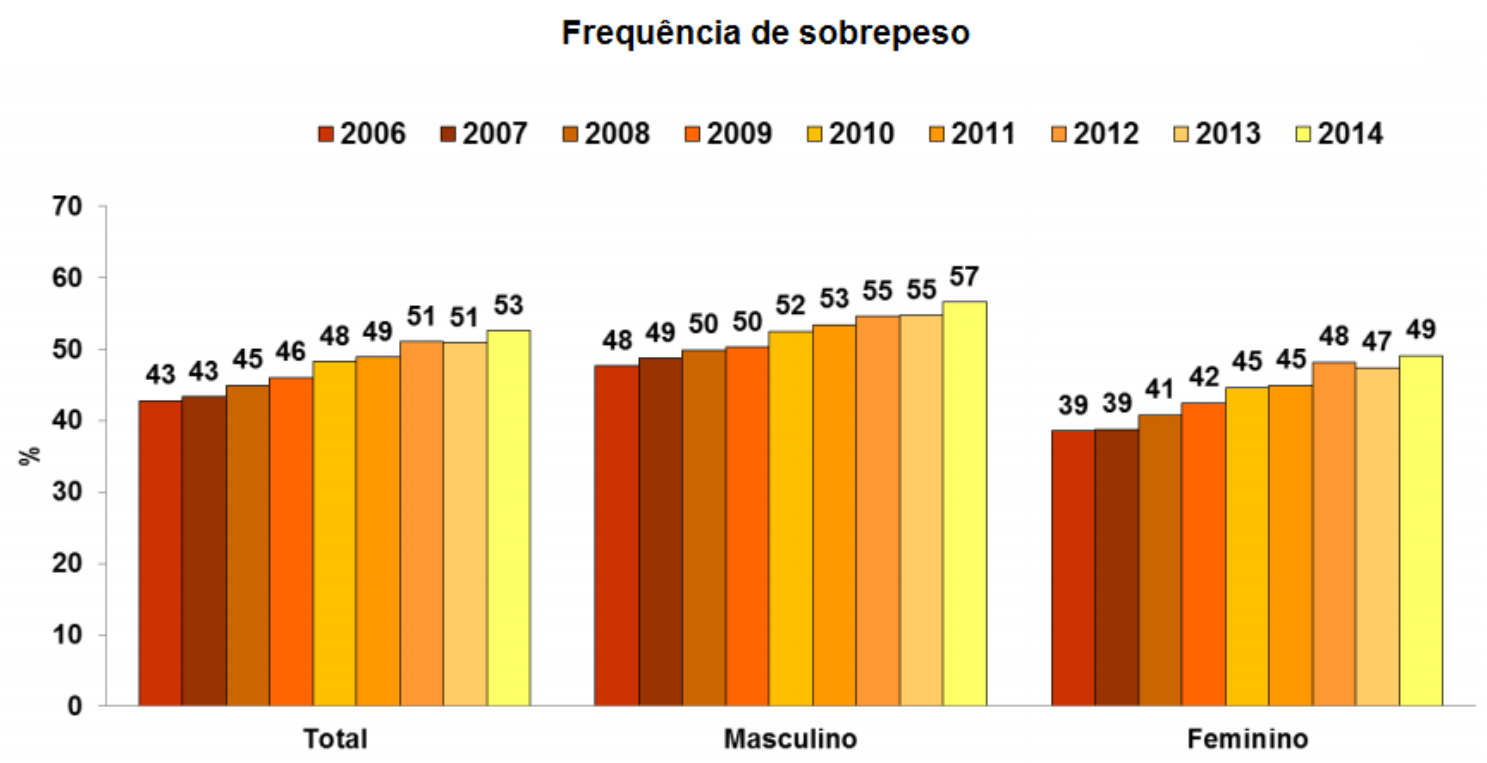

Fonte: Ministério da Saúde (2014).

Figura 32: Variação anual da incidência de obesidade na população brasileira.

\section{Frequência de obesidade}

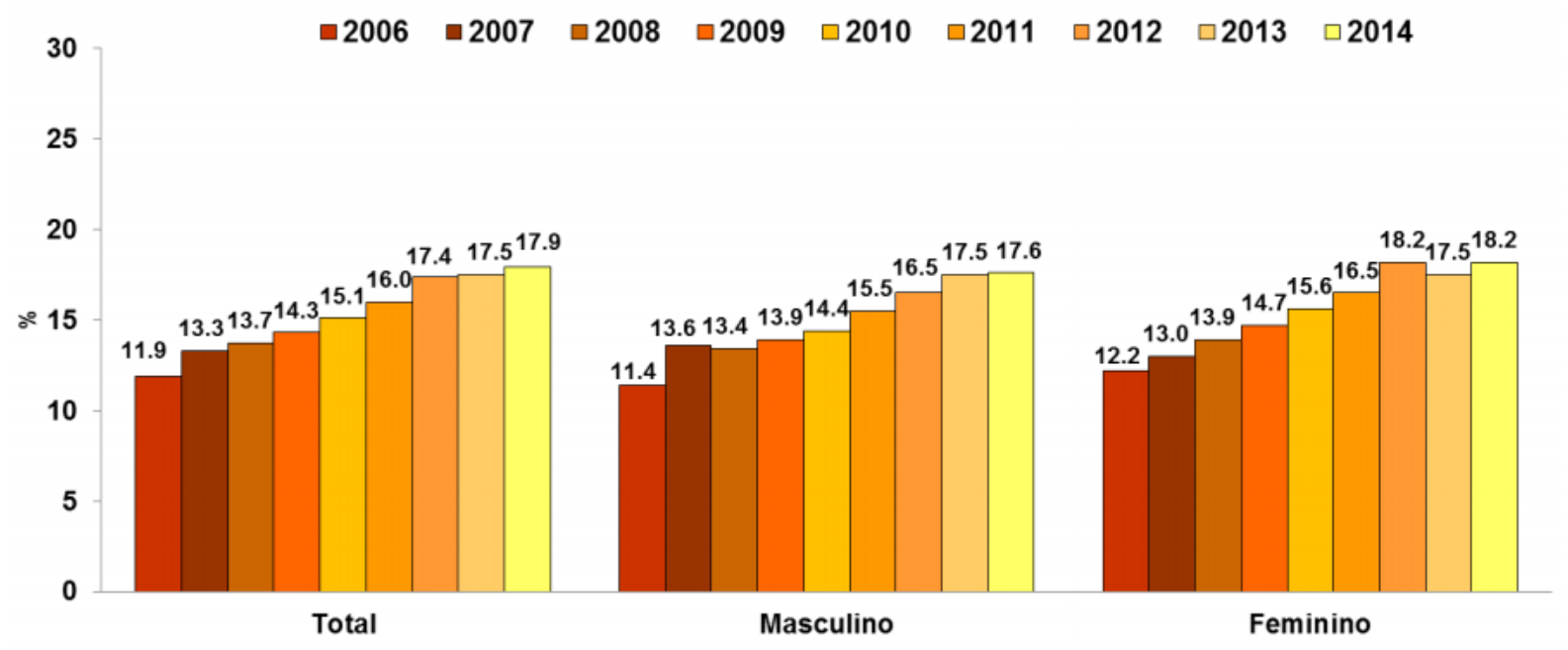

Fonte: Ministério da Saúde (2014).

Em 2009 um grupo colaborativo divulgou os resultados de um levantamento de dados de 57 estudos realizados sobre obesidade e mortalidade, incluindo ao todo 
quase novecentos mil indivíduos, a maioria da Europa e da América do Norte. O cruzamento de dados mostrou que cada $5 \mathrm{~kg} / \mathrm{m}^{2}$ excedentes no IMC, o risco de mortalidade devido a doenças associadas a obesidade aumenta em $30 \%$ (PROSPECTIVE STUDIES COLLABORATION, 2009).

Além do desenvolvimento das doenças cardiovasculares citadas na seção 3.6.1, a obesidade também pode causar diabetes, distúrbios musculoesqueléticos e alguns tipos de câncer, como de cólon e de mama.

Outro ponto a ser observado é a alteração do valor da taxa metabólica em obesos. A fim de investigar se o desenvolvimento da obesidade estava relacionado a uma redução no consumo energético, vários estudos relacionados a alterações nas reações metabólicas em obesos foram conduzidos. De acordo com Jéquier (1984), a obesidade em alguns indivíduos poderia ser consequência da incapacidade de modular o gasto de energia a partir da ingestão calórica. Além disso, o autor divide o metabolismo em três componentes: basal, termogênese e atividade física. Para um indivíduo de peso adequado vivendo em espaço confinado restrito a atividades sedentárias, cada parcela equivale a, respectivamente $73 \%, 15 \%$ e $12 \%$ do metabolismo total. O metabolismo basal depende da massa magra do indivíduo, dos hormônios da tireoide e da síntese de proteínas. O efeito termogênico se deve a ingestão de alimentos, exposição a ambientes frios, ingestão de substâncias termogênicas, estresse e influências psicológicas. Já a parcela da atividade física depende da duração e da intensidade das tarefas exercidas. A ideia de que o aumento da parcela termogênica em obesos seria inferior ao aumento da ingestão calórica, motivou alguns pesquisadores a desenvolver estudos com obesos em câmaras respiratórias para avaliar seu metabolismo em diferentes condições.

O estudo desenvolvido por Ravusin et al. (1982) merece destaque pelo seu pioneirismo e a abrangência dos resultados obtidos. Por meio de um experimento em uma câmara respiratória, os autores monitoraram o consumo energético diário de trinta indivíduos saudáveis divididos em três categorias de acordo com a relação entre o peso real e o peso ideal: controle, moderadamente obesos e obesos. Seus percentuais de gordura médios eram, respectivamente, 20,3, 29,8 e 36,1\%. Os indivíduos tinham permissão para realizar atividades classificadas como sedentárias, como por exemplo, ler, usar o telefone e assistir televisão. O metabolismo total em 
repouso durante as 24 horas de medição variou entre os grupos, sendo, em média, $6118 \mathrm{~kJ}$ para o grupo de controle, $6652 \mathrm{~kJ}$ para os moderadamente obesos e 7592 $\mathrm{kJ}$ para os obesos. Entretanto, quando a taxa metabólica é normalizada pela área superficial dos indivíduos, não há diferença substancial entre os grupos. Valores médios de 41,0, 40,3 e 42,1 W/m² foram obtidos, respectivamente, para os grupos de controle, moderadamente obesos e obesos. O gasto calórico em obesos é superior devido ao aumento da massa magra, que ocorre durante o processo de aumento de peso, uma vez que parte do excesso calórico contribui para construção dos tecidos musculares, que possuem altas taxas metabólicas, não somente para o aumento dos depósitos de gordura.

\subsubsection{Câncer}

De acordo com a Organização Mundial da Saúde (WHO, 2015a), câncer é caracterizado pelo aumento rápido e desordenado das células, que crescem para além de suas fronteiras habituais. $O$ início do processo se dá a partir de mutação de células saudáveis em tumores malignos, como resultado da combinação de fatores genéticos e externos, tais como exposição a radiação, produtos químicos tóxicos ou infecções. Por definição, o câncer não é uma doença metabólica, mas sua alta taxa de replicação implica alterações nas reações químicas de oxidação dos nutrientes, sendo algumas destas alterações comuns a células saudáveis em estágio de proliferação (GUPPY ET AL., 2002; DEBERARDINIS ET AL., 2008). Em uma célula saudável e quiescente, a primeira etapa do metabolismo da glicose, chamada de glicólise, consiste na quebra de um mol de glicose em dois de piruvato. Em condições aeróbias, esses dois mols vão para o ciclo do ácido cítrico, ou ciclo de Krebs, e são convertidos em dióxido de carbono e água, conforme indicado na parte central da Figura 33. 
Figura 33: Possibilidades de degradação do piruvato na glicólise.

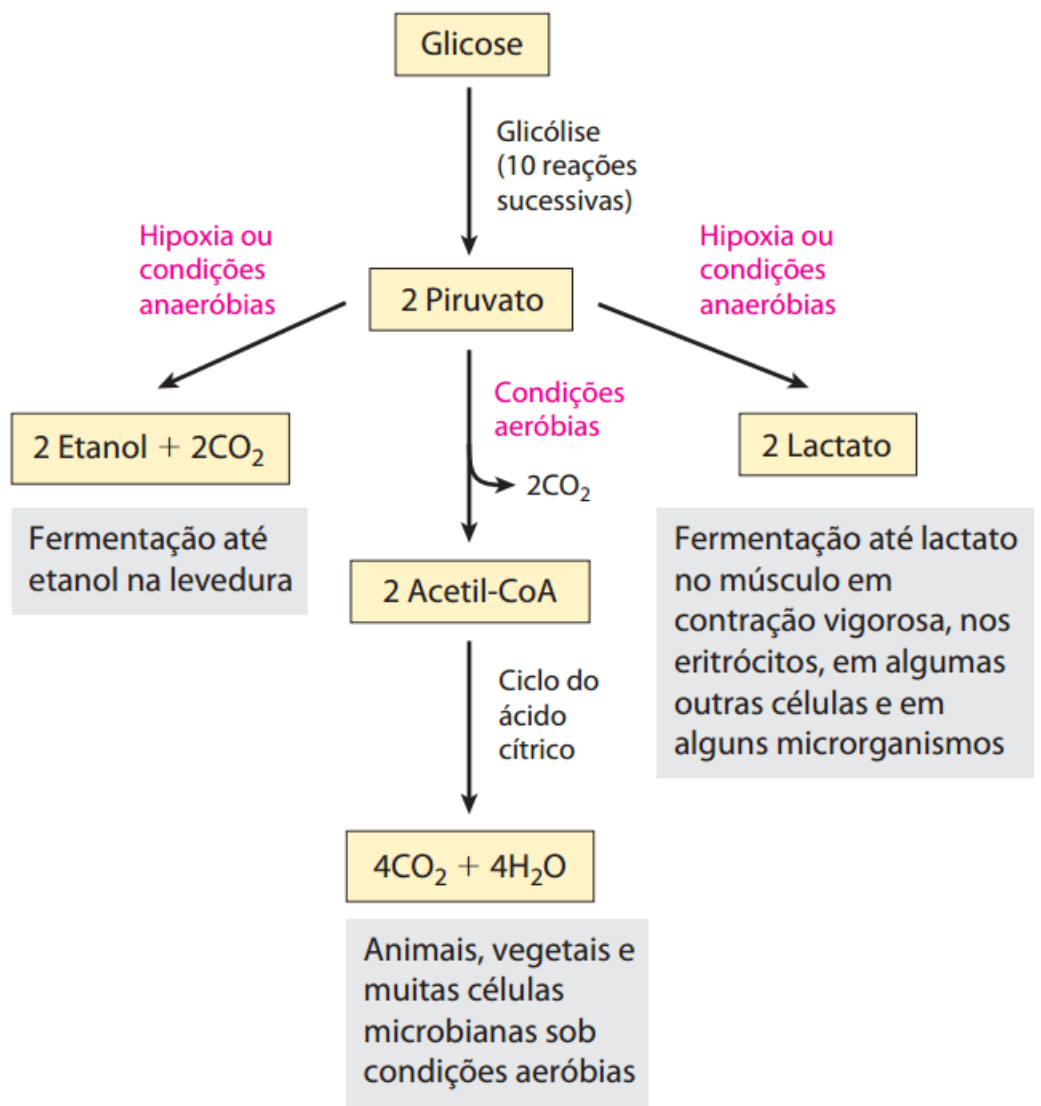

Fonte: Nelson e Cox (2014).

Entretanto, em células cancerígenas, o metabolismo da glicose é alterado. Este cenário foi discutido por Warburg et al. (1927), que observou que o consumo de glicose em células cancerígenas é superior ao registrado em células saudáveis. Além disso, nestas células, maior parte da glicose metabolizada, cerca de $70 \%$, é convertida de maneira anaeróbica em lactato e alanina após a glicólise, reduzindo o fornecimento de reagentes para a etapa seguinte do metabolismo celular, o ciclo de Krebs. Este fenômeno é chamado de efeito Warburg e está associado à taxa de divisão anormal das células do tumor e sua crescente necessidade de energia. A etapa da glicólise produz apenas dois mols de ATP por mol de glicose, enquanto o ciclo respiratório aeróbico completo produz 36 . Ainda assim, o caminho anaeróbio é vantajoso para o tumor por ser mais rápido e prover energia de maneira contínua para a célula (JONES; THOMPSON, 2009; HAN ET AL., 2015). A principal teoria que tenta explicar essa mudança metabólica se baseia na baixa disponibilidade de 
oxigênio nas células cancerígenas, que é consequência da diferença entre sua taxa de multiplicação e a velocidade de construção de novos vasos sanguíneos para abastecer o tumor com oxigênio. Por esta razão, o caminho metabólico que necessita de oxigênio é suprimido e a glicose é convertida em lactato (SHAW, 2006). Além disso, a oxidação incompleta da glicose, segundo Gatenby e Gillies (2007), apresenta algumas vantagens evolutivas para o tumor como, por exemplo, o excesso de piruvato disponível para síntese proteica, alta disponibilidade de substratos anabólicos e alta concentração de NADPH (fosfato de dinucleotídeo de nicotinamida e adenina), que reduz a toxicidade dos radicais livres e aumenta a resistência ao envelhecimento.

Ademais, para sustentar a alta taxa de proliferação, outro substrato também é utilizado como fonte de energia pelas células: a glutamina. Esta substância, que é o aminoácido mais abundante no corpo e o maior transportador de nitrogênio entre os órgãos (DEBERARDINIS; CHENG, 2010), também é degradada para fornecer ATP para a célula. Entretanto, no metabolismo celular, a principal função da glutamina, que é considerada um doador de nitrogênio e carbono (HENSLEY ET AL., 2013), é fornecer metabólitos intermediários, como NADH (dinucleotídeo de nicotinamida e adenina), NADPH e $\mathrm{FADH}_{2}$ (dinucleotídeo de flavina e adenina), para a síntese de ácidos graxos e nucleotídeos, essenciais no processo de divisão celular.

Em uma célula cancerígena, diz-se que o ciclo de Krebs, mostrado na Figura 34, é truncado porque, além de receber menor quantidade de acetil-CoA devido à degradação de uma fração do piruvato em lactato, parte do citrato obtido a partir deste acetil-CoA sai do ciclo para a síntese de ácidos graxos, necessários para a proliferação celular (DEBERARDINIS ET AL., 2008). O papel da glutamina, que é inicialmente degradada em amônia e a-cetoglutarato, no fornecimento de energia para célula é justamente fornecer o a-cetoglutarato proveniente de sua degradação para a continuidade do ciclo de Krebs. Em uma célula saudável, o ciclo continuaria conforme mostrado na Figura 34 até a formação de oxaloacetato e as moléculas de $\mathrm{NADH}$ e $\mathrm{FADH}_{2}$ produzidos iriam para a etapa final da respiração, chamada de cadeia respiratória. Porém, em uma célula cancerígena, a proporção de acetoglutarato para oxaloacetato não é 1:1 como na célula normal. A partir da entrada de a-cetoglutarato no ciclo de Krebs, as reações acontecem de maneira semelhante a uma célula saudável até a formação de malato, que terá apenas uma fração 
convertida em oxaloacetato. A outra parcela será degradada em lactato e alanina, assim como ocorre com o piruvato na etapa de glicólise (DEBERARDINIS ET AL., 2007; CANTOR; SABATINI, 2012).

Figura 34: Ciclo de Krebs.

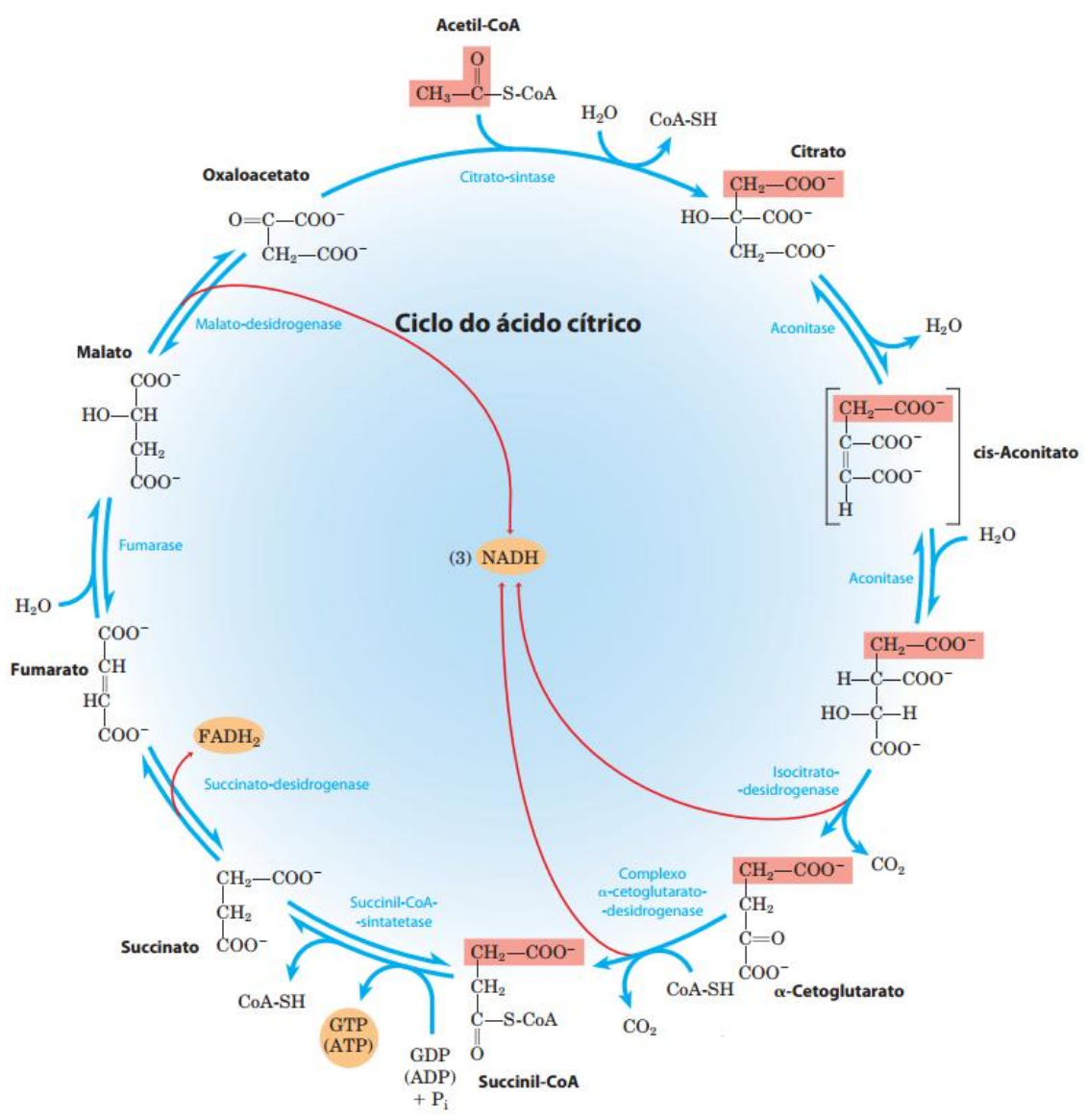

Fonte: Adaptado de Nelson e Cox (2014).

As alterações durante a glicólise e o ciclo de Krebs também afetam a cadeia respiratória, última etapa da respiração aeróbica e responsável pela maior parcela do ATP produzido em condições normais. Nesta fase, as moléculas de NADH e $\mathrm{FADH}_{2}$ produzidas anteriormente atuam como transportadores de elétrons para a produção de ATP. Havendo alteração na produção de $\mathrm{NADH}$ e $\mathrm{FADH}_{2}$, a síntese de ATP também é prejudicada.

\subsubsection{Crescimento celular}


A dinâmica do crescimento de tumores tem sido estudada por diversos autores na tentativa de identificar um padrão e deste modo poder prever o seu desenvolvimento ao longo do tempo (LAIRD, 1964; FRIBERG; MATTSON, 1997; SHERRATT; CHAPLAIN, 2001). Os primeiros estudos relativos a este tema indicaram que a divisão de células cancerígenas é um processo mais complexo que uma simples sucessão de duplicações, conforme sintetizado por Gerlee (2013). Se a primeira célula com mutações se dividisse em duas, e cada uma dessas duas também se duplicasse em intervalo de tempo igual e assim sucessivamente, o crescimento do tumor seguiria uma função exponencial com taxa de crescimento constante. Porém, observações experimentais indicam que a taxa de crescimento do tumor diminui com o tempo. Este comportamento ocorre devido à morte de algumas das células que compõem o tumor e também à entrada no chamado estado quiescente, no qual a célula está viva, mas não se replica.

Algumas funções comumente utilizadas em problemas matemáticos e estatísticos vêm sendo investigadas como possíveis modelos do crescimento de células cancerígenas, conforme mostrado na Figura 35. Dentre elas, há uma série de autores que indica a função de crescimento de Gompertz como a que melhor representa o crescimento de tumores (WINSOR, 1932; NORTON, 1988; HAHNFELDT ET AL., 1999; DOMINGUES, 2010).

Figura 35: Curva do tamanho do tumor em função do tempo de acordo com diferentes funções de crescimento.

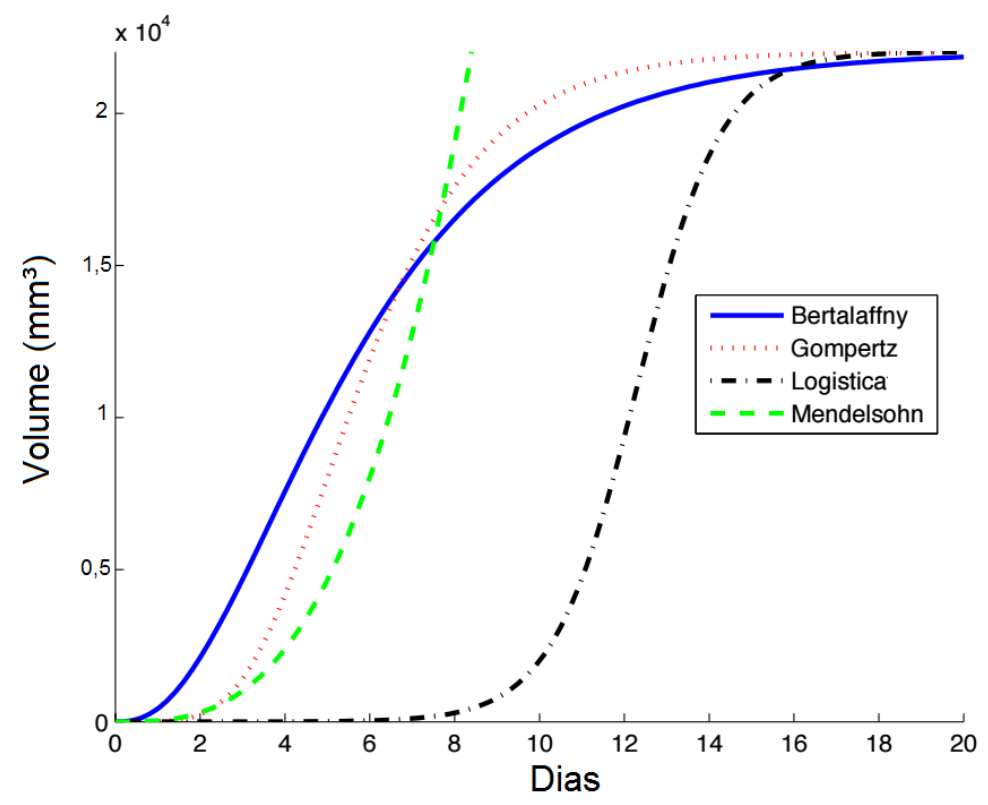

Fonte: Gerlee (2013). 
De acordo com a função de crescimento de Gompertz, a derivada com relação ao tempo do número de células que compõem um tumor é dada pela Equação 58, onde $N$ é o número de células no instante de tempo $t, r$ representa o número de divisões celulares por unidade de tempo, ou taxa de replicação, e $K$ é o valor limite da função, também chamado de capacidade de carga, que indica o número máximo de células que um tumor pode atingir, cujo valor é da ordem de grandeza de $10^{13}$ células (FRIBERG; MATTSON, 1997).

$$
\frac{d N}{d t}=-r N \ln \left(\frac{N}{K}\right)
$$




\section{MÉTODOS}

O desenvolvimento deste trabalho é dividido em seis partes. Primeiramente será apresentada a proposta de um indicador de idade exergética que, posteriormente, será utilizado como parte da avaliação dos efeitos das alterações nas reações metabólicas decorrentes do tabagismo e da obesidade no desempenho exergético do corpo humano. Um modelo exergético do coração capaz de avaliar os efeitos da hipertensão será proposto, bem como uma análise de artérias com estenose. Posteriormente, será apresentado um modelo do metabolismo exergético de uma célula cancerígena. Por fim, será avaliado o impacto dessas patologias na expectativa de vida.

\subsection{INDICADOR DE IDADE EXERGÉTICA}

A ideia defendida pela teoria da taxa de vida de que haveria um valor acumulado máximo de energia por unidade de massa que poderia ser obtida pelo corpo por meio do metabolismo e os posteriores trabalhos acerca de valores máximos de entropia gerada (SILVA; ANNAMALAI, 2008; SILVA; ANNAMALAI, 2009; HERSHEY; 2010) e exergia destruída (MADY, 2013) basearão a proposta do indicador de idade exergética. Conforme descrito na seção 3.3, ainda não existem provas definitivas da validade global da teoria da taxa de vida. Ainda assim, a ideia base desta teoria será utilizada, não com a pretensão de fornecer valores exatos de expectativa de vida, mas com o objetivo de fornecer um indicador que permita comparar diferentes cenários metabólicos com base nas alterações do comportamento exergético do corpo.

O chamado indicador de idade exergética será determinado a partir dos resultados de exergia destruída acumulada por unidade de massa obtidos por Mady (2013) para um indivíduo brasileiro padrão e mostrados na Figura 36. Para esse indivíduo padrão, cada ano de vida na escala cronológica apresenta um valor correspondente de exergia destruída acumulada por unidade de massa $\left(B_{d, a d} / m\right)$ que será tomado 
como referência. Após a análise exergética do indivíduo na condição avaliada, os valores de $B_{d, a d} / m$ obtidos para cada idade serão confrontados com os de referência e a idade do indivíduo padrão correspondente ao valor de $B_{d, a d} m$ do indivíduo analisado será chamada de idade exergética. Desta maneira, será determinada a correspondência entre as idades cronológica e exergética do indivíduo, indicando se a condição avaliada aumenta ou diminui a taxa com que o indivíduo chega ao valor máximo de exergia destruída que pode ser acumulada ao longo da vida.

Figura 36: Valores de referência para exergia destruída acumulada por unidade de massa.

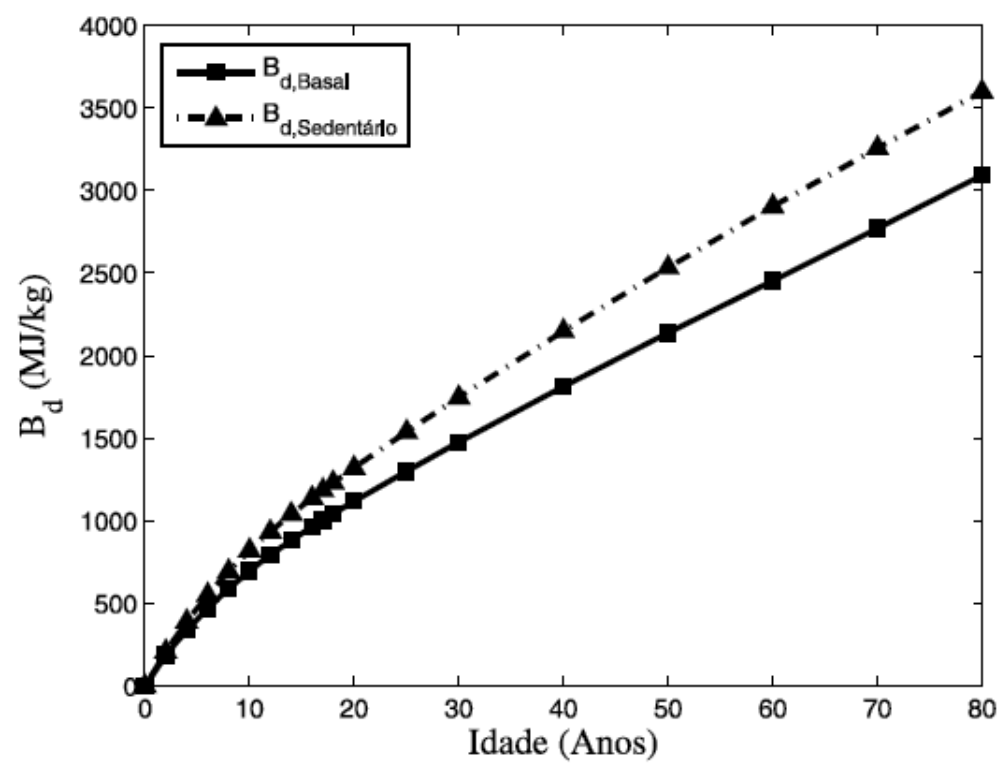

Fonte: Mady (2013).

\subsection{TABAGISMO}

O modelo exergético do corpo humano proposto por Mady (2013) e apresentado na seção 3.5 será utilizado na análise exergética do corpo de um fumante. Os dados relativos ao balanço energético, necessários para a análise exergética, são obtidos por meio do modelo do sistema térmico desenvolvido por Ferreira (2001), detalhado na seção 3.2.1.

A fim de analisar os impactos do aumento da taxa metabólica em fumantes nas variáveis exergéticas do corpo, assume-se que o consumo de cigarros tem início a partir dos 18 anos. Portanto, a variação do valor da taxa metabólica nos fumantes 
ocorre apenas a partir desta idade e, por esta razão, a análise exergética completa será aplicada apenas a essa faixa etária. Para o período de 18 a 80 anos, optou-se por utilizar o modelo de Ferreira (2001) para o balanço energético devido à sua maior complexidade e acurácia. Sua utilização implica a simplificação de que não há alterações morfológicas ao longo do tempo, tampouco entre fumantes e não fumantes. São consideradas apenas variações da taxa metabólica decorrentes da idade e do tabagismo. Uma vez que o metabolismo varia, a temperatura de neutralidade térmica também variará. Por essa razão, o balanço de energia, e posteriormente o de exergia, será determinado tanto na temperatura de neutralidade térmica quanto para a temperatura ambiente correspondente ao menor valor de metabolismo, que é a temperatura de neutralidade mais alta, neste caso $30,4^{\circ} \mathrm{C}$. Deste modo, garante-se que não haverá influência da ativação do mecanismo de tremores no valor total do metabolismo. A temperatura de neutralidade é obtida por meio da desativação dos mecanismos de controle de temperatura no modelo. As temperaturas de neutralidade térmica de fumante e não fumantes são mostradas na Figura 37 em função da idade. Observa-se um aumento da temperatura de neutralidade térmica devido à tendência de redução do metabolismo com a idade.

Figura 37: Temperatura de neutralidade de fumante e não fumante em função da idade.

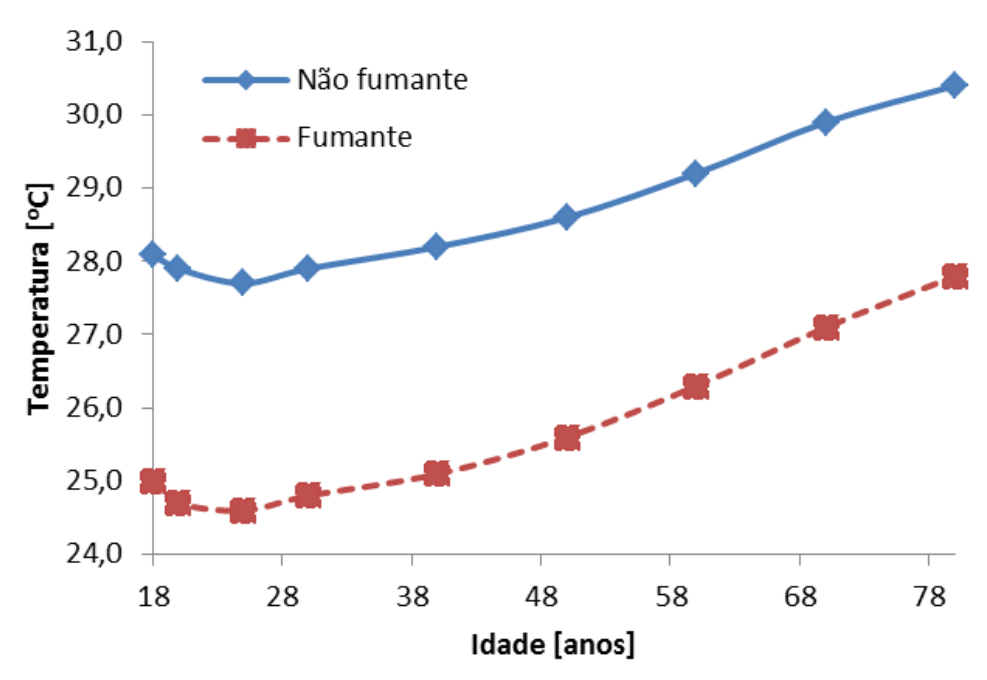

Fonte: O autor (2017).

Para o cálculo do indicador de idade exergética são necessários os valores relativos ao período de 0 a 17 anos. Durante este período ocorrem variações morfológicas 
significativas no corpo, não sendo possível utilizar diretamente o modelo de Ferreira (2001) para o balanço energético. Por isso, foram utilizados os resultados de exergia destruída apresentados por Mady (2013) para a faixa etária em questão. Esses valores foram determinados por meio do balanço exergético do corpo a partir do modelo simplificado do sistema térmico apresentado na seção 3.2.2.

Os valores de referência para o metabolismo de não fumantes são os apresentados por Mady (2013) em sua análise do ciclo de vida da população brasileira. Optou-se por utilizar os valores de metabolismo para a condição sedentária em vez da basal por ser mais condizente com os dados disponíveis para fumantes na literatura. Para fumantes, o valor de metabolismo por área superficial é considerado $20 \%$ maior que o de não fumantes (MOFFAT; OWENS, 1991). Ao valor absoluto, soma-se 12,7 W referentes ao efeito termogênico (KROMHOUT; 1988). Os valores finais são mostrados na Tabela 5.

Tabela 5: Valores de metabolismo utilizados para cada idade.

\begin{tabular}{rrr}
\hline Idade & $\begin{array}{c}\text { Metabolismo } \\
\text { não fumante } \\
\text { (W) }\end{array}$ & $\begin{array}{r}\text { Metabolismo } \\
\text { fumante (W) }\end{array}$ \\
\hline 0 & 29,1 & 29,1 \\
\hline 2 & 44,4 & 44,4 \\
\hline 4 & 50,1 & 50,1 \\
\hline 6 & 55,3 & 55,3 \\
\hline 8 & 60,9 & 60,9 \\
\hline 10 & 66,6 & 66,6 \\
\hline 12 & 76,5 & 76,5 \\
\hline 14 & 87,4 & 87,4 \\
\hline 16 & 94,7 & 94,7 \\
\hline 17 & 97,3 & 97,3 \\
\hline 18 & 98,8 & 131,3 \\
\hline 20 & 101,2 & 134,1 \\
\hline 25 & 102,4 & 135,6 \\
\hline 30 & 100,9 & 133,8 \\
\hline 40 & 97,5 & 129,7 \\
\hline 50 & 93,2 & 124,6 \\
\hline 60 & 87,1 & 117,2 \\
\hline 70 & 80,5 & 109,3 \\
\hline 80 & 74,1 & 101,7 \\
\hline Fonte: O autor (2017). &
\end{tabular}




\subsection{OBESIDADE}

O modelo exergético de Mady (2013) também será utilizado para determinação do desempenho exergético do corpo na presença de obesidade. Porém, para o balanço energético, o modelo de Ferreira (2001) se mostra inadequado devido à dificuldade de alteração dos parâmetros geométricos. Por esta razão, o modelo simplificado do sistema térmico, detalhado na seção 3.2.2, será utilizado. Neste modelo, o corpo é representado por um cilindro uniforme dividido em quatro camadas concêntricas: núcleo, músculo, gordura e pele. Esta configuração facilita a manipulação do modelo para representação de diferentes características antropométricas e composições corporais, o que é essencial para as análises energética e exergética ao longo do ciclo de vida e na presença de obesidade.

$\mathrm{Na}$ avaliação dos efeitos da obesidade, os dados do experimento de Ravusin et al. (1992) serão utilizados. A espessura e o comprimento das camadas do modelo térmico simplificado serão alterados de modo que as características globais se aproximem daquelas dos grupos de indivíduos avaliados. A análise será feita para três grupos (controle, moderadamente obeso e obeso), que foram definidos a partir dos valores de percentual de gordura (PG), que são, respectivamente, 20,3\%, 29,8\% e $36,1 \%$.

Assim como para o tabagismo, o ciclo de vida de 0 a 80 anos será avaliado. Como a progressão da altura de 0 a 80 anos segue os dados médios da população masculina brasileira, a massa de cada grupo para cada idade avaliada foi determinada de modo a manter o IMC característico do grupo. Assumiu-se que até a idade de 6 anos não há diferenças entre os grupos. Tanto para os moderadamente obesos quanto para os obesos, os sinais de ganho de peso começam a se manifestar, porém de maneira diferenciada, a partir dos 8 anos e se estabilizam aos 18 anos. Esses sinais são representados no modelo por meio do aumento da massa e do percentual de gordura corporal, conforme indicado na Tabela 6.

Uma vez que o experimento de Ravusin et al. (1992) não detectou diferenças substanciais entre os valores de metabolismo por área superficial de cada grupo, o valor apresentado por Mady (2013) para atividade sedentária foi usado como 
referência e multiplicado pela área superficial de cada grupo em cada idade. Por fim, as espessuras das camadas foram modificadas de modo a obter modelos representativos de cada grupo e idade. Devido à dificuldade de se obter um modelo com todas as características iguais às dos indivíduos avaliados, optou-se por priorizar a convergência dos valores de metabolismo $(M)$, massa e área superficial, por serem as variáveis mais relevantes para o balanço energético. Vale enfatizar que nenhum tipo de doença relacionada à obesidade foi reportado pelos indivíduos participantes do experimento de Ravusin et al. (1992). Portanto, considera-se que as alterações no valor do metabolismo apresentadas se devem exclusivamente à presença da obesidade, que é expressa no modelo apenas por alterações na composição corporal, não levando em conta possíveis alterações fisiológicas.

Tabela 6: Dados de referência para cada grupo em função da idade.

\begin{tabular}{|c|c|c|c|c|c|c|c|c|c|c|}
\hline & & \multicolumn{3}{|c|}{ Controle } & \multicolumn{3}{|c|}{ Moderadamente obeso } & \multicolumn{3}{|c|}{ Obeso } \\
\hline $\begin{array}{l}\text { Idade } \\
\text { [anos] }\end{array}$ & $\begin{array}{c}\text { Altura } \\
\text { [m] }\end{array}$ & $\begin{array}{c}\text { Massa } \\
{[\mathrm{kg}]}\end{array}$ & $\begin{array}{l}\text { PG } \\
\text { [\%] }\end{array}$ & $\begin{array}{c}\mathbf{M} \\
{[\mathbf{W}]}\end{array}$ & $\begin{array}{c}\text { Massa } \\
{[\mathrm{kg}]}\end{array}$ & $\begin{array}{l}\text { PG } \\
\text { [\%] }\end{array}$ & $\begin{array}{c}\mathbf{M} \\
{[\mathbf{W}]}\end{array}$ & $\begin{array}{c}\text { Massa } \\
{[\mathrm{kg}]}\end{array}$ & $\begin{array}{l}\text { PG } \\
{[\%]}\end{array}$ & $\begin{array}{c}\mathbf{M} \\
{[\mathbf{W}]}\end{array}$ \\
\hline 0 & 0,67 & 8 & 20,3 & 29,1 & 8 & 20,3 & 29,1 & 8 & 20,3 & 29,1 \\
\hline 2 & 0,92 & 14 & 20,3 & 44,4 & 14 & 20,3 & 44,4 & 14 & 20,3 & 44,4 \\
\hline 4 & 1,06 & 18 & 20,3 & 50,1 & 18 & 20,3 & 50,1 & 18 & 20,3 & 50,1 \\
\hline 6 & 1,18 & 22 & 20,3 & 55,3 & 22 & 20,3 & 55,3 & 22 & 20,3 & 55,3 \\
\hline 8 & 1,30 & 28 & 20,3 & 60,9 & 33 & 21,5 & 65,3 & 47 & 22,3 & 76,3 \\
\hline 10 & 1,39 & 33 & 20,3 & 66,6 & 39 & 22,8 & 71,4 & 57 & 24,4 & 83,4 \\
\hline 12 & 1,51 & 42 & 20,3 & 76,5 & 50 & 24,2 & 82,0 & 71 & 26,8 & 95,8 \\
\hline 14 & 1,64 & 52 & 20,3 & 87,4 & 62 & 25,6 & 93,8 & 89 & 29,4 & 109,5 \\
\hline 16 & 1,70 & 60 & 20,3 & 94,7 & 71 & 27,2 & 101,6 & 102 & 32,2 & 118,7 \\
\hline 17 & 1,72 & 62 & 20,3 & 96,4 & 74 & 28,8 & 104,3 & 107 & 35,4 & 121,9 \\
\hline 18 & 1,73 & 62 & 20,3 & 96,9 & 78 & 29,8 & 106,4 & 112 & 36,1 & 124,4 \\
\hline 20 & 1,73 & 63 & 20,3 & 96,9 & 78 & 29,8 & 106,4 & 113 & 36,1 & 124,4 \\
\hline 25 & 1,73 & 63 & 20,3 & 96,1 & 78 & 29,8 & 105,6 & 113 & 36,1 & 123,4 \\
\hline 30 & 1,72 & 62 & 20,3 & 93,3 & 77 & 29,8 & 102,4 & 111 & 36,1 & 119,8 \\
\hline 40 & 1,71 & 61 & 20,3 & 89,6 & 76 & 29,8 & 98,4 & 110 & 36,1 & 115,1 \\
\hline 50 & 1,70 & 60 & 20,3 & 85,3 & 75 & 29,8 & 93,6 & 109 & 36,1 & 109,5 \\
\hline 60 & 1,68 & 59 & 20,3 & 79,7 & 74 & 29,8 & 87,5 & 107 & 36,1 & 102,3 \\
\hline 70 & 1,67 & 58 & 20,3 & 74,3 & 73 & 29,8 & 81,6 & 105 & 36,1 & 95,4 \\
\hline 80 & 1,66 & 57 & 20,3 & 69,6 & 72 & 29,8 & 76,4 & 104 & 36,1 & 89,3 \\
\hline
\end{tabular}

Fonte: O autor (2017).

\subsection{MODELO EXERGÉTICO DO CORAÇÃO}

Uma vez que grande parte das doenças relacionadas à obesidade está associada ao sistema cardiovascular, faz-se necessária a modelagem exergética do coração. Este órgão, cujo funcionamento foi detalhado na seção 3.6, será modelado conforme esquematizado na Figura 38. O coração é dividido em partes direita e esquerda, 
onde a primeira recebe sangue venoso dos órgãos e o bombeia até os pulmões enquanto a segunda bombeia para os órgãos o sangue arterial proveniente dos pulmões. Os fluxos de entrada e saída de sangue ocorrem através de conjuntos de veias e artérias, que no modelo foram representados como entradas e saídas únicas com área transversal equivalente à soma das áreas das veias e artérias. As artérias coronárias, localizadas na parede externa do coração, são responsáveis pelo suprimento de nutrientes e oxigênio ao músculo cardíaco, bem como pela remoção dos produtos do metabolismo. Os átrios e ventrículos são originalmente separados por válvulas de operação passiva. Por esta razão, admite-se no modelo que cada parte é constituída por uma câmara única.

Figura 38: Esquema do modelo exergético do coração.

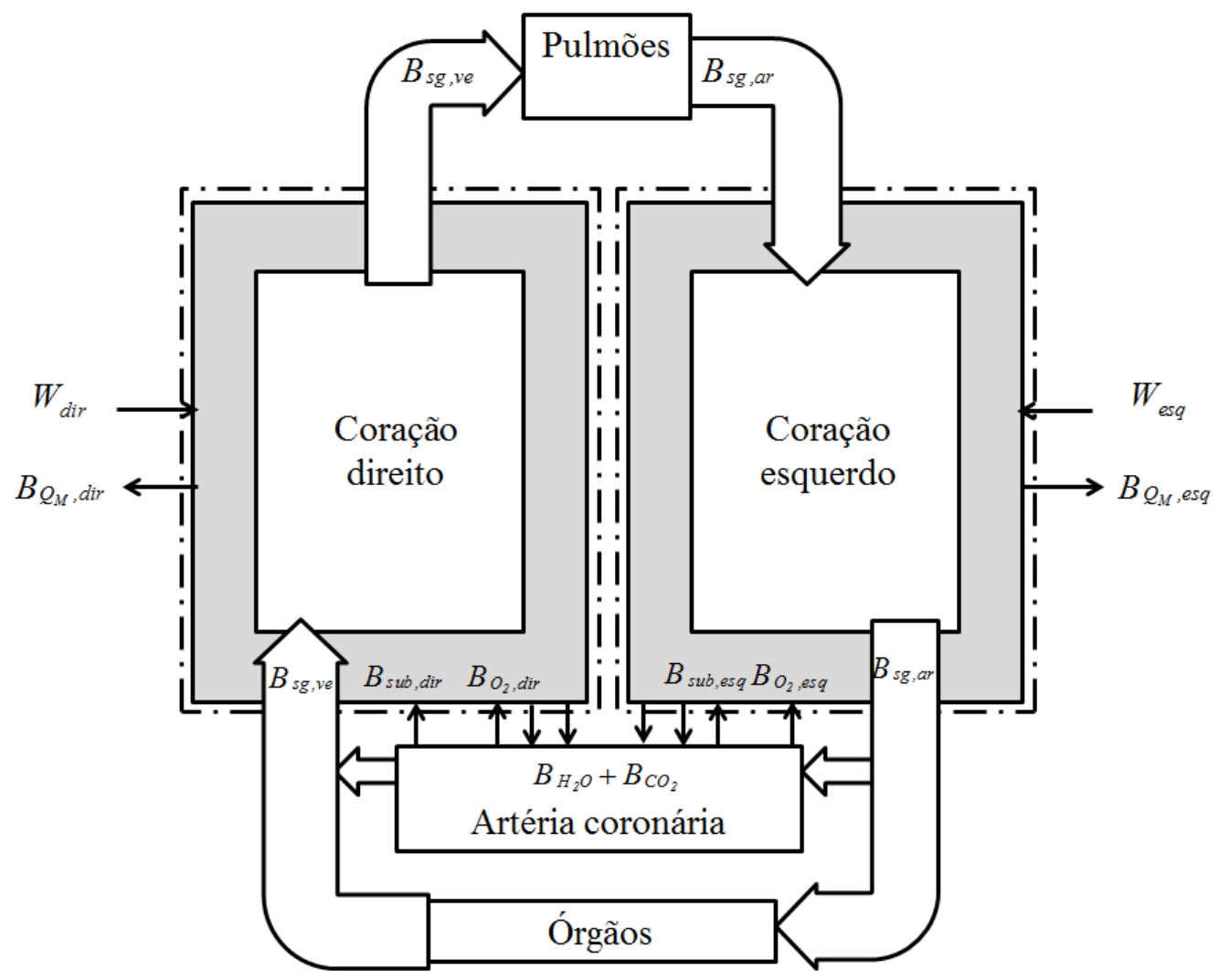

Fonte: O autor (2017).

A Figura 38 também mostra as parcelas de fluxos e transferências de exergia no coração, divididas para as partes direita (dir) e esquerda (esq). O índice crç é utilizado para representar a soma das parcelas correspondentes a cada parte do 
coração. São elas: transferência de exergia associada ao calor liberado devido à atividade metabólica do coração $\left(B_{Q M}\right)$, fluxos de exergia dos sangues venoso $\left(B_{s g, v e}\right)$ e arterial $\left(B_{s g, a r}\right)$, fluxos de exergia dos reagentes $\left(B_{s u b}\right.$ e $\left.B_{O 2}\right)$ e produtos $\left(B_{C O 2}\right.$ e $\left.B_{H 2 O}\right)$ das reações metabólicas e potência realizada $(W)$. O volume de controle foi definido em torno do músculo cardíaco a fim de englobar os fluxos associados ao metabolismo.

Apesar de sua operação cíclica, o balanço de exergia foi determinado assumindo-se operação contínua e permanente com valores médios das variáveis de modo que, ao fazer a integração ao longo do ciclo, as parcelas totais sejam iguais tanto na operação cíclica quanto na contínua. As taxas de exergia destruída são obtidas para as partes esquerda e direita por meio, respectivamente, das Equações 60 e 61. A exergia destruída total, bem como as outras parcelas, é a soma dos valores obtidos para cada parte. Os índices e e $s$ indicam, respectivamente, entrada e saída do volume de controle correspondente.

$$
\begin{aligned}
& \dot{B}_{d, \text { esq }}=\left.\dot{B}_{s g, a r}\right|_{e}+\dot{B}_{s u b, e s q}+\dot{B}_{O_{2}, \text { esq }}-\left.\dot{B}_{s g, a r}\right|_{s}-\dot{B}_{C O_{2}, \text { esq }}-\dot{B}_{H_{2} \mathrm{O}, \text { esq }}-\dot{B}_{Q_{M}, \text { esq }}+\dot{W}_{\text {esq }}(60) \\
& \dot{B}_{d, \text { dir }}=\left.\dot{B}_{s g, v e}\right|_{e}+\dot{B}_{s u b, d i r}+\dot{B}_{O_{2}, \text { dir }}-\left.\dot{B}_{s g, v e}\right|_{s}-\dot{B}_{C O_{2}, \text { dir }}-\dot{B}_{H_{2} \mathrm{O}, \text { dir }}-\dot{B}_{Q_{M}, \text { dir }}+\dot{W}_{\text {dir }}
\end{aligned}
$$

Conforme indicado na Equação 43, o metabolismo exergético $B_{M}$ é a diferença entre as exergias dos reagentes e dos produtos da reação metabólica. Portanto, o cálculo das taxas de exergia destruída apresentado nas equações anteriores pode ser obtido a partir dos valores de $B_{M}$, como mostrado nas Equações 62 e 63 .

$$
\begin{gathered}
\dot{B}_{d, \text { esq }}=\dot{B}_{M, e s q}-\Delta \dot{B}_{s g, a r}-\dot{B}_{Q_{M}, e s q}+\dot{W}_{e s q} \\
\dot{B}_{d, \text { dir }}=\dot{B}_{M, \text { dir }}-\Delta \dot{B}_{s g, v e}-\dot{B}_{Q_{M}, \text { dir }}+\dot{W}_{\text {dir }}
\end{gathered}
$$

Os valores do metabolismo, tanto energético quanto exergético, são obtidos por meio das Equações 33 e 46. Nestas equações, a taxa de metabolismo é função das vazões mássicas de oxigênio consumido, dióxido de carbono produzido e nitrogênio excretado pelo corpo. No caso do metabolismo do coração, os valores de vazão se referem somente a este órgão. Assume-se que a taxa de nitrogênio excretado seja 
nula. Para calcular as taxas de metabolismo das partes esquerda e direita, considera-se que a razão de seus valores é igual à razão dos valores de potência.

O calor liberado pelo metabolismo do coração $\left(Q_{M, \text { crç }}\right)$ é a diferença entre o metabolismo e o trabalho realizado. No caso do coração, onde o trabalho é realizado sobre o sistema, a taxa de calor é:

$$
\dot{Q}_{M, \text { crs }}=\dot{M}_{\text {crs }}+\dot{W}_{\text {crs }}
$$

Portanto, a taxa de exergia associada a esta parcela de calor é dada em função da temperatura do coração ( $\left.T_{\text {crç}}\right)$ a partir da Equação 65.

$$
\dot{B}_{Q_{M}, \text { crs }}=\dot{Q}_{M, \text { crg }}\left(1-\frac{T_{0}}{T_{\text {crg }}}\right)
$$

A taxa de exergia do fluxo sanguíneo $\left(B_{s g}\right)$ é composta pelas parcelas cinética $\left(B_{s g, c i n}\right)$ e física $\left(B_{s g, f i s}\right)$. Uma vez que não ocorrem reações químicas durante a passagem do sangue pelo coração, a variação da parcela química da exergia é nula. $B_{s g, c i n}$, como mostrado na Equação 66 é função da velocidade do sangue $\left(v_{s}\right)$, que é obtida por meio da vazão mássica, da densidade do sangue e da área da seção transversal das artérias.

$$
\dot{B}_{s g, \text { in }}=\dot{m}_{s g} \frac{v_{s g}^{2}}{2}
$$

O sangue, constituído macroscopicamente pelo plasma e glóbulos vermelhos, não possui uma classificação estrita, podendo ser considerado como um líquido bifásico, uma solução líquida com sólidos em suspensão ou ainda uma emulsão líquidolíquido, devido ao fato dos glóbulos vermelhos se comportarem como líquido quando submetidos a tensões cisalhantes (BASKURT; MEISELMAN, 2009). Além disso, ainda existem outras partículas menores dissolvidas no plasma, tais como íons, proteínas, glicose, lipídeos e lactato. Neste trabalho, para o cálculo da exergia física do fluxo, considera-se o sangue como uma mistura ideal de líquido, oxigênio e dióxido de carbono, sendo os dois últimos assumidos como gases ideias. Deste modo: 


$$
\dot{B}_{s g}=\dot{B}_{l i q}+\dot{B}_{O_{2}}+\dot{B}_{C O_{2}}
$$

onde

$$
\dot{B}_{\text {liq }}=\dot{m}_{s g}\left[c_{s g}\left(T_{s g}-T_{o}-T_{0} \ln \frac{T_{s g}}{T_{0}}\right)\right]
$$

Vale ressaltar que as propriedades do sangue já incluem todos os seus constituintes, incluindo os substratos dissolvidos no mesmo. No caso deste modelo, onde o sangue passa pelo coração sem a ocorrência de reações químicas, não é necessário analisar separadamente as exergias dos substratos. O fluxo de exergia do sangue venoso é dado pelas Equações 69, 70 e 71. A exergia do fluxo de sangue arterial é determinada de maneira análoga.

$$
\begin{gathered}
\dot{B}_{s g, v e}=\dot{B}_{\text {liq }, v e}+\dot{B}_{O_{2}, v e}+\dot{B}_{c O_{2}, v e} \\
\dot{B}_{\text {liq,ve }}=\dot{m}_{s g, v e}\left[c_{s g}\left(T_{s g, v e}-T_{0}-T_{0} \ln \frac{T_{s g, v e}}{T_{0}}\right)\right] \\
\dot{B}_{g, v e}=\dot{m}_{g, v e}\left[c_{p, g}\left(T_{s g, v e}-T_{0}-T_{0} \ln \frac{T_{s g, v e}}{T_{0}}\right)+R_{g} T_{0} \ln \frac{P_{g, v e}}{P_{g, 0}}\right]
\end{gathered}
$$

Retornando para as Equações 62 e 63, observa-se que a taxa de exergia destruída depende da diferença entre as exergias do fluxo de sangue na entrada e na saída. No caso da exergia cinética, esta alteração se deve à diferença entre as seções transversais das veias e artérias, o que leva a velocidades de entrada e saída distintas.

O cálculo da potência de cada parte do coração é realizado conforme descrito anteriormente na seção 3.6 por meio das Equações 55 e 56, que representam a multiplicação da vazão volumétrica de sangue pela diferença entre as pressões máxima e mínima de cada lado do órgão. Este cálculo é termodinamicamente coerente com a avaliação do trabalho para um volume de controle sujeito a processos internamente reversíveis, aproximação que será adotada neste trabalho. 
O coração é tratado como uma bomba. Entretanto, de modo distinto ao que ocorre em equipamentos industriais, a potência é obtida à custa do metabolismo exergético. Sendo assim, de maneira análoga à eficiência energética determinada por Guyton e Hall (2006), e eficiência exergética do coração é dada por:

$$
\eta_{c r c ̧}=\frac{\dot{W}_{c r \zeta}}{\dot{B}_{M, c r \zeta}}
$$

O modelo apresentado será utilizado para avaliar o comportamento exergético do coração durante o repouso e também na realização de caminhada e corrida, assim como foi feito por Henriques (2013) para o corpo e o sistema respiratório. Os dados do balanço de energia necessários para a análise exergética do coração, tais como vazões mássicas de sangue e gases, temperaturas e pressões parciais dos gases, serão obtidos a partir das simulações feitas por Henriques (2013) utilizando o modelo de Ferreira (2001).

Os valores de referência em repouso para as pressões necessárias para o cálculo da potência do coração estão apresentados em Horwich et al. (2001). Os dados de pressão sistólica obtidos por Miyai et al. (2002) para diferentes intensidades de atividade física, medidas por meio da potência realizada pelo corpo ( $\left.W_{\text {corpo }}\right)$, foram utilizados a fim de se obter a expressão da pressão sistólica, medida em kPa, em função da potência realizada, em W, mostrada na Equação 73. A pressão diastólica não apresenta variação significativa durante a prática de exercícios.

$$
P_{\text {sist }}=4 \times 10^{-6} \dot{W}_{\text {corpo }}^{3}-0,0005 \dot{W}_{\text {corpo }}^{2}+0,0483 \dot{W}_{\text {corpo }}+16,458
$$

Além da variação da intensidade do exercício, será avaliado também o efeito da hipertensão no desempenho exergético do coração. Para isso, os valores de pressão sistólica para cada potência realizada pelo corpo serão corrigidos em 34,9\% para os hipertensos, enquanto a pressão diastólica será admitida como 29,3\% superior, de acordo com os dados experimentais de Frohlich et al. (1983). Os valores de metabolismo energético e exergético do coração serão considerados, conforme apontado por Strauer (1979), 35,4\% maiores para hipertensos. 


\subsection{EFEITO DA ESTENOSE}

As artérias são responsáveis por transportar o sangue oxigenado nos pulmões, do coração para os órgãos e, assim como tubulações industriais, o escoamento de sangue está sujeito a perdas de carga distribuídas e localizadas e, consequentemente, irreversibilidades. O primeiro tipo de perda de carga resulta do atrito entre o fluido e a superfície interna do conduto e é função de parâmetros do escoamento, enquanto o segundo tipo ocorre devido a obstáculos presentes no duto, que levam a mudanças abruptas no vetor velocidade do fluido. No caso do sistema circulatório, o estreitamento pontual das artérias leva a perdas de carga localizadas. As denominadas estenoses têm o seu grau de severidade avaliado por meio da redução percentual do diâmetro da artéria.

A fim de avaliar os efeitos da presença de uma estenose no escoamento, parte-se inicialmente da equação de Bernoulli, que é obtida a partir da aplicação da Primeira Lei da Termodinâmica. Para levar em conta os efeitos de perda de carga, soma-se à equação ideal conservativa os termos $H_{\text {dist }}$ e $H_{\text {local, }}$, referentes às perdas de carga distribuída e localizada, respectivamente, conforme mostrado na equação 74 .

$$
\frac{P_{1}}{\rho g}+\frac{v_{1}^{2}}{2 g}+Z_{1}=\frac{P_{2}}{\rho g}+\frac{v_{2}^{2}}{2 g}+Z_{2}+H_{\text {dist }}+H_{\text {local }}
$$

onde: $P=$ pressão do sangue $[\mathrm{Pa}]$;

$\rho=$ massa específica do sangue $\left[\mathrm{kg} / \mathrm{m}^{3}\right]$;

$g=$ aceleração da gravidade $\left[\mathrm{m} / \mathrm{s}^{2}\right]$;

$v=$ velocidade do sangue $[\mathrm{m} / \mathrm{s}]$;

$Z=$ distância com relação ao plano horizontal de referência [m];

$H_{\text {dist }}=$ perda de carga distribuída [m];

$H_{\text {local }}=$ perda de carga localizada $[\mathrm{m}]$.

As perdas de carga provocadas tanto por efeitos de fricção quanto por singularidades são fonte de irreversibilidades no escoamento, levando, 
consequentemente, à destruição de exergia. A diferença entre a exergia específica do fluxo a montante e a jusante é dada por:

$$
b_{1}-b_{2}=-b_{Q}+w+b_{d}
$$

onde $b_{Q}$ é a exergia específica associada à transferência de calor que, no caso das artérias, é o calor recebido da veia adjacente, $w$ é o trabalho específico e $b_{d}$ é a exergia destruída específica. Definindo o volume de controle como parte da artéria que não compreende o coração, w é zero e a exergia destruída específica se torna

$$
b_{d}=b_{1}-b_{2}+b_{Q}
$$

A diferença entre as exergias específicas do fluxo, como mostrado na Equação 77, é composta pelas parcelas de exergias física, cinética e potencial, onde $h$ é a entalpia específica, $T_{0}$ a temperatura de referência e $s$ representa a entropia específica.

$$
b_{1}-b_{2}=h_{1}-h_{2}-T_{0}\left(s_{1}-s_{2}\right)+\frac{v_{1}^{2}-v_{2}^{2}}{2}+g\left(Z_{1}-Z_{2}\right)
$$

Assumindo o sangue como um fluido incompressível, a temperatura constante e sem variações em sua composição química, a diferença de entalpia específica entre dois pontos é

$$
h_{1}-h_{2}=T\left(s_{1}-s_{2}\right)+\frac{P_{1}-P_{2}}{\rho}
$$

Substituindo Equação 78 em 77 chega-se a

$$
b_{1}-b_{2}=\frac{P_{1}-P_{2}}{\rho}+\frac{v_{1}^{2}-v_{2}^{2}}{2}+g\left(Z_{1}-Z_{2}\right)+\left(T-T_{0}\right)\left(s_{1}-s_{2}\right)
$$

Mais além, ao substituir a Equação resultante 79 em 76, obtém-se uma expressão para a exergia destruída específica, apresentada na Equação 80.

$$
b_{d}=\frac{P_{1}-P_{2}}{\rho}+\frac{v_{1}^{2}-v_{2}^{2}}{2}+g\left(Z_{1}-Z_{2}\right)+\left(T-T_{0}\right)\left(s_{1}-s_{2}\right)+b_{Q}
$$

A exergia específica associada à transferência de calor entre a artéria e sua veia correspondente é calculada a partir do produto do calor transferido por unidade de massa e o fator de Carnot, conforme Equação 81. Além disso, o balanço de entropia 
no volume de controle é obtido por meio da Equação 82, onde $s_{g e r}$ é a entropia específica gerada.

$$
\begin{aligned}
b_{Q} & =q\left(1-\frac{T_{0}}{T}\right) \\
s_{1}-s_{2} & =-\left(\frac{q}{T}+s_{g e r}\right)
\end{aligned}
$$

Ao substituir as equações 81 e 82 na Equação 80, obtém-se a Equação 83. Além disso, de acordo com o teorema de Gouy-Stodola, a exergia destruída específica é $T_{0} s_{g e r}$ e, voltando à Equação 74 , os três primeiros termos do lado direito da igualdade na Equação 83 podem ser substituídos por $g\left(H_{\text {dist }}+H_{\text {local }}\right)$. Portanto, a entropia específica gerada no volume de controle é calculada por meio da Equação 84 , onde se torna evidente que as irreversibilidades associadas ao fluxo sanguíneo nas artérias são provocadas apenas pelas perdas de carga devido ao atrito entre fluido e a superfície interna e às singularidades presentes no escoamento, como, por exemplo, uma estenose.

$$
\begin{gathered}
b_{d}=\frac{P_{1}-P_{2}}{\rho}+\frac{v_{1}^{2}-v_{2}^{2}}{2}+g\left(Z_{1}-Z_{2}\right)+\left(T_{0}-T\right) s_{\text {ger }} \\
s_{\text {ger }}=\frac{g}{T}\left(H_{\text {dist }}+H_{\text {local }}\right)
\end{gathered}
$$

Portanto, a taxa de exergia destruída em um segmento de artéria, representada por

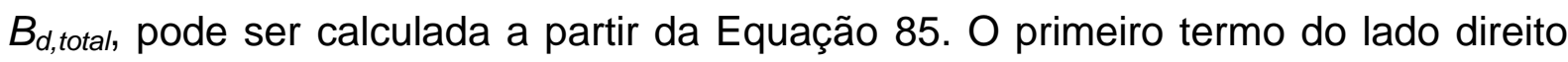
da igualdade é a parcela devido ao atrito, que está presente em qualquer segmento de artéria, estenótica ou saudável, e será indicada por $B_{d, s d v}$. O segundo termo, por sua vez, leva em conta a destruição de exergia devido à presença da estenose e é indicado por $B_{d, e s t}$ É conveniente destacar que, assim como no modelo do coração, o fluxo de sangue foi assumido como contínuo, apesar da variabilidade do ciclo cardíaco. Valores médios das variáveis são utilizados nos cálculos. A temperatura $T$ também foi considerada constante, independente da artéria analisada e assumida como a temperatura interna média do corpo no valor de $36,5^{\circ} \mathrm{C}$, ou $309,7 \mathrm{~K}$. Vale 
destacar também que, caso o volume de controle fosse externo, com $T=T_{0}, B_{d, t o t a l}$ não seria função da temperatura. Além disso, o termo $\left(T-T_{0}\right)\left(s_{1}-s_{2}\right)$ seria excluído da Equação 80, assim como $b_{Q}$, uma vez que o fator de Carnot seria nulo. Portanto, independente do valor da temperatura e das transferências de calor envolvidas, a exergia destruída em um escoamento é a medida das irreversibilidades associadas à perda de carga.

$$
B_{d, \text { total }}=\left(\frac{\dot{m} g T_{0}}{T}\right) H_{\text {dist }}+\left(\frac{\dot{m} g T_{0}}{T}\right) H_{\text {local }}
$$

A perda de carga distribuída $H_{\text {dist }}$ é calculada por meio da Equação 86, assumindo que o escoamento é laminar, onde $R e$ é o número de Reynolds, $L$ indica o comprimento do segmento arterial analisado e $D$ indica seu diâmetro. Além disso, o sangue é considerado um fluido Newtoniano, o que é uma boa aproximação para artérias médias e grandes (WESTERHOF ET AL., 2005). A perda de carga localizada $H_{\text {local }}$ é computada a partir da Equação 87, como função do coeficiente de perda de carga $K_{\text {eng, }}$ que é adimensional e determinado experimentalmente.

$$
\begin{gathered}
H_{\text {dist }}=\frac{64}{\operatorname{Re}}\left(\frac{L}{D}\right)\left(\frac{v^{2}}{2 g}\right) \\
H_{\text {local }}=K_{\text {eng }} \frac{v^{2}}{2 g}
\end{gathered}
$$

A contribuição da estenose para a exergia destruída total é avaliada por meio do índice $R$, indicado na Equação 88.

$$
R=\frac{B_{d, \text { est }}}{B_{d, \text { total }}}
$$

Conforme mostrado na Equação 87, o parâmetro $K_{\text {eng }}$ é necessário para o cálculo da perda de carga localizada devido à estenose. Para aplicações convencionais, este valor é tabelado, mas para o caso da estenose, serão utilizados os resultados dos experimentos de Oshinski et al. (1996), apresentados na seção 3.6.1. Porém, o coeficiente de perda estimado no experimento em questão possui significado físico diferente do $K_{\text {eng }}$ da Equação 87, pois não é adimensional e é utilizado para o cálculo de diferença de pressão, e não perda de carga. Ademais, este experimento 
foi projetado de modo que a diferença de pressão medida e, portanto, o valor de $K$ obtido, engloba não somente o efeito localizado da estenose, mas também o efeito distribuído do atrito. Deste modo, os valores mostrados na Tabela 3 não podem ser aplicados diretamente na Equação 87. Por esta razão, a partir dos dados primários do experimento de Oshinski et al. (1996) e assumindo a vazão mássica de sangue correspondente à artéria do tronco, cujas medidas se aproximam às usadas no experimento, as velocidades a montante e a jusante foram determinadas, assim como a perda de carga distribuída. Com o auxílio das Equações 86 e 87, o coeficiente $K_{\text {eng }}$ foi determinado em função da severidade Sev da estenose. Por meio de uma regressão linear, obteve-se uma expressão para esta função, indicada na Equação 89, válida para severidades entre 15 e 90\% com um coeficiente de determinação próximo de 1.

$$
K_{\text {eng }}=1,6514 . \operatorname{Sev}-0,2125
$$

Para fins comparativos, $K_{\text {eng }}$ também foi determinado teoricamente, fazendo uma aproximação entre a estenose e uma conexão do tipo convergente-divergente, de formato semelhante ao indicado na Figura 39, utilizando os gráficos e tabelas disponíveis em Idelchick (2008). Ainda, os resultados de diferença de pressão na artéria coronária obtidos por Cilla et al. (2015) por meio de simulações do tipo FSI (Fluid-structure Interaction) são comparados aos calculados.

Figura 39: Formato genérico de uma conexão do tipo convergente-divergente.

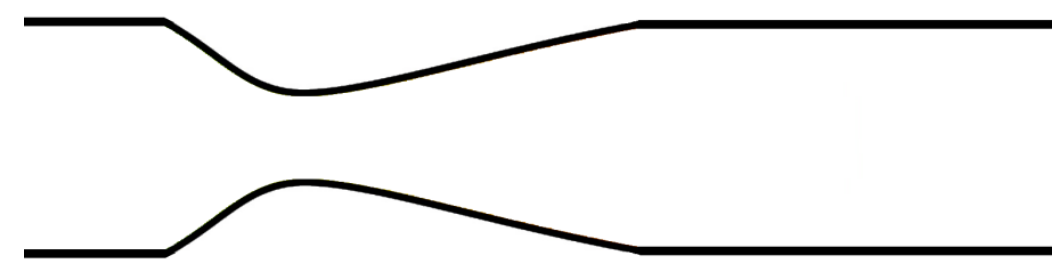

Fonte: O autor (2017).

A metodologia descrita nesta seção será aplicada a fim de determinar a taxa de exergia destruída em segmentos de diferentes artérias do corpo na presença de 
estenose, bem como a diferença de pressão provocada pelo estreitamento. Os valores relativos aos diâmetros e comprimentos dos segmentos de artérias do tronco, pescoço, braço e perna, além da artéria coronária, bem como as vazões mássicas de sangue em cada segmento, estão disponíveis nos trabalhos de Reymond et al. (2009) e Özcan et al. (2006).

\subsection{METABOLISMO EXERGÉTICO DE CÉLULAS CANCERÍGENAS}

Levando em conta que as reações químicas são processos com grande geração de entropia e também o peso do metabolismo exergético na taxa de exergia destruída no corpo, será proposto um modelo exergético do metabolismo de uma célula genérica de câncer. Conforme descrito na seção 3.7.3, uma série de autores têm se dedicado à investigação das reações metabólicas na presença de câncer, mas seus resultados não estão agrupados em um modelo único que sintetize as alterações nas rotas metabólicas apresentadas por um tumor. O modelo metabólico proposto é mostrado na Figura 40, onde as enzimas, produtos secundários e outras substâncias envolvidas nas reações representadas pelas setas foram omitidos e os números e variáveis que precedem os nomes dos substratos indicam o número de mols.

As reações principais estão elencadas na Tabela 7, incluindo alguns intermediários ocultos na Figura 40. É pertinente ressaltar que, conforme discutido por Guppy et al. (1993) e DeBerardinis et al. (2008), algumas das rotas metabólicas seguidas pelas células cancerígenas estão presentes também células saudáveis com altas taxas de proliferação. Porém, os valores numéricos utilizados neste modelo são provenientes de estudos experimentais com células cancerígenas. Portanto, as alterações metabólicas podem ser extrapoladas para a análise de outras células proliferativas, mas os valores numéricos estão restritos a células com câncer. Além disso, os dados numéricos coletados na literatura se referem a diferentes tipos de tumores. Logo, os valores apresentados devem ser interpretados como estimativas para um tipo genérico inespecífico de câncer. 
Figura 40: Representação dos caminhos metabólicos em uma célula cancerígena.

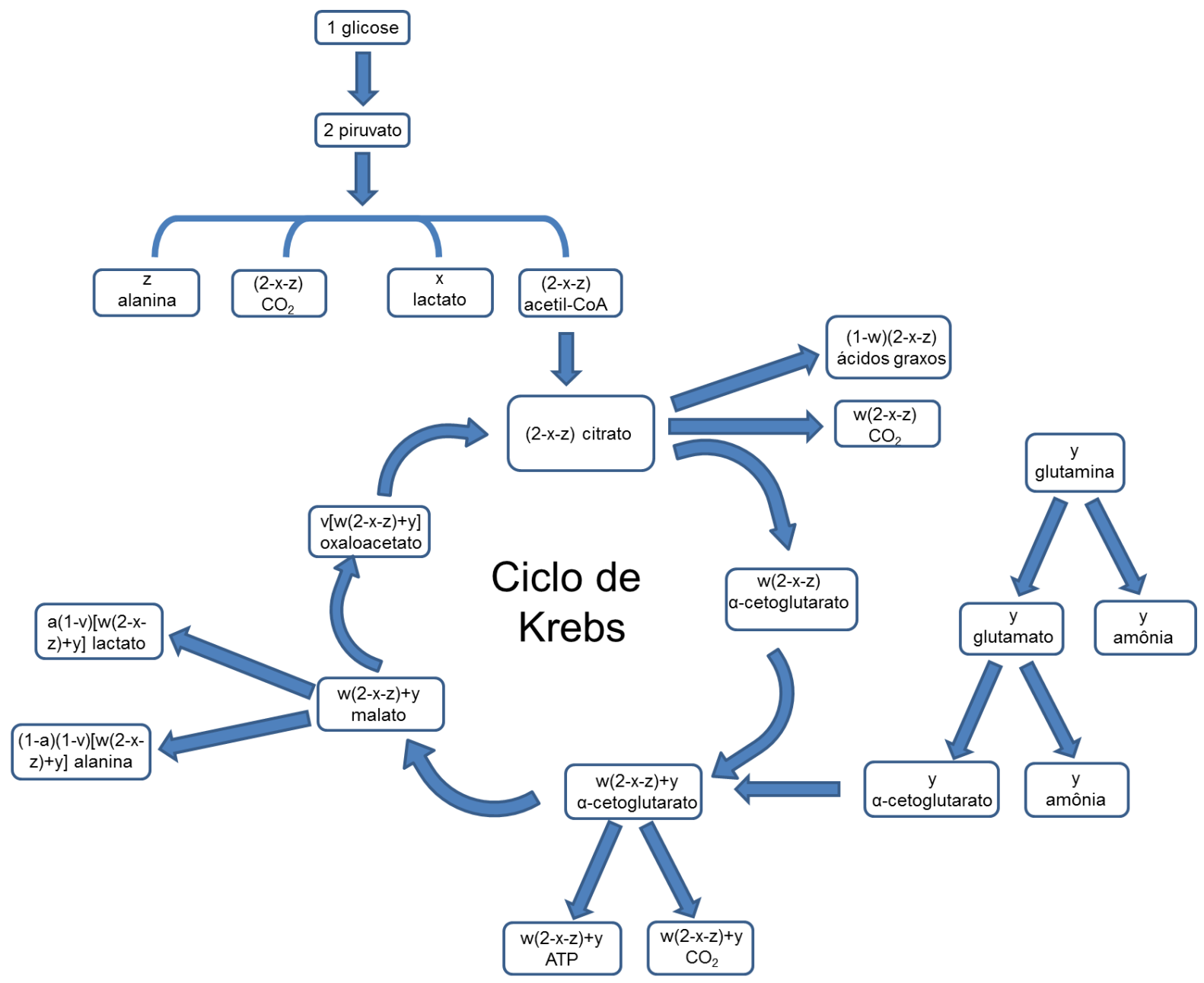

Fonte: O autor (2017).

Tabela 7: Principais reações presentes no metabolismo da glicose e da glutamina em um tumor.

\section{Reações a partir da glicose}

Reações a partir da glutamina

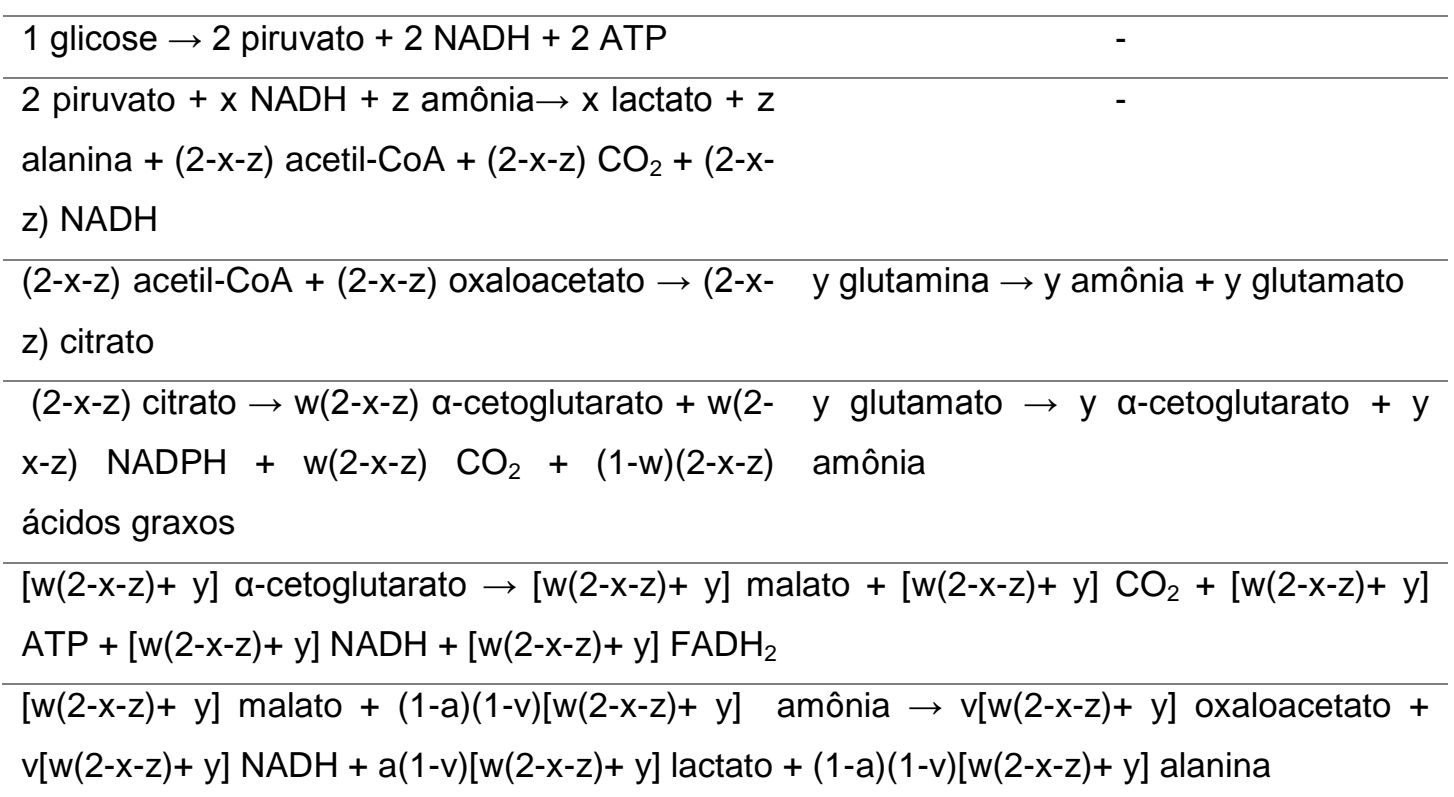

Fonte: $\mathrm{O}$ autor (2017). 
O processo se inicia na célula com a entrada de $1 \mathrm{~mol}$ de glicose que será degradado em 2 mols de piruvato. Em uma célula saudável, todo o piruvato é convertido em acetil-CoA. Porém, em uma célula cancerígena, mesmo na presença de oxigênio, o caminho anaeróbico é ativado e $x$ mols de lactato são formados, além de $z$ mols de alanina. Portanto, (2-x-z) mols de acetil-CoA entram no ciclo de Krebs e são convertidos em $(2-x-z)$ mols de citrato. A etapa seguinte, que é a formação de $\alpha-$ cetoglutarato, também sofre alterações. Apenas uma fração $w$ de citrato segue a reação padrão, resultando em $w(2-x-z)$ mols de a-cetoglutarato e $\mathrm{CO}_{2}$, sendo que apenas o primeiro continua no ciclo. O restante do citrato, $(1-w)(2-x-z)$ mols, é utilizado na síntese dos ácidos graxos necessários para a proliferação da célula. Paralelamente, $y$ mols de glutamina entram na célula e são metabolizados para formar $\alpha$-cetoglutarato e amônia na mesma quantidade. Os y mols de a-cetoglutarato formados entram no ciclo de Krebs se juntando aos $w(2-x-z)$ mols provenientes da glicose, resultando em $[w(2-x-z)+y]$ mols, que no estágio seguinte formam, em igual quantidade, $\mathrm{CO}_{2}$, ATP e malato. Este último, que continua no ciclo, é convertido apenas parcialmente em oxaloacetato com uma proporção de $v$. A outra parcela é convertida em lactato com uma proporção $a$, enquanto o restante forma alanina. É importante mencionar que durante a formação da alanina, amônia é consumida na mesma proporção, como indicado nas reações da Tabela 7. O oxaloacetato produzido reage com o citrato proveniente da glicose e o ciclo recomeça. Como pode ser observado, as quantidades molares de oxaloacetato e citrato são diferentes, afetando as reações subsequentes. A maior parte das reações do ciclo de Krebs é reversível, podendo ocorrer nos dois sentidos, mas a reação de formação do citrato é uma das exceções, como mostrado na Figura 34 da seção 3.7.3. Por isso, para avaliar a continuidade do ciclo, não é necessário utilizar a constante de equilíbrio da reação. Nesta etapa assume-se que, caso o número de mols de oxaloacetato seja inferior ao de citrato, haverá oxaloacetato disponível no citoplasma da célula para garantir a continuidade do ciclo. Se este número for superior, admite-se que a parcela excedente de oxaloacetato será liberada no citoplasma.

A Figura 41 sintetiza, a partir das alterações das vias metabólicas, as diferenças entre os reagentes e produtos das reações em células saudáveis e cancerígenas. Assumindo a membrana celular como a fronteira do volume de controle, os 
elementos intermediários das reações não são considerados. Admite-se também que todo o ATP produzido pela célula é utilizado internamente para sua manutenção e duplicação. Porém, para avaliar a quantidade de água produzida pela célula cancerígena é necessário conhecer o número de mols produzidos de NADH, representado pela letra $c$. Por questão de clareza, este intermediário não foi representado na Figura 40, apenas na Tabela 7. Na quebra da glicose em piruvato são produzidos 2 mols de NADH, bem como 2 mols de ATP, porém, para a formação do lactato, $x$ mols de NADH são consumidos. Adicionalmente, (2-x-z) mols são produzidos juntamente com acetil-CoA, $w(2-x-z)$ na formação de $\alpha$-cetoglutarato, $[w(2-x-z)+y]$ na formação de malato e por fim, mais $v[w(2-x-z)+y]$ para a liberação de oxaloacetato. Portanto, são liberados, até o fim do ciclo de Krebs $\{2-x+(2-x-z)+w(2-x-$ $z)+w(2-x-z)+y+v[w(2-x-z)+y]\}$ mols de $\mathrm{NADH}$, que serão utilizados na cadeia respiratória como transportadores de elétrons juntamente com os $[w(2-x-z)+y]$ mols de $\mathrm{FADH}_{2}$, produzidos na quebra do a-cetoglutarato.

Figura 41: Representação das diferenças metabólicas entre uma célula saudável e uma com câncer.

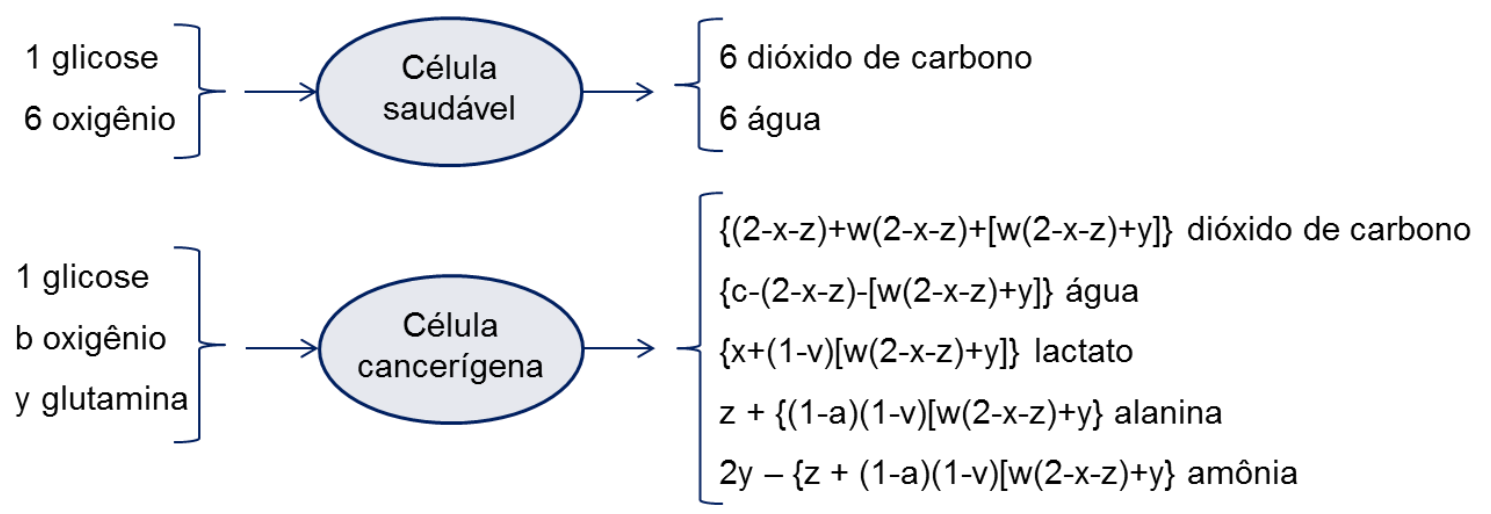

Fonte: O autor (2017).

Os valores das variáveis $x, y, z, w, v$ e a são obtidos a partir de resultados experimentais disponíveis na literatura e estão relacionados, com suas respectivas fontes, na Tabela 8. Como pode ser observado, cada estudo se refere a um tipo de célula cancerígena diferente e os valores das variáveis pode ter relação com a origem do tumor. Deste modo, as rotas metabólicas apresentadas são comuns a diferentes tipos de tumor, mas os valores numéricos obtidos correspondem a um modelo resultante da combinação de informações de diferentes tipos de célula. A partir dos valores da Tabela 8, contabiliza-se uma entrada de 0,20 mols de citrato e 
0,30 mols de oxaloacetato no ciclo de Krebs. Portanto, há oxaloacetato excedente, o que não compromete a continuidade do ciclo conforme a estequiometria esboçada na Figura 40. Se esta etapa do ciclo fosse reversível, seria necessária uma análise mais detalhada para avaliar o sentido da reação.

Tabela 8: Valores das variáveis envolvidas nos cálculos estequiométricos e suas respectivas fontes.

\begin{tabular}{ccll}
\multicolumn{1}{c}{ Variável } & Valor & \multicolumn{1}{c}{ Tipo de célula } & \multicolumn{1}{c}{ Referência } \\
\hline $\mathrm{a}$ & 0,73 & glioma (cérebro) & DEBERARDINIS ET AL. (2007); \\
\cline { 3 - 4 } & & mama & CASCIARI ET AL. (1992) \\
\hline $\mathrm{v}$ & 0,40 & glioma (cérebro) & DEBERARDINIS ET AL. (2007) \\
\hline $\mathrm{w}$ & 0,37 & glioma (cérebro) & DEBERARDINIS ET AL. (2007) \\
\hline $\mathrm{x}$ & 1,31 & Flexner-Jobling e Jensen & WARBURG ET AL. (1927) \\
\hline $\mathrm{y}$ & 0,67 & célula HeLa & REITZER ET AL. (1979) \\
\hline $\mathrm{z}$ & 0,49 & glioma (cérebro) & DEBERARDINIS ET AL. (2007) \\
\hline
\end{tabular}

Fonte: O autor (2017).

Conforme definido na Equação 43, a taxa de metabolismo exergético por célula é calculada a partir da diferença entre as taxas de exergia dos reagentes e produtos da reação metabólica. Portanto, no caso da célula cancerígena, o metabolismo exergético de uma célula $\dot{B}_{\text {met,cancer }}$ é definido pela Equação 90 . Porém, como todas as reações estão atreladas à entrada da glicose na célula, o metabolismo será calculado a partir da energia liberada para um mol de glicose consumido $b_{\text {met,cancer }} \mathrm{e}$ a taxa molar de consumo de glicose $\dot{m}_{\text {gli }}$, cujo valor é $7,3 \times 10^{-17} \mathrm{~mol} /$ célula.s (CASCIARI ET AL., 1992), como mostrado na Equação 91. Os índices gli, $O_{2}$, gtm, lct, $\mathrm{CO}_{2}, \mathrm{NH}_{3}, \mathrm{H}_{2} \mathrm{O}$ e ala se referem a, respectivamente, glicose, oxigênio, glutamina, lactato, dióxido de carbono, amônia, água e alanina.

$$
\begin{gathered}
\dot{B}_{M, \text { cancer }}=\dot{B}_{g l i}+\dot{B}_{\mathrm{O}_{2}}+\dot{B}_{g t m}-\dot{B}_{l c t}-\dot{B}_{\mathrm{CO}_{2}}-\dot{B}_{\mathrm{NH}_{3}}-\dot{B}_{\mathrm{H}_{2} \mathrm{O}}-\dot{B}_{a l a} \\
\dot{B}_{M, \text { cancer }}=\dot{m}_{g l i} b_{M, \text { cancer }}=\dot{m}_{g l i}\left(b_{g l i}+b_{\mathrm{O}_{2}}+b_{g t m}-b_{l c t}-b_{\mathrm{CO}_{2}}-b_{\mathrm{NH}_{3}}-b_{\mathrm{H}_{2} \mathrm{O}}-b_{a l a}\right)
\end{gathered}
$$

A exergia de cada substância será calculada levando em conta o número de mols apresentado na Figura 40, que já é contabilizado para 1 mol de glicose. Além disso, como as substâncias analisadas passam por reações químicas dentro do volume de controle, a exergia química por mol $b_{q u}$ deve ser considerada nos cálculos, bem como a parcela física $b_{f}$, como mostrado na Equação 92 para cada substância $i$. Os valores das exergias químicas estão listados na Tabela 9 e o cálculo da exergia 
física, realizado a partir do calor específico $c$ e da constante do gás $R$, é indicado na Equação 93. Para as substâncias sólidas, apenas a primeira parte da Equação 93 é válida. O valor da exergia química do lactato não está disponível na literatura. Por isso, seu valor foi determinado a partir do método da contribuição descrito na seção 3.1 utilizando os valores disponíveis em Szargut et al. (1988).

$$
\begin{gathered}
b_{i}=\frac{n_{i}}{n_{g l i}}\left(b_{q u, i}+b_{f, i}\right) \\
b_{t, i}=c_{i}\left(T-T_{0}-T_{0} \ln \frac{T}{T_{0}}\right)+R_{i} T_{0} \ln \frac{p}{p_{0}}
\end{gathered}
$$

Tabela 9: Exergias químicas.

\begin{tabular}{lcl}
\hline \multicolumn{1}{c}{ Substância } & $\begin{array}{c}\text { Exergia química } \\
\boldsymbol{b}_{\text {qu }}[\mathbf{k J / m o l}]\end{array}$ & Referência \\
\hline Glicose & 2955 & LEMS (2009) \\
\hline Glutamina & 2022 & MADY (2013) \\
\hline Oxigênio & 4,0 & KOTAS (1995) \\
\hline Lactato & 1339 & Método da contribuição \\
\hline Dióxido de carbono & 20,1 & KOTAS (1995) \\
\hline Água & 11,7 & KOTAS (1995) \\
\hline Amônia & 337,0 & SZARGUT ET AL. (1988) \\
\hline Alanina & 1347 & LEMS (2009) \\
\hline \multicolumn{3}{c}{}
\end{tabular}

Entretanto, devido aos baixos valores de $c$ e de $R$, a parcela física da exergia se torna desprezível frente à química. A exergia química da glicose, por exemplo, vale $2955 \mathrm{~kJ} / \mathrm{mol}$, enquanto sua exergia física é $0,06 \mathrm{~kJ} / \mathrm{mol}$. Por esta razão, será considerada apenas a exergia química dos reagentes e produtos do metabolismo.

A partir do valor da taxa de metabolismo exergético por célula, é possível calcular o metabolismo do tumor em função do tempo, por meio da função de crescimento de Gompertz apresentada na seção 3.7.3.1. Com a variação do número de células cancerígenas, a taxa de metabolismo exergético do tumor também variará com o tempo. Este valor será somado ao metabolismo de uma pessoa saudável e integrado ao longo do tempo para obtenção da exergia destruída acumulada e do indicador de idade exergética. Com relação à evolução do número de células do tumor, diferentes possibilidades serão contempladas. A taxa de replicação $r$ varia 
com o tipo de tumor, conforme indicado na Tabela 10. Porém, os valores encontrados na literatura para cada tipo de tumor são divergentes, pois variam de acordo com as condições de cada experimento. Por esta razão, serão avaliados valores de taxa de replicação entre 0,04 e 1,4, sem discriminar a qual tipo de câncer a taxa avaliada corresponde.

Adicionalmente, o número de mols produzidos de ATP será calculado e comparado com valores da literatura. A Equação 94 leva em conta os dois mols de ATP produzidos na glicólise, a produção no ciclo de Krebs e também na cadeia respiratória a partir das moléculas de $\mathrm{NADH}$ e $\mathrm{FADH}_{2}$ liberadas nas etapas anteriores. A relação entre o número de mols de ATP, $\mathrm{NADH}$ e $\mathrm{FADH}_{2}$ é fornecida por Nelson e Cox (2014).

Tabela 10: Taxa de crescimento para diferentes tipos de câncer.

\begin{tabular}{lll}
$\begin{array}{c}\text { Taxa de } \\
\text { crescimento (dia }{ }^{-1} \text { ) }\end{array}$ & Tipo de câncer & \multicolumn{1}{c}{ Referência } \\
\hline 0,16 & glioma & PHIPPS (2009) \\
\hline 0,086 & glioma & BECK-BORNHOLDT ET AL. (1987) \\
\hline 0,38 & glioma & CASTRO ET AL. (2003) \\
\hline 0,084 & cérebro & KRONIK ET AL. (2007) \\
\hline 0,075 & pescoço & POLESZCZUK (2013) \\
\hline 1,34 & colorretal & RIBBA ET AL. (2011) \\
\hline 0,83 & colón & CASTRO ET AL. (2003) \\
\hline 0,206 & medula óssea & DINGLI ET AL. (2006) \\
\hline 1,488 & leucemia & KIMMEL; TRAGANOS (1986) \\
\hline 0,040 & osteosarcoma & CHAPPELL ET AL. (2008) \\
\hline 0,643 & mama e ovário & PANETTA (1997) \\
\hline 0,49 & pulmão & CASTRO ET AL. (2003) \\
\hline 0,084 & pulmão & LEDZEWICZ ET AL. (2008) \\
\hline
\end{tabular}

Fonte: O autor (2017).

$$
n_{A T P}=2+[w(2-x-z)+y]+2,5 n_{N A D H}+1,5 n_{F A D H_{2}}
$$




\section{RESULTADOS E DISCUSSÃO}

\subsection{TABAGISMO}

As parcelas de exergia ao longo do ciclo de vida obtidas por meio da análise exergética do corpo para fumantes e não fumantes são apresentadas nas figuras seguintes. O metabolismo exergético $\left(B_{M}\right)$ é mostrado na Figura 42 para ambos os grupos e temperaturas ambiente. À temperatura de $30,4 \stackrel{\circ}{\circ}$, incrementos de $34,5 \%$ e $38,4 \%$ são registrados para, respectivamente, 18 e 80 anos. No caso de neutralidade térmica, esses valores observados são 32,8\% e 37,1\%. Comparando os resultados de um mesmo grupo para as diferentes temperaturas, observa-se que, para fumantes, $B_{M}$ é $2,1 \%$ maior na idade de 18 anos a $30,4 \stackrel{\circ}{\circ}$ e apenas $0,8 \%$ para não fumantes, sendo que a diferença tende a diminuir conforme a idade aumenta, uma vez que o metabolismo diminui e a temperatura de neutralidade se aproxima de $30,4 \stackrel{\circ}{ } \mathrm{C}$.

Figura 42: Metabolismo exergético em função da idade para fumantes e não fumantes para temperaturas de $30,4^{\circ} \mathrm{C}$ (a) e neutralidade térmica (b).

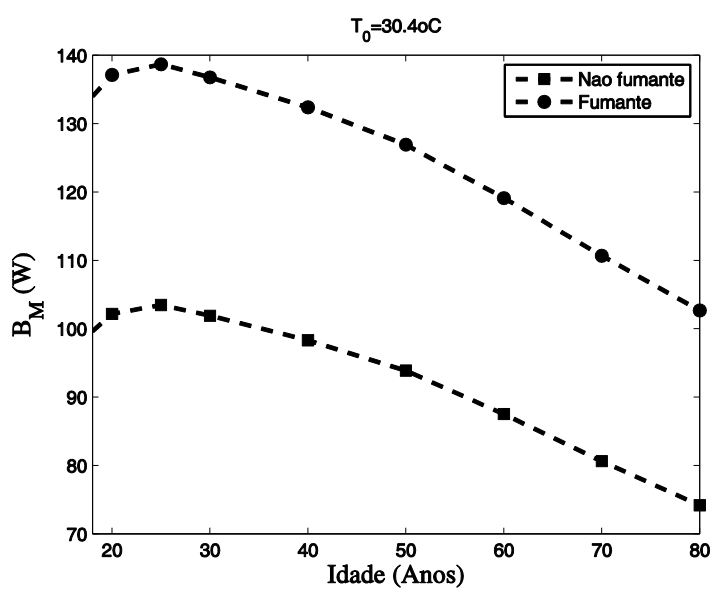

a

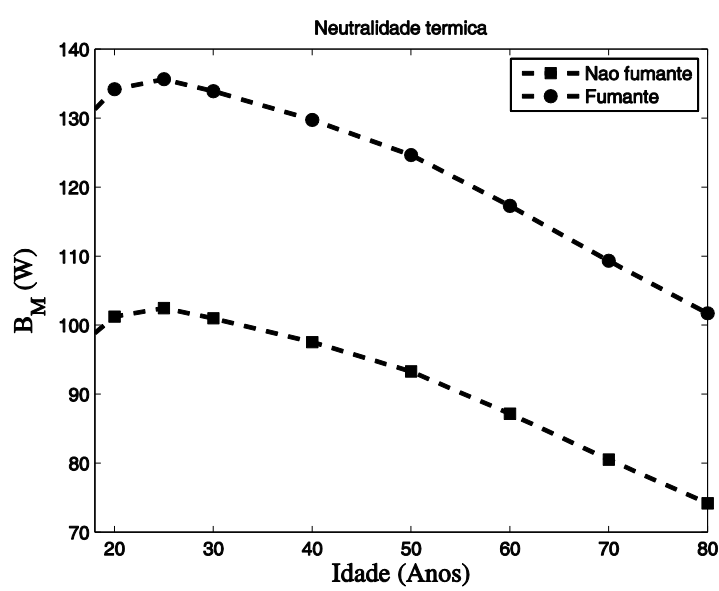

b

Fonte: O autor (2017).

A variação da taxa de exergia destruída $\left(B_{d}\right)$, mostrada na Figura 43 segue a mesma tendência observada no metabolismo exergético, com incremento um pouco menor, com valores à temperatura $30,4 \stackrel{\circ}{\circ}$ de $33,7 \%$ e $36,9 \%$ às idades de 18 e 80 anos, 
respectivamente. Na neutralidade térmica, os incrementos são de 32,2\% e 36,7\%. Para estas mesmas idades, os aumentos de $B_{d}$ entre a neutralidade e $30,4{ }^{\circ} \mathrm{C}$ são $1,2 \%$ e $1,3 \%$ para fumantes e $0,6 \%$ e $0 \%$ para não fumantes.

Figura 43: Taxa de exergia destruída em função da idade para fumantes e não fumantes para temperaturas de $30,4^{\circ} \mathrm{C}$ (a) e neutralidade térmica (b).

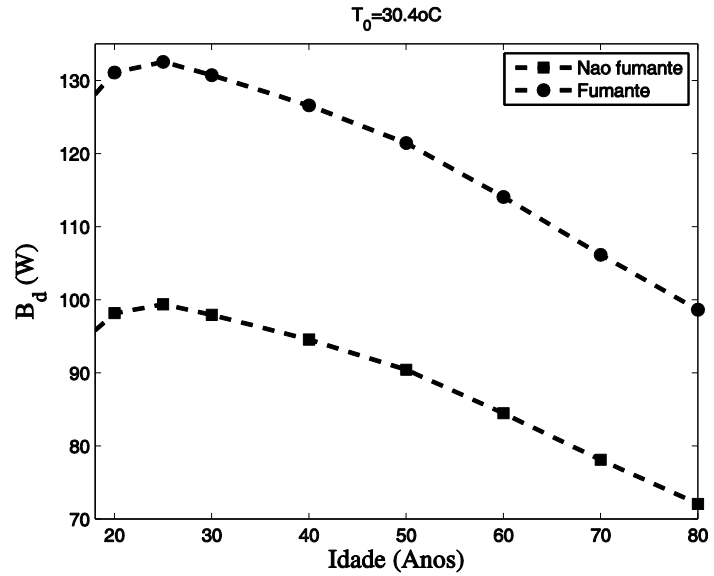

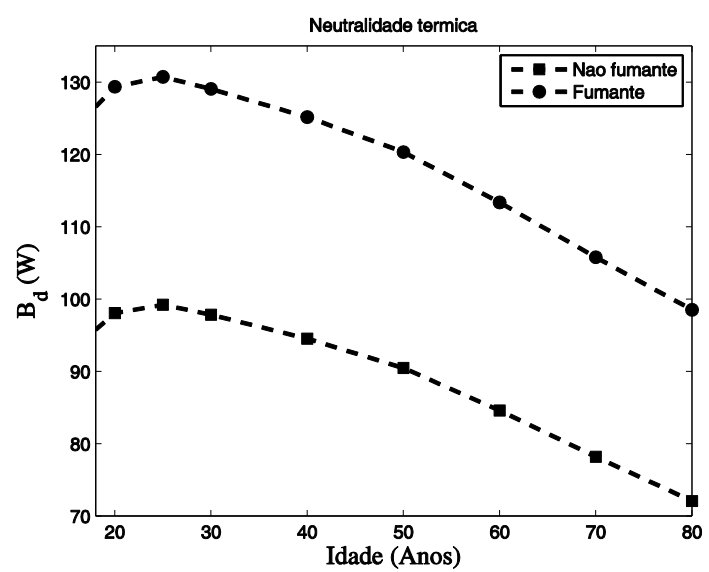

$\mathrm{b}$

Fonte: O autor (217).

A taxa de exergia destruída acumulada por unidade de massa $\left(B_{d, a d} / m\right)$ não apresenta diferenças significativas com a alteração da temperatura ambiente, como mostra a Figura 44. Como esperado, fumantes acumulam mais exergia destruída ao longo da vida. $\mathrm{Na}$ idade de 80 anos, um indivíduo classificado como fumante compulsivo terá acumulado, devido apenas a variações na taxa do metabolismo, cerca de $690 \mathrm{MJ} / \mathrm{kg}$ a mais de exergia destruída em comparação com um não fumante. Tomando o valor de $3412 \mathrm{MJ} / \mathrm{kg}$ como referência para a expectativa de vida de um brasileiro (MADY, 2013), um fumante perderia 15,1 anos de vida. Fora da neutralidade térmica, este valor é acrescido de quatro meses. Existem trabalhos disponíveis na literatura médica acerca deste tema, mas os resultados diferem entre si devido à heterogeneidade da amostra de indivíduos e dos parâmetros envolvidos, como o tempo e a intensidade do vício. A título de comparação, 15 anos também é a perda de expectativa de vida para fumantes estimada pela OMS (WHO, 2008), enquanto valores entre 20 e 25 anos foram obtidos por Fagerström (2002) para indivíduos que fumam desde a adolescência. Em contrapartida, Jha et al. (2013) indicam um valor intermediário de 10 anos. Além disso, Taylor et al. (2002) 
observaram uma recuperação de 6,9 a 8,5 anos de vida no caso de abandono do vício até os 35 anos de idade.

Figura 44: Exergia destruída acumulada por unidade de massa em função da idade para fumantes e não fumantes para temperaturas de $30,4^{\circ} \mathrm{C}$ (a) e neutralidade térmica (b).

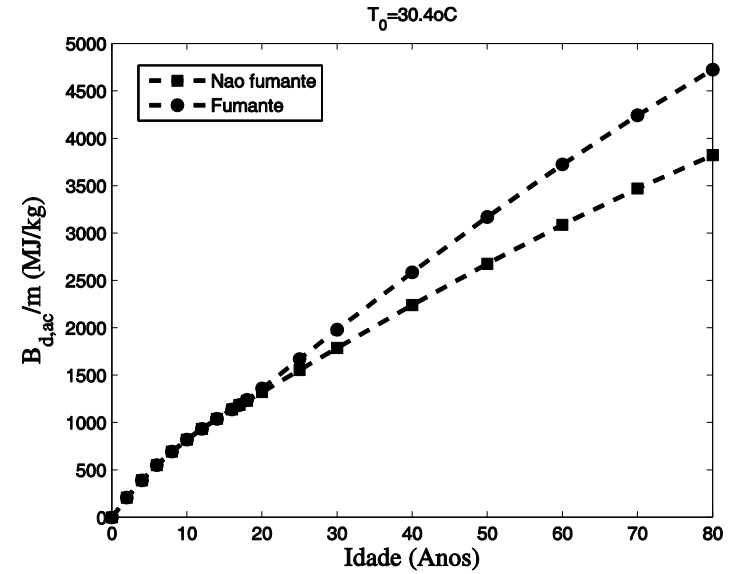

a

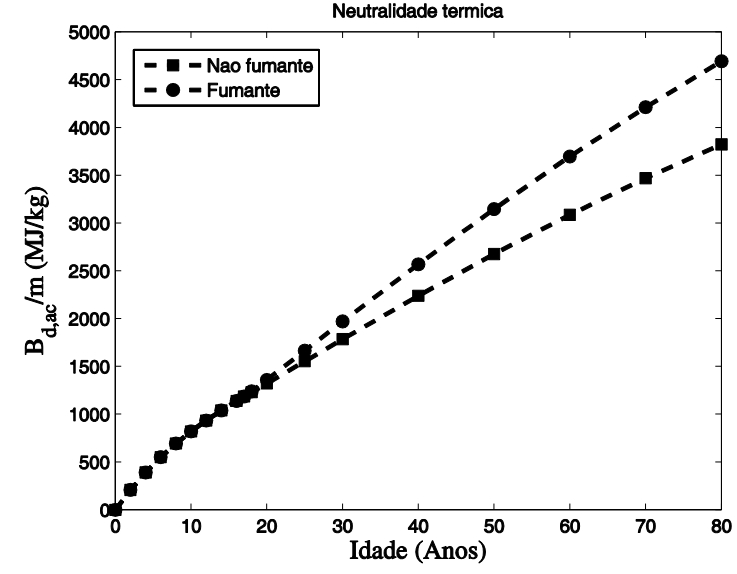

$\mathrm{b}$

Fonte: O autor (2017).

A Figura 45 exibe os resultados obtidos para a eficiência exergética $\left(\eta_{e x}\right)$. Conforme mostrado na Equação 48, $\eta_{e x}$, em condições de regime permanente, depende apenas da razão entre as taxas de exergia destruída e de metabolismo exergético. $A$ princípio, observando as Figura 42 e Figura 43, pode parecer que $B_{M}$ e $B_{d}$ variam a uma proporção bem próxima para fumantes e não fumantes. Portanto, grandes diferenças de eficiência exergética não seriam esperadas. Entretanto, quando os resultados de eficiência exergética são analisados, o impacto das pequenas diferenças de $B_{M}$ e $B_{d}$ entre os grupos avaliados, descritas nos parágrafos anteriores, se torna claro. Para a temperatura de $30,4^{\circ} \mathrm{C}$, o aumento de $B_{M}$ para fumantes é em média $2,7 \%$ maior que o observado em $B_{d}$, provocando um aumento médio de 19,1\% na eficiência exergética deste grupo. Já na neutralidade térmica, um aumento de apenas 1,8\% em $B_{M}$ leva a um crescimento de $13,8 \%$ de $\eta_{e x}$. 
Figura 45: Eficiência exergética em função da idade para fumantes e não fumantes para temperaturas de $30,4^{\circ} \mathrm{C}$ (a) e neutralidade térmica (b).

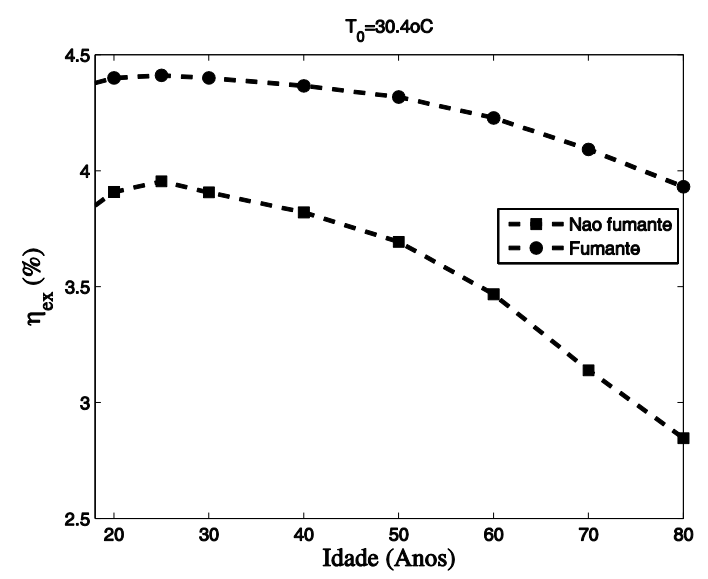

a

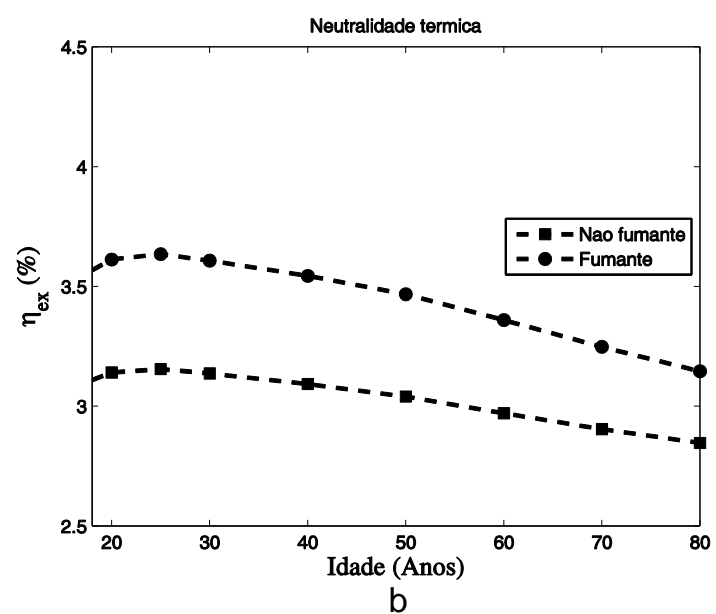

b

Fonte: O autor (2017).

A Figura 46 fornece uma informação adicional relativa aos fluxos e transferências de exergia para o ambiente $\left(B_{a m b}\right)$. Quando o indivíduo está à temperatura ambiente de $30,4^{\circ} \mathrm{C}$, superior à neutralidade térmica, $B_{a m b}$ aumenta. Levando em conta o balanço exergético, o aumento de $B_{\text {amb }}$ provoca um incremento da taxa de exergia destruída $B_{d}$ menor que o observado no metabolismo exergético, levando, por fim, a maiores eficiências exergéticas fora da neutralidade.

Figura 46: Soma das parcelas de fluxo e transferência de exergia para o ambiente em função da idade para fumantes e não fumantes para temperaturas de $30,4^{\circ} \mathrm{C}$ (a) e neutralidade térmica (b).

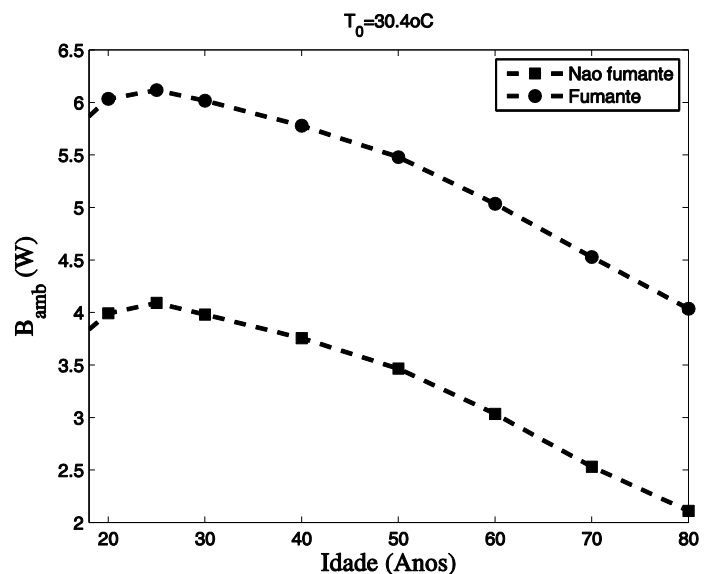

a

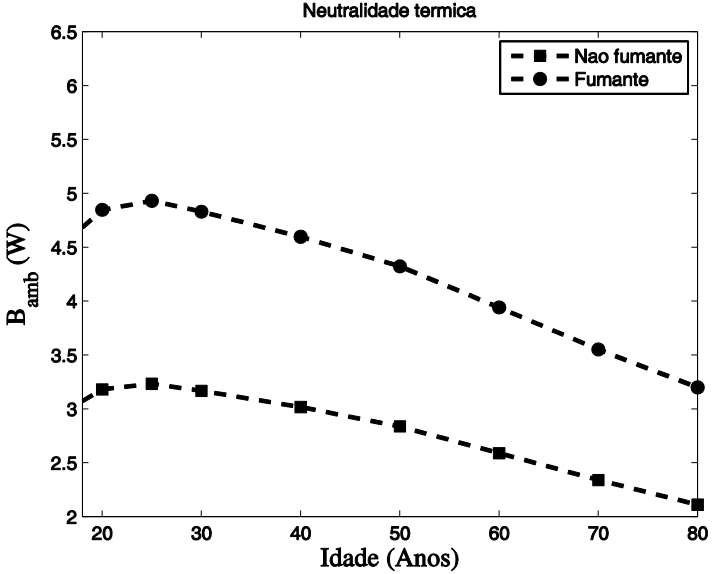

b

Fonte: O autor (2017). 


\subsection{OBESIDADE}

Os valores das taxas de exergia destruída são mostrados na Figura 47. O primeiro gráfico indica um aumento da exergia destruída $\left(B_{d}\right)$ na ocorrência de obesidade em todas as idades. Indivíduos obesos na idade adulta destroem $22,8 \%$ mais exergia que os moderadamente obesos que, por sua vez, possuem a taxa de destruição de exergia 6,3\% maior que o grupo de controle. Este aumento está associado principalmente ao aumento do metabolismo exergético na presença de obesidade. Entretanto, quando a taxa é analisada por unidade de massa $\left(B_{d} / m\right)$, a relação se inverte. A taxa de exergia destruída por unidade de massa em obesos é 16,7\% superior à observada em moderadamente obesos e 37,5\% maior que a do grupo de controle. Estes dados indicam que, proporcionalmente, o ganho de peso se sobrepõe ao aumento da exergia destruída. Nos grupos avaliados, o percentual de gordura nos obesos é maior, indicando um maior aumento proporcional do tecido adiposo com relação ao tecido muscular, que possui maior taxa metabólica. Portanto, o aumento percentual da massa do indivíduo é maior que o aumento percentual de seu metabolismo. Deste modo, quando o metabolismo exergético por massa é avaliado, ocorre uma redução com relação ao grupo de controle.

Figura 47: Taxa de exergia destruída (a) e taxa de exergia destruída por unidade de massa (b) em função da idade para o grupo de controle, moderadamente obesos e obesos.

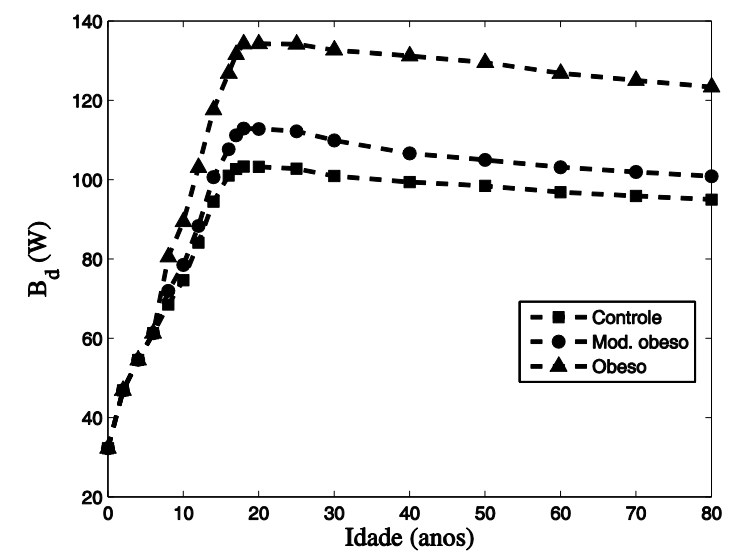

a

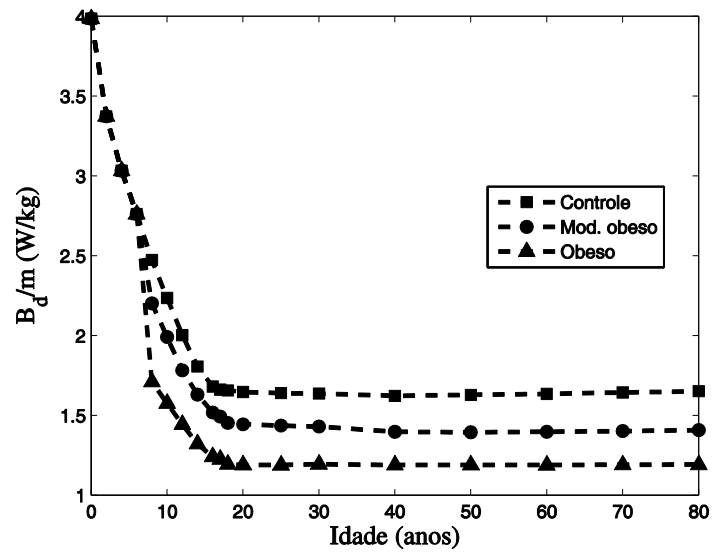

b

Fonte: O autor (2017).

A integração ao longo do ciclo de vida da taxa de exergia destruída proporciona os valores de exergia destruída acumulada até cada idade, como indicado na Figura 
48. Até os 80 anos, os obesos acumulam 20,0\% mais exergia destruída que os moderadamente obesos e $30,4 \%$ mais que os indivíduos sem sobrepeso. Porém, assim como a taxa de exergia destruída, a exergia destruída acumulada por unidade de massa é superior para o grupo de controle em aproximadamente $29 \%$. Conforme apresentado anteriormente na seção 3.4, os valores acumulados de entropia gerada e exergia destruída por unidade de massa no ciclo de vida poderiam ser indicativos mais adequados da progressão da vida que a escala cronológica.

Portanto, os resultados da Figura 48 indicariam que os obesos levariam mais tempo para atingir o valor limite de máxima exergia destruída por unidade de massa, contrariando, a princípio, os dados estatísticos disponíveis, que informam que a presença de obesidade reduz a expectativa de vida. Na realidade, os valores obtidos de $B_{d, a d} / m$ corroboram a ideia levantada por alguns pesquisadores da área de que o aumento da taxa de mortalidade em obesos se deve ao desenvolvimento de doenças associadas à obesidade, não à condição morfológica de obesidade em si. Huffman e Barzilai (2010) destacam que a gordura subcutânea pode ser benéfica, por proteger o corpo contra distúrbios metabólicos, ao passo que a gordura visceral é prejudicial à atuação de alguns hormônios. Beleigoli e Diniz (2014) apontam falhas na correlação direta entre os indicadores atuais de obesidade e riscos a saúde. As autoras destacam a questão da gordura subcutânea, que não é levada em conta nestes indicadores, e sugerem o uso de indicadores cardiometabólicos para a avaliação da categoria de risco dos pacientes.

Durante a modelagem, a diferenciação entre os três grupos avaliados se deu por meio da alteração das camadas do modelo, especialmente de gordura superficial. Deste modo, alterações fisiológicas, tais como estreitamento de artérias, acúmulo de gordura visceral e disfunções hormonais, não foram consideradas. Portanto, os resultados apresentados indicam que o aumento do metabolismo e a presença de uma camada de gordura superficial mais espessa não levam à redução da expectativa de vida em obesos. 
Figura 48: Exergia destruída acumulada (a) e exergia destruída acumulada por unidade de massa (b) em função da idade para o grupo de controle, moderadamente obesos e obesos.

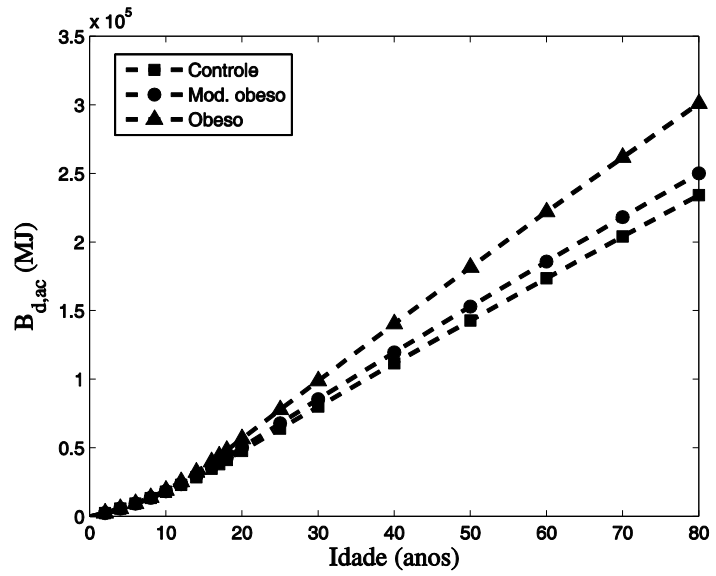

a

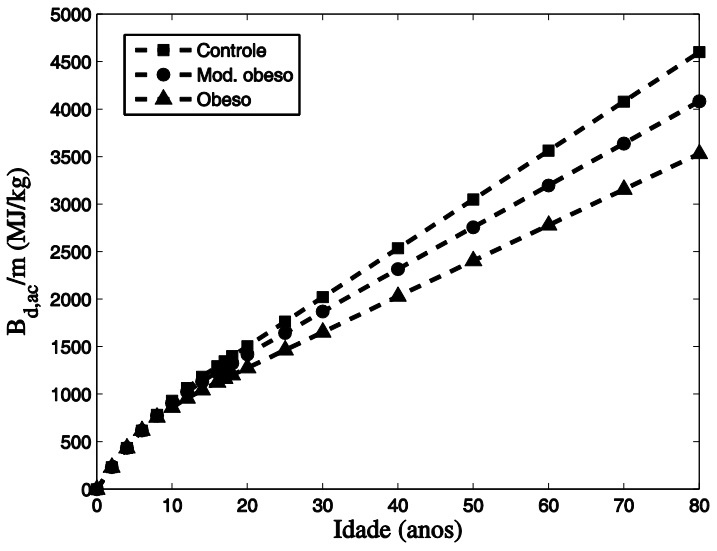

b

Fonte: O autor (2017).

A eficiência exergética também foi determinada para os três grupos ao longo do ciclo de vida. A Figura 49 indica que os obesos apresentam eficiência exergética inferior aos demais grupos. Observa-se também que a queda dos valores de $\eta_{e x}$ é superior entre os grupos de controle e moderadamente obeso que entre este último e obeso. Uma vez que tanto o metabolismo exergético quanto a taxa de exergia destruída são superiores em obesos, conclui-se que o aumento de $B_{d}$ supera o observado em $B_{M}$., resultando em valores de $\eta_{e x}$ inferiores neste grupo.

Figura 49: Eficiência exergética para o grupo de controle, moderadamente obesos e obesos.

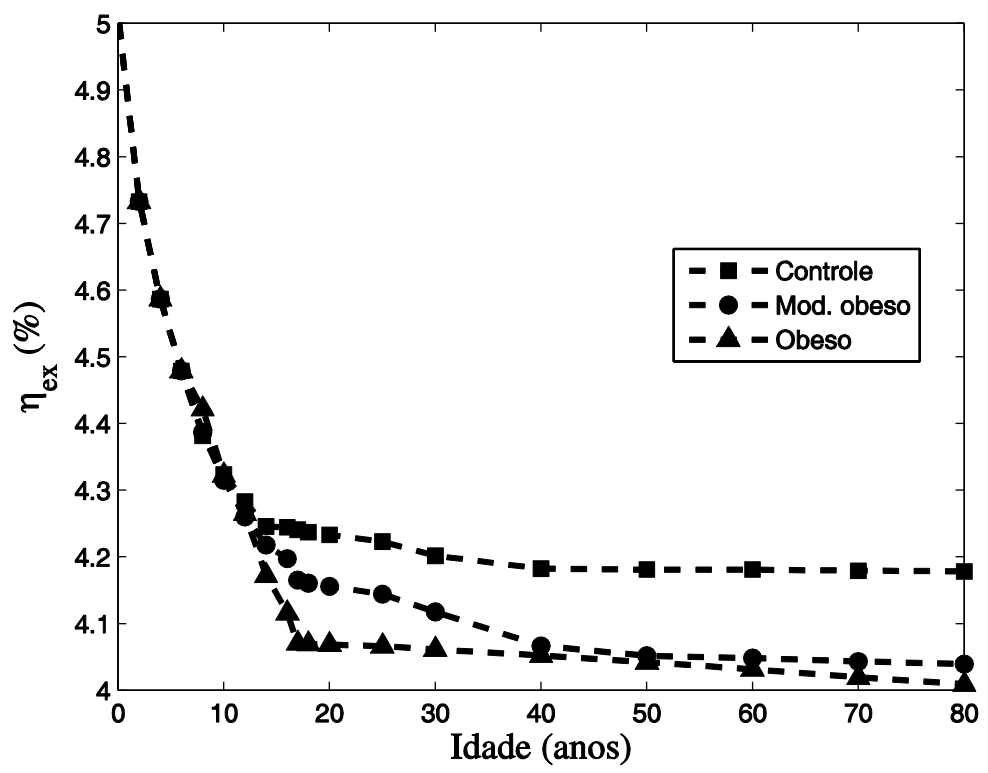

Fonte: O autor (2017). 


\subsection{HIPERTENSÃO}

Os resultados relativos à aplicação do modelo exergético do coração para diferentes condições de atividade física para normotensos e hipertensos são mostrados nos gráficos a seguir.

Figura 50: Comparativo da taxa de exergia destruída em função da potência realizada pelo corpo para normotensos (a) e hipertensos (b).

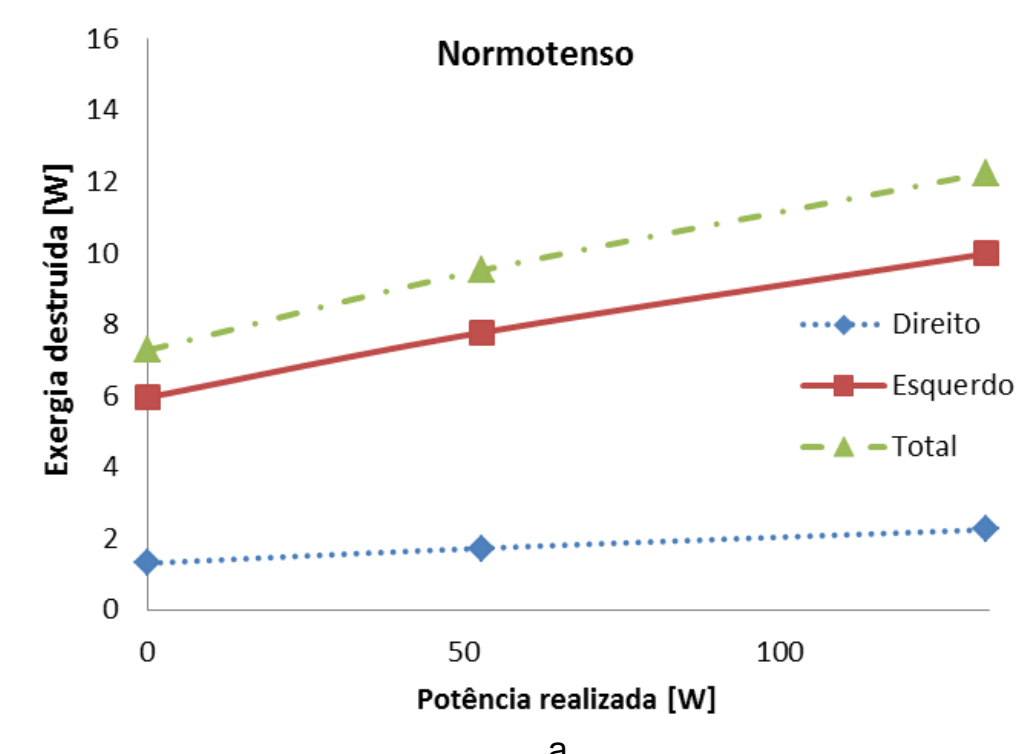

a

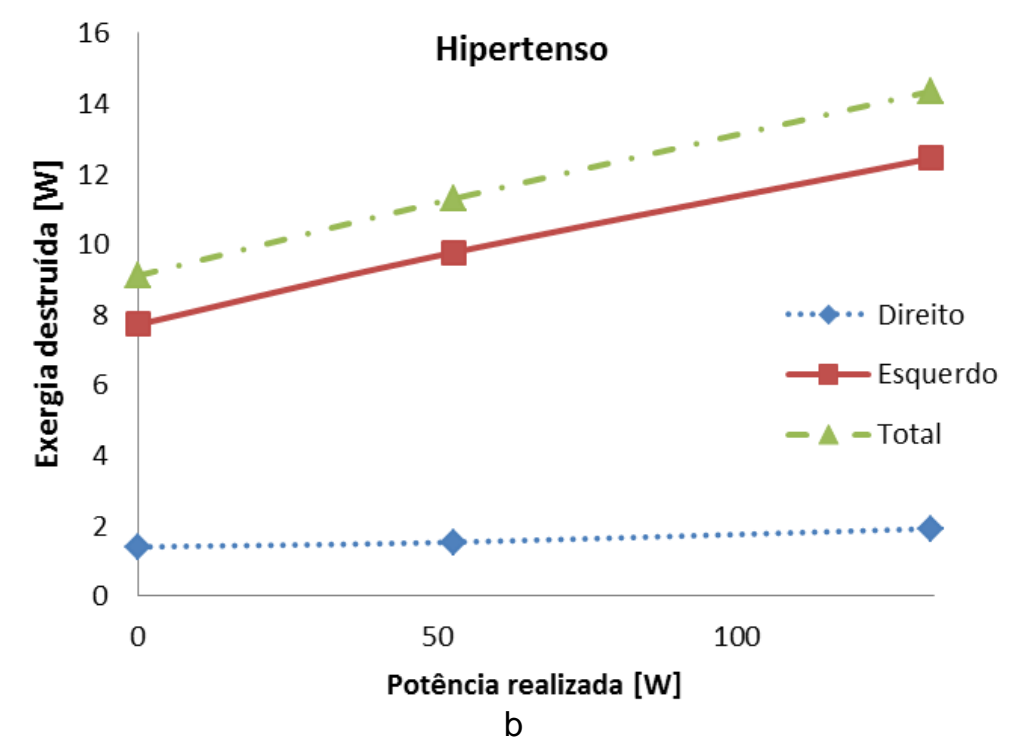

Fonte: $\mathrm{O}$ autor (2017). 
A Figura 50 permite observar como as partes direita e esquerda do coração contribuem para a destruição de exergia total no coração, tanto para normotensos quanto para hipertensos, para diferentes intensidades de atividade física, indicadas nos gráficos por meio da potência realizada pelo corpo em cada exercício. Os gráficos também mostram como a exergia destruída aumenta com a intensidade do exercício e também na presença de hipertensão como consequência do aumento da potência do coração, que ocorre em resposta às maiores pressões sistólica e diastólica. No caso da atividade física, o aumento da vazão de sangue também contribui para o aumento da exergia destruída. Entre normotensos e hipertensos, o acréscimo sofrido pela exergia destruída no coração é de $24,0 \%, 18,0 \%$ e 16,7\% para, respectivamente, repouso, caminhada e corrida.

Uma vez que o coração esquerdo bombeia o sangue oxigenado proveniente dos pulmões para os outros órgãos do corpo, uma maior potência de bombeamento é esperada nesta parte do coração. É possível observar na Figura 51 que a potência do coração aumenta tanto com o aumento da intensidade da atividade quanto na presença de hipertensão. Com relação à inclinação das curvas, nota-se que a taxa de crescimento da potência do coração esquerdo é superior à do direito em ambas as situações. Porém, comparando-se os cenários com e sem hipertensão, fica claro que a taxa de crescimento é superior em hipertensos nas duas partes do coração. Além disso, o aumento do trabalho de bombeamento eleva o consumo de oxigênio do músculo cardíaco, levando ao incremento do metabolismo exergético. A combinação destes dois fatores faz com que a contribuição da parte esquerda para a exergia destruída total do coração seja superior à da direita. A Figura 52 mostra como a razão $B_{d, e s} / B_{d, \text { crg }}$ varia em função da atividade para os indivíduos normotenso e hipertenso. Além da informação relativa ao maior valor da exergia destruída do lado esquerdo com relação ao direito, uma vez que a razão $B_{d, \text { es }} / B_{d, \text { crs }}$ é maior que 0,5 em todos os cenários avaliados, é possível também perceber por meio da Figura 52 que esta razão tem comportamento diferenciado na presença de hipertensão. Para hipertensos, a contribuição da parte esquerda para a exergia destruída do coração é maior e aumenta com a intensidade do exercício, enquanto que no caso dos normotensos, seu valor é praticamente constante, com uma leve tendência de queda de 1\%. Este fato é mais uma evidência do efeito pronunciado da 
hipertensão no coração esquerdo, o que, em casos extremos, pode levar à hipertrofia do ventrículo esquerdo.

Figura 51: Potência aplicada no coração $\left(W_{c r c ̧}\right)$ em função da potência realizada pelo corpo para as partes esquerda e direita do coração para e normotensos e hipertensos.

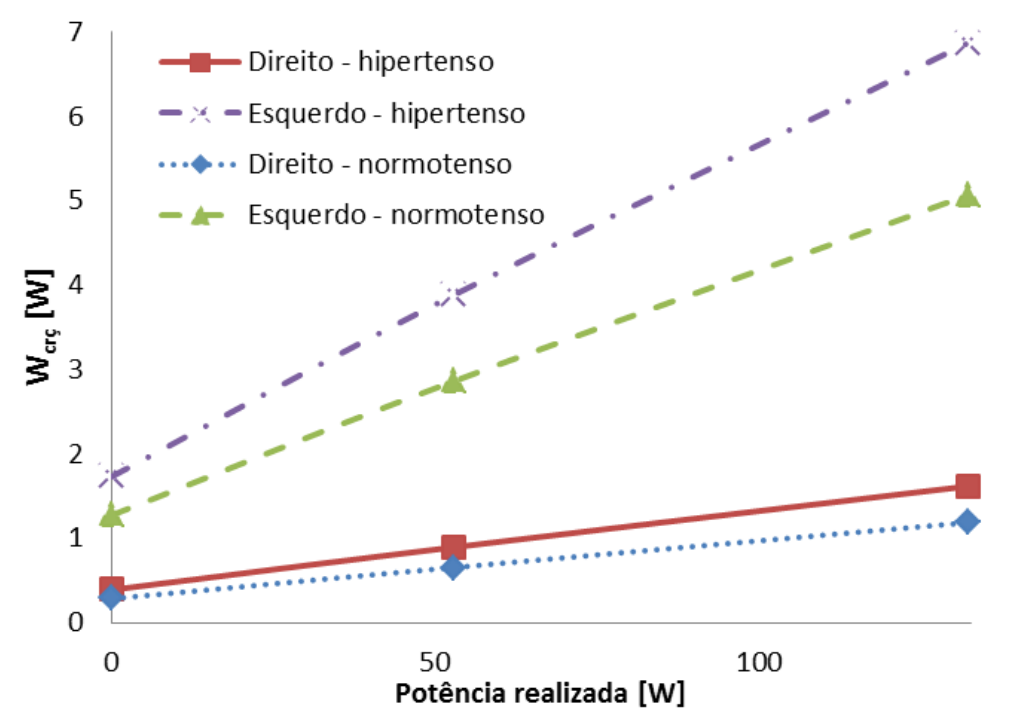

Fonte: O autor (2017).

Figura 52: Contribuição da parte esquerda para a exergia destruída total no coração em função da intensidade do exercício para normotensos e hipertensos.

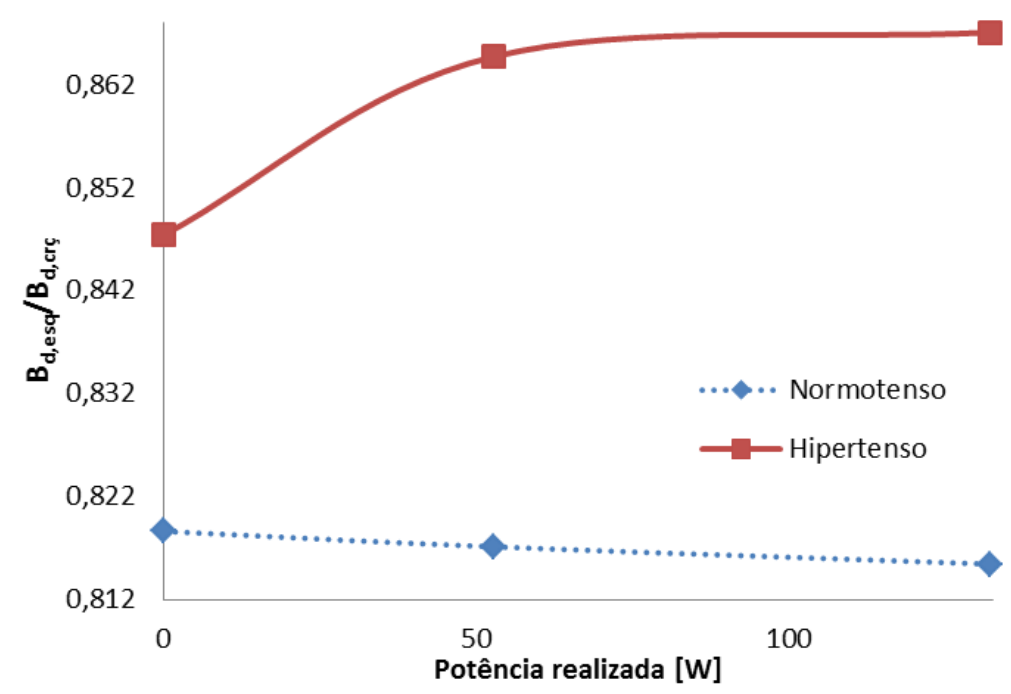

Fonte: O autor (2017). 
Analisando os valores das parcelas individuais de exergia, observa-se o efeito da diferença entre o fluxo de exergia do sangue na saída e na entrada $\left(\Delta B_{s g}\right)$ na exergia destruída no coração. Os valores de $\Delta B_{s g}$ nas partes direita e esquerda do coração em função da atividade para normotensos e hipertensos são mostrados na Figura 53. Pode-se observar um aumento pronunciado de $\Delta B_{s g}$ com a intensidade do exercício no caso de hipertensão, tanto no lado esquerdo quando no direito, enquanto esta parcela permanece praticamente constante para normotensos. Este aumento se deve à elevação da pressão sanguínea, o que está diretamente relacionado às pressões parciais de oxigênio e dióxido de carbono no fluxo de sangue. De acordo com a Equação 64, o cálculo da exergia do fluxo leva em conta o logaritmo natural da razão entre a pressão parcial do gás em questão no sangue e no ambiente de referência. Na função logarítmica natural, quando a variável independente é menor que um, o valor da função é negativo e possui alta taxa de crescimento. Para valores maiores que um, o resultado é positivo e sua inclinação é pequena. A pressão parcial de dióxido de carbono no sangue, tanto arterial quanto venoso, é maior que no ambiente de referência. Portanto, sua exergia é sempre positiva e não sofre grande influência dos valores de pressão. Por outro lado, nos cenários avaliados, a pressão parcial de oxigênio no sangue é menor que na referência, tornando sua exergia negativa. Entretanto, quanto maior a pressão sanguínea, mais a pressão parcial de oxigênio se aproxima do valor de referência. Deste modo, sua exergia se aproxima rapidamente de zero e a exergia total do fluxo de sangue, que é sempre positiva, aumenta.

Figura 53: Variação do fluxo de exergia do sangue com a intensidade do exercício para os lados direito e esquerdo do coração em normotensos e hipertensos.

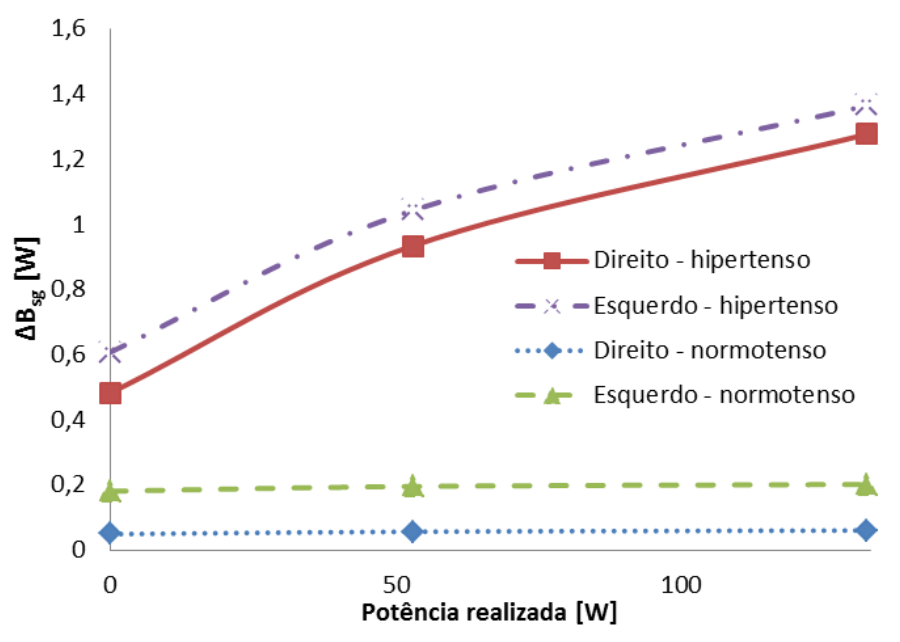

Fonte: O autor (2017). 
A partir dos resultados anteriores, observa-se que, em média, um coração hipertenso destrói 1,8 $\mathrm{W}$ a mais de exergia que um normotenso. Assumindo que o indivíduo comece a desenvolver hipertensão aos 25 anos, o aumento de 1,8 W na taxa de exergia destruída pelo coração, quando integrado ao longo do ciclo de vida, leva a um aumento de $170 \mathrm{MJ} / \mathrm{kg}$ na exergia acumulada até os 80 anos de vida, como mostrado na Figura 54.

Figura 54: Exergia destruída acumulada por unidade de massa em função da idade para normotensos e hipertensos.

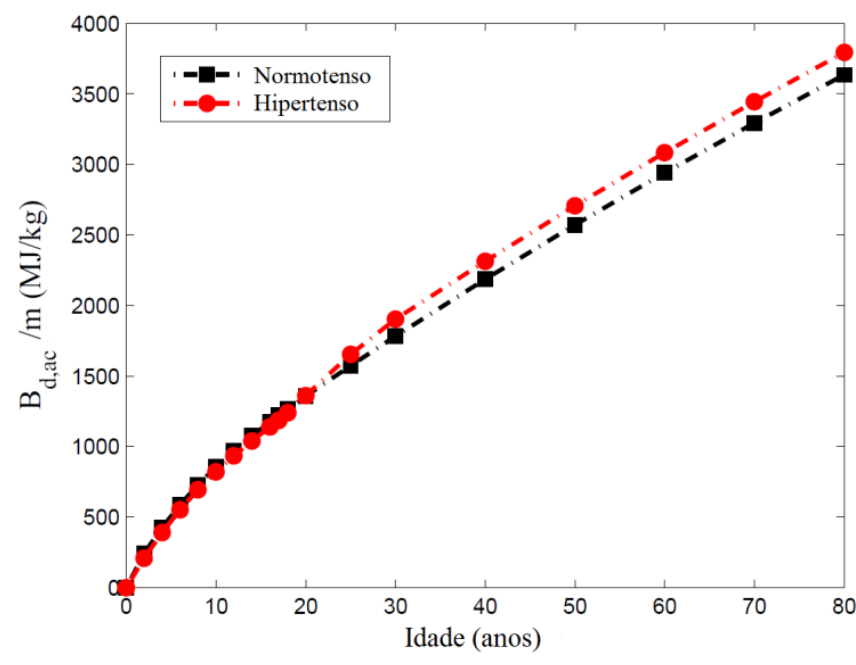

Fonte: O autor (2017).

A partir dos dados apresentados por Henriques (2013) relativos à exergia destruída no corpo, obteve-se a contribuição da exergia destruída no coração $\left(B_{d, \text { crģ }}\right)$ para a exergia destruída total $\left(B_{d, c o r p o}\right)$, como mostrado na Figura 55 Esta análise é feita apenas para normotensos, uma vez que a análise do corpo como um todo foi realizada apenas para este grupo. Em comparação com a condição de repouso, observa-se que a contribuição do coração para a exergia destruída no corpo é menor durante a realização de atividade física, indicando que o efeito do exercício é mais evidente em outros órgãos. Entretanto, uma leve tendência de crescimento é notada entre a caminhada e a corrida. Este fato pode indicar que a contribuição de $B_{d, \text { crç }}$ aumenta para exercícios mais vigorosos. 
Figura 55: Contribuição da exergia destruída no coração para a exergia destruída no corpo em função da intensidade do exercício.

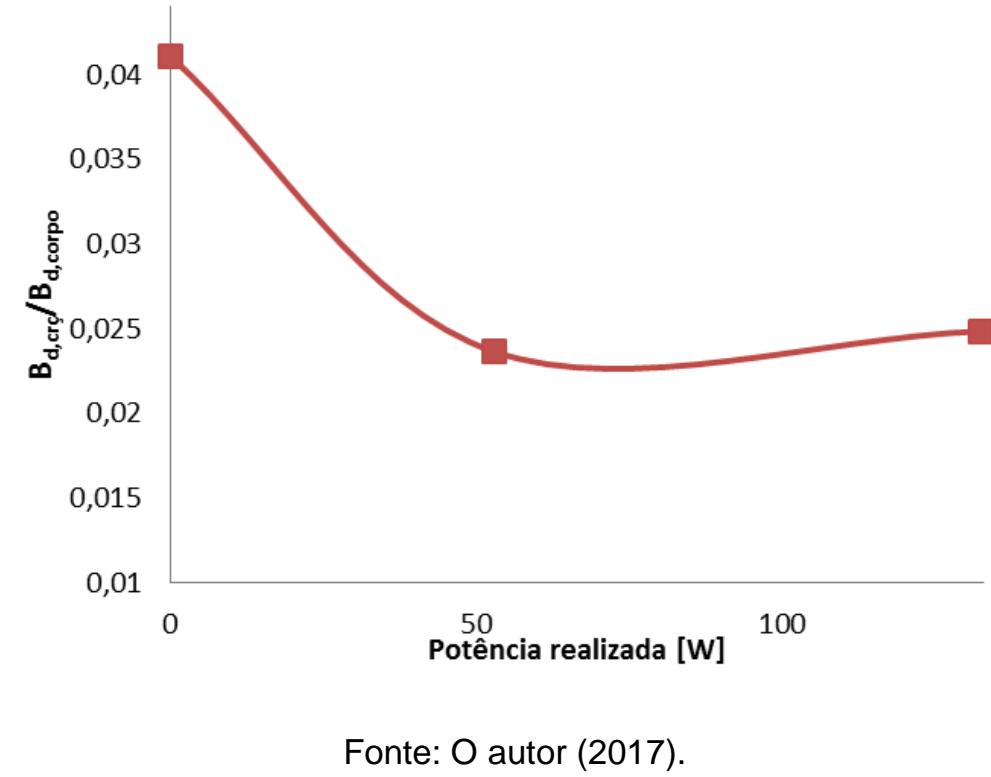

A eficiência exergética do coração também foi determinada e comparada aos dados de Henriques (2013) para o corpo e também para o sistema respiratório. Na Figura 56 é possível observar que não há diferença entre as eficiências exergéticas do coração de normotensos e hipertensos. Uma vez que, em caso de hipertensão, as pressões diastólica e sistólica, necessárias para o cálculo da potência do coração, sofrem aumento de, respectivamente, $34,9 \%$ e 29,3 e o metabolismo aumenta em $35,4 \%$, não haverá mudança significativa no valor de eficiência exergética, que é determinada como a razão entre a potência e a taxa de metabolismo exergético. Este resultado é coerente com dados da literatura médica (KAMEYANA ET AL., 1992). Entretanto, verifica-se que a eficiência exergética do coração aumenta com a atividade física a uma taxa superior que a registrada para o corpo, reforçando a hipótese lançada anteriormente sobre o efeito do exercício ser mais sentido por outros órgãos do que pelo coração. Como enfatizado por Henriques (2013), os pulmões operam como trocares de massa. Por essa razão, seus valores de eficiência exergética são altos, apresentando tendência de redução com o incremento do exercício apenas na terceira casa decimal. 
Figura 56: Comparativo entre as eficiências exergéticas do corpo, dos pulmões e do coração de normotensos e hipertensos em função da potência realizada pelo corpo.

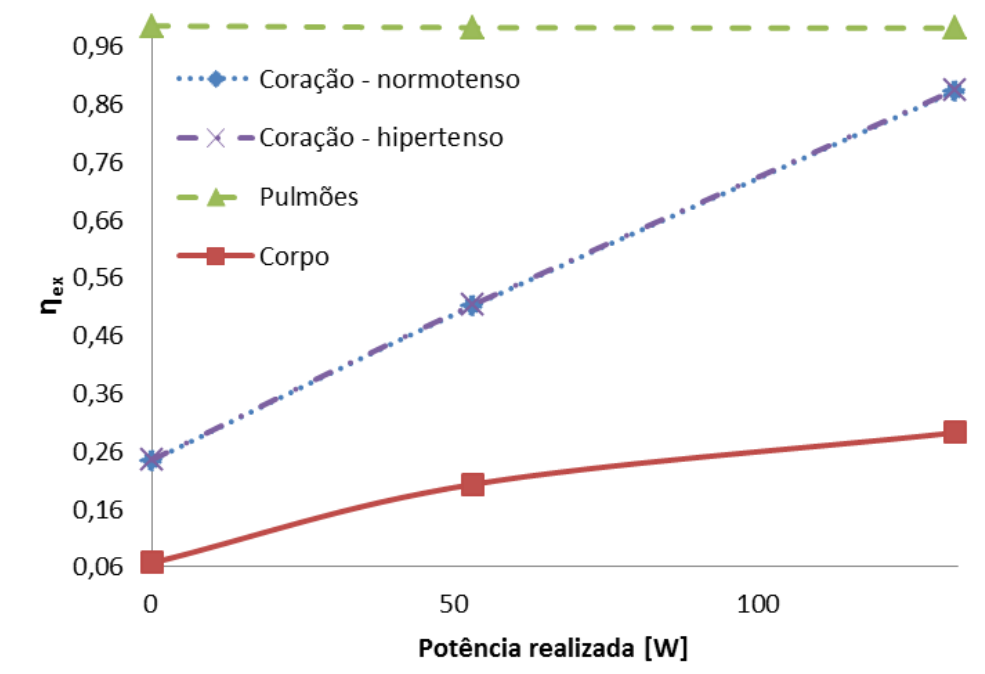

Fonte: O autor (2017).

\subsection{EFEITO DA ESTENOSE}

Os resultados principais relativos à análise de artérias com estenose em diferentes partes do corpo são mostrados da Figura 57 à Figura 64. A taxa total de exergia destruída em uma artéria estenótica em função da severidade da estenose para segmentos no tronco, pescoço, braço, perna e na artéria coronária é mostrada na Figura 57 , onde é possível observar que, para severidades inferiores a $75 \%, B_{d, \text { total }}$ é próxima de zero. A partir deste ponto, a taxa de destruição de exergia cresce exponencialmente, exceto para a artéria do braço, cujos valores são inferiores a 0,5 W. Devido à ampla faixa de resultados, optou-se por mostrar o parâmetro também em escala logarítmica na Figura $57 \mathrm{~b}$. Até $55 \%$ de severidade, a artéria do tronco apresenta o valor mais alto de exergia destruída, porém com uma taxa de aumento inferior à apresentada pelos outros segmentos. Deste ponto em diante, $B_{d, \text { total }}$ apresenta o mesmo valor para tronco e perna e aumenta à mesma taxa para todos os segmentos analisados, onde os maiores valores estão presentes no tronco e na perna, seguidos por, pescoço, coronária e braço. Os resultados mostrados na seção relativa ao modelo exergético do coração indicam que a potência realizada e a exergia destruída em um coração hipertenso são, respectivamente, 0,5 e 1,5 W 
superiores aos valores apresentados por um coração normotenso. Seguindo a hipótese de que o comportamento exergético do coração hipertenso pode estar associado à presença de estenoses, o valor de $B_{d, \text { total }}$ de $1,5 \mathrm{~W}$ seria atingido apenas em estenoses muito severas, com redução de cerca de $85 \%$ do diâmetro da artéria.

Figura 57: Taxa total de exergia destruída em uma artéria estenótica $\left(B_{d, \text { total }}\right)$ de diferentes segmentos do corpo em função da severidade em escala linear (a) e logarítmica (b).

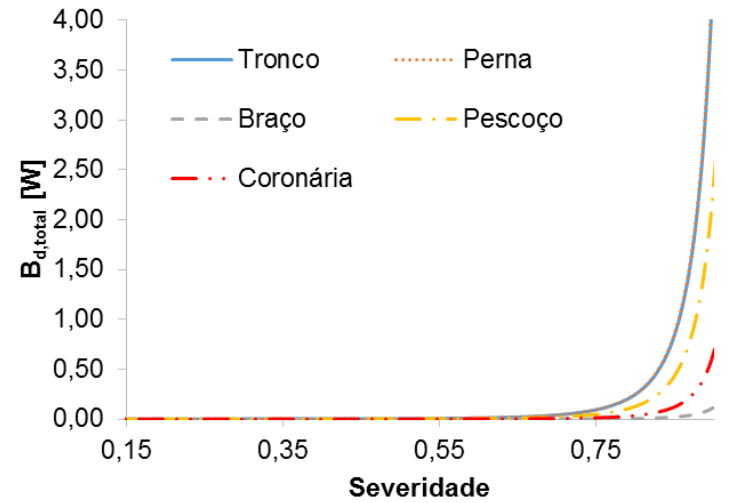

a

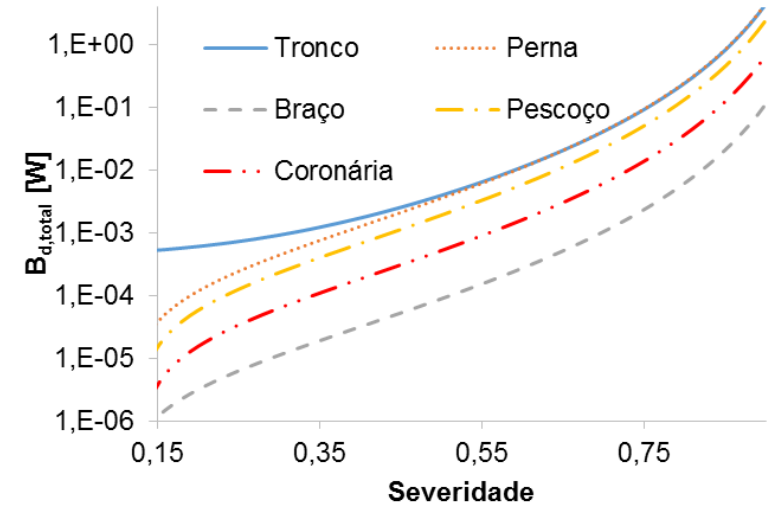

b

Fonte: O autor (2017).

Os valores da taxa de exergia destruída devido ao efeito apenas do atrito, assim como da perda de carga distribuída e a vazão mássica de sangue são apresentados na Tabela 11. Por estar associada apenas ao atrito entre o sangue e a parede interna arterial, $B_{d, s d v}$ corresponde à parcela de $B_{d, t o t a l}$ que está presente em qualquer artéria, seja saudável ou estenótica. Portanto, seu valor não depende da severidade da estenose, apenas das características do escoamento. Como pode ser observado na última coluna da Tabela 11, o tronco apresenta os valores mais altos de $B_{d, s d v}$, enquanto a artéria coronária apresenta os mais baixos. As artérias da perna, pescoço e braço apresentam valores intermediários e a diferença entre cada segmento é de uma ordem de grandeza. Entretanto, em comparação com a magnitude de $B_{d, t o t a l}$ os valores de $B_{d, s d v}$ para todos os segmentos são baixos. A contribuição do atrito para a exergia destruída total será avaliada mais adiante. 
Tabela 11: Perda de carga distribuída $\left(H_{\text {dist }}\right)$, vazão mássica de sangue $(\dot{m})$ e taxa de exergia destruída em uma artéria saudável $\left(B_{d, s d v}\right)$ para cada segmento analisado.

\begin{tabular}{lccc}
\hline Segmento & $\mathbf{H}_{\text {dist }}[\mathbf{m}]$ & $\dot{\mathbf{m}}[\mathbf{k g} / \mathbf{s}]$ & $\mathbf{B}_{\mathrm{d}, \text { sdv }}[\mathrm{W}]$ \\
\hline Tronco & $2,45 \mathrm{E}-03$ & $2.11 \mathrm{E}-02$ & $5.06 \mathrm{E}-04$ \\
\hline Perna & $2,45 \mathrm{E}-04$ & $5.38 \mathrm{E}-03$ & $1.29 \mathrm{E}-05$ \\
\hline Pescoço & $2,20 \mathrm{E}-05$ & $6,85 \mathrm{E}-03$ & $1,48 \mathrm{E}-06$ \\
\hline Braço & $1,88 \mathrm{E}-05$ & $2,98 \mathrm{E}-03$ & $5,05 \mathrm{E}-07$ \\
\hline Coronária & $3,00 \mathrm{E}-06$ & $1,05 \mathrm{E}-03$ & $3,10 \mathrm{E}-08$ \\
\hline \multicolumn{4}{l}{ Fonte: O autor (2017). }
\end{tabular}

A outra componente de $B_{d, \text { total }}$ é a exergia destruída devido à estenose $B_{d, e s t}$, que também apresenta uma faixa larga de valores, por isso seus resultados também serão apresentados em escala logarítmica na Figura 58. As curvas de todos os segmentos possuem o mesmo formato e aumentam quase linearmente com a severidade. Com relação aos valores, os mais baixos ocorrem no braço, o que, combinado com os resultados de $B_{d, \text { est, }}$ explica o comportamento da sua curva para a taxa total de exergia destruída. É importante destacar a coincidência das curvas do tronco e da perna, uma vez que para $B_{d, \text { total }}$ isto só ocorre para severidades superiores a $55 \%$. Para reduções diametrais de $15 \%$, a ordem de grandeza de $B_{d \text {,est }}$ para o tronco e a perna é de $10^{-5} \mathrm{~W}$, uma ordem menor que $B_{d, s d v}$ do tronco e a mesma perna. Por essa razão, a diferença entre as taxas de exergia destruída devido ao atrito nestes segmentos tem um papel significativo no comportamento de $B_{d, \text { total }}$ a baixas severidades. Ademais, a coincidência de $B_{d, \text { est }}$ neste dois segmentos também pode ser explicada por meio dos valores de vazão mássica de sangue e exergia destruída específica $b_{d, e s t}$. 
Figura 58: Taxa de exergia destruída devido à estenose em função da severidade em escala logarítmica.

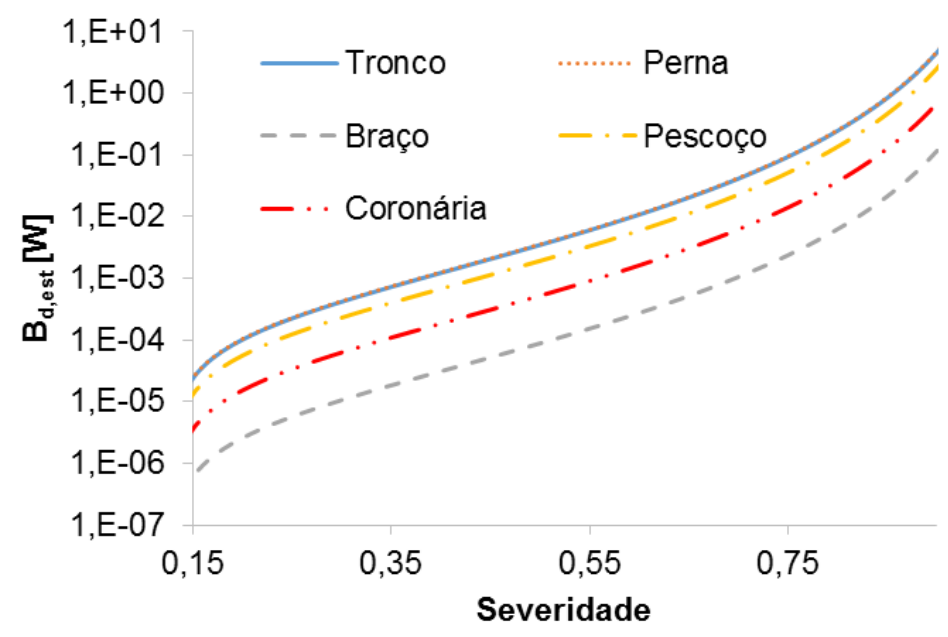

Fonte: O autor (2017).

A fim de compreender o comportamento da taxa de exergia destruída devido à estenose na perna e no tronco, a exergia destruída específica devido à estenose foi plotada na Figura 59. Pode-se observar que o valor de $b_{d, \text { est }}$ no segmento de artéria do tronco é inferior ao observado na perna e também no pescoço. Porém, a vazão sanguínea nesta artéria, como mostrado na terceira coluna da Tabela 11, é maior que nos outros segmentos. Portanto, quando $B_{d, \text { est }}$ é determinada, seu valor no tronco supera o do pescoço e se iguala ao da perna. Como mostrado na Equação 80 , o cálculo da perna de carga devido à singularidade, neste caso a estenose, é diretamente proporcional ao quadrado da velocidade do escoamento, que por sua vez é determinada a partir da vazão e da seção transversal da artéria. A velocidade mais alta é observada na artéria da perna, seguida pelo pescoço, tronco, coronária e por fim o braço. Por esta razão, a ordem dos valores de $b_{d, \text { est }}$ é a mesma.

Os resultados apresentados até então levam em conta a vazão sanguínea de um indivíduo em repouso. Este valor pode aumentar até seis vezes durante atividade física, o que afetaria diretamente a taxa de destruição de exergia. Na Figura 60, a taxa de exergia destruída devido à estenose é mostrada em função do aumento vazão sanguínea, onde $\mathrm{N}=1$ é a condição de repouso e $\mathrm{N}=6$ corresponde a uma condição de atividade física extenuante. Os valores são apresentados para as severidades de 40,60 e $80 \%$. Nota-se um crescimento acentuado de $B_{d, \text { est }}$ nas artérias do tronco e da perna, Portanto, estenoses de severidades moderadas 
podem atingir, durante atividade, altas taxas de destruição de exergia, características de obstrução quase total da artéria.

Figura 59: Exergia destruída específica devido à estenose em função da severidade em escala logarítmica.

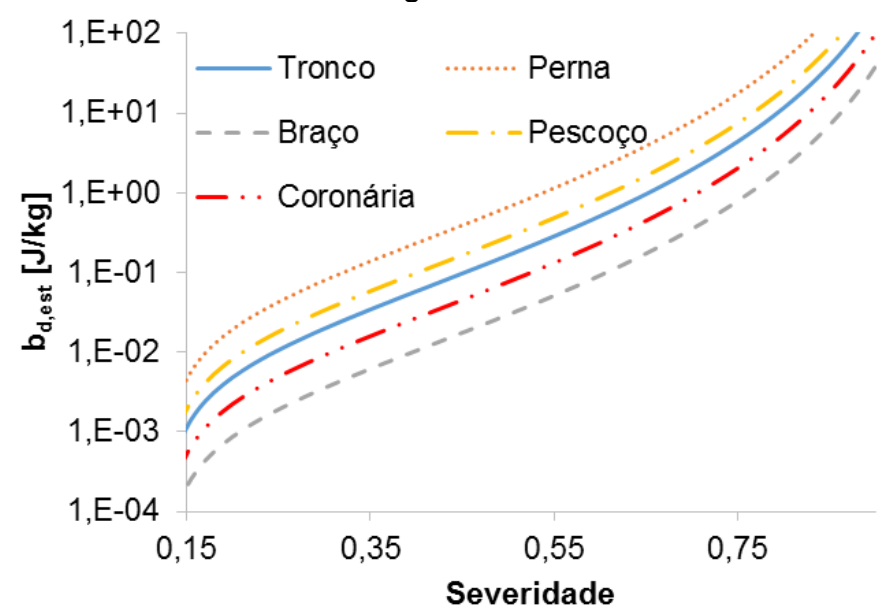

Fonte: O autor (2017).

Figura 60: Taxa de destruição de exergia devido à estenose em função do aumento da vazão mássica de sangue para severidades de 40 (a), 60 (b) e 80\% (c).
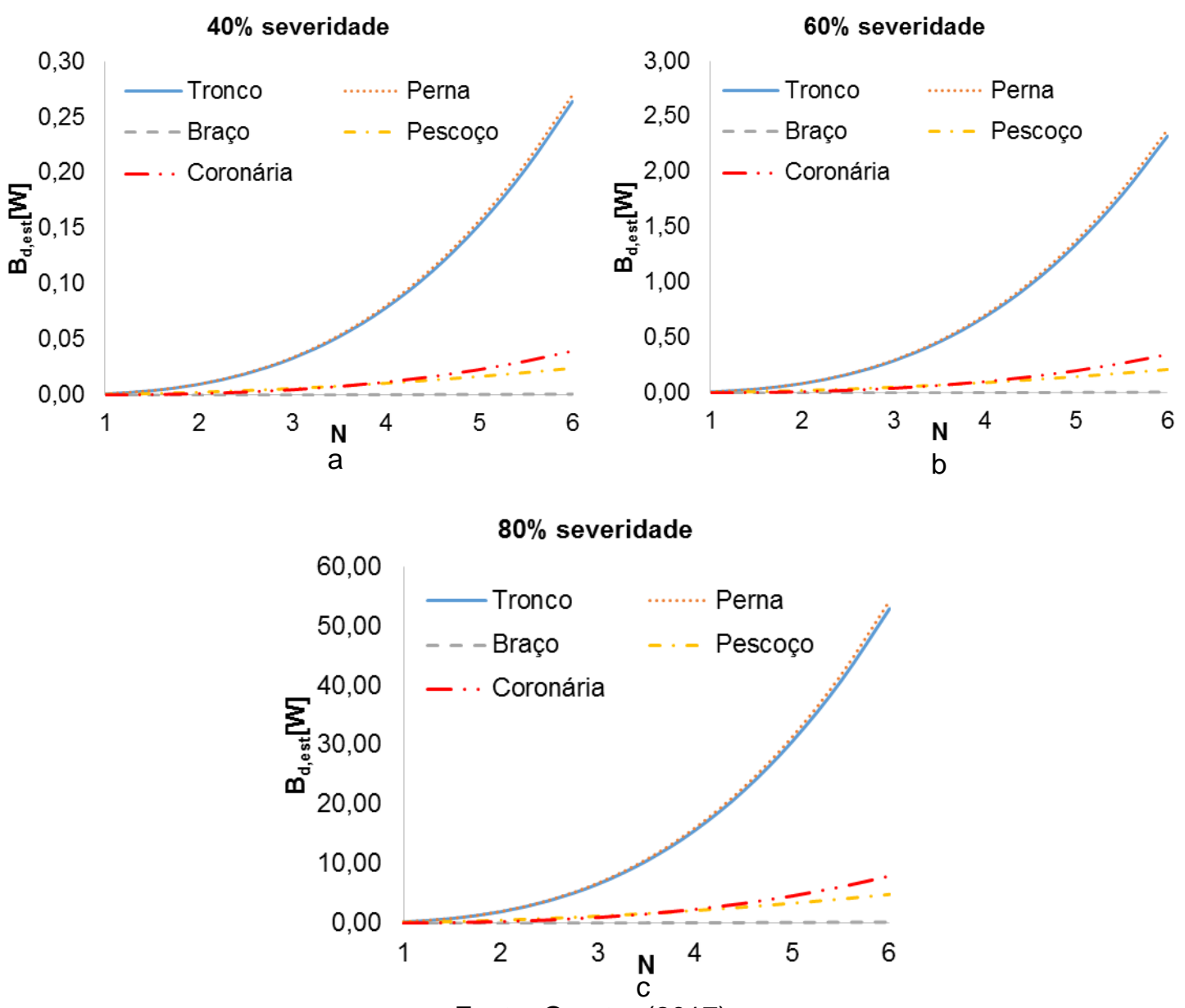

Fonte: $\mathrm{O}$ autor (2017). 
Por fim, a contribuição da estenose para a taxa total de exergia destruída em uma artéria estenótica para o indivíduo em repouso é avaliada pro meio do índice $R$ e mostrada na Figura 61. Em todos os segmentos do corpo, a contribuição da estenose atinge $100 \%$ para severidades maiores que $70 \%$. Entretanto, a curva de cada segmento antes desse ponto é diferente. Para baixas severidades, o tronco apresenta a menor contribuição, enquanto os valores de $R$ para os outros segmentos já são maiores que $60 \%$ para a severidade de $15 \%$. Este comportamento é associado à ordem de grandeza de $B_{d, s d v}$ no tronco, que é superior aos demais. Apesar da diferença observada nos outros parâmetros analisados, a contribuição da estenose é similar na perna e no braço. Por outro lado, para baixas severidades, o valor de $R$ nas coronárias é o mais elevado, devido ao seu baixo $B_{d, s d v}$.

Figura 61: Contribuição da estenose para a taxa total de exergia destruída em função da severidade.

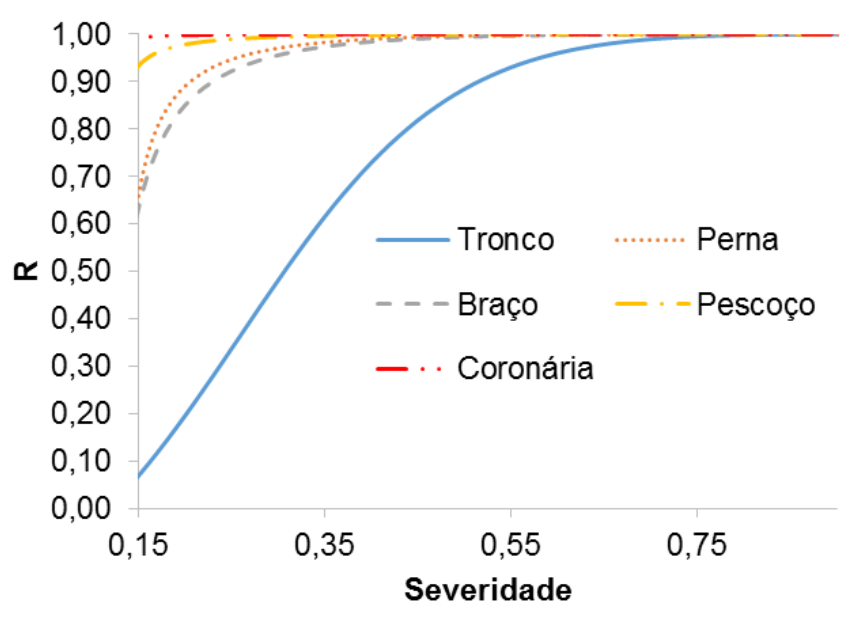

Fonte: O autor (2017).

Adicionalmente, os valores da diferença de pressão através da estenose são mostrados na Figura 62, salientando que os valores de $P$ são apresentados em $\mathrm{mmHg}$ em vez de Pa porque essa é a unidade convencional para medidas de pressão arterial. Os valores limite de pressão para um indivíduo saudável são 140 $\mathrm{mmHg}$ para a pressão sistólica e $90 \mathrm{mmHg}$ para a diastólica, resultando uma pressão média de $106 \mathrm{mmHg}$, resultante da média ponderada onde a pressão diastólica tem peso dois. Pressões acima destes valores indicam quadro de hipertensão. $P$ aumenta de maneira similar a $B_{d, t o t a l}$ e $B_{d, \text { est, }}$ por isso também é apresentada na escala logarítmica na Figura 62b. Hipertensão extrema, por sua vez, 
é caracterizada por valores médios de pressão arterial de $132 \mathrm{mmHg}, 26 \mathrm{mmHg}$ a mais que o valor limite. Por esta razão, na Figura 62a, o eixo vertical tem seu valor limitado a $26 \mathrm{mmHg}$, a fim de facilitar a visualização, em cada segmento, do valor da severidade onde a diferença entre a pressão média limite e a característica de hipertensão severa é alcançada. A artéria da perna atinge esta diferença de pressão a uma severidade de $64 \%$, seguida pelo pescoço, tronco, coronária e braço, onde os valores observados são 70, 73, 78 e 82\%. Como consequência, para escoar através de uma estenose com essas reduções de diâmetro, chegar aos órgãos periféricos com pressão adequada e voltar para o coração, a pressão de saída do coração tem que ser incrementada em $26 \mathrm{mmHg}$, caracterizando hipertensão severa. Portanto, mais do que uma doença idiopática, sem causa definida, a hipertensão, em alguns casos, por ser um indício de alguma anomalia no sistema cardiovascular que esteja levando a um aumento das quedas de pressão ao longo da circulação, forçando o coração a operar a altas pressões e fornecer mais potência para o ciclo a fim de aumentar a pressão de saída do sangue e garantir o seu fornecimento adequado aos órgãos periféricos do corpo.

Figura 62: Diferença de pressão em artérias estenótica em função da severidade em escala linear (a) e logarítmica (b).

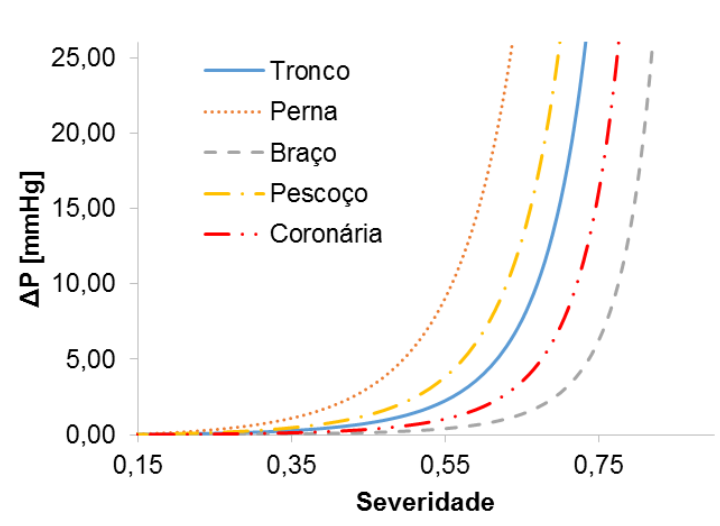

a

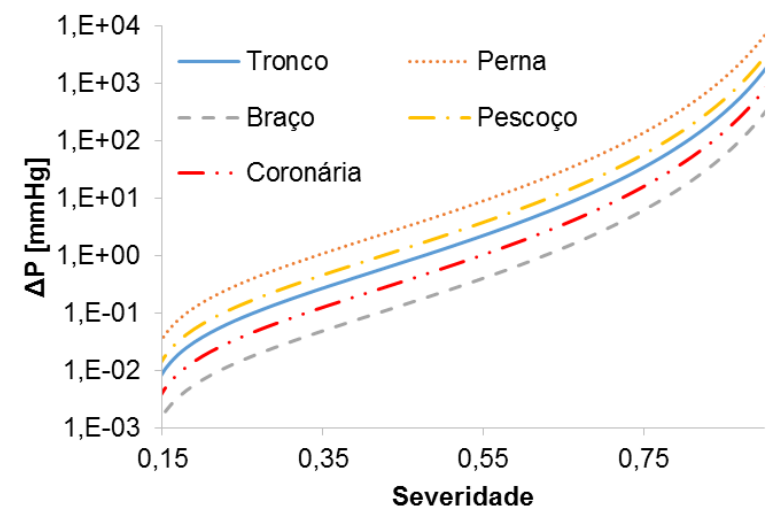

b

Fonte: $\mathrm{O}$ autor (2017).

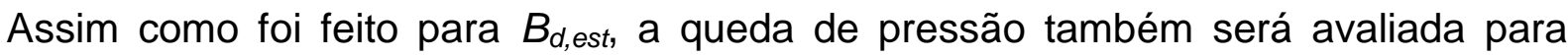
diferentes vazões de sangue. Na Figura 63, os resultados para severidades de 40, 60 e $80 \%$ são mostradas e pode-se observar que a diferença de $26 \mathrm{mmHg}$, característica de hipertensão severa, é atingida, em caso de atividade física, a severidades inferiores das observadas na Figura 62a. A artéria da perna, que 
apresenta as maiores quedas de pressão, pode atingir o valor de referência a uma severidade de $40 \%$ durante uma atividade física que leve a um aumento de 4 vezes do fluxo sanguíneo. Enquanto isso, para o braço o $\Delta \mathrm{P}$ de referência ocorre a uma severidade de $60 \%$, mas apenas para a máxima vazão. Por outro lado, no mesmo segmento, a uma severidade de $80 \%$ a diferença de $26 \mathrm{mmHg}$ é alcançada com um aumento de 1,5 do fluxo sanguíneo, levando em conta que o braço é o segmento onde o efeito da estenose é menos acentuado. Portanto, quando a obstrução chega a $80 \%$, se a vazão de sangue for $50 \%$ maior do que a condição basal, todas as artérias sofreram os efeitos do aumento de pressão.

Figura 63: Diferença de pressão em função da vazão de sangue para diferentes segmentos para severidade de 40 (a), 60 (b) e $80 \%$ (c).

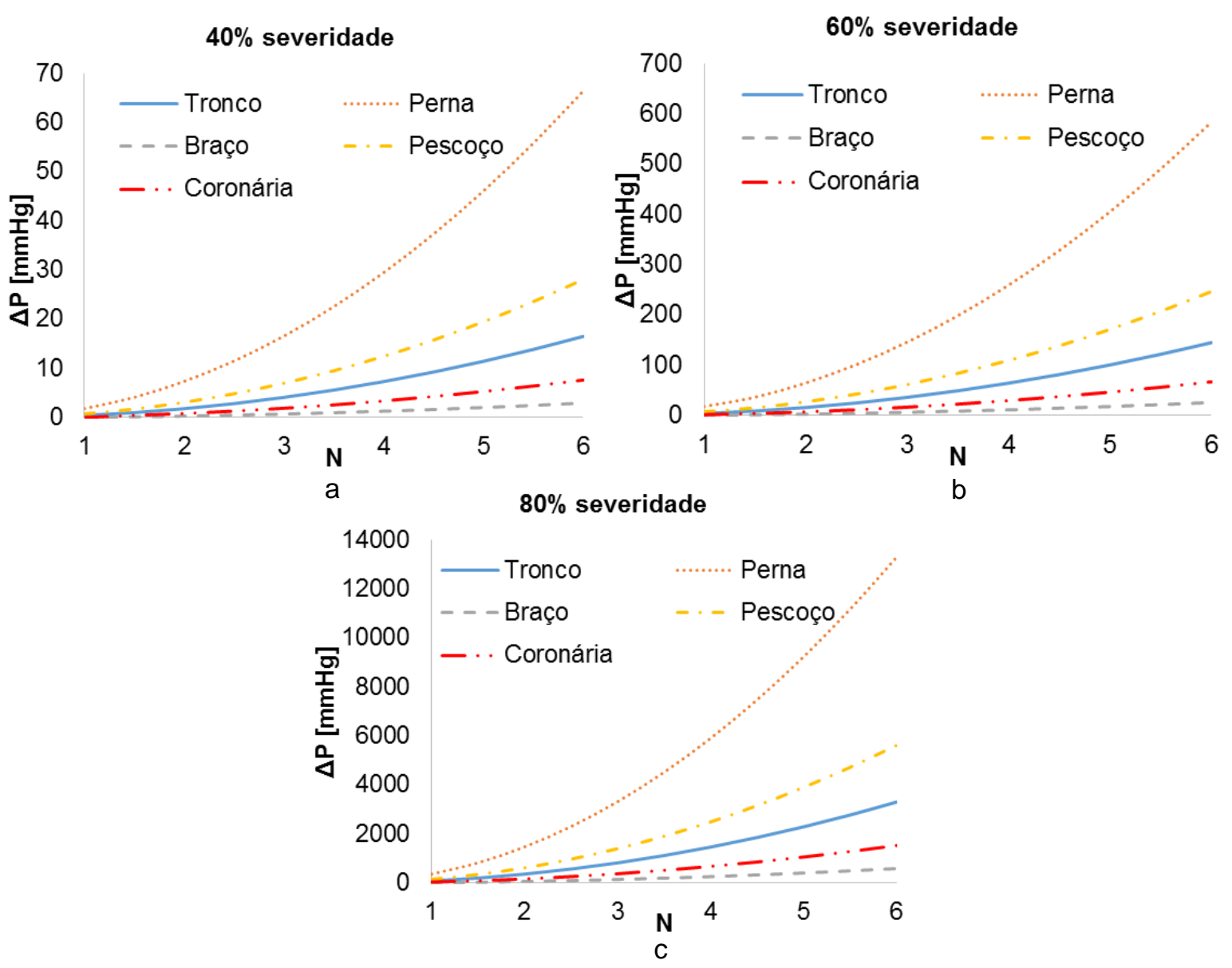

Fonte: O autor (2017). 
Outro parâmetro avaliado é o valor teórico do coeficiente de perda da carga $K_{\text {eng, }}$ calculado conforme descrito na seção 4.5. Os resultados utilizados neste trabalho, obtidos por meio de dados experimentais da literatura, são comparados aos teóricos na Figura 64. Nota-se que os valores extremos dos coeficientes, obtidos para severidades de $15 \%$ e $90 \%$ são bem próximos. Entretanto, os valores intermediários, bem como o formato das curvas, são distintos. Para a determinação do valor teórico de $K_{\text {eng, }}$ uma série de parâmetros intermediários deve ser determinada. Por outro lado, estes parâmetros estão disponíveis para faixas de redução de diâmetros, por essa razão o gráfico apresenta alguns valores constantes e descontinuidades. Sua curva se aproxima a uma função de segundo grau, enquanto os valores experimentais seguem uma reta $e$, por esta razão, seus valores são sempre superiores aos teóricos. Além disso, a curvatura do dispositivo teórico a jusante é mais suave que a estenose, contribuindo também para a diferença entre os valores.

Figura 64: Comparação entre os resultados experimentais da literatura utilizados neste trabalho e os valores teóricos do coeficiente $K_{e n g}$

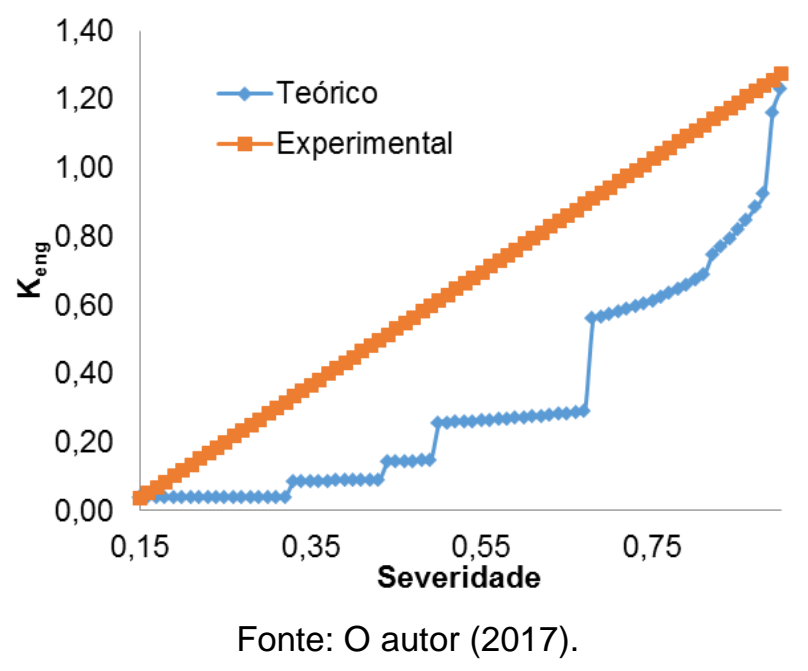

Por fim, os valores da diferença de pressão na artéria coronária são comparados aos obtidos por Cilla et al. (2015) por meio de simulações FSI para severidades de 50, 60, 70 e $80 \%$ para diferentes momentos do ciclo cardíaco. Para fins comparativos, os valores calculados para estas severidades são, respectivamente, 0,6, 1,9,7,16 e 42,9 mmHg, enquanto os valores médios da simulação são 5,8, 14,2, 36,3 e 124,0 mmHg, mais que três vezes superiores aos calculados. Os valores mais baixos obtidos por Cilla et al. (2015) durante o ciclo cardíaco foram 1,8, 3,6, 9,1, 34,2 $\mathrm{mmHg}$, que ainda são superiores aos calculados. Portanto os valores apresentados 
neste trabalho são maiores que os obtidos teoricamente, como mostrado na Figura 64, mas inferiores aos obtidos por meio de simulações FSI.

\subsection{METABOLISMO EXERGÉTICO DE CÉLULAS CANCERÍGENAS}

O valor do metabolismo exergético de uma célula cancerígena inespecífica foi calculado a partir de dados experimentais da literatura levando em conta as alterações nas vias metabólicas apresentadas na Figura 40 e o resultado obtido indica um valor de 1,018 MJ por mol de glicose por célula. Assumindo a oxidação completa de um mol de glicose numa reação estequiométrica, o metabolismo de uma célula saudável seria 2,788 $\mathrm{MJ} / \mathrm{mol}$, valor quase três vezes maior que o da célula cancerígena, que indicaria uma queda na eficiência do metabolismo em caso de câncer. Porém, quando a taxa de metabolismo por célula é calculada, multiplicando o valor em $\mathrm{MJ} / \mathrm{mol}$ pela taxa de consumo de glicose por célula, o valor

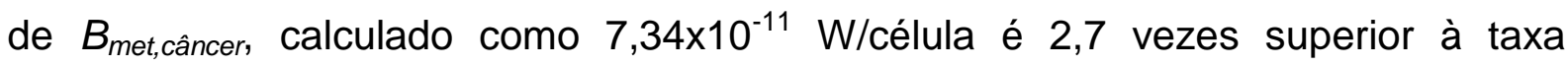
apresentada pela célula saudável. Este resultado se deve à acentuada diferença entre as taxas de consumo de glicose, que é aproximadamente 7 vezes superior em casos de câncer, conforme observado por Warburg (1927) e é justamente este fenômeno que é conhecido como efeito Warburg. Portanto, o aumento da taxa metabólica de uma célula de câncer está associado ao aumento da taxa de consumo de glicose, e não às alterações nos caminhos metabólicos provocadas pela doença.

Com relação à conversão de energia, o modelo de rota metabólica proposto indica que uma célula cancerígena produz 8,9 mols de ATP para cada mol de glicose, frente a 32 mols obtidos por uma célula saudável, representando um fornecimento de energia para a célula 3,6 vezes menor. Este valor está em conformidade com experimentos reportados na literatura, onde 8 mols de ATP foram obtidos (REITZER et al., 1979). Entretanto, uma vez que a taxa de consumo de glicose é cerca de 7 vezes superior na presença de câncer, a taxa de produção de ATP é superior em um tumor. Para um mesmo intervalo de tempo, uma célula cancerígena produz o dobro de ATP que uma célula saudável. Deste modo, mais energia é liberada para as 
demandas internas da célula, que são elevadas devido à sua alta taxa de proliferação.

O metabolismo do tumor varia com o número de células, que, por sua vez, segue uma função de crescimento de Gompertz. Para a análise do impacto do câncer na exergia destruída no corpo, admitiu-se o surgimento da primeira célula mutante aos 50 anos de idade do indivíduo. A taxa de metabolismo total a partir desta idade corresponde à soma do metabolismo do indivíduo saudável mais o metabolismo do tumor, que é obtido a partir da multiplicação do metabolismo por célula pelo número de células em determinado instante de tempo, que é calculado para diferentes taxas de proliferação. Assumindo que as demais parcelas envolvidas na destruição de exergia do corpo não se alterem na presença de câncer, tendo em vista que o metabolismo exergético corresponde a cerca de $95 \%$ da destruição de exergia no corpo, a taxa de exergia destruída neste caso será a soma da exergia destruída no indivíduo saudável com o metabolismo do tumor. A exergia destruída acumulada por unidade de massa do indivíduo $\left(B_{d, a c}\right)$ é obtida por meio da integração da taxa de destruição de exergia ao longo do ciclo de vida. A Figura 65 mostra os valores de $B_{d, a c}$ para diferentes taxas de divisão celular, expressas em dia $^{-1}$, bem como para o indivíduo saudável. Para analisar o efeito da origem do tumor em outras idades, basta deslocar as curvas para a esquerda ou direita.

Figura 65: Exergia destruída acumulada ao longo do ciclo de vida para taxas de divisão celular de 0,04 a 1,4 .

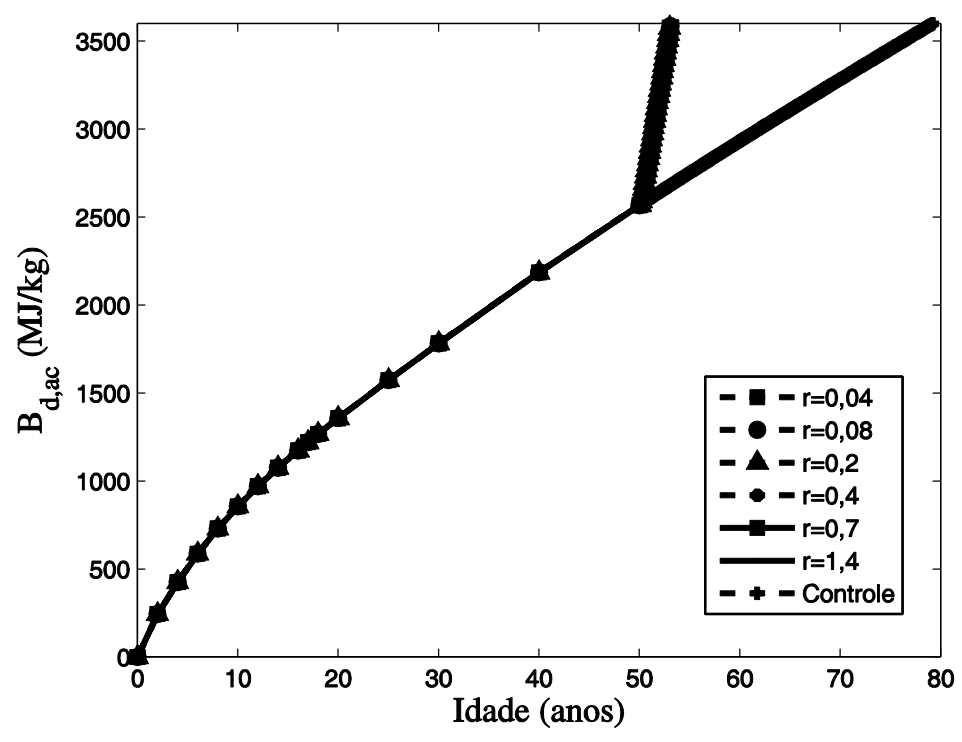

Fonte: O autor (2017). 
Como pode ser observado na Figura 65, na ocorrência de câncer há um aumento abrupto da exergia destruída acumulada. A partir dos 50 anos, a destruição de exergia esperada para os 30 anos seguintes acontece em menos de três. A Figura 66 mostra o gráfico anterior ampliado, onde se nota que o efeito da variação da taxa de divisão celular no acúmulo de exergia é pequeno. Com os valores de taxas analisados, em todos os casos os tumores chegariam ao tamanho máximo de $10^{13}$ células em até seis meses. Consequentemente, a partir deste momento, não há mais diferença entre o tamanho dos tumores e, portanto, também não se observa variação significativa na taxa de metabolismo e na exergia destruída acumulada. A pequena diferença se deve aos valores nos seis primeiros meses. Tomando como referência o valor médio de 52,8 anos, pode-se dizer que a presença de câncer sem tratamento faria com que o indivíduo atingisse a valor de exergia destruída acumulada característico dos 80 anos, 27,2 anos antes. Ou, em outras palavras, a sobrevida seria de 2,8 anos.

Figura 66: Imagens ampliadas da relação entre a exergia destruída acumulada em caso de câncer para diferentes taxas de replicação.
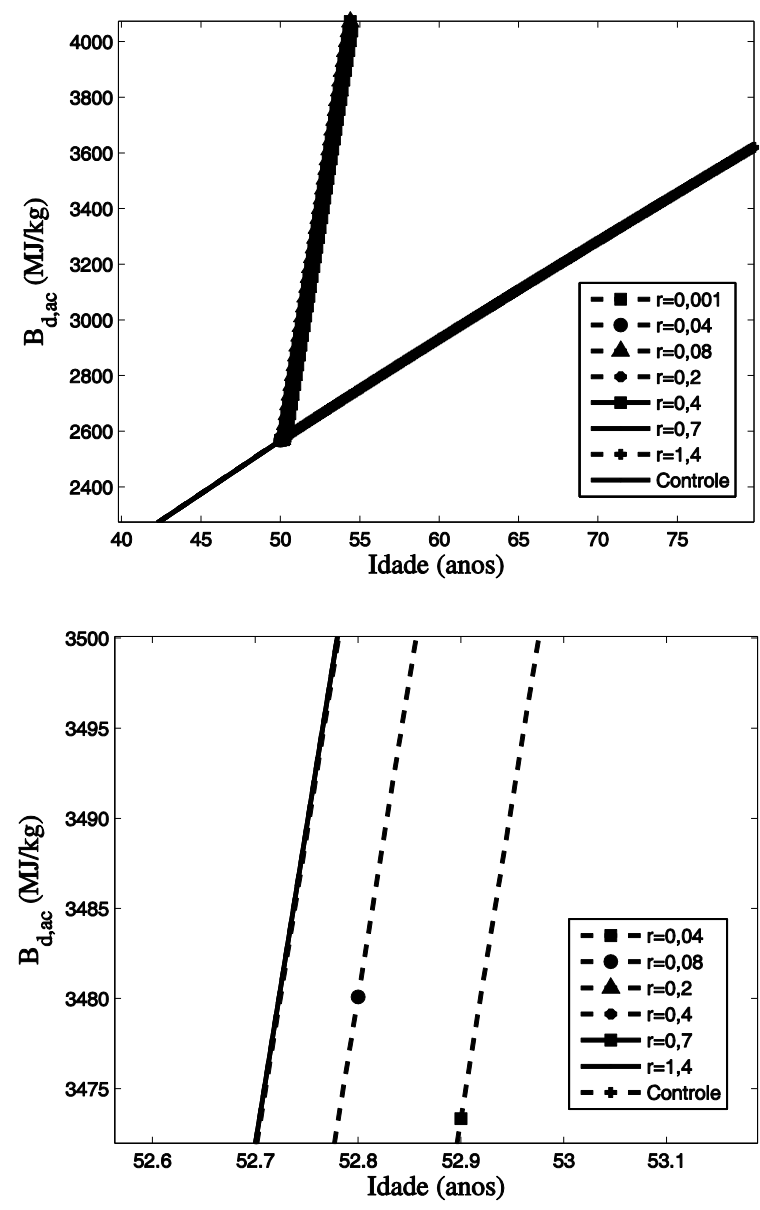

Fonte: O autor (2017). 
Um estudo de Shimkin et al. (1984) compilou uma série de dados sobre a taxa de sobrevivência após 5 anos para diferentes tipos de câncer na ausência de tratamentos. Os dados são antigos, mas para a análise dos efeitos do câncer sem influência de fatores externos não há prejuízo. Enquanto 20,1\% dos pacientes com câncer de mama sobreviviam por ao menos 5 anos, este percentual era de 6,7\% para câncer de próstata e 0\% para ovário, cólon, pulmão, esôfago, pâncreas e fígado. Dados da fundação Macmillan Cancer Support (2011) indicam que o tempo médio de sobrevida para tipos de câncer mais agressivos, como pulmão, esôfago e pâncreas é da ordem de meses. Para o caso específico do pâncreas, a sobrevida é de aproximadamente três meses. Entretanto, no caso de câncer de mama e bexiga, valores próximos a 9 anos foram obtidos. Pode-se dizer que os resultados aqui obtidos, por se tratar de um modelo baseado em diferentes tipos de células, representam formas da doença de agressividade intermediária. Conclui-se também que apenas a taxa de divisão não é suficiente para diferenciar os tipos de câncer quanto a seu impacto na saúde global e sobrevida do indivíduo. É importante mencionar que os estudos relativos à taxa de sobrevida e expectativa de vida póscâncer tem como referência temporal a detecção do tumor, enquanto o presente modelo assume o momento da primeira divisão celular da célula mutante. Como mencionado na seção 3.7.3.1, um tumor pode ser detectado a partir do valor de $10^{9}$ células. Para cada taxa de proliferação, esse valor é atingido em um tempo diferente. Entretanto, como as taxas diárias de divisão celular são relativamente altas, para todos os valores analisados, o tumor atingiria o estágio detectável até seis meses.

O modelo proposto não inclui o efeito de terapias anticâncer. Entretanto, é possível estimar o efeito do tempo de tratamento até a cura na exergia destruída acumulada e quão distante este valor está do indivíduo que nunca apresentou a doença. $\mathrm{Na}$ Figura 67a é possível observar que quando o indivíduo convive com o tumor durante 6 meses, o acúmulo de exergia destruída característico dos 80 anos é atingido cerca de 5 anos antes. A Figura 67b mostra o gráfico ampliado, onde se pode notar que para uma taxa de 0,2 dia $^{-1}$ ocorre uma perda de expectativa de vida de 4,5 anos, enquanto uma redução de 2,5 é observada para tumores com a progressão mais lenta. Quando o tumor leva um ano para ser eliminado, a redução na expectativa de vida é maior, como mostrado na Figura 68. Para a taxa de 0,2 dia ${ }^{-1}$ observa-se uma 
redução de nove anos, contra um valor de sete anos para 0,04 dia $^{-1}$. O último cenário avaliado corresponde ao período de um ano e meio e os efeitos são mostrados na Figura 69. Neste caso, reduções de expectativa de vida de 13,5 e 11,5 anos foram estimadas para taxas iguais a, respectivamente, $0,2 \mathrm{dia}^{-1}$ e $0,04 \mathrm{dia}^{-1}$. Portanto, mesmo com a cura da doença, o tempo durante o qual o indivíduo conviveu com a doença, ou seja, o intervalo de tempo que o metabolismo do tumor contribuiu para o metabolismo total influencia na exergia destruída acumulada e, consequentemente, na expectativa de vida. Por isso, além da maior probabilidade de sucesso do tratamento, é importante obter o diagnóstico da doença nos primeiros estágios de seu desenvolvimento.

Figura 67: Exergia destruída acumulada por unidade de massa para eliminação do tumor em 6 meses para diferentes taxas de proliferação (a). Gráfico ampliado para valores próximos a $3600 \mathrm{MJ} / \mathrm{kg}$ (b).

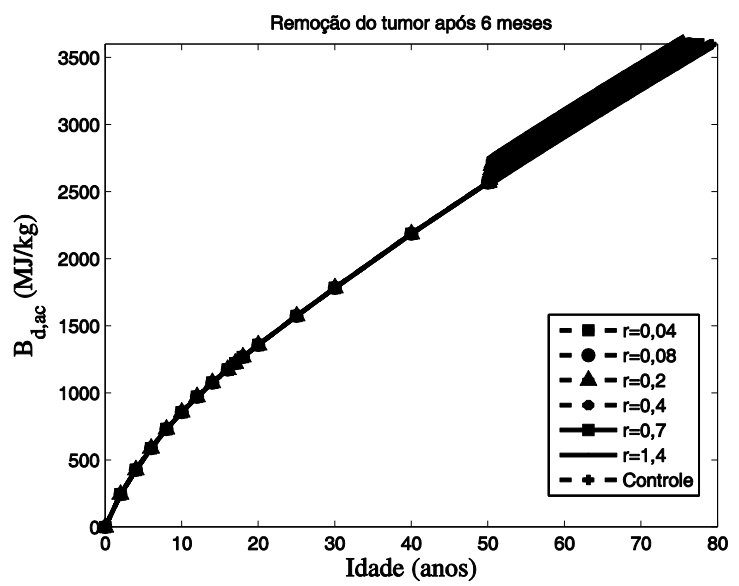

a

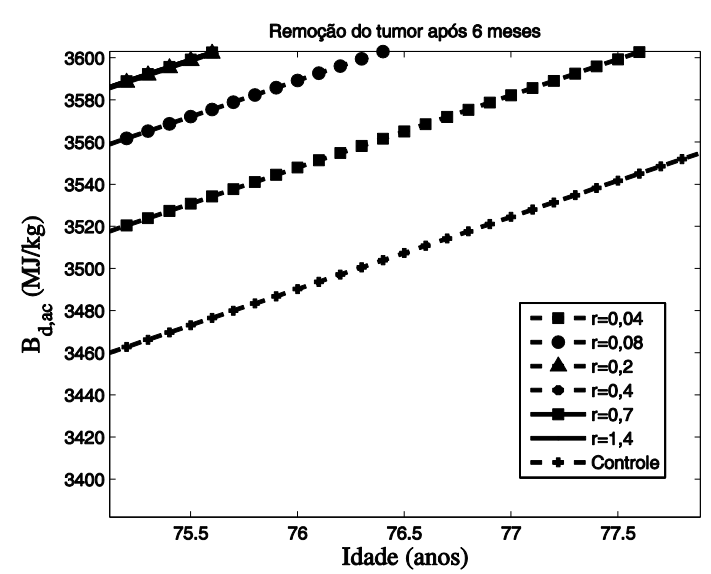

b

Fonte: O autor (2017).

Figura 68: Exergia destruída acumulada por unidade de massa para eliminação do tumor em um ano para diferentes taxas de proliferação (a). Gráfico ampliado para valores próximos a $3600 \mathrm{MJ} / \mathrm{kg}$ (b).

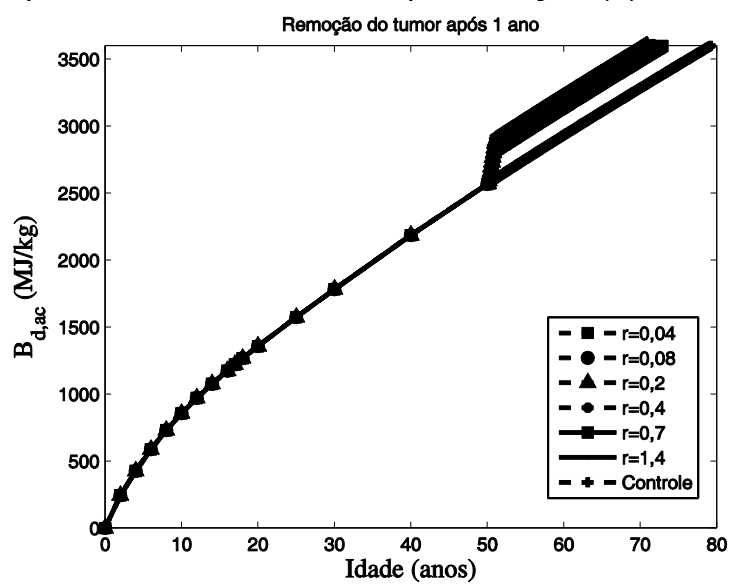

a

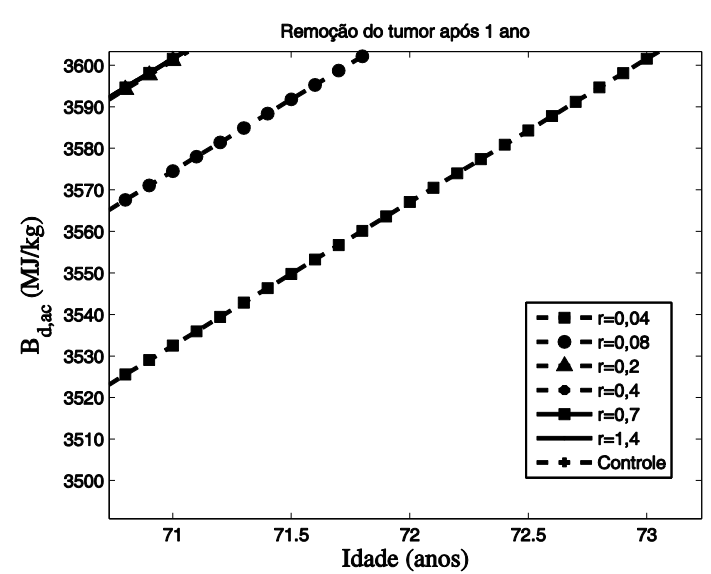

b

Fonte: O autor (2017). 
Figura 69: Exergia destruída acumulada por unidade de massa para eliminação do tumor em um ano e meio para diferentes taxas de proliferação (a). Gráfico ampliado para valores próximos a 3600 $\mathrm{MJ} / \mathrm{kg}(\mathrm{b})$.

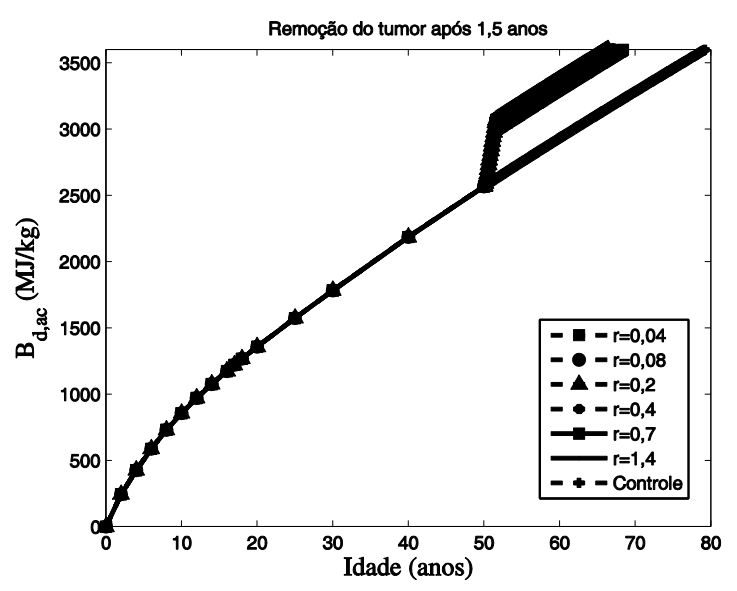

a

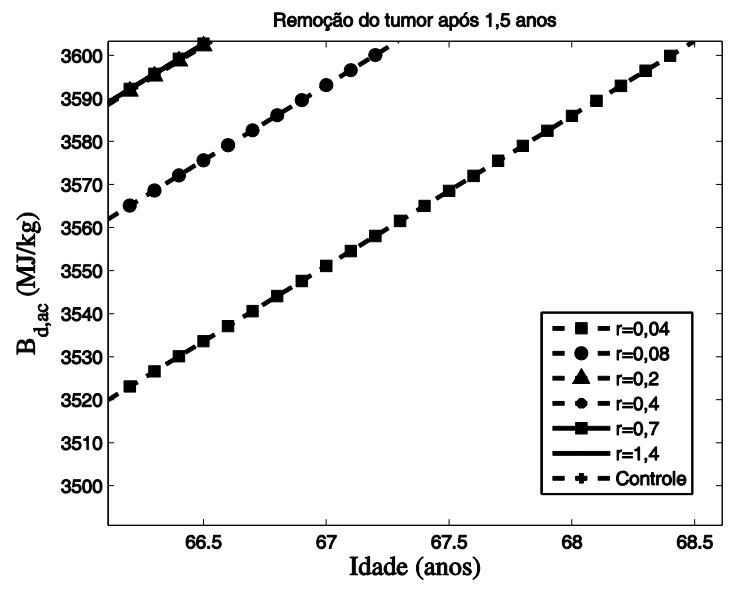

b

Fonte: O autor (2017).

Nos estudos da área médica relativos à expectativa de vida após a ocorrência de um tumor, a definição de cura depende do constante acompanhamento do paciente para avaliação não apenas da reincidência de tumores, mas também para a análise estatística da sobrevida. Deste modo, na prática, é difícil definir um ponto exato a partir do qual o paciente está curado. Além disso, a atualização dos dados dos indivíduos, que alimentarão as análises estatísticas de expectativa de vida, é um fator limitante (VISCOMI ET AL., 2006; CHU ET AL., 2008; ANDERSSON ET AL., 2013; CAPOCACCIA ET AL., 2015). Devido à baixa taxa de retorno dos pacientes para acompanhamento, Andersson et al. (2013) propuseram um modelo matemático baseado em extrapolações a partir dos dados reais a fim de determinar a perda de expectativa de vida associada a diferentes tipos de câncer, mas sem levar em conta o tempo de tratamento, como no modelo aqui proposto. Os resultados indicaram quedas de 1,9, 3,0, 3,5 e 4,7 anos para, respectivamente, câncer de mama, colón, melanoma e bexiga. A comparação entre os dados do modelo de Andersson et al. (2013) e os apresentados neste trabalho é falha, pois as condições para os cálculos são diferentes. Mas de modo geral, os resultados são similares para o caso hipotético da remoção completa do tumor em seis meses, indicando que, tanto o aperfeiçoamento do presente modelo, quanto a sistematização da coleta de dados de pacientes com câncer pode ajudar na avaliação do impacto do câncer na expectativa de vida, o que é um dado importante não apenas para o próprio 
paciente, mas também por questões de saúde pública e planejamento orçamentário dos governos.

\subsection{INDICADOR DE IDADE EXERGÉTICA}

Esta seção apresenta 0 indicador de idade exergética para os diferentes cenários abordados, mostrados da Figura 70 à Figura 74. A idade exergética indica, com base nos valores de exergia destruída acumulada por unidade de massa para o indivíduo padrão, o quanto a condição analisada se afasta da referência para cada idade cronológica. A Figura 70 mostra como o indicador de idade exergética progride mais rapidamente para fumantes devido apenas ao aumento de metabolismo associado ao tabagismo. Observa-se que, para a idade cronológica de 80 anos, a idade exergética de um fumante está próxima de 100 anos. Alternativamente, buscando no eixo das ordenadas o valor de 75,5 anos, que corresponde à expectativa de vida média do brasileiro no ano de 2015 (IBGE, 2016), nota-se que este valor corresponde à idade cronológica de 59,5 anos para fumantes, indicando 16 anos de redução na expectativa de vida.

Figura 70: Comparativo entre idades cronológica e exergética para fumantes e não fumantes.

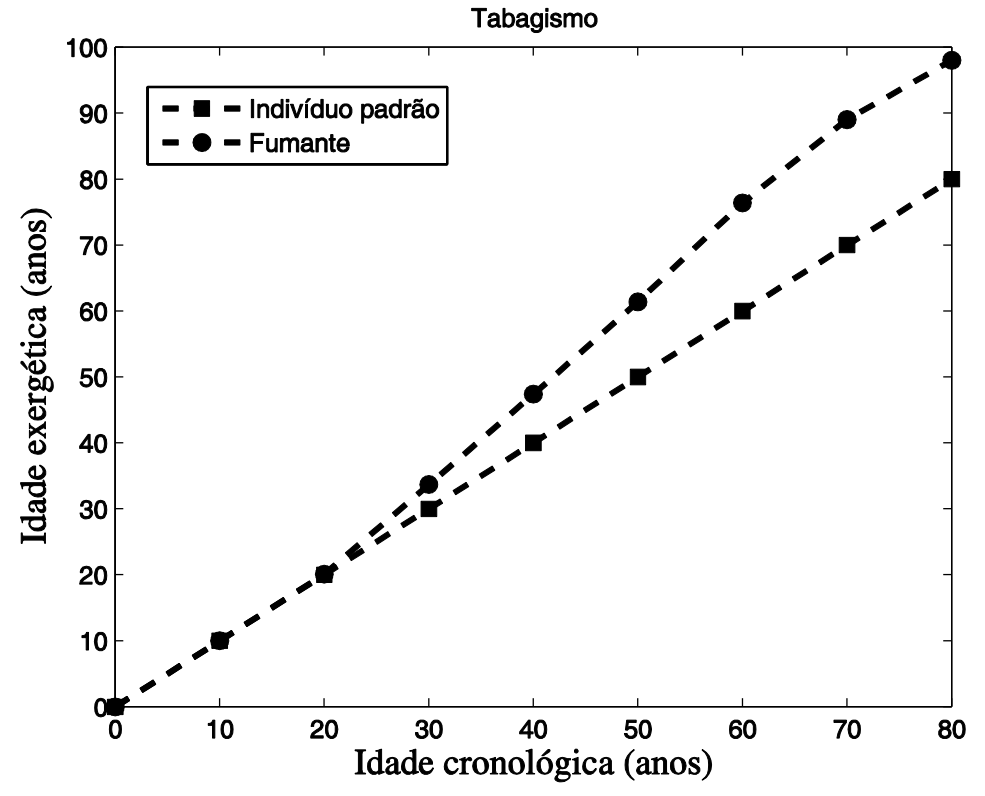

Fonte: O autor (2017). 
$\mathrm{Na}$ Figura 71 está representada a correspondência entre idades cronológica e exergética para indivíduos com diferentes índices de massa corporal e percentual de gordura. Diferente dos demais cenários avaliados, o modelo do corpo utilizado para a avaliação da obesidade é diferente do usado nos cálculos do indivíduo padrão, sendo uma versão mais simplificada para facilitar a alteração da composição corporal. Por esta razão, a comparação dos valores numéricos de exergia destruída acumulada por massa será feita apenas entre os resultados com o mesmo modelo, obtidos a partir dos dados antropométricos do estudo de Ravusin (1982). Conforme discutido na seção 5.2, a ocorrência de obesidade sem o desenvolvimento de doenças associadas não apresenta impacto negativo na destruição de exergia. $O$ indicador de idade exergética, mostrado na Figura 71, evidencia um aumento da expectativa de vida com o aumento do IMC e da camada superficial de gordura. Para a idade cronológica de 75 anos, a diferença no indicador de idade exergética entre o grupo obeso e o moderadamente obeso é de aproximadamente 14 anos, e a mesma diferença é observada entre moderadamente obesos e o grupo de controle.

Outra análise possível está associada à teoria da taxa de vida, segundo a qual o metabolismo por unidade de massa é inversamente proporcional à expectativa de vida (Pearl, 1928). Sob esta óptica, os resultados indicam que, para a espécie humana, a ideia de que animais maiores vivem mais também é válida.

Figura 71: Comparativo entre idades cronológica e exergética para os grupos de controle moderadamente obesos e obesos do estudo de Ravusin (1982).

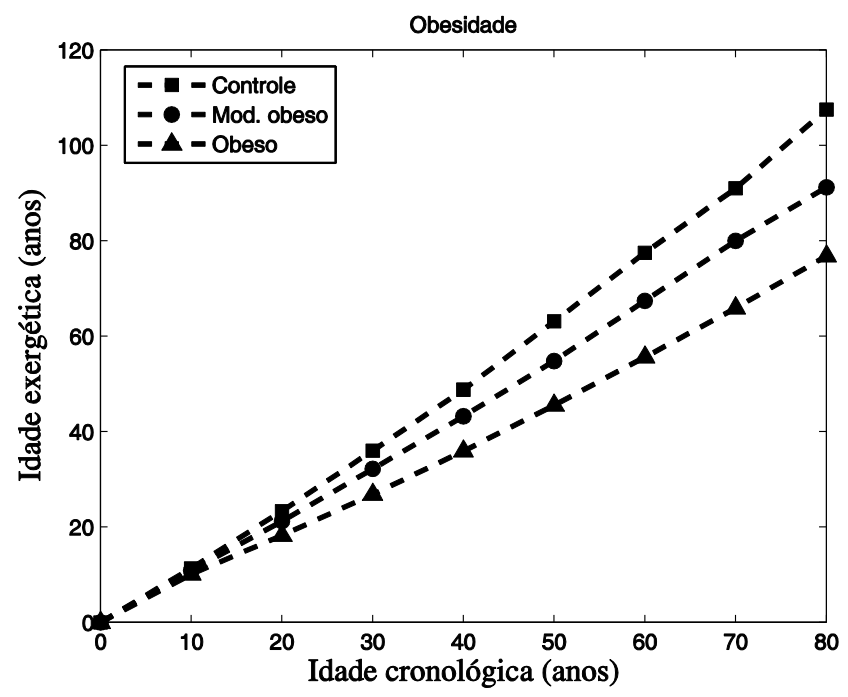

Fonte: O autor (2017). 
A partir da aplicação do modelo exergético do coração ao caso de hipertensão, é possível estimar uma perda de 4,4 anos na expectativa de vida devida apenas ao aumento da pressão arterial, quando esta condição surge a partir dos 30 anos de idade, conforme mostrado na Figura 72.

Figura 72: Comparativo entre idades cronológica e exergética para hipertensos e normotensos.

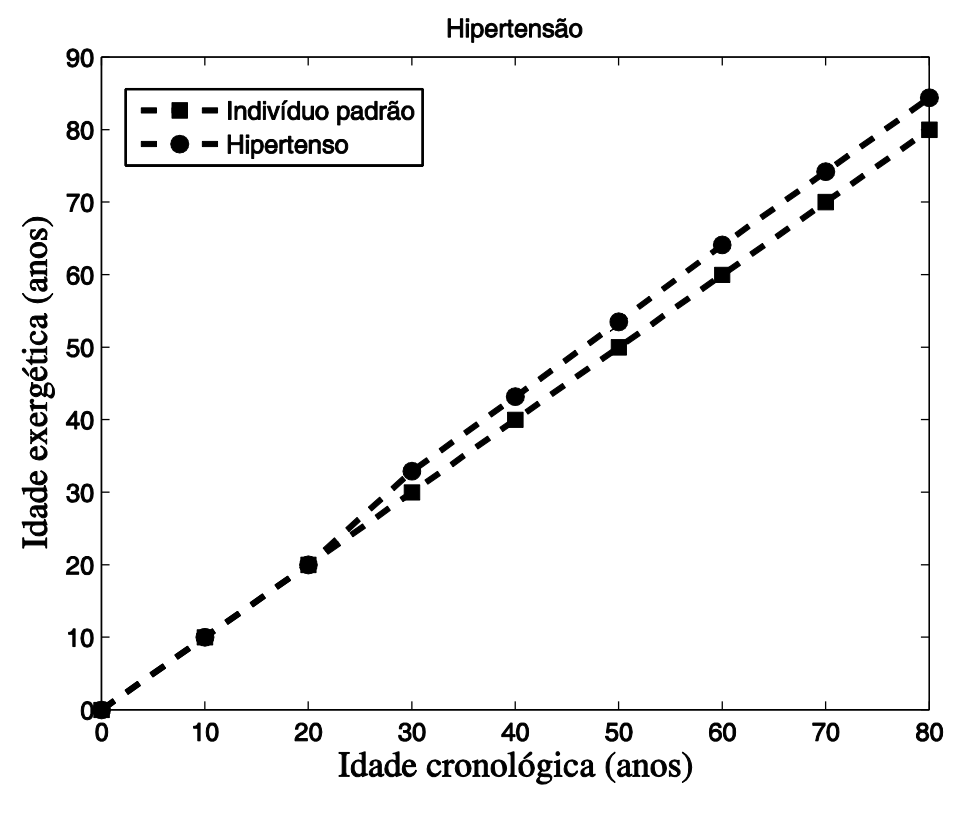

Fonte: O autor (2017).

Finalmente, o impacto da presença de um tumor genérico na expectativa de vida é demonstrado na Figura 73, onde se observa que a idade exergética de 75 anos é atingida antes dos 53 anos cronológicos, indicando uma perda de 22 anos na expectativa de vida para o caso de um câncer não tratado. 
Figura 73: Comparativo entre idades cronológica e exergética para indivíduos com e sem câncer.

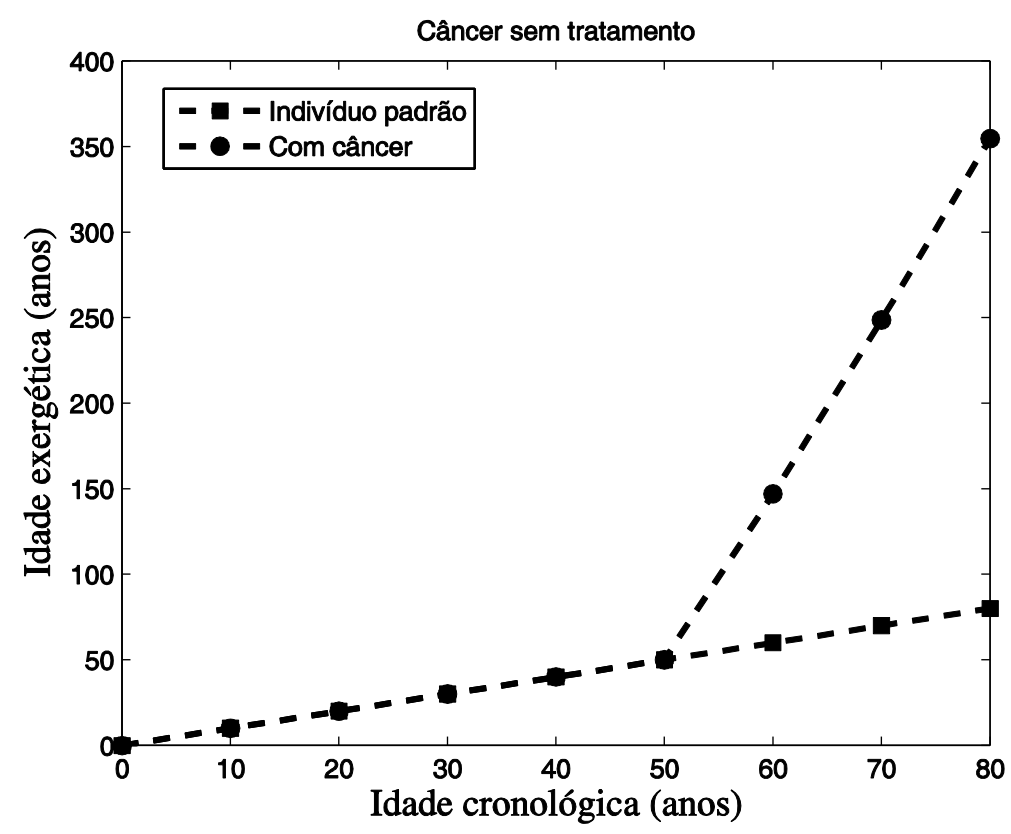

Fonte: O autor (2017).

Quando o paciente se submete a algum tipo de tratamento e o tumor é totalmente eliminado, ainda há impacto no indicador de idade exergética devido ao tempo no qual a doença esteve presente. A Figura 74 indica este efeito para diferentes intervalos de tempo entre o início do desenvolvimento do tumor e sua eliminação total. O efeito do tratamento na destruição de exergia durante este intervalo de tempo não foi considerado. Segundo o indicador de idade exergética, um período de seis meses com câncer impactaria 2,3 anos na expectativa de vida do indivíduo, em comparação com o indivíduo padrão, ao passo que valores de 6,8 e 11,3 anos são estimados para períodos de um ano e um ano e meio, respectivamente.

A análise do indicador de idade exergética leva à conclusão que, dos cenários avaliados, o câncer é o que apresenta maior impacto na redução da expectativa de vida no caso em que este não é tratado. Em caso de tratamento, esta redução depende do tempo decorrido entre o início da proliferação do tumor e sua eliminação. Na sequência se destaca o tabagismo, que mesmo desconsiderando as possíveis patologias que podem surgir em decorrência deste hábito, pode provocar uma redução da expectativa de até 16 anos, se o indivíduo mantiver este hábito até o fim da vida. A análise da hipertensão indicou uma redução de cerca de 4 anos. A obesidade, por sua vez, não mostrou ser um fator determinante na redução da expectativa de vida, desde que não esteja associada a outras patologias. 
Figura 74: Efeito do tempo para eliminação do câncer na relação entre idades cronológica e exergética.

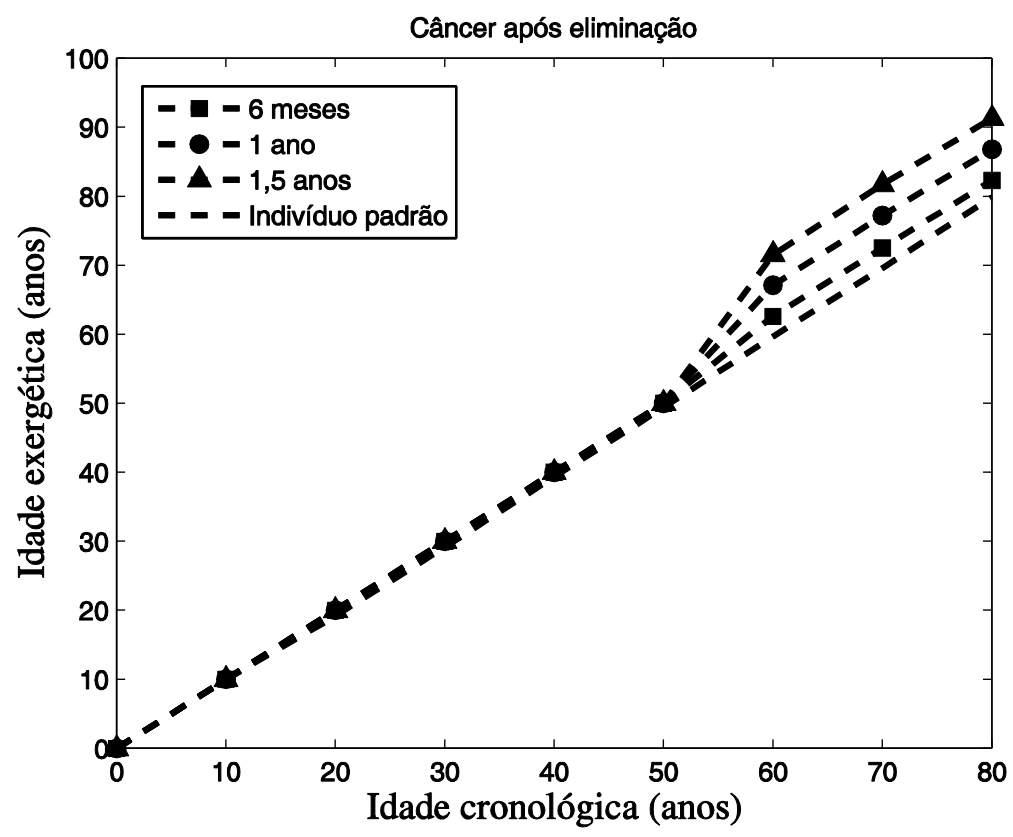

Fonte: O autor (2017). 


\section{CONCLUSÕES}

$\mathrm{Na}$ primeira parte deste trabalho foram avaliados os efeitos de variações na taxa metabólica provocadas pelo tabagismo e pela obesidade nos parâmetros exergéticos do corpo. No caso do tabagismo, a análise exergética foi realizada considerando duas temperaturas de referência: a de neutralidade térmica e 30,4ํㅡ. Observou-se que o metabolismo exergético e a taxa de exergia destruída em fumantes seguem a mesma tendência de aumento em comparação com os não fumantes, sendo o incremento do metabolismo cerca de $2 \%$ superior ao da exergia destruída. A priori, não foram notadas diferenças significativas entre as duas temperaturas de referência analisadas. Uma vez que foi assumida durante a modelagem a condição de que não ocorrem variações antropométricas entre os indivíduos fumantes e não fumantes, a exergia destruída acumulada por unidade de massa ao longo da vida também foi maior para fumantes. Deste modo, o indicador de idade exergética para este grupo progride mais rapidamente do que para os não fumantes, indicando uma redução da expectativa de vida em torno de 15 anos. Com relação à eficiência exergética, este foi o único parâmetro com alterações relevantes entre as temperaturas de referência avaliadas. Nos dois cenários a eficiência exergética dos fumantes foi maior devido ao aumento superior observado no metabolismo exergético em comparação com a taxa de exergia destruída. Entretanto, este valor foi ainda maior para a temperatura de $30,4 \stackrel{\circ}{\circ}$, uma vez que a diferença entre o aumento de $B_{M}$ e $B_{d}$ foi superior a esta temperatura. A origem desta diferença é a soma dos fluxos e transferências de exergia para o ambiente, superior fora da neutralidade térmica.

Para a avaliação dos efeitos da obesidade, foram considerados três grupos: controle, moderadamente obeso e obeso. A taxa de exergia destruída aumentou com o grau de obesidade. Porém, quando seu valor foi dividido pela massa corporal correspondente a cada categoria, a relação se inverteu, indicando que o aumento da massa é proporcionalmente superior ao da exergia destruída. Deste modo, quando a taxa de exergia destruída por unidade de massa é integrada ao longo do ciclo de vida, o valor obtido para obesos é inferior aos demais grupos, o que indicaria que este grupo apresenta uma progressão de vida mais lenta, possuindo maior 
expectativa de vida, o que contraria os dados estatísticos sobre mortalidade. Por outro lado, como a representação dos obesos no modelo se deu apenas por modificações nos valores de metabolismo e espessura das camadas, não levando em conta alterações fisiológicas, tais como estreitamento de artérias e disfunções hormonais, pode-se concluir que o aumento da taxa de mortalidade entre obesos está associado ao surgimento de doenças associadas à obesidade, e não apenas à presença de uma camada mais espessa de gordura. Alternativamente, os resultados indicam que a teoria da taxa de vida, que diz que animais maiores vivem mais, também se aplica à espécie humana. A eficiência exergética também foi avaliada para os três grupos, e os menores valores foram apresentados pelos obesos, indicando que o aumento da exergia destruída é maior que o do metabolismo, tornando o funcionamento do corpo menos eficiente.

Na sequência, foi proposto um modelo exergético do coração a ser aplicado a diferentes intensidades de exercício físico para normotensos e hipertensos. Os resultados mostraram que a taxa de exergia destruída no coração aumenta tanto com a intensidade do exercício quanto na hipertensão. Ambos os casos levam ao aumento da pressão sanguínea e, consequentemente, da potência e do metabolismo exergético deste órgão. Para todos os cenários, o lado esquerdo apresentou maior exergia destruída. No caso de hipertensão, a contribuição da parte esquerda para a exergia destruída total, além de ser maior que em normotensos, aumentou com a intensidade da atividade física. Isso se deve à variação da exergia do fluxo de sangue, influenciada pelas pressões parciais dos gases. A taxa de exergia destruída no coração hipertenso foi integrada ao longo da vida e observouse uma redução de 4,4 anos na expectativa de vida devida apenas ao aumento das pressões de operação do coração. Comparando os dados do coração aos do corpo e do sistema respiratório obtidos na literatura, pode-se observar que a contribuição do coração para a destruição total de exergia no corpo diminui na caminhada, mas apresenta uma ligeira tendência de aumento na corrida, indicando que o comportamento exergético do coração pode ser diferenciado na realização de exercícios mais vigorosos. Com relação à eficiência exergética do coração, seu valor não se altera na presença de hipertensão, pois o aumento da exergia destruída é proporcional ao aumento do metabolismo exergético. Além disso, a eficiência 
exergética do coração aumenta com a atividade física a uma taxa superior à observada para o corpo, enquanto a do sistema respiratório tende a cair.

A aplicação da análise exergética a artérias estenóticas de diferentes partes do corpo indicou que a taxa de exergia destruída total assume valores relevantes apenas para severidades superiores a $75 \%$ para um indivíduo em repouso. A partir deste ponto, a destruição de exergia aumenta exponencialmente. Quando apenas a parcela relativa à estenose é avaliada, os valores para o tronco e a perna são coincidentes. Porém, quando a exergia destruída específica é avaliada, segmentos de artéria da perna e do pescoço possuem valores superiores aos apresentados pelo tronco, indicando a relevância do fluxo sanguíneo no cálculo. Por esta razão, também foram analisadas variações da vazão de sangue, mostrando que, em caso de atividade física, o incremento do fluxo de sangue faz com que a destruição de exergia a baixas severidades aumente. A queda de pressão na estenose também foi avaliada, e os resultados indicaram que a diferença de pressão característica de hipertensão severa pode ocorrer a severidades acima de $65 \%$. Porém, em caso de atividade física, este valor é significantemente reduzido.

Por fim, foi proposto um modelo para o cálculo do metabolismo exergético de um tumor inespecífico que leva em conta as alterações das rotas metabólicas de uma célula genérica de câncer. Os resultados obtidos indicam uma célula cancerígena possui uma taxa metabólica 2,7 vezes maior que uma célula saudável devido ao aumento da taxa de consumo de oxigênio e não ao aumento do metabolismo por mol de glicose. Além disso, a oxidação de um mol de glicose por uma célula cancerígena produz 8,9 mols de ATP, contra 32 mols de uma célula saudável. Porém, uma vez que o consumo de glicose é 7 vezes maior no tumor, a energia liberada na forma de ATP no mesmo intervalo de tempo dobra. Com relação ao desenvolvimento do tumor, os valores de exergia destruída por unidade de massa indicam que um tumor não tratado anteciparia para três anos a destruição de exergia prevista para trinta, indicando uma redução de aproximadamente 27 anos na expectativa de vida. $O$ efeito do tempo de duração do ciclo da doença indicou que a remoção do tumor nos primeiros seis meses leva a uma perda de expectativa de vida entre 2,5 e 4,5 anos. Para cada seis meses adicionais, cerca de 4 anos são perdidos, ressaltando a importância do diagnóstico precoce da doença. 


\subsection{SUGESTÃO PARA TRABALHOS FUTUROS}

O presente trabalho apresentou resultados em diferentes frentes dentro do mesmo tema global, possibilitando o desenvolvimento de futuras pesquisas com diferentes enfoques.

a) Análise da expectativa de vida de fumantes utilizando o modelo integrado entre corpo humano e sistema respiratório de Albuquerque Neto (2010), levando em conta as alterações fisiológicas de possíveis patologias decorrentes do tabagismo.

b) Avaliação da obesidade levando em conta os efeitos das diferenças entre gordura visceral e superficial, bem como a utilização do modelo do corpo humano proposto por Ferreira (2001), que apresenta maior grau de complexidade que o utilizado nesta tese.

c) Desenvolvimento de um modelo computacional do coração e do sistema circulatório que seja capaz de determinar as variáveis necessárias para a análise exergética e também sensível a alterações associadas a patologias cardiovasculares.

d) Análise bioquímica detalhada do modelo da célula de câncer, levando em conta as constantes de equilíbrio das reações reversíveis.

e) Modelagem do efeito de diferentes tipos de tratamento contra o câncer na evolução da doença e, consequentemente, no metabolismo exergético do tumor. 


\section{REFERÊNCIAS}

ALBUQUERQUE NETO, C. Um modelo do transporte de monóxido de carbono no sistema respiratório do corpo humano. Dissertação (Mestrado) - Escola Politécnica, Universidade de São Paulo. São Paulo, 2005.

ALEXANDER, J. K. Obesity and Cardiac Performance. The American Journal of Cardiology, v.14, p. 860-865, 1964.

ANDERSSON, T. M-L; DICKMAN, P. W.; ELORANTA, S.; LAMBE, M.; LAMBERT, P. $C$. Estimating the loss in expectation of life due to cancer using flexible parametric survival models. Statistics in Medicine, v. 32, p. 5286-5300, 2013.

AOKI, I. Entropy balance of white-tailed deer during a winter night. Bulletin of mathematical biology, v. 49, n. 3, p. 321-327, 1987.

AOKI, I. Entropy flow and entropy production in the human body in basal conditions. Journal of theoretical biology, v. 141, n. 1, p. 11-21, 1989.

AOKI, I. Effects of exercise and chills on entropy production in human body. Journal of theoretical biology, v. 145, n. 3, p. 421-428, 1990.

AOKI, I. Entropy principle for human development, growth and aging. Journal of theoretical biology, v. 150, n. 2, p. 215-223, 1991.

ASHRAE, F. Handbook of fundamentals. [S.I.]: American Society of Heating, Refrigerating and Air Conditioning Engineers Inc. ASHRAE. Atlanta, 2005.

BALMER, R. T. Entropy and aging in biological systems. Chemical Engineering Communications, v. 17, n. 1, p. 171-181, 1982.

BASKURT, O. K.; MEISELMAN, H. J. Blood Rheology and Hemodynamics. Seminars in thrombosis and hemostasis, v. 29, n. 5, p. 435-450, 2009. 
BATATO, M.; DERIAZ, O.; BOREL, L.; JEQUIER, E. Analyse exergétique, théorique et expérimentale, du corps human. Entropie, v. 26, p. 120-130, 1990.

BECK-BORNHOLDT, H.; WÜRSCHMIDT, F.; VOGLER, H. Net growth delay: a novel parameter derived from tumor growth curves. International Journal of Radiation Oncology*Biologyphysics, v. 13, p. 773-777, 1987.

BELEIGOLI, A.; DINIZ, M.F. Two (or more) sides of a coin. Heart, v. 100, n. 18, p. 1399-1401, 2014.

BURSE, R. L.; GOLDMAN, R. F.; DANFORTH, E.; HORTON, E. S.; SIMS, E. A. H. Effects of cigarette smoking on body weight, energy expenditure, appetite, and endocrine function. US Army Research Report, n. M25/82, 1982.

CANTOR, J. R.; SABATINI, D. M. Cancer cell metabolism: one hallmark, many faces. Cancer Discovery, v. 2, n. 10, p. 881-898, 2012.

CAPOCACCIA, R.; GATTA, G.; DAL MASO, L. Life expectancy of colon, breast and testicular cancer patients: an analysis of US-SEER population-based data. Annals of Oncology, v. 26, p. 1263-1268, 2015.

CASCIARI, J. J.; SOTIRCHOS, S. V.; SUTHERLAND, R. M. Variations in tumor cell growth rates and metabolism with oxygen concentration, glucose concentration, and extracellular pH. Journal of Cellular Physiology, v. 151, p. 386-394, 1992.

CASTRO, M. A. A.; KLAMT, F.; GRIENEISEN, V. A.; GRIVICICH, I.; MOREIRA, J. C. $F$. Gompertzian growth pattern correlated with phenotypic organization of colon carcinoma, malignant glioma and non-small cell lung carcinoma cell lines. Cell Proliferation, v. 36, p. 65-73, 2003.

CERVI, A.; FRANCESCHINI, S. C. C.; PRIORE, S. E. Análise crítica do uso do índice de massa corporal para idosos. Revista de Nutrição, v. 18, n. 6, p. 765-775, 2005.

CHAPPELL, M. J.; EVANS, N. D.; ERRINGTON, R. J.; KHAN, I. A.; CAMPBELL, L.; ALI, R.; GODFREY, K. R.; SMITH, P. J. A coupled drug kinetics-cell cycle model to 
analyze the response of human cells to intervention by topotecan. Computer methods and programs in Biomedicine, v. 89, p. 169-178, 2008.

CHU, P.; WANG, J.; HWANG, L.; CHANG, Y. Estimation of life expectancy and the expected years of life lost in patients with major cancers: extrapolation of survival curves under high-censored rates. Value in Health, v. 11, n. 7, p. 1102-1109, 2008.

CILLA, M.; BORRÁS, I.; PEÑA, E.; MARTíNEZ, M. A.; MALVÈ, M. A parametric model for analyzing atherosclerotic arteries: on the FSI coupling. International Communications in Heat and Mass Transfer, v. 67, p. 29-38, 2015.

COSTA, V. C. I. Anatomia Geral Humana. Apostila para fins didáticos, Ribeirão Preto, 2008.

DEBERARDINIS, R. J.; MANCUSO, A.; DAIKIN, E.; NISSIM, I.; YUDKOFF, M.; WEHRLI, S.; THOMPSON, C. B. Beyond aerobic glycolysis: transformed cells can engage in glutamine metabolism that exceeds the requirement for protein and nucleotide synthesis. Cell biology, v. 104, n. 49, p. 19345-19350, 2007.

DEBERARDINIS, R. J.; LUM, J. J.; HATZIVASSILIOU, G.; THOMPSON, C. B. The biology of cancer: metabolic reprogramming fuels cell growth and proliferation. Cell metabolism, n. 7, 11-20, 2008.

DEBERARDINIS, R. J.; CHENG, T. Q's next: the diverse functions of glutamine in metabolism, cell biology and cancer. Oncogene, n. 29, p. 313-324, 2010.

DINGLI, D.; CASCINO, M. D.; JOSIC, K.; RUSSELL, S. J.; BAJZER, Z. Mathematical modeling of cancer radiovirotherapy. Mathematical Biosciences, v. 199, p. 55-78, 2006.

DINI, F. L.; GUARINI, G.; MORRONE, D.; MARZILLI, M. The Second Law of Thermodynamics and the heart. Future Cardiology. v. 8, n. 5, p. 697-709, 2012.

DOMINGUES, J. S. Modelo matemático e computacional da angiogênese em tumores e sua conexão com as células-tronco. Dissertação (Mestrado). Centro Federal de Educação Tecnológica de Minas Gerais, Belo Horizonte, 2010. 
FAGERSTRÖM, K. The epidemiology of smoking: health consequences and benefits of cessation. Drugs, v. 62, n. 2, p. 1-9, 2002.

FANGER, P. O. Calculation of thermal comfort: introduction of a basic comfort equation. ASHRAE Transactions, v. 73, n. 2, p. III.4.1-20, 1967.

FEHER, J. A. Quantitative Human Physiology: An Introduction, Elsevier, 2012.

FERREIRA, M. S. Um modelo do sistema termorregulador do corpo humano: exposição a ambientes quentes. Dissertação (Mestrado) - Escola Politécnica, Universidade de São Paulo. São Paulo, 1997.

FERREIRA, M. S. Um modelo do sistema térmico do corpo humano. Tese (Doutorado) - Escola Politécnica, Universidade de São Paulo. São Paulo, 2001.

FIALA, D.; LOMAS, K. J.; STOHRER, M. A computer model of human thermoregulation for a wide range of environmental conditions: the passive system. Journal of Applied Physiology, v. 87, p. 1957-72, 1999.

FOX, R. W.; MC DONALD, A. T.; PRITCHARD, P. J. Introduction to fluid dynamics. John Wiley \& Sons, 2004.

FRIBERG, S.; MATTSON,S. On the growth rates of human malignant tumors: implications for medical decision making. Journal of Surgical Oncology, n. 65, p. 284-297, 1997.

FROHLICH, E. D.; MESSERLI, F. H.; REISIN, E.; DUNN, F. G. The problem of obesity and hypertension. Hypertension, v. 5, n. 5, p. 71-79, 1983.

GAGGE, A. P.; STOLWIJK, J. A. J.; NISHI, Y. An Effective Temperature Scale Based on a Simple Model of Human Physiological Regularity Response. Memoirs of the Faculty of Engineering, Hokkaido University, v. 13, p. 21-36, 1972. 
GATENBY, R. A., GILLIES, R. J. Glycolysis in cancer: a potential target for therapy. The International Journal of Biochemistry \& Cell Biology, n. 39, p. 1358-1366, 2007.

GENC, S.; SORGUVEN, E.; OZILGEN, M.; KURNAZ, I. Unsteady exergy destruction of the neuron under dynamic stress conditions. Energy, v. 59, p. 422-431, 2013.

GERLEE, P. The model muddle: in search of tumor growth laws. Cancer Research, v. 73 , n. 8 , p. $2407-2411,2013$

GUYTON, A. C.; HALL, J. E. Tratado de Fisiologia Médica. 11 ed. Rio de Janeiro: Elsevier, 2006.

HAN, L.; ZHANG, L.; GUO, H.; WYSHAM, W. Z.; ROQUE, D. R.; WILSON, A. K.; SHENG, X.; ZHOU, C.; BAE-JUMP, V. L. Glucose promotes cell proliferation, glucose uptake and invasion in endometrial cancer via AMPK/mTOR/S6 and MAPK signaling. Gynecology Oncology, n. 138, p. 668-675, 2015.

HAHNFELDT, P.; PANIGRAHY, D.; FOLKMAN, J.; HLATKY, L. Tumor development under angiogenic signaling: a dynamical theory of tumor growth, treatment response, and postvascular dormancy. Cancer Research, v. 59, p. 4770-4775, 1999.

HARDY, J. D.; DU BOIS, E. F. The Technic of Measuring Radiation and Convection: OneFigure. Journal of Nutrition, v. 15, n. 5, p. 461, 1938.

HARLEY, C. B. Telomere loss: miotic clock or genetic time bomb? Mutation Research, v. 256, p. 271-282, 1991.

HARMAN, D. Aging: a theory based on free radical and radiation chemistry. $p$. 298-300, 1955.

HAWKING, S. W. Arrow of time in cosmology. Physical Review D, v. 32, n. 10, p. 2489-2495, 1985. 
HENRIQUES, I. B. Desempenho exergético do corpo humano e de seu sistema respiratório em função de parâmetros ambientais e da intensidade de atividade física. Dissertação (Mestrado) - Escola Politécnica, Universidade de São Paulo. São Paulo, 2013.

HENSLEY, C. T.; WASTI, A. T.; DEBERARDINIS, R.J. Glutamine and cancer: cell biology, physiology, and clinical opportunities. The Journal of Clinical Investigation, v. 123, n. 9, p. 3678-3684, 2013.

HERSHEY D. Entropy theory of aging systems. London: Imperial College Press, 2010

HORWICH, T. B.; FONAROW, G. C.; HAMILTON, M. A.; MACLELLAN, W. R.; WOO, M. A.; TILLISCH, J. H. The relationship between obesity and mortality in patients with heart failure. Journal of the American College of Cardiology, v. 38, n. 3, p. 789795, 2001.

HUFFMAN, D. M.; BARZILAI, N. Contribution of adipose tissue to health span and longevity. Body composition and aging, v. 37, p. 1-19, 2010.

IBGE. Pesquisa de orçamentos familiares. Antropometria e estado nutricional de crianças, adolescentes e adultos no Brasil (2008-2009). Rio de Janeiro: Ministério da Saúde, 2010.

IBGE. Tábua completa de mortalidade para o Brasil - 2015. Rio de Janeiro, 2016.

IDELCHICK, I. E. Handbook of hydraulic resistance: coefficients of local resistance and friction. Jaico Publishing House, 2008.

JÉQUIER, E. Energy expenditure in obesity. Clinics in Endocrinology and Metabolism, v. 13, n. 3, p. 563-580, 1984.

JHA, P.; RAMASUNDARAHETTIGE, C.; LANDSMAN, V.; ROSTRON, B.; THUN, M.; ANDERSON, R. N.; MCAFEE, T.; PETO, R. 21st-century hazards of smoking and benefits of cessation in the United States. The New England Journal of Medicine, v. 368, n. 4, p. 341-350, 2013.

JIN, K. Modern Biological Theories of Aging. Aging and Disease, v. 1, n. 2, p. 72-74, 2010. 
JONES, R. G.; THOMPSON, C. B. Tumor suppressors and cell metabolism: a recipe for cancer growth. Genes and development, n. 23, p. 537-548, 2009.

KAMEYAMA, T.; ASANOI, H.; ISHIZAKA, S.; YAMANISHI, K.; FUJITA, M.; SASAYAMA, S. Energy conversion efficiency in human left ventricle. Circulation, $v$. 85, p. 988-996. 1992.

KIMMEL, M.; TRAGANOS, F. Estimation and prediction of cell cycle specific effects of anticancer drugs. Mathematical Biosciences, v. 80, p. 187-208, 1986.

KOTAS, T. The exergy method of thermal plant analysis. Krieger Publishing Company, 1995.

KROMHOUT, D.; SARIS, W. H. M.; HORST, C. H. Energy intake, energy expenditure and smoking in relation to body fatness: the Zutphen Study. American Journal of Clinical Nutrition, v. 47, p. 668-674, 1988.

KRONIK, N.; KOGAN, Y.; VAINSTEIN, V.; AGUR, Z. Improving alloreactive CTL immunotherapy for malignant gliomas using a simulation model of their interactive dynamics. Cancer Immunology, Immunatherapy, v. 57, n. 3, p. 425-439, 2008.

KU, H. H.; BRUNK, U. T.; SOHAL, R. S. Relationship between mitochondrial superoxide and hydrogen peroxide production and longevity of mammalian species. Free Radical Biology \& Medicine, v. 15, p. 621-627, 1993.

LAIRD, A. K. Dynamics of tumor growth. British Journal of Cancer, v. 18, n. 3, p. 490-502, 1964.

LAYZER, D. The arrow of time. Scientific American, p. 56-69, 1975.

LEDZEWICZ, U.; SCHÄTTLER, H.; D'ONOFRIO, A. Optimal control for combination therapy in cancer. Proceedings of the $47^{\text {th }}$ IEEE Conference on Decision and Control, p. 1-6, 2008.

LUO, L. Entropy production in a cell and reversal of entropy flow as an anticancer therapy. Frontiers of Physics in China, v. 4, n. 1, p. 122-136, 2009. 
MACMILLAN CANCER SUPPORT. Living after diagnosis: median cancer survival times. 2011. Disponível em: < http://www.macmillan.org.uk/documents /aboutus/newsroom/livingaftercancermediancancersurvivaltimes.pdf> (Acessado em 26 de setembro de 2017).

MADY, C. E. K. Desempenho termodinâmico do corpo humano e seus subsistemas. Aplicações à medicina, desempenho esportivo e conforto térmico. Tese (Doutorado) - Escola Politécnica, Universidade de São Paulo. São Paulo, 2013.

MINISTÉRIO DA SAÚDE. Vigilância de fatores de risco e proteção para doenças crônicas por inquérito telefônico. Vigitel 2014, Ministério da Saúde, 2014.

MIYAI, N.; ARITA, M.; MIYASHITA, K.; MORIOKA, I.; SHIRAISHI, T.; NISHIO, I. Blood pressure response to heart rate during exercise test and risk of future hypertension. Hypertension, v. 39, p. 761-766, 2002.

MOFFAT, R. J.; OWENS, S.G. Cessation from cigarette smoking: changes in body weight, body composition, resting metabolism and energy consumption. Metabolism, v. 40, n. 5, p. 465-470, 1991.

MOTA, M. P.; FIGUEIREDO, P. A.; DUARTE, J. A. Teorias biológicas do envelhecimento. Revista Portuguesa de Ciências do Desporto, v. 4, n. 1, p. 81110, 2004.

MUÑOZ-DIOSDADO, A. Thermodynamic efficiency of the cardiac cycle and irreversibility in the interbeat interval time series. Revista Mexicana de Ingeniería Biomédica, v. 31, n. 2, 2010.

NELSON, D. L.; COX, M. M. Princípios de Bioquímica de Lehninger, 6. ed., Porto Alegre: Artmed, 2014.

NORTON, L. A Gompertzian model of human breast cancer growth. Cancer Research, v. 48, p. 7067-7071, 1988.

OSHINSKI, J. N.; PARKS, W. J.; MARKOU, C. P.; BERGMAN, H. L.; LARSON, B. E.; KU, D. N.; MUKUNDAN JR., S.; PETTIGREW, R. I. Improved measurement of pressure gradients in aortic coarctation by magnetic resonance imaging. Journal of the American College of Cardiology, v. 28, n. 7, p. 1818-1826, 1996. 
OLIVEIRA JR., S. Exergy: production, cost and renewability. London: Springer, 2013.

OLOVNIKOV, A. M. Telomeres, telomerase, and aging: origin of the theory. Experimental Gerontology, v. 31, n. 4, p. 443-448, 1996.

ÖZCAN, H.; ÖZTEKIN, P. S.; ZERGEROGLU, A. M.; ERSÖZ, G.; FIÇICILAR, H. Doppler ultrasound evaluation of the structural and hemodynamic changes in the brachial artery following two different exercise protocols. Diagnostic and Interventional Radiology, v. 12, n. 2, p. 80-84, 2006.

PANETTA, J. C. A mathematical model of breast and ovarian cancer treated with paclitaxel. Mathematical Biosciences, v. 146, p. 89-113, 1997.

PHIPPS, C. Combination of chemotherapy and antiangiogenic therapies: a mathematical modeling approach. Dissertação (Mestrado) - University of Waterloo. Ontário, Canadá, 2009.

POLESZCZUK, J. Mathematical modeling of tumour angiogenesis. Mathematica Applicanda, v. 41, n. 1, p. 1-12, 2013.

PREK, M. Thermodynamical analysis of human thermal comfort. Energy, v. 31, n. 5, p. $732-743,2006$.

PREK, M.; BUTALA, V. Principles of exergy analysis of human heat and mass exchange with the indoor environment. International Journal of Heat and Mass Transfer, v. 53, p. 5806-5814, 2010.

PRIGOGINE, I.; WIAME, J. M. Biologie et thermodynamique des phénomènes irréversibles. Cellular and Molecular Life Sciences, v. 2, n. 11, p. 451-453, 1946.

Prospective Studies Collaboration. Body-mass index and cause-specific mortality in 900000 adults: collaborative analyses of 57 prospective studies. Lancet, v. 373, p. 1083-1096, 2009.

RAHMAN, A. A novel method for estimating the entropy generation rate in a human body. Thermal Science, v. 11, n. 1, p. 75-92, 2007. 
RAVUSIN, E.; BURNAND, B.; SCHUTZ, Y.; JÉQUIER, E. Twenty-four-hour energy expenditure and resting metabolic rate in obese, moderately obese and control subjects. The American Journal of Clinical Nutrition, v. 35, p. 566-573, 1982.

REGOLIN, F.; KARNIKOWSKI, M. G. O. Teorias biológicas que justificam a necessidade de envelhecimento individual. Kairós, v. 12, n. 1, p. 233-245, 2009.

REITZER, L. J.; WICE, B. M.; KENNELL, D. Evidence that glutamine, not sugar, is the major energy source for cultured HeLa cells. The Journal of Biological Chemistry, v. 254, n. 8, p. 2669-2676, 1979.

REYMOND, P.; MERENDA, F.; PERREN, F.; RÜFENACHT, D.; STERGIOPULOS, $\mathrm{N}$. Validation of a one-dimensional model of the systemic arterial tree. American Journal of Heart and Circulation Physiology, v. 297, p. 208-222, 2009.

RIBBA, B.; WATKIN, E.; TOD, M.; GIRARD, P.; GRENIER, E.; YOU, B.; GIRAUDO, E.; FREYER, G. A model of vascular tumour growth in mice combining longitudinal tumour size data with histological biomarkers. European Journal of Cancer, v. 47, p. 479-490, 2011.

RODRIGEZ-ILLERA, M.; NIKIFORIDIS, C.; VAN DER GOOT, A.; BOOM, R. Exergy efficiency from staple food ingredients to body metabolism: the case of carbohydrates. Journal of Cleaner Production, v. 142, p. 4101-4113, 2017.

ROMERO-CORRAL, A.; SOMERS, V. K.; SIERRA-JOHNSON, J.; THOMAS, R. J.; COLLAZO-CLAVELL, M. L.; KORINEK, J.; ALLISON, T. G.; BATSIS, J. A.; SERTKUNIYOSHI, F. H.; LOPEZ-JIMENEZ, F. Accuracy of body mass index in diagnosing obesity in the adult general population. International Journal of Obesity, n. 32, p. 959-966, 2008.

RUBNER, M. Das Problem der Lebensdauer und seine Beziehung zum Wachstum und Ernährung. Oldenberg, Munich, 1908.

SACHS, R. K., HLATKY, L. R., HAHNFELD, P. Simple ODE models of tumor growth and anti-angiogenic or radiation treatment. Mathematical Computer Modeling, $n$. 33, p. 1297-1305, 2001. 
SCHRÖDINGER, E. What is life?: the physical aspect of the living cell; with, Mind and matter; \& Autobiographical sketches. Cambridge: Cambridge University Press, 1944.

SHAW, R. J. Glucose metabolism and cancer. Cell metabolism and cancer, n. 18, p. 598-608, 2006.

SHERRATT, J. A.; CHAPLAIN, M. A. J. A new mathematical model for avascular tumour growth. Mathematical Biology, v. 43, p. 291-312, 2001.

SHIMKIN, M. B.; GRISWOLD, M. H.; CUTLER, S. J. Survival in untreated an treated cancer. Cancer Journal for Clinicians, v. 34, n. 5, p. 282-294, 1984.

SILVA, C.; ANNAMALAI, K. Entropy generation and human aging: lifespan entropy and effect of physical activity level. Entropy, v. 10, n. 2, p. 100-123, 2008.

SILVA, C.; ANNAMALAI, K. Entropy generation and human aging: lifespan entropy and effect of diet composition and caloric restriction diets. Journal of Thermodynamics, v. 2009, p. 1-10, 2009.

SIMONE, A.; KOLARIK, J.; IWAMATSU, T.; ASADA, H.; DOVJAK, M.; SCHELLEN, L.; SHUKUYA, M.; OLESEN, B. W. A relation between calculated human body exergy consumption rate and subjectively assessed thermal sensation. Energy and Buildings, v. 43, n. 1, p. 1-9, 2011.

SPEAKMAN, J. R. Body size, energy metabolism and lifespan - A review. Journal of Experimental Biology, v. 208, p. 1717-1730, 2005.

STRAUER, B. E. Myocardial oxygen consumption in chronic heart disease: role of wall stress, hypertrophy and coronary reserve. The American journal of cardiology, v. 44, n. 4, p. 730-740, 1979.

SZARGUT, J. Exergy Analysis. Research in Progress Thermodynamics, v. 7, n. 3, p. 31-33, 2005. 
SZARGUT, J.; MORRIS, D.R.; STEWARD, F.R. Energy analysis of thermal, chemical, and metallurgical processes. Nova York: Hemisphere Publishing Corporation, 1988.

TAYLOR JR, D. H.; HASSELBLAD, V.; HENLEY, J.; THUN, M. J.; SLOAN, F. A. Benefits of smoking cessation for longevity. American Journal of Public Health, $v$. 92, n. 6, p. 990-996, 2002.

TEIXEIRA, I. N .D. O; GUARIENTO, M. E. Biologia do envelhecimento: teorias, mecanismos e perspectivas. Ciência \& Saúde Coletiva, v. 15, n. 6, p. 2845-2857, 2010.

VAANHOLT, L. M. The Rate of Living in Mice: impacts of activity and temperature on energy metabolism and longevity. Tese de Doutorado do Grupo de Biologia Comportamental da Universidade de Groningen, Holanda, 2007.

VENEZIANO, G. Pre-bangian origin of our entropy and time arrow. Physical Letters B, v. 454, p. 22-26, 1999.

VISCOMI, S.; PASTORE, G.; DAMA, E.; ZUCCOLA, L.; PEARCE, N.; MERLETTI, F.; MAGNANI, C. Life expectancy as an indicator of outcome in follow-up of populationbased cancer registries: the example of childhood leukemia. Annals of Oncology, v. 17, p. 167-171, 2006.

WARBURG, O.; WIND, F.; NEGELEN, E. The metabolism of tumors in the body. The Journal of General Physiology, v. 8, n. 6, p. 519-530, 1927.

WEINERT, B. T.; TIMIRAS, P. S. Invited Review: Theories of aging. Journal of Applied Physiology, v. 95, p. 1706-1716, 2003.

WESTERHOF, N.; STERGIOPULOS, N. NOBLE, M.I.M. Snapshots of hemodynamics: an aid for clinical research and graduate education. Boston: Springer, 2005.

WHO. The global tobacco crisis: tobacco - global agent of death. WHO report on the global tobacco epidemic, World Health Organization, 2008. 
WHO. Tobacco Free Initiative (TFI). Tobacco facts. World Health Organization, 2014a.

WHO. World Health Statistics. World Health Organization, 2014b.

WHO. Cancer. Fact sheet n. 297, World Health Organization, 2015a.

WHO. Obesity and overweight. Fact sheet n. 311, World Health Organization, 2015b.

WILTON, E.; JAHANGIRI, M. Post-stenotic dilatation. Journal of Cardiothoracic Surgery, v. 1, n. 1, p. 1-7, 2006.

WINSOR, C. P. The Gompertz curve as a growth curve. Proceedings of the National Academy of Sciences, v. 18, n. 1, p. 1-8, 1932.

WISSLER, E. H. Steady-state temperature distribution in man. Journal of Applied Physiology. v.16, n. 4, p. 734, 1961.

WISSLER, E. H. Mathematical simulation of human thermal behavior using whole body models. Heat transfer in medicine and biology. Analysis and applications, v. 1 , p. 325-74, 1985.

ZOTIN, A. I.; ZOTINA, R. S. Thermodynamic aspects of developmental biology. Journal of Theoretical Biology, v. 17, n. 1, p. 57-75, 1967. 